
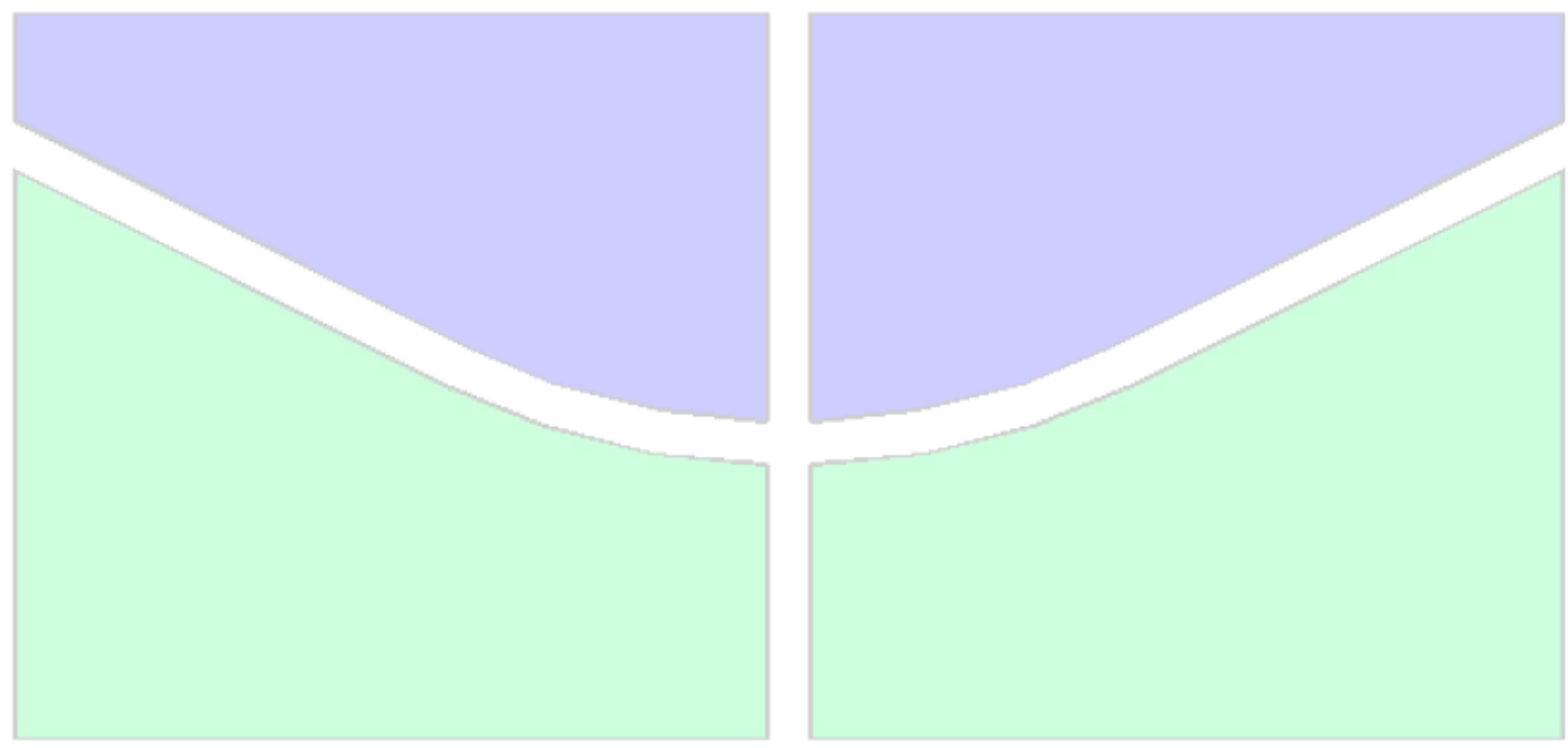

OTIMIZAÇÃO TOPOLÓGICA DE DISSIPADORES METÁLICOS APLICADOS AO CONTROLE DE VIBRAÇÕES EM ESTRUTURAS

FERNANDO DOS SANTOS OLIVEIRA

TESE DE DOUTORADO EM ESTRUTURAS E CONSTRUÇÃO CIVIL

DEPARTAMENTO DE ENGENHARIA CIVIL E AMBIENTAL

FACULDADE DE TECNOLOGIA

UNIVERSIDADE DE BRASÍLIA 
UNIVERSIDADE DE BRASÍLIA

FACULDADE DE TECNOLOGIA

DEPARTAMENTO DE ENGENHARIA CIVIL E AMBIENTAL

OTIMIZAÇÃO TOPOLÓGICA DE DISSIPADORES METÁLICOS APLICADOS AO CONTROLE DE VIBRAÇÕES EM ESTRUTURAS

FERNANDO DOS SANTOS OLIVEIRA

ORIENTADOR: JOSÉ LUÍS VITAL DE BRITO COORIENTADORA: SUZANA MOREIRA ÁVILA

TESE DE DOUTORADO EM ESTRUTURAS E CONSTRUÇÃO CIVIL

PUBLICAÇÃO: E.TD - 001A/16

BRASÍLIA/DF: JUN/2016 
UNIVERSIDADE DE BRASÍLIA

FACULDADE DE TECNOLOGIA

DEPARTAMENTO DE ENGENHARIA CIVIL E AMBIENTAL

OTIMIZAÇÃO TOPOLÓGICA DE DISSIPADORES METÁLICOS

APLICADOS AO CONTROLE DE VIBRAÇÕES EM ESTRUTURAS

FERNANDO DOS SANTOS OLIVEIRA

TESE SUBMETIDA AO DEPARTAMENTO DE ENGENHARIA CIVIL E AMBIENTAL DA FACULDADE DE TECNOLOGIA DA UNIVERSIDADE DE BRASílIA COMO PARTE DOS REQUISÍTOS NECESSÁRIOS PARA A OBTENÇÃO DO GRAU DE DOUTOR EM ESTRUTURAS E CONSTRUÇÃO CIVIL.

APROVADA POR:

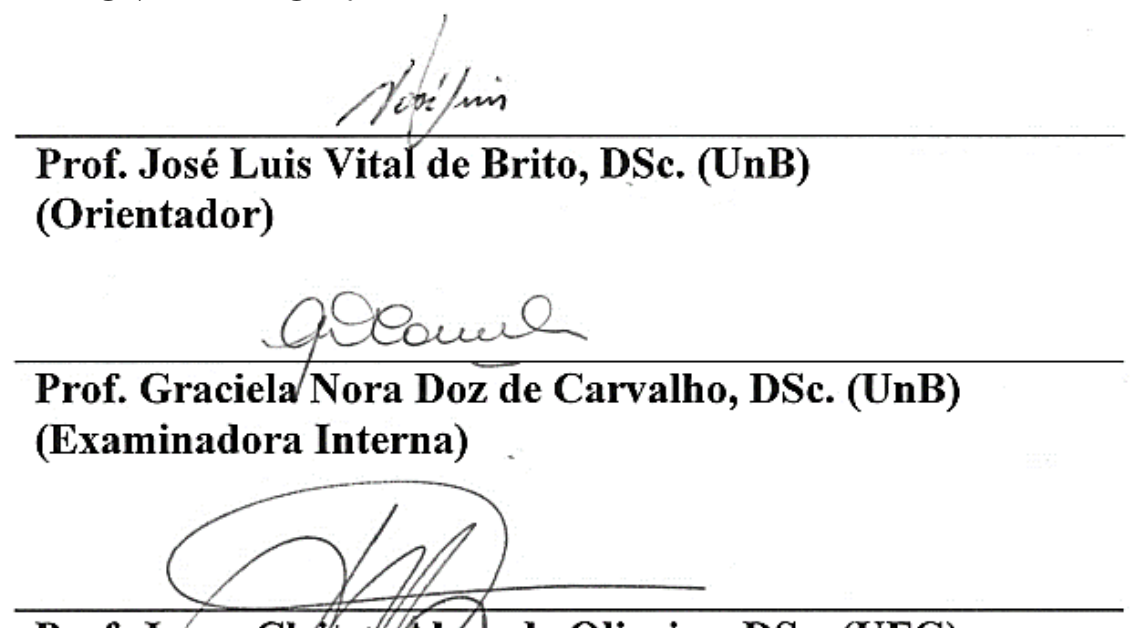

Prof. Janes Cleiton Avves de Oliveira, DSc. (UFG)

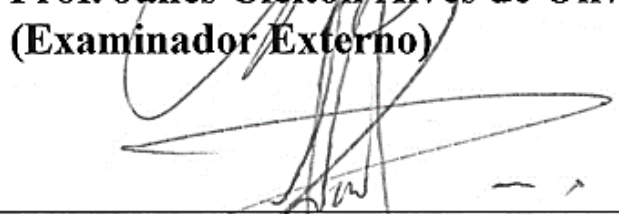

Prof. João da Costa Pantoja, DSc. (UnB)

(Examinador Externo ao Programa)

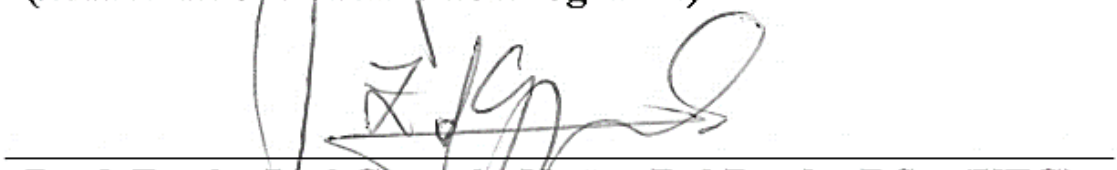

Prof. Zenón José Guzmán Nuñez Del Prado, DSc. (UFG) (Examinador Externo)

BRASÍLIA/DF, 29 DE JUNHO DE 2016 


\section{FICHA CATALOGRÁFICA}

OLIVEIRA, FERNANDO DOS SANTOS

Otimização Topológica de Dissipadores Metálicos Aplicados ao Controle de Vibrações em Estruturas. [Distrito Federal] 2016.

xx, 155p., 297mm (ENC/FT/UnB), Doutor, Estruturas e Construção Civil, 2016.

Tese de Doutorado - Universidade de Brasília, Faculdade de Tecnologia.

Departamento de Engenharia Civil e Ambiental.
1. Dinâmica Estrutural
2. Controle de Vibrações
3. Controle Passivo
4. Otimização Topológica
I. $\quad \mathrm{ENC} / \mathrm{FT} / \mathrm{UNB}$
II. Título (Doutor)

\section{REFERÊNCIA BIBLIOGRÁFICA}

OLIVEIRA, Fernando dos Santos (2016). Otimização Topológica de Dissipadores Metálicos Aplicados ao Controle de Vibrações em Estruturas. Tese de Doutorado, Publicação E.TD - 001A/16, Departamento de Engenharia Civil e Ambiental, Universidade de Brasília, DF, 155p.

\section{CESSÃO DE DIREITOS}

AUTOR: Fernando dos Santos Oliveira

TÍTULO: OTIMIZAÇÃO TOPOLÓGICA DE DISSIPADORES METÁLICOS APLICADOS AO CONTROLE DE VIBRAÇÕES EM ESTRUTURAS.

GRAU: Doutor ANO: 2016

É concedida a Universidade de Brasília permissão para reproduzir cópias desta tese de doutorado e para emprestar ou vender tais cópias somente para propósitos acadêmicos e científicos. O autor reserva outros direitos de publicação e nenhuma parte dessa tese de doutorado pode ser reproduzida sem autorização por escrito do autor.

Sernando dos S. Qhiveio.

Fernando dos Santos Oliveira

Avenida Ouro Branco Q.51, L.17A Vila Jayara.

CEP 75064030 Anápolis-GO, Brasil

oliveirafs@outlook.com 


\section{DEDICATÓRIA}

Dedico este trabalho a todos os amigos e familiares, que sempre me ajudaram na busca dos meus objetivos.

E tudo quanto fizerdes, fazei-o de coração, como ao Senhor, e não aos homens. Colossenses 3:23. 


\section{AGRADECIMENTOS}

Ao soberano Deus, Pai de nosso Senhor e Salvador Jesus Cristo, que sempre esteve ao meu lado nas variações das amplitudes.

À minha querida esposa Raquel, pelo apoio e dedicação à nossa união.

Aos meus queridos pais Divani e Vilmar e aos meus familiares que sempre acreditaram em mim, depositando sempre força e confiança para que eu pudesse seguir em frente.

Aos professores Brito e Suzana pelo auxílio constante na realização deste trabalho, pela paciência e, sobretudo pela grande amizade e bons momentos compartilhados.

Aos professores Graciela, Janes, Pantoja e Zenon que participaram da comissão examinadora.

Especial agradecimento ao grande amigo Hugo Luiz que sempre se colocou à disposição para partilhar seu conhecimento e amizade.

Ao corpo docente e administrativo do Programa de Pós-Graduação em Estruturas e Construção Civil (PECC) da Universidade de Brasília (UnB).

Aos professores Alexander Araújo, Jorge Luiz e todo corpo técnico do Departamento de Engenharia Mecânica ENM-UnB, que foram extremamente prestativos e solícitos durante a realização das análises experimentais.

Ao professor Elton Bauer que não nos deixa esquecer que a vida também é feita de dificuldades.

Ao Centro de Apoio ao Desenvolvimento Tecnológico CDT- UnB que viabilizou todo o processo de patente do modelo desenvolvido.

Que a graça do Pai, o amor de Deus e a comunhão do Espírito Santo, sejam com todos, não só agora, mas para todo o sempre. 


\title{
OTIMIZAÇÃO TOPOLÓGICA DE DISSIPADORES METÁLICOS APLICADOS AO CONTROLE DE VIBRAÇÕES EM ESTRUTURAS
}

\begin{abstract}
RESUMO
A construção de edificações cada vez mais altas e esbeltas tem se tornado bastante comum nos grandes centros, desafiando assim os projetistas estruturais a elaborarem projetos cada vez mais eficientes de forma que o arranjo adotado possa utilizar da melhor forma as características dos materiais. O uso de dispositivos que adicionam rigidez e amortecimento às estruturas sujeitas a ações dinâmicas, como cargas de vento e terremotos, tem se tornado cada vez mais comum nas estruturas civis. Um desses dispositivos mecânicos que tem sido amplamente utilizado é o dissipador do tipo Added Damping and Stiffness (ADAS), que se corretamente instalado, pode aumentar significativamente a resistência, rigidez e capacidade de dissipação de energia das estruturas das edificações. Os dispositivos do tipo ADAS são basicamente dissipadores de energia instalados na estrutura com o objetivo de que a dissipação ocorra de forma concentrada nesses elementos, protegendo assim a estrutura principal de maiores danos. Uma vez ocorrida a ação dinâmica que danifique esses elementos, eles podem ser facilmente substituídos sem maiores dificuldades. Esses dissipadores de energia apresentam a vantagem de não precisarem de tecnologia avançada para sua produção e podem ser facilmente instalados na estrutura. Possuem ainda a vantagem de que fatores ambientais tais como temperatura e umidade, pouco ou nada afetam seu desempenho. No presente estudo, como uma alternativa ao ADAS, é realizada a otimização topológica de um dissipador metálico aplicado à redução de vibração em edificações sujeitas a terremotos, considerando através de análise numérica e experimental o formato adequado desse tipo de dispositivo. Em seguida busca-se a obtenção da probabilidade de falha desse sistema estrutural, levando-se em consideração as incertezas inerentes ao projeto, através da análise de confiabilidade.
\end{abstract}

Palavras-chave: Dinâmica estrutural; Controle de Vibrações; Adição de Rigidez e Amortecimento; Controle passivo; Otimização Topológica; Análise de confiabilidade. 


\title{
TOPOLOGICAL OPTIMIZATION OF METALLIC DAMPERS APPLIED TO VIBRATION CONTROL IN STRUCTURES
}

\begin{abstract}
The construction of increasingly tall and slender buildings has become quite common in large cities, challenging the structural engineers to develop increasingly efficient designs so that the adopted arrangement can make best use of the characteristics of materials. The use of devices that add stiffness and damping to structures subjected to dynamic actions such as wind and earthquake loads, has become increasingly common in civil structures. One of the mechanical devices that have been widely used is the Added Damping and Stiffness (ADAS), which if correctly installed, can significantly increase the strength, stiffness and energy dissipation capacity of the structures. ADAS devices are basically energy dissipators installed in the structure in order that dissipation occurs in these elements in a concentrated way, thereby protecting the main structure from further damage. Once the dynamic action that damages these elements occurs, they can be easily replaced without major costs. These energy dissipators have the further advantage of not require advanced technology for its production and can be easily installed in the structure. They also have the advantage that environmental factors such as temperature and humidity, has little or no effect in their performance. In the present study, as an alternative to ADAS, is performed the topology optimization of a metallic dissipator applied to the reduction of vibration in buildings subject to earthquakes, raising through numerical and experimental analysis the appropriate device type format. Then is searched the probability of failure of this structural system, taking into consideration the uncertainty inherent in the design, through reliability analysis.
\end{abstract}

Keywords: Structural dynamics; Vibration Control; Adding Stiffness and Damping; Passive control; Topology Optimization; Reliability analysis. 


\section{SUMÁRIO}

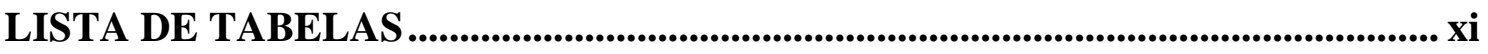

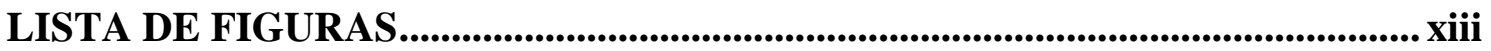

1 INTRODUÇÃ

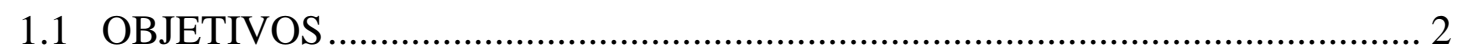

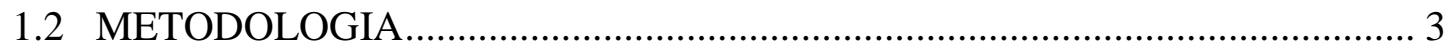

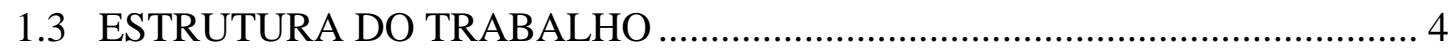

2 REVISÃO BIBLIOGRÁFICA ........................................................................6 6

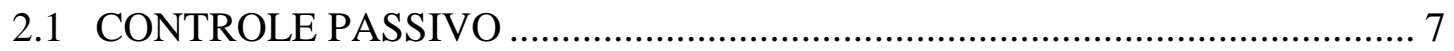

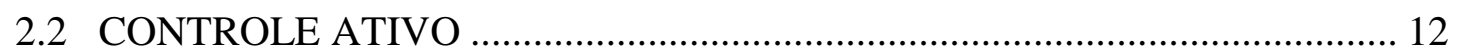

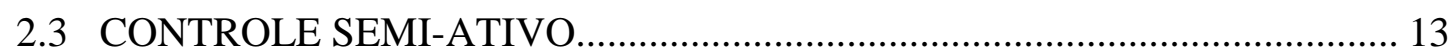

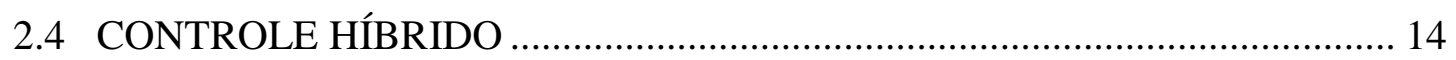

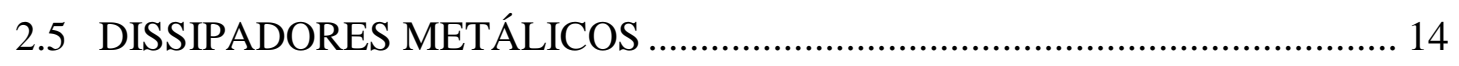

2.5.1 EXEMPLOS DE APLICAÇÃO DA LITERATURA ............................... 26

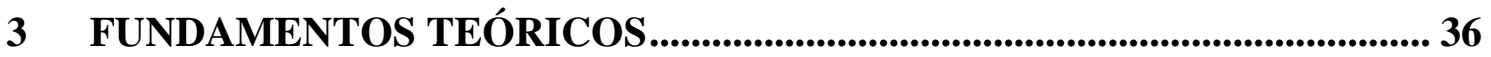

3.1 FORMULAÇÃO MATEMÁTICA DO ADAS ................................................ 36

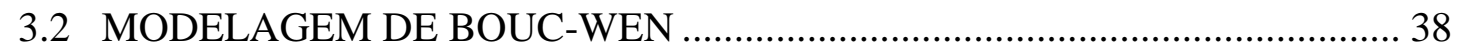

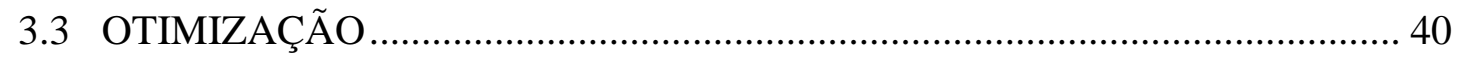

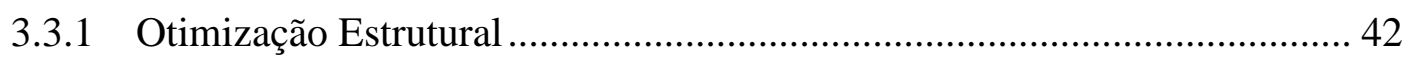

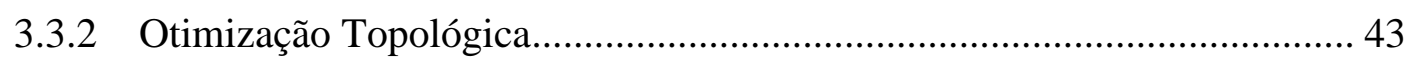

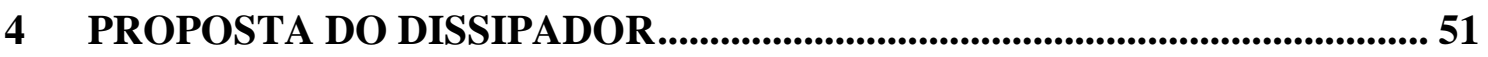

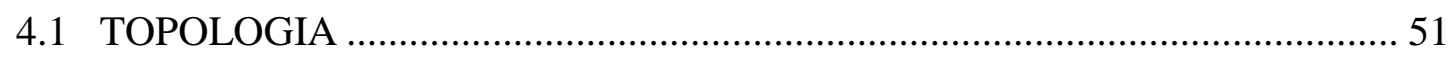

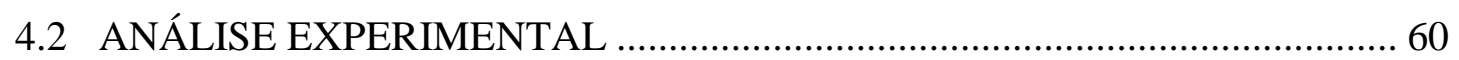

4.2.1 Preparação das Placas Metálicas ................................................................. 60

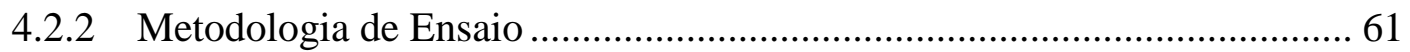

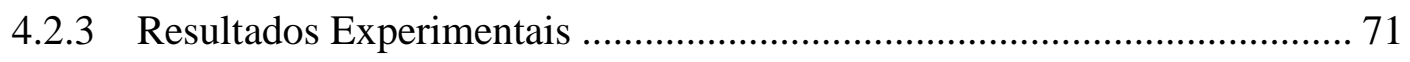

5 ANÁLISE NUMÉRICA ................................................................................... 85

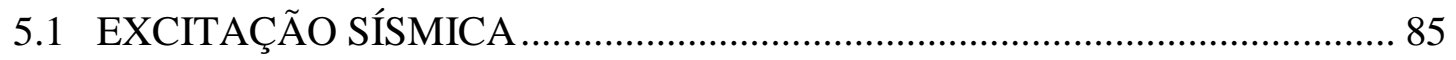

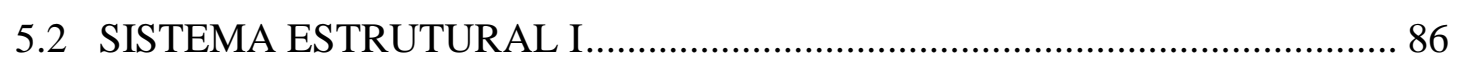

5.2.1 Apresentação e comparação dos resultados........................................... 88 


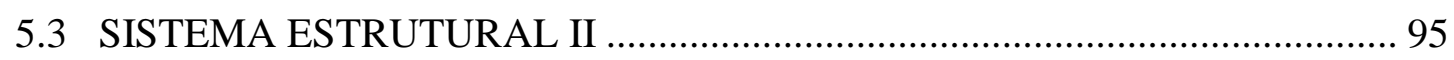

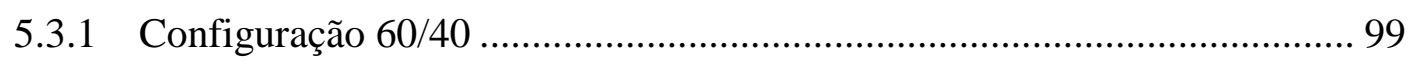

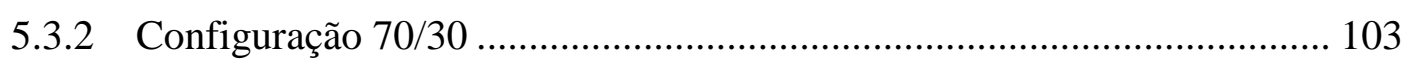

5.3.3 Influência da posição dos dissipadores................................................. 108

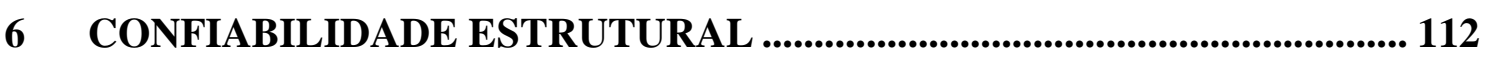

6.1 PROBABILIDADE E FUNÇÕES DE PROBABILIDADE ........................... 113

6.2 ÍNDICE DE CONFIABILIDADE .............................................................. 115

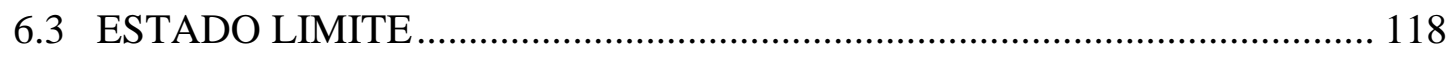

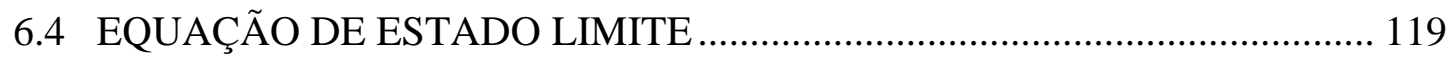

6.5 MÉTODO DE CÁLCULO DA PROBABILIDADE DE FALHA .................. 121

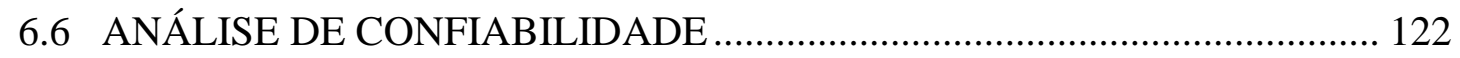

6.6.1 Interface de programação de aplicações (API) ....................................... 123

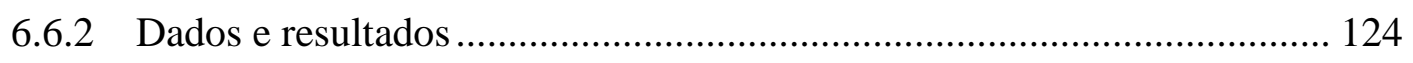

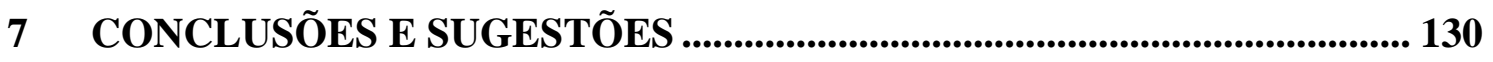

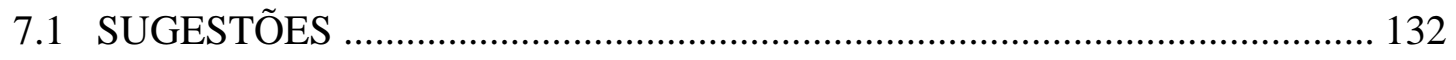

REFERÊNCIAS BIBLIOGRÁFICAS ..................................................................... 134

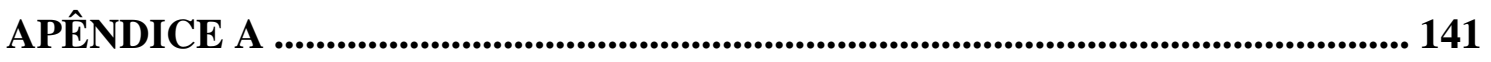

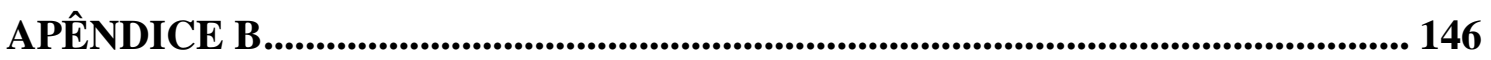

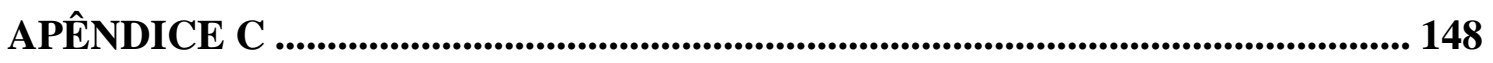

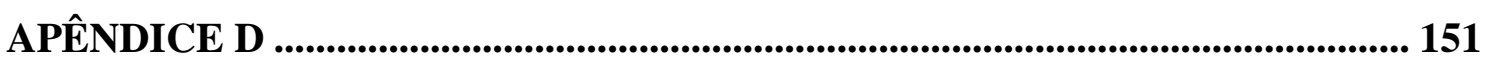




\section{LISTA DE TABELAS}

Tabela 2.1 - Placas dissipadoras de energia. Fonte: Whittaker et al. (1989), modificado 20

Tabela 2.2 - Estruturas típicas de controle passivo no Japão 34

Tabela 4.1 - Comparação da rigidez de cisalhamento elástica entres os modelos $X$ Shape e Bottle Shape 59

Tabela 4.2 - Comparação entre modelos quando submetidos a um carregamento triangular.

Tabela 4.3 - Comparação entre modelos quando submetidos a um carregamento senoidal crescente 76

Tabela 4.4 - Comparação entre modelos quando submetidos a um carregamento senoidal constante 78

Tabela 4.5 - Variáveis encontradas para o modelo de Bouc-Wen relativa aos dissipadores 81

Tabela 4.6 - Comparação entre modelo numérico e experimental 81

Tabela 5.1 - Propriedades dos elementos estruturais do pórtico plano analisado. Fonte: Whittaker et. al. (1989). 86

Tabela 5.2 - Rigidez elástica aplicada aos modelos 87

Tabela 5.3 - Modos de vibração do Sistema Estrutural I. 87

Tabela 5.4 - Comparação entre deslocamentos do pórtico plano 88

Tabela 5.5 - Comparação entre deslocamentos absolutos máximos de pontos do pórtico plano 91

Tabela 5.6 - Comparação entre RMS dos deslocamentos absolutos do pórtico plano .. 92

Tabela 5.7 - Comparação entre forças absolutas máximas atuantes nos dissipadores metálicos 93

Tabela 5.8 - Comparação entre RMS das forças atuantes nos dissipadores metálicos .. 94

Tabela 5.9 - Rigidez elástica aplicada aos modelos 96

Tabela 5.10 - Modos de vibração do Sistema Estrutural II .......................................... 97

Tabela 5.11 - Configurações de dissipadores para o Sistema Estrutural II ................... 98

Tabela 5.12 - Comparação entre deslocamentos para diferentes pontos da estrutura ... 99

Tabela 5.13 - Comparação entre deslocamentos (m) sofridos pelos dissipadores para diferentes pontos da estrutura 101 
Tabela 5.14 - Comparação entre forças $(\mathrm{kN})$ aplicadas aos dissipadores para diferentes

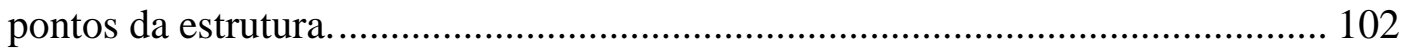

Tabela 5.15 - Comparação entre deslocamentos para diferentes pontos da estrutura .. 104

Tabela 5.16 - Comparação entre deslocamentos (m) sofridos pelos dissipadores para

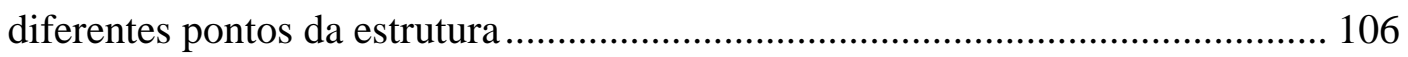

Tabela 5.17 - Comparação entre forças $(\mathrm{kN})$ aplicadas aos dissipadores para diferentes

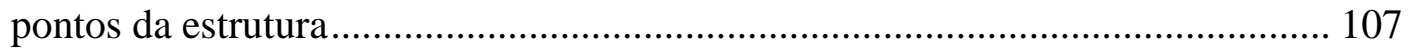

Tabela 5.18 - Comparação entre deslocamentos apresentados pela estrutura com a variação das posições dos dissipadores ............................................................. 109

Tabela 6.1 - Algumas funções de distribuição contínua de probabilidade. Fonte: Kalos (1986)

Tabela 6.2 - Relação entre $\beta$ e $P f$. Souza (2011) ...................................................... 118

Tabela 6.3 - Limitação para deslocamentos relativos de um pavimento $\Delta x$. .............. 119

Tabela 6.4 - Definição das categorias de utilização. ABNT NBR 15421:2006 ........... 120

Tabela 6.5 - Descrição das variáveis aleatórias ........................................................ 125

Tabela 6.6 - Comparação da probabilidade de falha para os modelos analisados......... 125

Tabela 6.7 - Valores de confiabilidade e probabilidade de falha em função da variação da aceleraçãa na base do pórtico estrutural ....................................................... 126

Tabela 6.8- Valores de confiabilidade e probabilidade de falha em função do

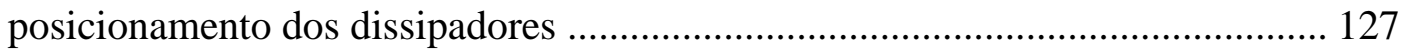

Tabela 6.9 - Valores de confiabilidade e probabilidade de falha em função do posicionamento dos dissipadores 128 


\section{LISTA DE FIGURAS}

Figura 1.1 - Pórtico plano analisado (Sistema Estrutural I) ........................................... 3

Figura 2.1 - Classificação dos sistemas de controle. Fonte: ISO 3010 (2001) ............... 7

Figura 2.2 - Ciclo histerético idealizado de Coulomb para amortecedores de fricção .... 8

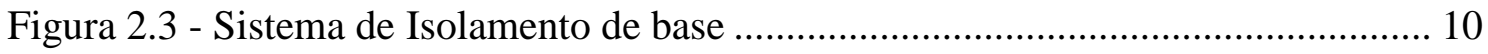

Figura 2.4 - Amortecedor de massa sintonizado passivo. Ospina, 2008, modificado.... 10

Figura 2.5 - Sistema de controle ativo esquemático. (Soong \& Dargush, 1997)........... 13

Figura 2.6 - Geometria de dissipadores metálicos. Fonte: Kelly et al. (1972) ............... 16

Figura 2.7 - Edifício Union House localizado na QuayStreet, Auckland. ..................... 17

Figura 2.8 - Deslocamento do topo do Edifício Union House. ....................................... 18

Figura 2.9 - Dissipador de energia típico. Fonte: Boardman et. al. (1983) .................... 18

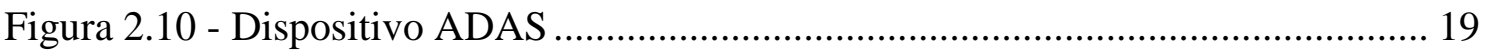

Figura 2.11 - Estrutura de testes. Fonte: Whittaker et al. (1989), modificado ................ 20

Figura 2.12 - Dispositivo ADAS instalado na estrutura ............................................. 21

Figura 2.13 - Modelos testados durante otimização topológica .................................... 22

Figura 2.14 - Comparação de curvas força-deslocamento. Ghabraie et. al., (2010) ...... 23

Figura 2.15 - Configuração do sistema de ensaio. Carpineto et al., (2013) ................... 23

Figura 2.16 - Representação do SPD. Liu et al., (2013) ............................................... 24

Figura 2.17 - Formato ótimo proposto para o SPD. Liu et al., (2013) ........................... 25

Figura 2.18 - detalhe de instalação do amortecedor em forma de U ............................. 25

Figura 2.19 - Arranjo direcional do dissipador metálico............................................ 26

Figura 2.20 - Detalhes da ponte Rangitikei. Fonte: Skinner et. al., 1974 ..................... 27

Figura 2.21 - Imagem atual da Ponte Rangitikei...................................................... 27

Figura 2.22 - Análise de deslocamentos da superestrutura da chaminé. Fonte: Skinner et.

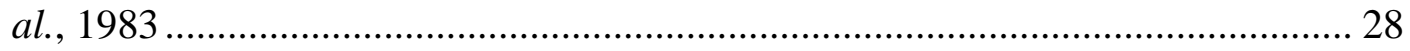

Figura 2.23- Detalhe da torre de fumaça. Fonte: Skinner et. al., 1983 ........................ 29

Figura 2.24 - Modelo de análise estrutural para o edifício do banco Wells Fargo........ 30

Figura 2.25 - Avaliação numérica para o edifício do banco Wells Fargo. Perry et

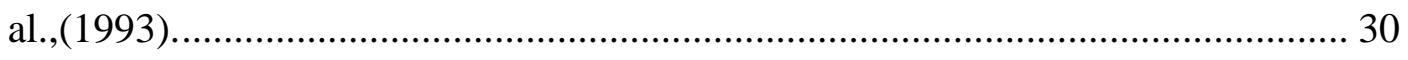

Figura 2.26- Vista do Edifício - Reforma utilizando contraventamentos diagonais.

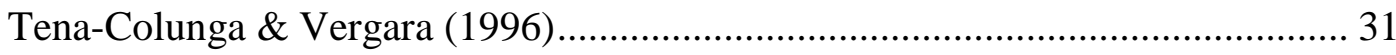

Figura 2.27 - Vista do Edifício - Reforma utilizando ADAS. Tena-Colunga \& Vergara (1996) 
Figura 2.28 - Fluxograma para o projeto de instalação de dissipadores de energia em edifícios. Fonte: Peng et al., (2012) modificado.

Figura 3.1 - Geometrias idealizadas para o dispositivo ADAS. Fonte: Tena-Colunga (1997) 37

Figura 3.2 - Parâmetros para o modelo Bouc-Wen 39

Figura 3.3 - Comportamento da variável z para distintos valores de $\beta$ e $\gamma$. Wen (1976) 39 Figura 3.4 - Comparação entre métodos de projeto. Fonte: Arora (2012), modificado. 41 Figura 3.5 - Tipos de Otimização Estrutural. Fonte: Bendsøe \& Sigmund (2002) ........ 43 Figura 3.6 - Modelo generalizado de busca da distribuição ótima de material para um dado elemento. Sigmund \& Bendsøe, (2002) modificado)

Figura 3.7 - Problema do tabuleiro demonstrado em uma estrutura sujeita à tensões biaxiais. (Bendsøe \& Sigmund (2002) modificado) 47

Figura 3.8 - Variação de Eijkl com Eijkl0 unitário para diferentes densidades .......... 48

Figura 3.9 - Fluxograma de Otimização Topológica ...................................................... 50

Figura 4.1 - Dimensões do ADAS. Whittaker et. al. (1989), modificado....................... 51

Figura 4.2 -Modelo estrutural de placa metálica ............................................................. 52

Figura 4.3 - Distribuição densidades para uma parte da placa ...................................... 53

Figura 4.4 -Distribuição densidades durante processo iterativo.................................... 54

Figura 4.5 - Topologia proposta de acordo com a distribuição de densidades................ 54

Figura 4.6 - Representação da topologia modelada através do sistema de coordenadas 55

Figura 4.7 - Modelagem em elementos finitos do dissipador metálico do tipo X Shape 57 Figura 4.8 - Modelagem em elementos finitos do dissipador metálico do tipo Bottle Shape 58

Figura 4.9 - Deslocamento dos dissipadores metálicos após a aplicação do carregamento 58

Figura 4.10 - Deformação em dupla curvatura dos modelos analisados (Escala: 5x) .... 59

Figura 4.11 - Sistema de corte automatizado ..... 60

Figura 4.12 - Placas submetidas ao processo de corte 61

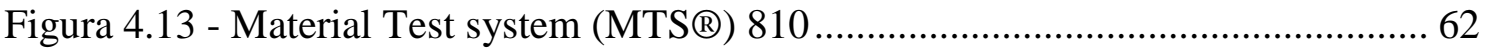

Figura 4.14 - Desempenho dinâmico do equipamento utilizado ..................................... 62

Figura 4.15 - Representação de eixo de simetria adotado ............................................ 64

Figura 4.16 - Representação esquemática tridimensional do sistema de fixação e

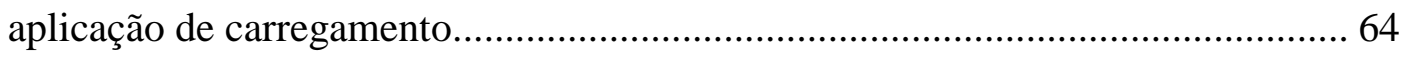

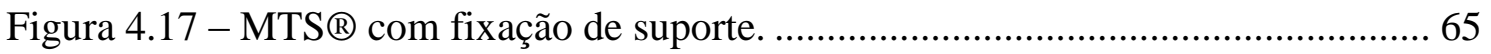




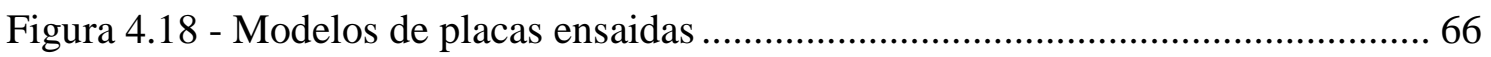

Figura 4.19 - Dimensões das placas ensaiadas (unidade: $\mathrm{mm}$ ) …................................. 67

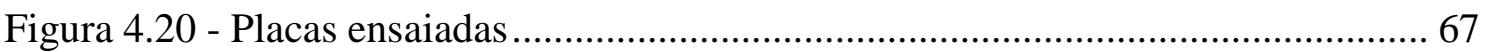

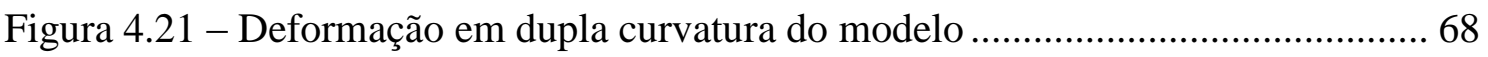

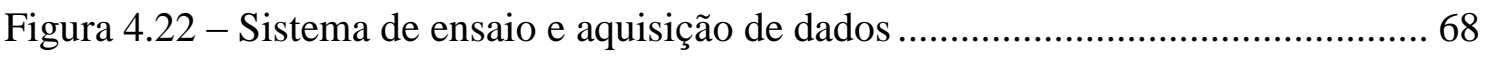

Figura 4.23 - Tela principal do software Station Mananger da MTS............................ 69

Figura 4.24 - Ensaio de Placa do Tipo X Shape ........................................................... 70

Figura 4.25 - Ensaio de Placa do Tipo Bottle Shape ...................................................... 70

Figura 4.26 - Carregamento triangular crescente aplicado ao modelo $X$ Shape com

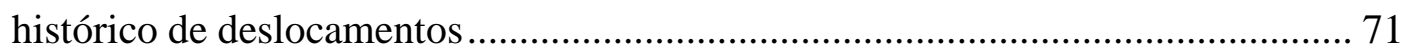

Figura 4.27 - Carregamento triangular crescente aplicado ao modelo $X$ Shape ............. 72

Figura 4.28 - Carregamento triangular crescente aplicado ao modelo Bottle Shape com

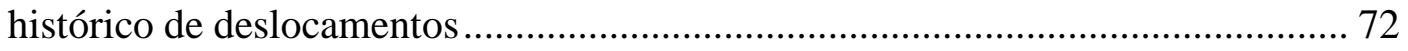

Figura 4.29 - Histerese do modelo Bottle Shape …........................................................ 73

Figura 4.30 - Carregamento Harmônico Crescente aplicado ao modelo X Shape com

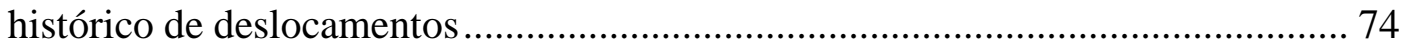

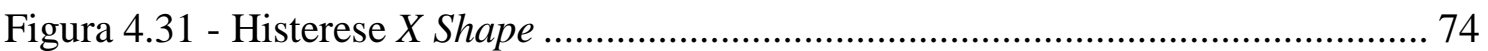

Figura 4.32 - Carregamento Harmônico Crescente aplicado ao modelo Bottle Shape com

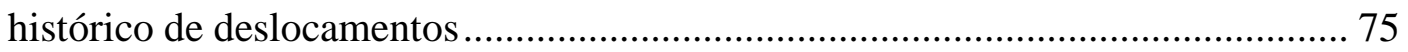

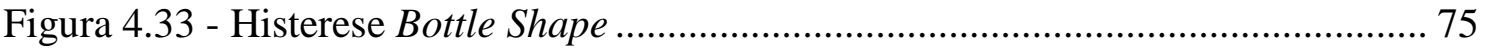

Figura 4.34 - Carregamento harmônico com amplitude constante aplicado ao modelo $X$ Shape com histórico de deslocamentos .............................................................. 76

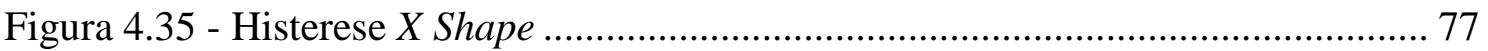

Figura 4.36 - Carregamento harmônico com amplitude constante aplicado ao modelo

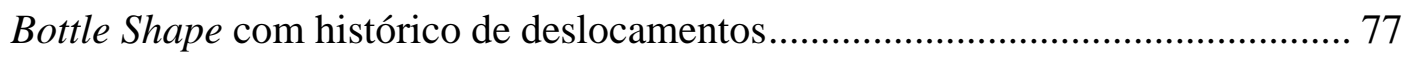

Figura 4.37 - Histerese Bottle Shape …................................................................... 78

Figura 4.38 - Carregamento senoidal crescente aplicado ao modelo Bottle Shape com

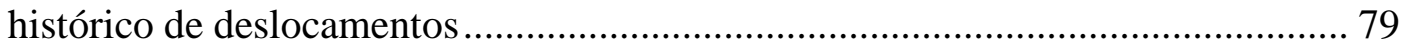

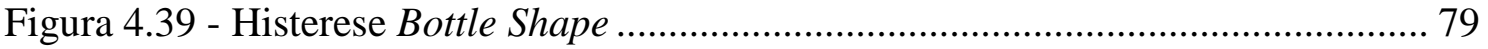

Figura 4.40 - Fase inicial de carregamento do modelo $X$ Shape …............................... 80

Figura 4.41 - Fase inicial de carregamento do modelo Bottle Shape ............................ 80

Figura 4.42 - Comportamento histerético do dissipador metálico DM\#3 do tipo X Shape quando a estrutura é submetida à excitação sísmica............................................... 82 
Figura 4.43 - Comportamento histerético do dissipador metálico DM\#2 do tipo X Shape quando a estrutura é submetida à excitação sísmica

Figura 4.44 - Comportamento histerético do dissipador metálico DM\#1 do tipo X Shape quando a estrutura é submetida à excitação sísmica

Figura 4.45 - Comportamento histerético do dissipador metálico DM\#3 do tipo Bottle Shape quando a estrutura é submetida à excitação sísmica 83

Figura 4.46 - Comportamento histerético do dissipador metálico DM\#2 do tipo Bottle Shape quando a estrutura é submetida à excitação sísmica 84

Figura 4.47 - Comportamento histerético do dissipador metálico DM\#1 do tipo Bottle Shape quando a estrutura é submetida à excitação sísmica 84

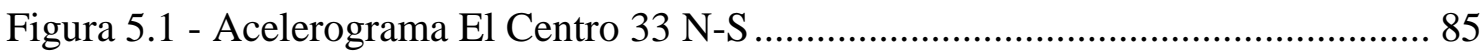

Figura 5.2 - Espectro de Potência do Acelerograma .................................................. 85

Figura 5.3 - Pórtico Plano de 03 andares com amortecedores histeréticos instalados

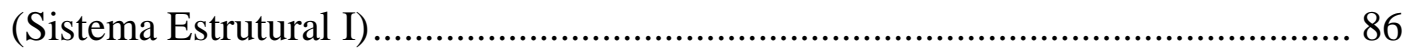

Figura 5.4 - Representação gráfica dos modos de vibração …….................................... 87

Figura 5.5 - Comparação de deslocamentos no nó C para estrutura com e sem controle 89

Figura 5.6 - Comparação de deslocamentos no nó B para estrutura com e sem controle 89

Figura 5.7 - Comparação de deslocamentos no nó A para estrutura com e sem controle 90

Figura 5.8 - Comparação de deslocamentos da estrutura equipada com o dispositivo $X$ Shape quando a mesma é submetida à excitação sísmica 90

Figura 5.9 - Comparação de deslocamentos da estrutura equipada com o dispositivo Bottle Shape quando a mesma é submetida à excitação sísmica. 91

Figura 5.10 - Comportamento histerético do dissipador metálico DM\#3 do tipo X Shape quando a estrutura é submetida à excitação sísmica 92

Figura 5.11 - Comportamento histerético do dissipador metálico DM\#3 do tipo Bottle Shape quando a estrutura é submetida à excitação sísmica 93

Figura 5.12 - Comportamento histerético do dissipador metálico DM\#2 do tipo X Shape quando a estrutura é submetida à excitação sísmica. 94

Figura 5.13 - Comportamento histerético do dissipador metálico DM\#2 do tipo Bottle Shape quando a estrutura é submetida à excitação sísmica 94 
Figura 5.14 - Comportamento histerético do dissipador metálico DM\#1 do tipo X Shape quando a estrutura é submetida à excitação sísmica

Figura 5.15 - Comportamento histerético do dissipador metálico DM\#1 do tipo Bottle Shape quando a estrutura é submetida à excitação sísmica 95

Figura 5.16 - Pórtico Plano com amortecedores histeréticos instalados (Sistema

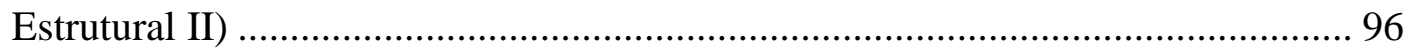

Figura 5.17 - Representação gráfica dos seis primeiros modos de vibração................... 98

Figura 5.18 - Histórico de deslocamentos do nó A. Unid.: m ...................................... 100

Figura 5.19 - Histórico de deslocamentos do nó B. Unid.: m ...................................... 100

Figura 5.20 - Histórico de deslocamentos do nó C. Unid.: m ....................................... 101

Figura 5.21 - Comportamento histerético dos dissipadores metálicos quando a estrutura é submetida à excitação sísmica (configuração 60/40) ....................................... 103

Figura 5.22 - Histórico de deslocamentos do nó A. ..................................................... 105

Figura 5.23 - Histórico de deslocamentos do nó E...................................................... 105

Figura 5.24 - Histórico de deslocamentos do nó J....................................................... 106

Figura 5.25 - Comportamento histerético dos dissipadores metálicos quando a estrutura é submetida à excitação sísmica (configuração 70/30) ........................................ 108

Figura 5.26 - Comparação entre deslocamentos apresentados pelo nó A com a variação das posições dos dissipadores

Figura 5.27 - Comparação entre deslocamentos apresentados pelo nó E com a variação das posições dos dissipadores 110

Figura 5.28 - Comparação entre deslocamentos apresentados pelo nó J com a variação

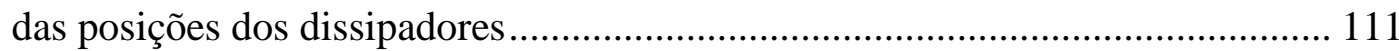

Figura 6.1 - Distribuição da margem de segurança. Melchers (1987) ......................... 116

Figura 6.2 - Relação entre $\beta$ e $P f$. Souza (2011)..................................................... 117

Figura 6.3 - Definição dos domínios de falha, segurança e estado limite para uma análise de confiabilidade ................................................................................. 119

Figura 6.4 - Representação gráfica do método FORM............................................... 122

Figura 6.5 - Fluxograma API Matlab® SAP2000® ................................................. 124

Figura 6.6 - Valores de confiabilidade e probabilidade de falha em função da variação da aceleração na base do pórtico estrutural ........................................................ 126

Figura 6.7 - Valores de $\beta$ em função do posicionamento dos dissipadores ................. 127

Figura 6.8 - Valores de $\beta$ em função do posicionamento dos dissipadores ................. 128

Figura 6.9 - Valores de $\beta$ e $P_{f}$ em função do posicionamento dos dissipadores........... 129 


\section{LISTA DE SÍMBOLOS, NOMENCLATURAS E ABREVIAÇÕES}

ADAS: $\quad$ Added Damping and Stiffness;

AMS: $\quad$ Amortecedor de massa sintonizado;

APDL ANSYS Parametric Design Language

API: $\quad$ Application Programming Interface;

CAD: $\quad$ Computer Aided Design;

CNC: $\quad$ Controle Numérico Computadorizado;

ESL: $\quad$ Earthquake Simulator Laboratory;

FORM: $\quad$ First Order Reliability Method;

LVDT: $\quad$ Linear Variable Differential Transformer;

MEF: $\quad$ Método dos elementos finitos;

MTS: $\quad$ Material Testing System;

OC: $\quad$ Optimality Criteria;

RMS: $\quad$ Valor Quadrático Médio;

SIMP: $\quad$ Solid Isotropic Microstructure with Penalization;

TADAS: Triangular-plate Added Damping and Stiffness;

\$2k, S2k Arquivo de texto que o software SAP2000 é capaz de importar;

$A_{\text {sup }}: \quad$ Área superficial da placa metálica;

$b_{1}$ : Largura de topo da placa metálica no modelo idealizado de ampulheta proposto por Tena-Colunga;

$b_{1 \text { eq }}: \quad$ Largura equivalente do topo da placa metálica no modelo $X$ Shape;

$b_{2}$ : $\quad$ Largura de centro da placa metálica no modelo idealizado de ampulheta proposto por Tena-Colunga;

c: $\quad$ Coeficiente de amortecimento;

$C_{f}: \quad$ Coeficiente de fricção;

$E_{a d}: \quad$ Rigidez admissível;

$E_{e}: \quad$ Rigidez do elemento;

E: $\quad$ Módulo de elasticidade;

f: $\quad$ Forças internas; 
$f(\boldsymbol{X}): \quad$ Função objetivo;

$\boldsymbol{f}: \quad$ Vetor carregamento;

$F_{f}: \quad$ Força de fricção;

$F_{v d}: \quad$ Força de amortecimento viscoso;

$g_{j}(\boldsymbol{X}): \quad$ Restrições de desigualdade;

$h_{s x}$ : Distância entre as duas elevações correspondentes a um pavimento;

$I_{x}: \quad$ Momento de inércia da seção transversal da placa em torno do eixo x;

K: $\quad$ Matriz de rigidez;

Ke Rigidez Elástica;

Ky Rigidez pós escoamento;

$l: \quad$ Altura da placa;

$l_{j}(\boldsymbol{X}): \quad$ Restrições de igualdade.

$M_{p x}: \quad$ Capacidade de momento plástico;

$N: \quad$ Força Normal;

$p_{x}(x)$ Função de densidade de probabilidade de ligação da variável aleatória básica $x$.

$P_{y}: \quad$ Força de escoamento;

$r$ : Taxa de endurecimento representada pela razão entre a rigidez plástica e elástica;

$r(x)$ : Deslocamento relativo horizontal de um pavimento em função de todas as variáveis do problema analisado;

$t_{p}: \quad$ Espessura da placa;

$t: \quad$ Tração;

u: $\quad$ Campo de deslocamentos na condição de equilíbrio;

$\boldsymbol{u}$ : Vetor deslocamento;

U: $\quad$ Espaço de deslocamento cinemático admissível;

$v$ : $\quad$ Campo de deslocamentos virtuais;

Vol: $\quad$ Volume da placa;

$\dot{x}: \quad$ Velocidade do movimento;

$X: \quad$ Vetor de dimensão $n$ chamado de vetor projeto; 
$\alpha(u, v) \quad$ Trabalho virtual interno de um corpo elástico no equilíbrio $u$ para um deslocamento virtual arbitrário $v$;

$\Delta_{y}{ }^{A D A S}: \quad$ Deslocamento de escoamento do dispositivo ADAS;

$\Delta_{y}{ }^{P L}: \quad$ Deslocamento de escoamento da placa metálica;

$\Delta_{x}: \quad$ Deslocamento relativo de um pavimento;

$\varepsilon: \quad$ Deformação associada ao campo $u$ ou $v$;

$\mu: \quad$ Taxa de ductilidade;

$\sigma_{y}: \quad$ Tensão de escoamento do material.

Q: $\quad$ Domínio geométrico de referência;

$\Omega_{F}: \quad$ Domínio de falha caracterizado pela região em que a equação de estado limite apresenta valores menores que zero. 


\section{INTRODUÇÃO}

A presença de edifícios altos é cada vez mais frequente nos grandes centros urbanos e desafiam a cada dia os projetistas de estruturas, na concepção de arranjos estruturais eficientes, capazes de suportar ações que lhes são impostas com deslocamentos admissíveis. Os avanços obtidos com a tecnologia dos materiais, projetos mais sofisticados de elevadores, o surgimento de computadores e softwares que permitam uma análise mais realista do comportamento das estruturas são alguns dos fatores que viabilizaram a construção de concepções cada vez mais altas e esbeltas (Oliveira, 2009).

As estruturas civis frequentemente são submetidas às ações severas e aleatórias de terremotos (Takewaki, 2009). Tipicamente, o desempenho sísmico das estruturas tem sido melhorado através da adição de elementos estruturais que aumentam a resistência e rigidez do sistema. Esses elementos reduzem as deformações, no entanto, essa redução muitas vezes se dá à custa do aumento das forças sísmicas, devido a uma redução do período de vibração. A redução do período de vibração acarreta também o aumento das acelerações na base da estrutura, provocando assim o acréscimo dos danos aos componentes do sistema estrutural (Kelly, 2007).

Nos últimos anos, como alternativa ao enrijecimento de toda a estrutura, tem sido dada uma grande atenção à pesquisa e ao desenvolvimento de dispositivos de controle estrutural com ênfase específica na mitigação dos danos causados por cargas dinâmicas, tais como ventos e terremotos em edifícios e pontes.

Os dissipadores metálicos são um tipo de dispositivo de controle passivo que durante a ação de terremotos podem mitigar as vibrações do sistema estrutural através da dissipação de energia por meio da deformação inelástica de um metal. Devido a sua simplicidade, desempenho confiável e fácil instalação, pesquisadores ao redor do mundo têm conduzido estudos teóricos e experimentais para o desenvolvimento de várias formas estruturais no sentido de que cada uma atenda um problema específico.

Nesse sentido, vários trabalhos têm sido desenvolvidos na busca do dispositivo suplementar ideal que de alguma forma possa atender a relação custo benefício, garantido assim o conforto e segurança das estruturas sem que isso onere 
excessivamente a sua construção. Uma análise detalhada da instalação desses dispositivos é apresentada no item 2.5.1.

Junto ao desenvolvimento dos computadores nas últimas décadas, métodos computacionais e técnicas numéricas estabeleceram seu lugar como ferramentas de engenharia de valor inestimável. Entre estes, os métodos numéricos de otimização têm atraído um grande número de pesquisadores em todo o mundo que, através dos trabalhos desenvolvidos e publicados, tem produzido um grande incremento de conhecimento e tecnologia. Particularmente, as técnicas de otimização topológica, que consiste na distribuição ótima de material para definição de um elemento qualquer, podem sem aplicadas a uma variedade de problemas físicos e tem apresentado excelentes resultados, gerando assim economia de material, melhor desempenho estrutural e maior conforto aos usuários desses dispositivos.

\subsection{OBJETIVOS}

O objetivo principal deste trabalho é determinar, através do método de otimização topológica, uma geometria alternativa aos dissipadores de energia Added Damping and Stiffness (ADAS), do tipo X Shape, propostos por Whittaker et al. (1989).

De modo a avaliar essa nova geometria encontrada, são realizas análises numéricas e experimentais comparando seu desempenho frente ao dispositivo do tipo $X$ Shape.

Nesse sentido, é realizado nesse trabalho a avaliação do comportamento de dissipadores metálicos aplicados ao controle de vibração de estruturas reticuladas sujeitas a sismos, com um levantamento bibliográfico para caracterização adequada desses dispositivos assim como a verificação de sua aplicabilidade.

Esta é uma pesquisa pioneira no Programa de Pós Graduação em Estruturas e Construção Civil da Universidade de Brasília (PECC - UnB), desse modo, o formato alternativo proposto ao dispositivo de dissipação de energia vai ao encontro da inovação e originalidade, tendo em vista que se desenvolve um novo formato para um dispositivo já amplamente utilizado. 


\subsection{METODOLOGIA}

Avalia-se, numericamente, a eficiência do controle estrutural aplicado a dois pórticos planos denominados Sistema Estrutural I e II. O controle é exercido através da instalação de dissipadores metálicos nos pontos de ligação do contraventamento com as vigas de cada um dos níveis.

Os pórticos são submetidos a uma aceleração na base correspondente ao registro El Centro-1940 com uma aceleração máxima de projeto de 0,33 unidades de $g$. A excitação é aplicada na base dos pórticos na direção $X$ conforme apresentado na Figura 1.1.

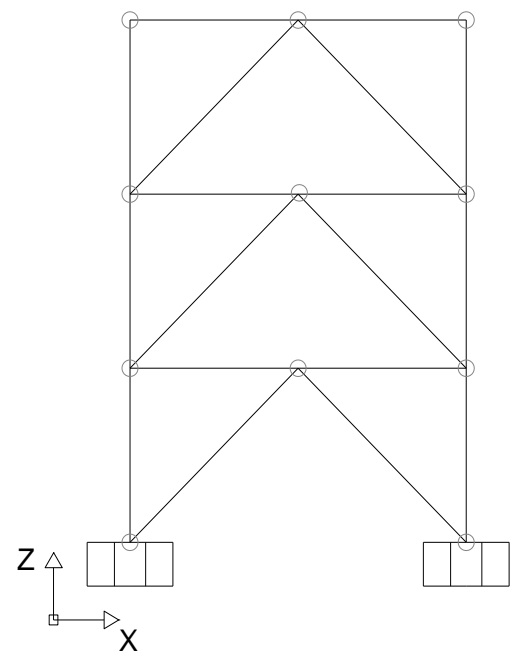

Figura 1.1 - Pórtico plano analisado (Sistema Estrutural I)

Em cada um dos pontos de contraventamento, são modelados dissipadores metálicos com o intuito de que a energia gerada pela excitação dissipe de forma concentrada nesses dispositivos. São modelados dois formatos de dispositivos metálicos, um baseado nas proposições de Whittaker et. al.(1989) e outro obtido a partir da determinação da posição ótima de cada fração de material, denominada otimização topológica. Os conceitos relativos à otimização topológica são apresentados em 0.

Em seguida, realiza-se a análise experimental em laboratório para os dissipadores que, além de ratificar os resultados numéricos encontrados, busca a determinação dos parâmetros de histerese de cada um desses dispositivos.

Posteriormente é analisada a segurança do modelo Sistema Estrutural I, em que se considera na avaliação da confiabilidade três situações, uma sem nenhum tipo de controle e outras duas com os dissipadores metálicos modelados. Na avaliação da confiabilidade, utiliza-se o FORM (First Order Reliability Method) como método de 
cálculo da probabilidade de falha do sistema. Como são necessárias dezenas de análises para obtenção de cada um dos índices de confiabilidade, foi realizada, através de rotinas escritas em Matlab®, a integração automática entre o método FORM e o programa de análise estrutural em elementos finitos SAP2000®.

\subsection{ESTRUTURA DO TRABALHO}

A presente tese de doutorado encontra-se estruturada em sete capítulos, incluindo o presente capítulo que faz uma introdução ao assunto, apresenta os objetivos, metodologia e estrutura. O conteúdo dos capítulos restantes é apresentado a seguir.

No capítulo dois é feita uma revisão bibliográfica sobre controle estrutural apresentando os conceitos dos diferentes tipos de controle: passivo, ativo, semi-ativo e híbrido. São apresentados também os conceitos relativos aos dissipadores metálicos que dissipam energia através da deformação inelástica de um metal.

No terceiro capítulo são tratados os fundamentos teóricos relativos à otimização estrutural e topológica. São abordados os assuntos relativos à maximização da rigidez, disposição do material e critérios de otimização. Nesse estudo é apresentada a modelagem analítica para os elementos do tipo ADAS, o modelo de comportamento inelástico que se dá através da dissipação de energia histerética durante os ciclos de carregamento e também a formulação matemática da otimização topológica.

No quarto capítulo é apresentada a proposta do dissipador metálico desenvolvido nesse trabalho em que se trabalha uma nova topologia de dispositivo metálico de dissipação. Nessa abordagem são relatados os experimentos realizados em laboratório bem como a análise dos resultados obtidos a partir dos ensaios realizados.

No quinto capítulo é realizada uma análise numérica baseada nos parâmetros encontrados nos ensaios para o dissipador metálico proposto. São considerados dois modelos estruturais, um mais simples, de três pavimentos, e outro mais completo, de dez pavimentos. Ambos os modelos estruturais foram submetidos à uma aceleração na base de forma a simular a ação de um sismo.

No sexto capítulo é apresentado um estudo da confiabilidade estrutural. São abordados os conceitos de estado limite, probabilidade e funções de probabilidade, incluindo o método de cálculo de probabilidade de falha adotado no trabalho. Realiza-se também 
um estudo da confiabilidade do modelo proposto de forma a determinar a segurança do sistema estrutural.

No sétimo capítulo são apresentadas as conclusões do trabalho desenvolvido nessa tese de doutorado e algumas sugestões para trabalhos futuros.

Por fim, são apresentadas as referências bibliográficas, que serviram como embasamento para a realização desse estudo e os apêndices que contém informações e códigos fonte utilizados no trabalho. 


\section{REVISÃO BIBLIOGRÁFICA}

A formação de grandes centros urbanos densamente povoados tem provocado soluções de engenharia no sentido da verticalização. A evolução das técnicas de análise e dimensionamento estruturais aliada aos avanços na área de ciência dos materiais e técnicas construtivas, tem tornado possível a construção de estruturas cada vez mais altas, esbeltas e, portanto, mais flexíveis. Essas estruturas são vulneráveis à ocorrência de vibrações excessivas causadas por carregamentos dinâmicos, tais como, terremotos, ventos, ondas, tráfego intenso, ocupação humana, entre outras (Avila, 2002, modificado).

Para reduzir as vibrações excessivas, pode ser utilizado um sistema de controle estrutural que possa absorver parte da energia da estrutura melhorando o seu desempenho frente a tais perturbações. Nos últimos anos tem se empregado esforços na pesquisa e desenvolvimento de dispositivos de controle estrutural, especialmente na mitigação da resposta das edificações em relação aos ventos, aos sismos e às vibrações induzidas pelo homem.

A redução das vibrações causadas pelos carregamentos dinâmicos inicia-se com a consideração da distribuição da energia ao longo da estrutura. Durante um evento sísmico, por exemplo, uma quantidade finita de energia é aplicada sobre a estrutura. Essa energia é transformada em energia cinética e também em energia potencial que deve ser absorvida ou dissipada através de calor. Se não há amortecimento, as vibrações continuarão indefinidamente. No entanto, sempre há algum nível de amortecimento que dissipa energia do sistema e reduz a amplitude de vibração até que o movimento cesse. O desempenho estrutural pode ser melhorado se parte da energia aplicada puder ser absorvida, não pela própria estrutura, mas por algum dispositivo suplementar (Soong \& Constatinou, 1994).

O controle estrutural, basicamente, promove uma alteração nas propriedades de rigidez e amortecimento da estrutura, seja pela adição de dispositivos externos, seja pela ação de forças externas. Conforme ISO 3010 (2001), a classificação dos sistemas de controle pode ser dividida em: controle passivo, controle ativo, semi-ativo e híbrido. Um esquema dessa categorização é apresentado na Figura 2.1. 


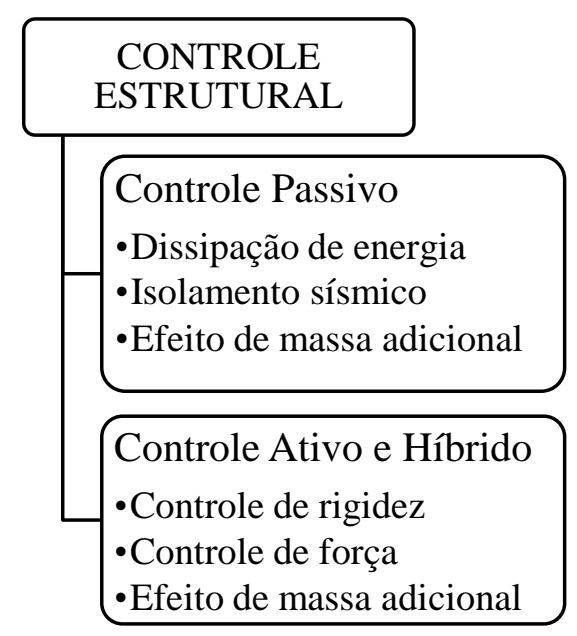

Figura 2.1 - Classificação dos sistemas de controle. Fonte: ISO 3010 (2001)

\subsection{CONTROLE PASSIVO}

Os sistemas de controle passivo operam sem a utilização de qualquer suprimento de energia externo, é transferida, basicamente, a energia gerada pela própria estrutura quando submetida a algum carregamento externo.

Um sistema de controle passivo se resume à instalação de um ou mais dispositivos incorporados à estrutura que absorvem ou transferem parte da energia transmitida pelo carregamento dinâmico, reduzindo, assim, a dissipação dessa energia nos membros da estrutura principal (Ávila, 2002).

Apresenta-se a seguir um resumo dos sistemas de controle passivo mais comuns utilizados na engenharia civil:

\section{$\checkmark$ Sistema de amortecimento suplementar:}

- Amortecedores Histeréticos: A base do mecanismo de dissipação consiste na deformação inelástica de um metal, normalmente um aço macio, ou mesmo ligas metálicas de chumbo ou outras mais complexas. Sob a ação de pequenos terremotos, um amortecedor histerético atua como um elemento de rigidez que auxilia na resistência estrutural às deformações, já quando sujeito a um terremoto mais severo, ele atua como um absorvedor de energia.

De uma maneira geral, amortecedores histeréticos apresentam comportamento estável diante de um grande número de ciclos de carregamento, apresentam efeitos 
insignificantes em relação ao tempo de uso e possuem resistência às ações ambientais e aos efeitos da temperatura adequados (Maldonado, 1995). Os amortecedores histeréticos, objeto de estudo desse trabalho, são apresentados com maiores detalhes no item 2.5 .

- Amortecedores de fricção: Amplamente utilizados em freios automotivos e posteriormente na engenharia estrutural, os amortecedores de fricção constituem um sistema de dissipação de energia através do atrito entre dois elementos sólidos com o deslizamento de um em relação ao outro. Eles são projetados para deslizar antes que qualquer escoamento ocorra nas estruturas. Esses dispositivos apresentam características do ciclo histerético idealizado de Coulomb, conforme apresentado na Figura 2.2.

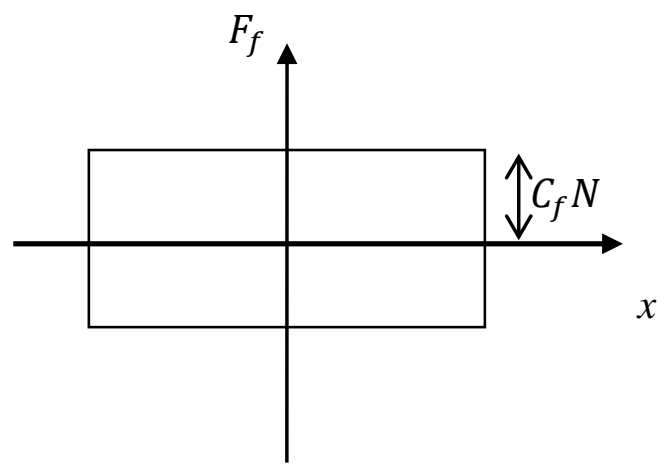

Figura 2.2 - Ciclo histerético idealizado de Coulomb para amortecedores de fricção

Onde :

$\begin{array}{ll}F_{f}: & \text { Força de fricção } \\ C_{f}: & \text { Coeficiente de fricção } \\ N: & \text { Força Normal }\end{array}$

- Amortecedores Viscoelásticos: Os materiais viscoelásticos apresentam tanto as características de um sólido elástico bem como aquelas de um líquido viscoso. Devido a essas propriedades, o material retorna à sua forma inicial após sofrer deformação com certo grau de perda de energia em forma de calor. Os amortecedores viscoelásticos são dispositivos que utilizam a deformação desses materiais como forma de dissipar energia.

- Amortecedores Viscofluidos: Esses dispositivos foram amplamente estudados no passado com o emprego significativo de esforços para a sua implementação estrutural (Soong \& Dargush, 1997). Amortecedores viscofluidos geralmente 
trabalham com o princípio de dissipação de energia através do fluxo de fluidos incompressíveis através de orifícios (Constantinou \& Symans, 1993). A força de amortecimento viscoso é proporcional à velocidade do movimento, dada pela Equação 2.1.

$$
F_{v d}=c|\dot{x}|^{\beta} \operatorname{sgn}(\dot{x})
$$

sendo:

$$
\begin{aligned}
F_{v d}: & \text { Força de amortecimento viscoso } \\
c: & \text { Coeficiente de amortecimento } \\
\beta: & \text { Para aplicações na engenharia estrutural, como sistemas resistentes a vento } \\
\dot{x}: & \text { Velocidade do movimento }
\end{aligned}
$$

- Amortecedores Líquidos sintonizados (ALS): Amortecedores líquidos são práticos, uma vez que em geral existem tanques d'água na estrutura para abastecimento do edifício. Este tipo de amortecedor consiste em configurar as partições internas de forma a criar diversos amortecedores, sem comprometer o funcionamento original dos tanques. Esse sistema é indicado para estruturas com pequenas vibrações, e pode reduzir a resposta de aceleração da estrutura em até 1/3. Esses amortecedores dissipam energia através da ação viscosa da água e das ondas provocadas pela movimentação da água. A frequência natural de um ALS pode ser ajustada através da profundidade da água no tanque e de suas dimensões. Portanto, há limitações práticas em relação à frequência obtida por esse sistema (Rios, 2015).

$\checkmark$ Sistema de isolamento de base: A caracterização de isolamento de base consiste em desacoplar a superestrutura das componentes horizontais do movimento do solo, pela interposição de elementos estruturais de baixa rigidez horizontal, entre a superestrutura e a fundação. Dessa maneira, possibilita-se que a frequência fundamental do edifício com isolamento de base seja inferior à frequência fundamental do mesmo, caso seja executado com base fixa, assim como à frequência predominante da excitação sísmica. De forma simplificada, pode se dizer que o sistema de isolamento de base consiste na mitigação da transferência das forças sísmicas para a superestrutura através do isolamento da infraestrutura, ou seja, das fundações do edifício. A representação esquemática do sistema de isolamento de base é apresentada na Figura 2.3. 


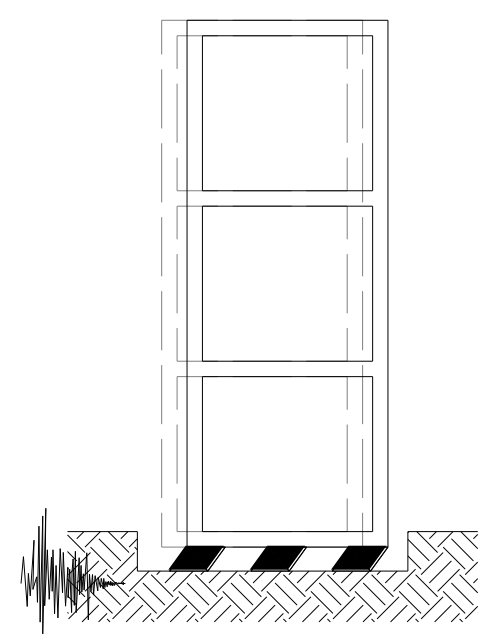

Figura 2.3 - Sistema de Isolamento de base

$\checkmark$ Sistema de amortecedores de massa sintonizados (AMS): Um amortecedor de massa sintonizado (AMS) é um dispositivo composto de uma massa, uma mola e um amortecedor que é ligado à estrutura com o objetivo de reduzir a resposta dinâmica da mesma. A frequência do amortecedor é sintonizada para uma frequência particular da estrutura, pois, uma vez que a estrutura for excitada, o amortecedor irá vibrar fora de fase com o movimento da estrutura. A energia atuante sobre o sistema principal é transferida para o sistema secundário, reduzindo assim sua vibração. Uma representação esquemática do AMS é apresentada na Figura 2.4.

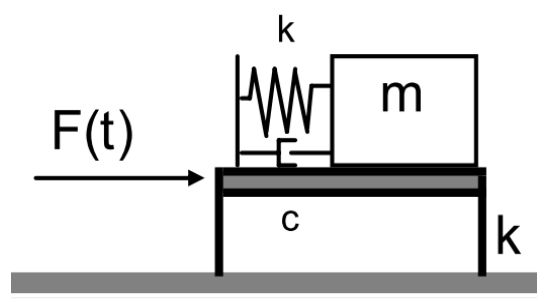

Figura 2.4 - Amortecedor de massa sintonizado passivo. Ospina, 2008, modificado.

O conceito de amortecedor de massa sintonizado foi primeiro utilizado por Frahm em 1909 para reduzir o balanço dos navios devido às ondas, logo depois foi apresentada uma teoria sobre o assunto por Ormondroyd e Den Hartog, seguida por uma discussão detalhada da busca de parâmetros (Den Hartog, 1956). A teoria inicial foi desenvolvida para um sistema de um único grau de liberdade sujeito a uma força harmônica senoidal. A continuação do estudo dos amortecedores de 
massa sintonizados foi feita por outros estudiosos com importantes contribuições. Da mesma forma, o tema tem sido amplamente estudado pelos pesquisadores da Universidade de Brasília (UnB).

Carneiro (2004) se dedicou à avaliação de amortecedores de massa sintonizados múltiplos (AMSM) aplicados à redução de vibrações em edifícios altos, verificando a influência e os efeitos do número total de massas e da interligação das massas no seu desempenho.

Lara (2007) analisou numericamente, por meio do programa Ansys®, a eficiência de um sistema de controle passivo (AMS) instalado em vigas metálicas de seção retangular, com distintas condições de apoio.

Lima (2007) avaliou a resposta dinâmica do piso de um edifício comercial submetido carregamento oriundo das atividades humanas como, pular e dançar, atividades, típicas de academias de ginástica. Após análise foi proposto um sistema de controle estrutural por meio da instalação de um conjunto de Amortecedores de Massa Sintonizados.

Zuluaga (2007) apresentou os parâmetros ótimos (comprimento do cabo e razão de amortecimento) de um amortecedor de massa sintonizado (AMS) na geometria de pêndulo quando o sistema principal ou estrutura está submetida à excitações ambientais aleatórias dadas por funções de densidade espectral de potência.

Ospina (2008) obteve parâmetros ótimos para os amortecedores de massa sintonizados múltiplos interligados (AMSM I), trabalhando com variáveis como o número de amortecedores, razão de frequência, razão de amortecimento e razão de massa, entre outras.

Carmona (2011) trabalhou no projeto e construção de uma plataforma de ensaios dinâmicos para realização pesquisas numérico-experimentais de lajes submetidas a cargas dinâmicas geradas por grupos de pessoas em movimento. Foram realizadas análises numéricas da plataforma de ensaios dinâmicos em vibração livre e forçada para obter as frequências naturais e os modos de vibração correspondentes, considerando peso próprio da estrutura e carregamento que simula o peso das pessoas.

Oliveira (2012) avaliou a eficiência de um amortecedor de massa sintonizado (AMS) na geometria de pêndulo, apresentando os critérios de projeto obtidos por busca numérica, quando o sistema é submetido a uma força harmônica e a uma aceleração na base. 
Entretanto, há limitações no uso desta tecnologia, já que os dispositivos são projetados de forma a funcionar eficientemente dentro de uma determinada faixa de frequência. As características dinâmicas da maioria dos carregamentos naturais, como ventos e terremotos, não são conhecidas a priori, sendo de natureza aleatória. Se a estrutura projetada com controle passivo for excitada fora da faixa de frequência de projeto, este tipo de controle perde a sua eficiência (Avila, 2002).

\subsection{CONTROLE ATIVO}

O controle ativo consiste na aplicação de forças à estrutura através de atuadores alimentados por fontes de energia externa. A magnitude dessas forças é calculada em tempo real por um computador, utilizando um dos variados algoritmos de controle ativo, sendo função da resposta da estrutura medida através de sensores, também em tempo real. O sistema de controle ativo não possui as limitações do controle passivo no que se refere à frequência da excitação, já que é capaz de se adaptar às mudanças de parâmetros tanto do carregamento, como também da estrutura. Este sistema apresenta como desvantagem a necessidade de fonte de energia externa em grande quantidade, que geralmente é deficiente após eventos de natureza aleatória como sismos (Avila, 2002).

A configuração básica de um sistema de controle ativo está apresentada na Figura 2.5. Este consiste, essencialmente, em sensores localizados em determinados pontos da estrutura com o objetivo de medir tanto a resposta como a excitação; em dispositivos para o processamento destes dados que, através dos algoritmos de controle, calculam as forças de controle necessárias e; em atuadores alimentados por fontes de energia externa que aplicam as forças de controle sobre o sistema. 


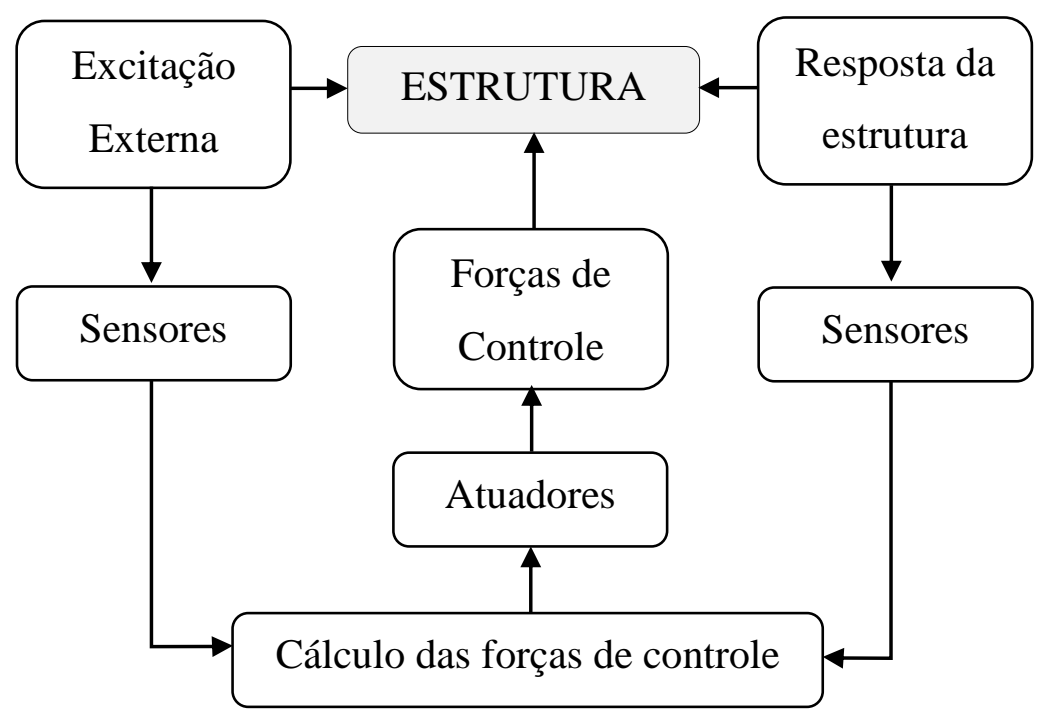

Figura 2.5 - Sistema de controle ativo esquemático. (Soong \& Dargush, 1997)

\subsection{CONTROLE SEMI-ATIVO}

Existem também os controladores semi-ativos, que não adicionam energia ao sistema estrutural controlado, mas possuem propriedades, as quais, controladas de forma ótima, reduzem a resposta do sistema. Têm a vantagem de possuir a adaptabilidade dos controladores ativos sem demandar grandes quantidades de energia, podendo, em muitas aplicações, operar com baterias de emergência, no caso de falta de energia. $O$ ajuste das propriedades mecânicas do sistema geralmente é feito retroalimentando os dispositivos semi-ativos com os dados da resposta e da excitação medidos, assim, da mesma maneira que em um sistema ativo, um controlador monitora os registros obtidos e gera através de um comando apropriado, baseado em um algoritmo de controle predeterminado, um sinal para o dispositivo semi-ativo. Já as forças de controle são desenvolvidas da mesma forma que em um sistema passivo, como resultado do movimento da estrutura. O caráter de adaptabilidade desses dispositivos torna-os muito eficientes na redução da resposta estrutural para uma vasta gama de condições de carregamentos. Sistemas semi-ativos corretamente implementados apresentam performance superior aos dispositivos passivos e tem o potencial de atingir ou, em alguns casos, até mesmo superar a performance dos sistemas ativos. Em suma, é uma espécie de dispositivo passivo controlável (Soong, 1990; Carneiro, 2009; Dyke, 1996, Lara Valencia, 2011). 


\subsection{CONTROLE HÍBRIDO}

Uma forma de controle alternativa ao controle ativo e passivo foi desenvolvida, trata-se do controle híbrido que nada mais é do que uma combinação do controle passivo e do ativo. A parcela ativa entra em funcionamento somente quando a resposta da estrutura excede a capacidade de dissipação de energia da parcela passiva (Xue et al., 1997).

Este tipo de controle pode ser visto como uma forma alternativa que suprime as principais desvantagens dos controles passivo e ativo isoladamente. A principal desvantagem do controle passivo seria a perda de eficiência para excitações fora da faixa de frequência para a qual foi projetado, enquanto o controle puramente ativo teria como desvantagem a demanda de grandes quantidades de energia para a geração das forças de controle. A vantagem está no fato deste sistema exigir forças de magnitudes bem menores nos atuadores, o que gera uma considerável redução no custo, além de um desempenho mais eficiente comparado ao sistema passivo, ampliando a faixa de frequência em que o mesmo funciona de forma eficiente. Outra vantagem do controle híbrido é a de que, no caso de falta de energia, o seu componente passivo ainda oferece certo grau de proteção à estrutura (Avila, 2002; Carneiro, 2009).

\subsection{DISSIPADORES METÁLICOS}

A ação de um terremoto em uma estrutura se dá através da interação da aceleração aleatória do solo e da própria inércia da sistema estrutural. Uma vez que a frequência natural de um grande edifício está próxima da frequência dominante da aceleração do solo, para resistir à ação de um grande terremoto é necessário algum grau de deformação plástica na estrutura (Kelly et. al.,1972). A deformação plástica, que acontece quando os limites de deslocamento são excedidos, dá um grande incremento no amortecimento mecânico e permite que as deformações ultrapassem àquelas projetadas no estado elástico.

Um dos mecanismos mais efetivos para a dissipação de energia, introduzida em uma estrutura durante um terremoto, se dá através da deformação inelástica de dispositivos metálicos (Soong \& Dargush, 1997). 
Ao longo dos anos vários trabalhos foram publicados a respeito do comportamento desse tipo de dispositivo, sendo que, essas pesquisas agregaram relevante progresso no desenvolvimento dos dissipadores metálicos.

Um dos trabalhos pioneiros foi o de Kelly et al. (1972) que, partindo da concepção que as conexões das estruturas, quando sujeitas às cargas cíclicas, não eram confiáveis, eles se concentraram em incorporar dispositivos no sistema estrutural com o objetivo de se absorver energia cinética gerada na estrutura durante um terremoto. Dessa forma, as instabilidades locais em vigas metálicas, bem como as tensões cisalhantes alternadas nas vigas de concreto armado, são reduzidas de forma considerável, pois boa parte da energia passa a ser dissipada nos dispositivos metálicos incorporados. Durante seus estudos, três tipos principais de dispositivos foram propostos e testados, eles se diferenciavam essencialmente na forma de dissipação de energia, sendo cada um aplicado para uma situação estrutural específica.

O dispositivo denominado TIPO A trabalha basicamente através do aplanamento da curvatura de placas planas fabricadas em aço macio. Sua utilização é indicada para locais onde o esforço de cisalhamento é preponderante.

O dispositivo TIPO B utiliza a combinação de torção e flexão, com predominância de torção, de barras retangulares ou quadradas. Seu funcionamento se baseia no movimento relativo cíclico entre duas superfícies e, como a capacidade de dissipação é bastante elevada, pode ser utilizado em fundações associados a paredes estruturais.

Já o TIPO C utiliza o comportamento de flexão de pequenas placas retangulares tornando o dispositivo apropriado para utilização em contraventamentos em vigas de aço ou mesmo de concreto armado.

A Figura 2.6 mostra o modo de operação dos três modelos de dissipadores metálicos propostos por Kelly et al. (1972). 


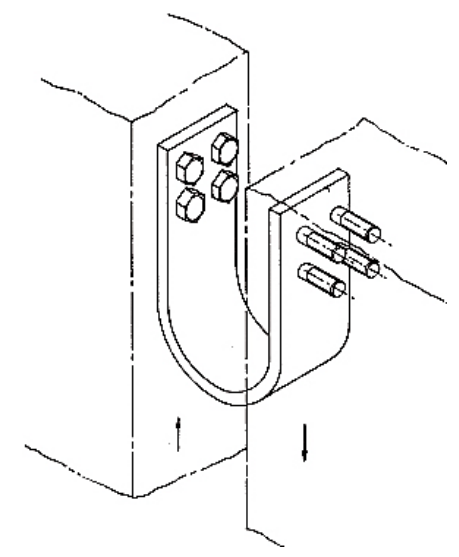

(a) Dissipador de energia de cisalhamento (TIPO A)

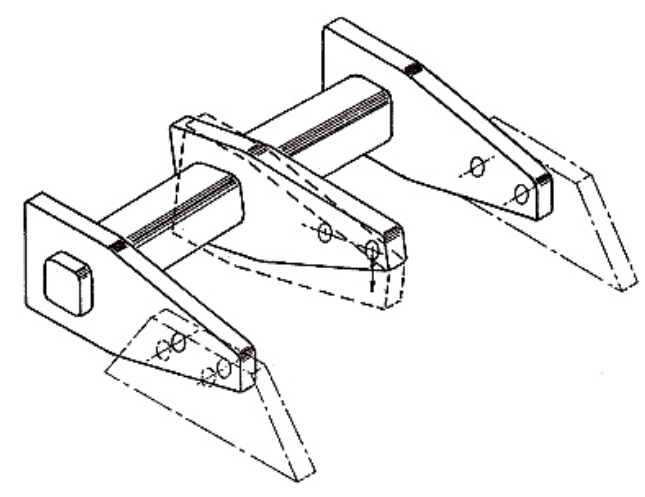

(b) Dissipador de energia de torção

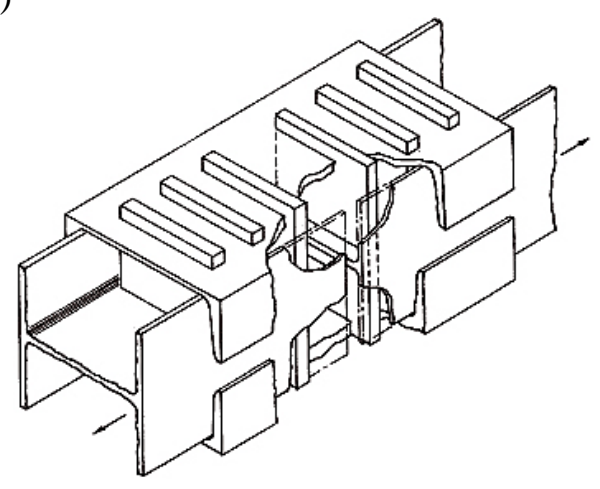

(TIPO B)

(c) Dissipador de energia de flexão (TIPO C)

Figura 2.6 - Geometria de dissipadores metálicos. Fonte: Kelly et al. (1972)

Após análises para obtenção da magnitude de energia que esses dispositivos poderiam dissipar, foi concluído que os mesmos apresentaram bom desempenho não só na dissipação de energia, mas também na elevada capacidade resistente à fadiga.

Alguns anos depois, Boardman et. al. (1983) descreveram o projeto e construção de um edifício para escritórios de doze pavimentos com dissipadores na base bem como contraventamento externo para resistir às cargas laterais. Uma imagem recente da edificação e quando foi construída é apresentada na Figura 2.7. 


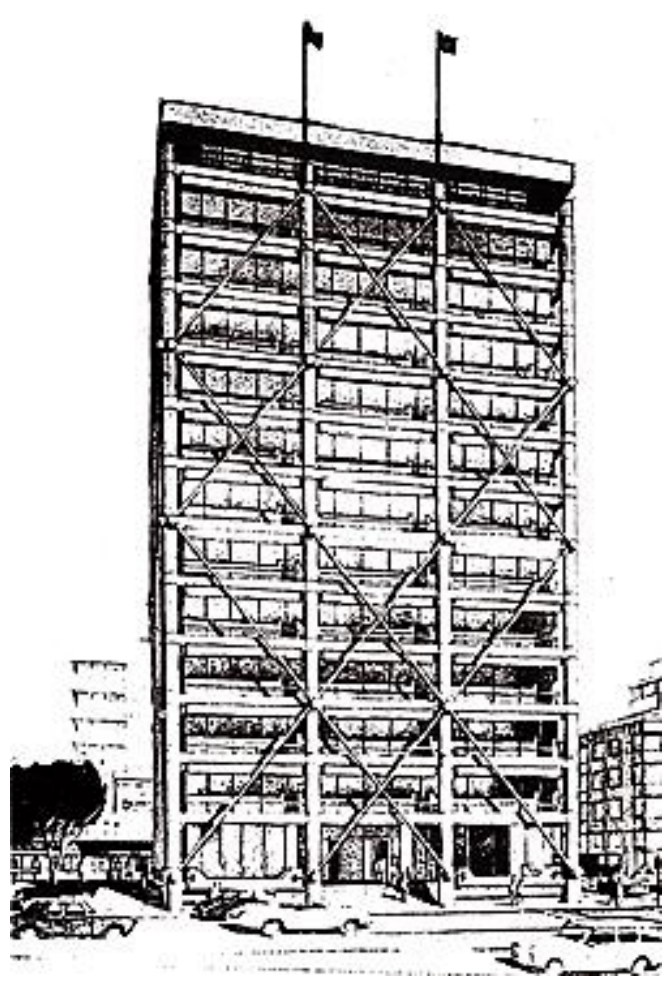

a) Vista Frontal. Boardman et. al. (1983)

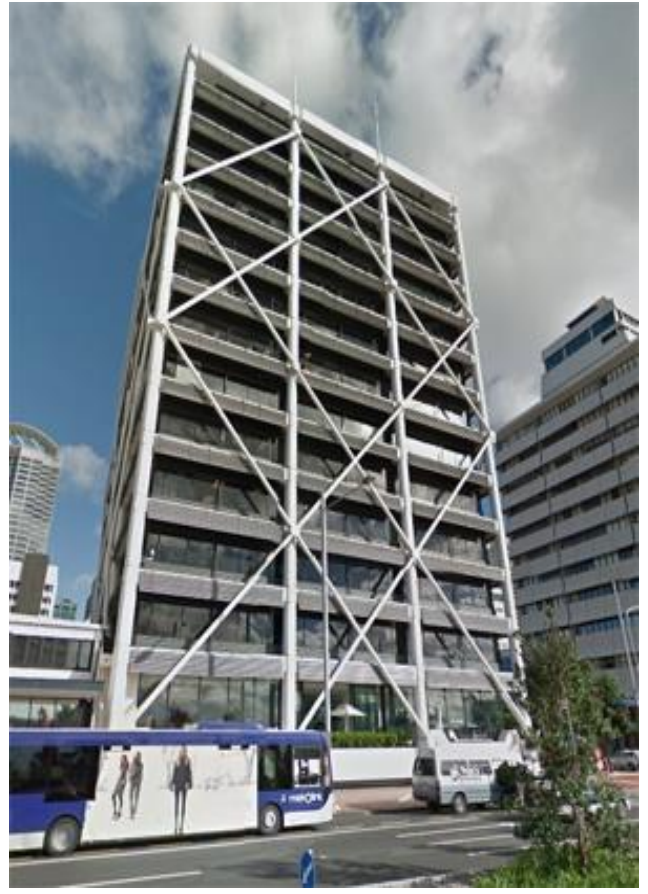

b) Vista Frontal. Google Street View (2014)

Figura 2.7 - Edifício Union House localizado na QuayStreet, Auckland.

De forma preliminar, foi realizada uma análise de esforços solicitantes sem a ajuda de computadores, dessa maneira conseguiu-se realizar um pré-dimensionamento dos elementos estruturais bem como realizar uma previsão do custo da obra, em seguida foi realizada uma análise estática.

Para aprimorar os resultados encontrados, foram realizadas mais duas análises. A primeira delas, uma análise dinâmica simplificada, onde se considerou um sistema com uma mola com comportamento elastoplástico bilinear representando os quatro dissipadores reais, e outra mola elástica acoplada junto a um amortecedor representando o solo. Finalmente realizou-se uma análise dinâmica considerando os parâmetros de excitação do solo de San Fernando - 1971 e do El Centro - 1940.

Após análise dos resultados observou-se que a instalação dos dissipadores metálicos reduziu significativamente os deslocamentos da estrutura, garantindo assim maior conforto e segurança para os seus usuários. O gráfico da Figura 2.8 mostra os deslocamentos no topo do edifício para três situações, a primeira considerando o 
dissipador infinitamente rígido, a segunda como ele foi realmente construído e finalmente considerando-o infinitamente flexível.

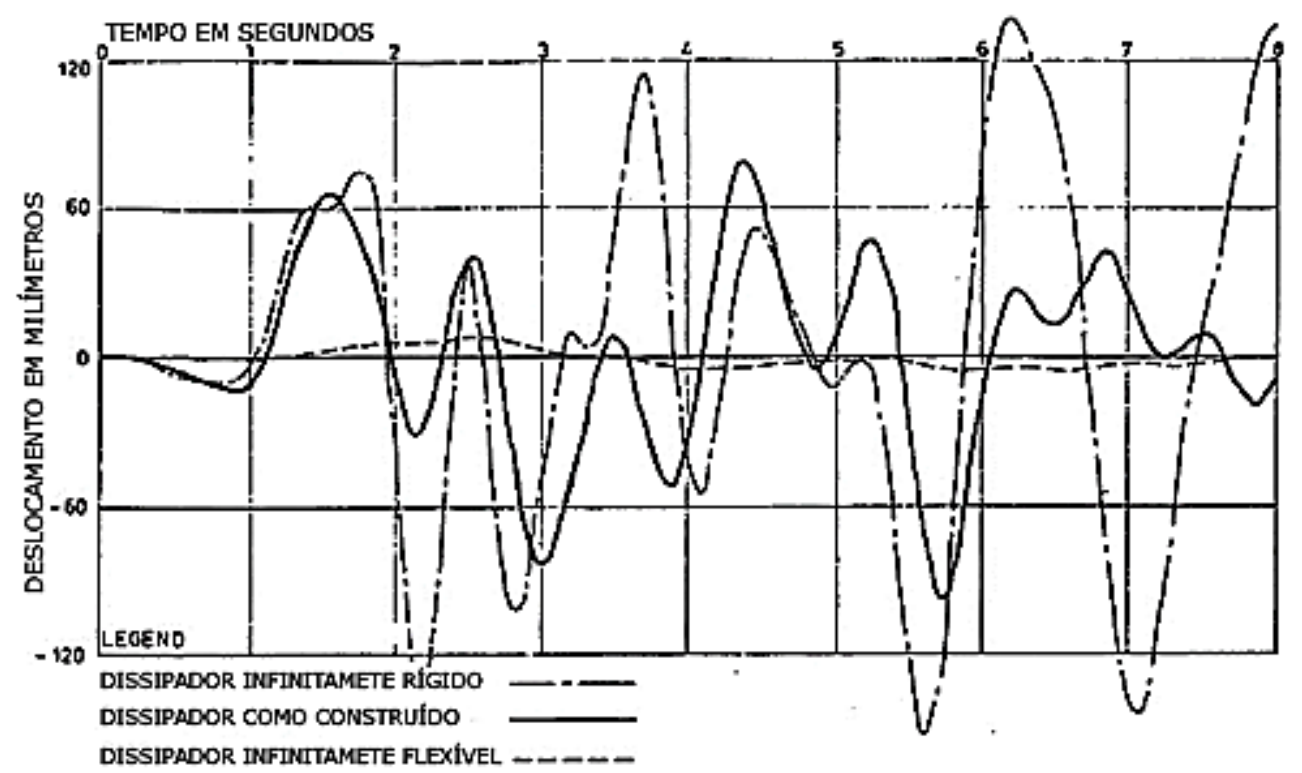

Figura 2.8 - Deslocamento do topo do Edifício Union House.

Fonte: Boardman et. al. (1983)

Uma representação esquemática do dissipador metálico utilizado, assim como o esquema de instalação é apresentada na Figura 2.9.

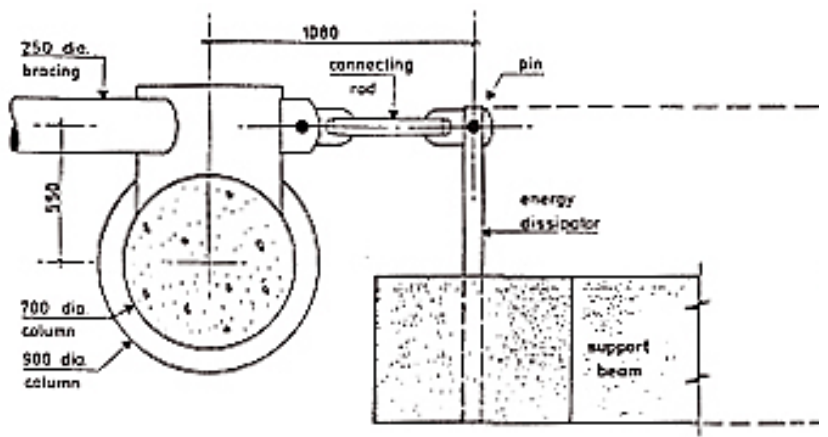

(a) Planta baixa

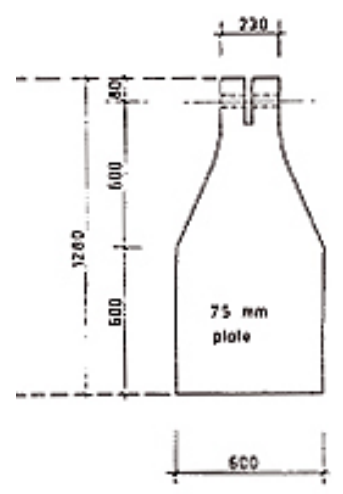

(b) Vista Frontal

Figura 2.9 - Dissipador de energia típico. Fonte: Boardman et. al. (1983)

Outra grande contribuição a respeito dos dissipadores metálicos se deu com a publicação de Whittaker et al. (1989), que investigou o comportamento de placas paralelas no formato "X" denominadas ADAS (Added Damping and Stiffness) de forma a determinar o grau de efetividade para aplicações sísmicas em geral. Uma representação esquemática do ADAS é apresentada na Figura 2.10. 


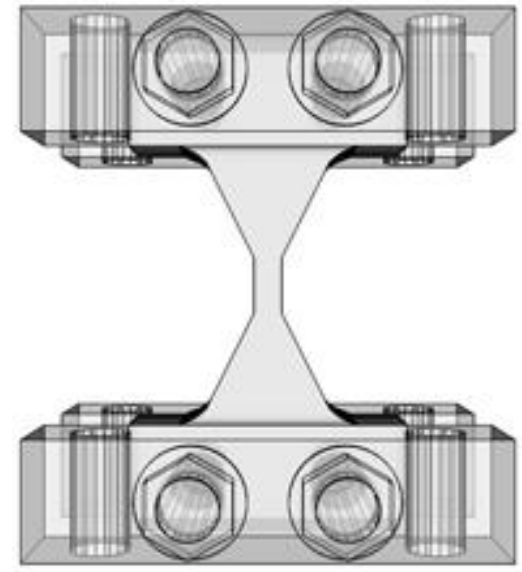

(a) Vista frontal

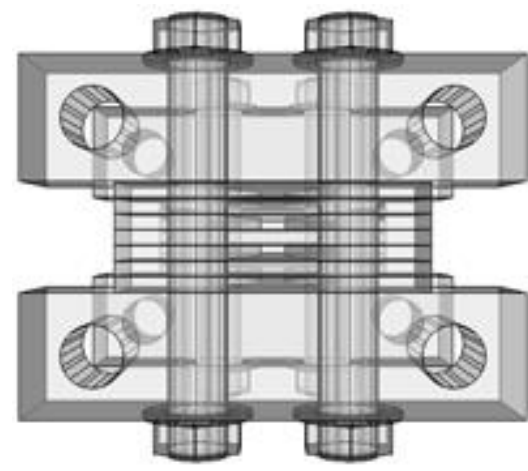

(c) Vista Superior

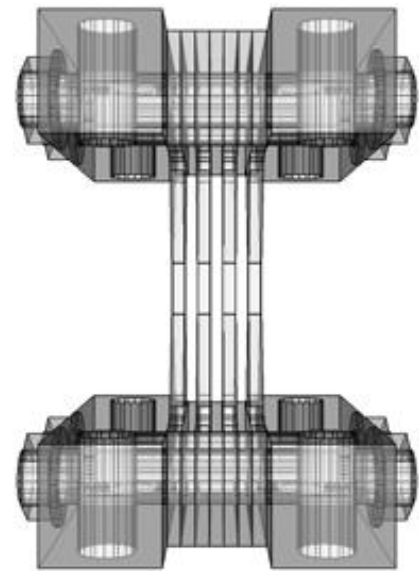

(b) Vista lateral

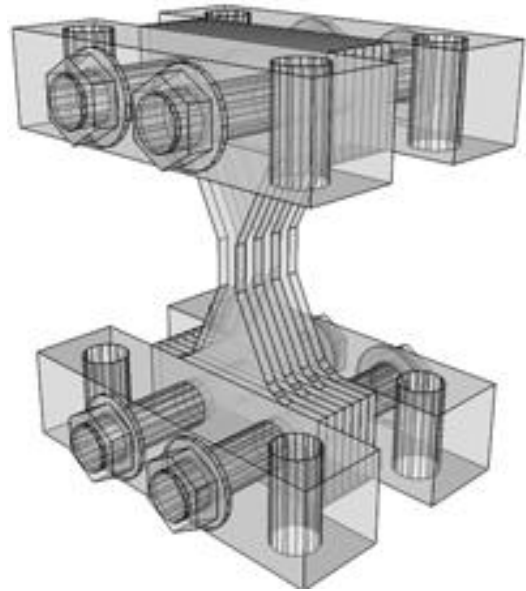

(d) Perspectiva

Figura 2.10 - Dispositivo ADAS

O dispositivo ADAS é projetado para auxiliar a reduzir a resposta sísmica de estruturas através da sua deformação plástica, que produz um aumento substancial da energia histerética dissipada na estrutura. Esta dissipação de energia histerética adicional devido aos dispositivos de ADAS também pode ser entendida como um aumento do amortecimento interno equivalente da estrutura (Chalco, 2014).

Ao ser instalada na estrutura, as placas ficam engastadas em ambos os extremos, impedidas assim as rotações. $\mathrm{O}$ formato da placa foi determinado com o objetivo de que a ela se deforme com dupla curvatura em relação ao seu ponto médio e que apresente escoamento ao longo de toda sua altura, não apenas ao longo dos extremos, como aconteceria se fosse retangular, por exemplo. A representação da deformação, assim como a distribuição de tensões, são apresentadas na Tabela 2.1 para as placas na configuração retangular e no formato " $\mathrm{X}$ ". 
Tabela 2.1 - Placas dissipadoras de energia. Fonte: Whittaker et al. (1989), modificado

\begin{tabular}{|c|c|c|c|c|}
\hline $\begin{array}{c}\text { Configuração da } \\
\text { placa }\end{array}$ & Perfil & Deformação & $\begin{array}{c}\text { Distribuição de } \\
\text { Tensões }\end{array}$ & Aplicabilidade \\
\hline Retangular & & & & $\begin{array}{c}\text { Não aplicável } \\
\text { devido ao } \\
\text { escoamento } \\
\text { local apenas }\end{array}$ \\
\hline Formato "X" & & & & Aplicável \\
\hline
\end{tabular}

As placas no formato "X", patenteadas pela Bechtel Power Corporation, foram avaliadas através de estudos analíticos e experimentais com o objetivo de se determinar as características mecânicas do ADAS composto por 4, 6 e 7 placas metálicas. O experimento, como pode ser observado na Figura 2.11, foi realizado no Earthquake Simulator Laboratory (ESL) na Universidade da Califórnia em Berkeley.

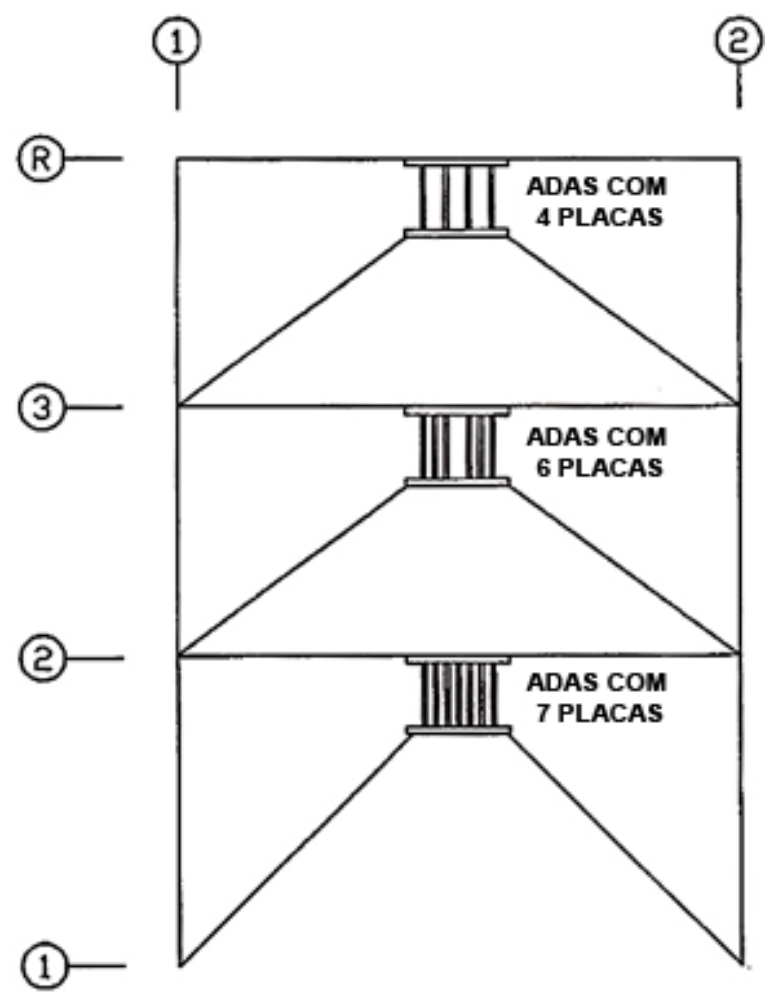

Figura 2.11 - Estrutura de testes. Fonte: Whittaker et al. (1989), modificado

Após a análise, observou-se que todos os dispositivos ADAS apresentaram comportamento histerético estável sem sinais de perda de rigidez ou resistência até o 
limite de $14 \Delta_{y}{ }^{A D A S}$ para as amplitudes de deslocamentos, sendo $\Delta_{y}{ }^{A D A S}$ o deslocamento de escoamento do dispositivo. Os testes demonstraram que os dispositivos ADAS podem suportar um grande número de ciclos de escoamento e acumular grande quantidade de deformação plástica sem sinais de degradação.

Xia \& Hanson (1992) definem os dispositivos ADAS como um conjunto de placas com deslocamento relativo do topo em relação à base, conforme representado na Figura 2.12. Eles apresentaram ainda alguns benefícios além de se dissipar energia através do escoamento dessas placas, foram eles:

1. A dissipação da energia dos terremotos é concentrada nos locais onde foi projetada para esse propósito;

2. A demanda de dissipação de energia nos outros elementos estruturais é significativamente reduzida;

3. Uma vez que esses dispositivos compõem o sistema estrutural apenas no que se refere à resistência às cargas laterais, o escoamento deles não afetará a capacidade relativa às cargas de serviço do sistema estrutural, além do mais, os dispositivos ADAS podem ser facilmente substituídos caso seja necessário.

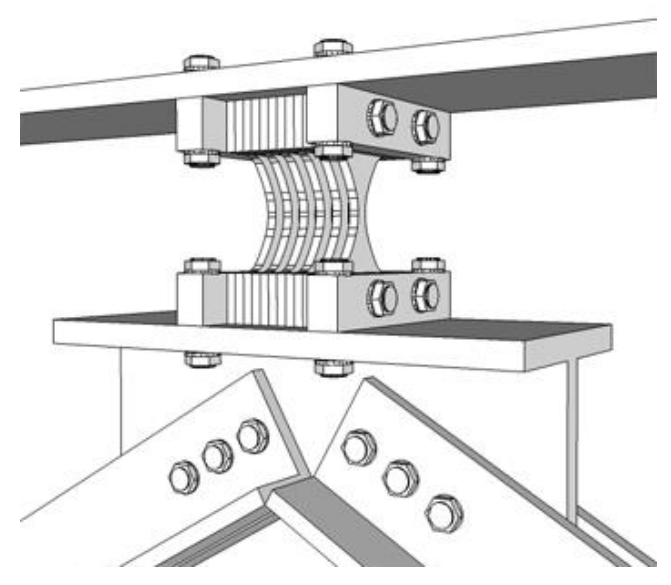

(a) Estrutura indeformada

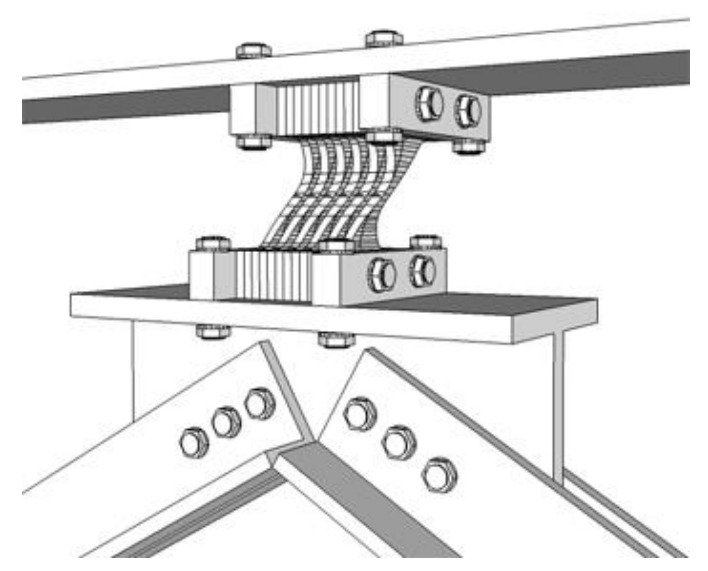

(b) Estrutura deformada

Figura 2.12 - Dispositivo ADAS instalado na estrutura

Em seus estudos eles consideraram um modelo de escoamento bilinear devido a sua simplicidade matemática, bem como devido a sua capacidade de representar o endurecimento por deformação e o comportamento histerético. Os detalhes da formulação matemática são apresentados no item 3.2. Entre os dispositivos metálicos que trabalham através da deformação inelástica, o ADAS (Added Damping and 
Stiffness) e o TADAS (Triangular-plate Added Damping and Stiffness) são os mais populares nas aplicações sísmicas (Moreschie \& Singh, 2003).

Uma contribuição importante na área de otimização topológica de dissipadores metálicos foi dada por Ghabraie et al., (2010), que utilizando uma técnica modificada do algoritmo denominado BESO (Bi-directional Evolutionary Structural Optimization), propuseram uma nova topologia de um dissipador metálico.

A técnica BESO consiste na busca iterativa de uma topologia ideal através da retirada de material das áreas ineficientes da peça e na adição de material próximo às áreas mais eficientes. Segundo Ghabraie et al., (2010), desde a sua introdução, o algoritmo BESO foi melhorado significativamente e aplicado com sucesso tanto em problemas de otimização topológica como em problemas de otimização de forma.

Durante a análise e busca de uma topologia otimizada, diversos modelos foram testados com diferentes materiais e volumes buscando sempre melhorias na capacidade de absorção de energia. A representação de parte de duas amostras analisadas, caso V76 e V84, são apresentados na Figura 2.13.

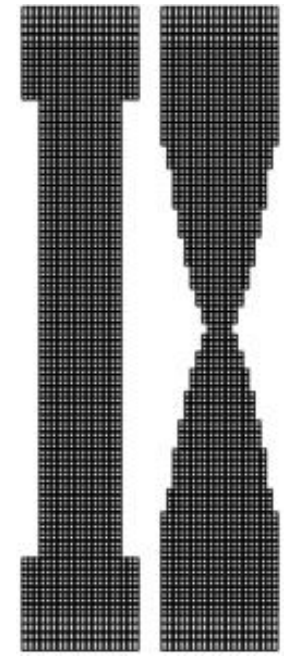

a) Otimização Topológica - Caso V76. Ghabraie et. al., (2010)
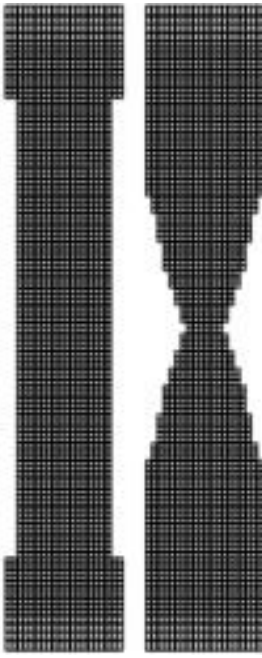

b) Otimização Topológica - Caso V84. Ghabraie et al., (2010)

Após a análise dos resultados dos casos analisados observou-se que a placa otimizada gera uma rigidez maior quando comparada à forma inicial. Como pode ser observado na Figura 2.14, após sofrer um deslocamento cíclico de $10 \mathrm{~mm}$, o modelo inicial produz uma reação de 16,4 kN, já o modelo otimizado produz uma reação de $24,3 \mathrm{kN}$ para esse 
mesmo deslocamento, ou seja, com a peça otimizada conseguiu-se uma capacidade reativa $48 \%$ maior.

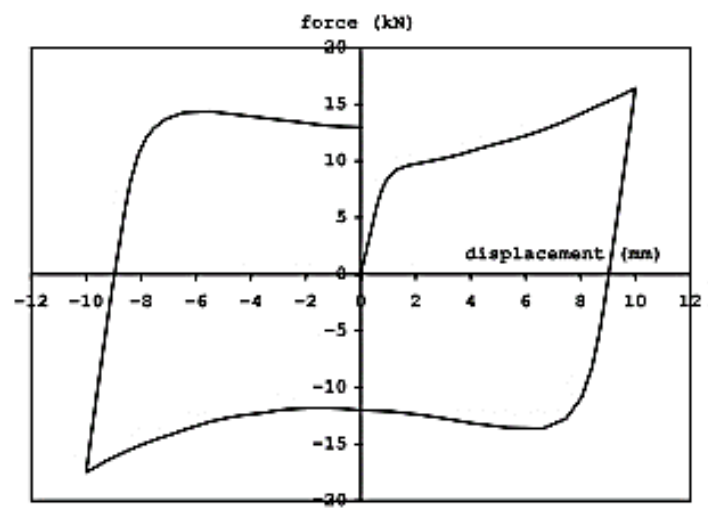

(a) Modelo inicial

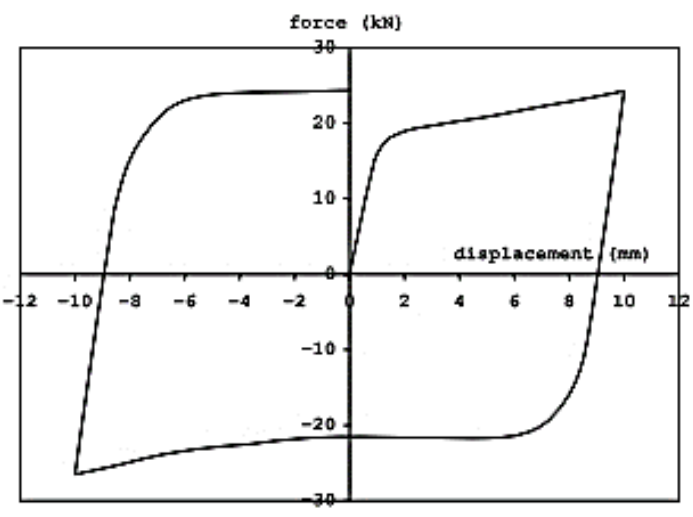

(b) Modelo otimizado

Figura 2.14 - Comparação de curvas força-deslocamento. Ghabraie et. al., (2010)

Carpineto et al., (2013) se dedicaram ao estudo da histerese exibida por cabos de aço curtos aplicados na configuração de amortecedores metálicos. Estudos numéricos e experimentais foram realizados considerando uma estrutura de teste representada por uma viga simplesmente apoiada juntamente com um protótipo de amortecedor histerético sujeito à excitação. Os detalhes da configuração do modelo são apresentados na Figura 2.15.

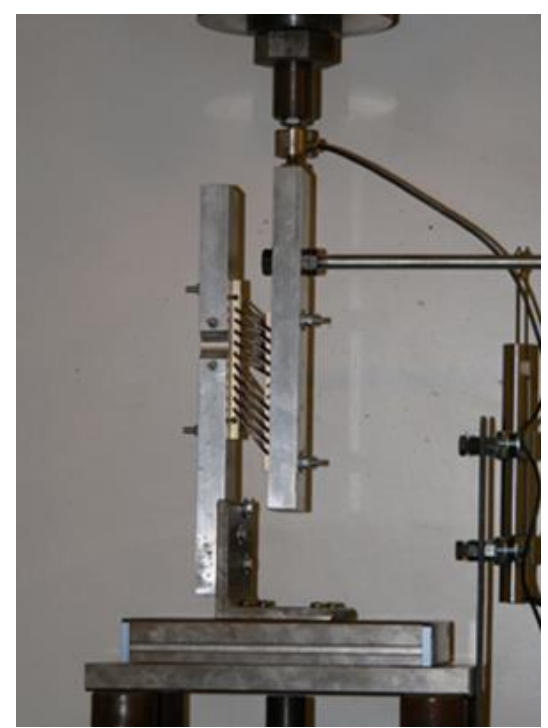

(a) Viga com instalação do amortecedor Figura 2.15 - Configuração do sistema de ensaio. Carpineto et al., (2013)

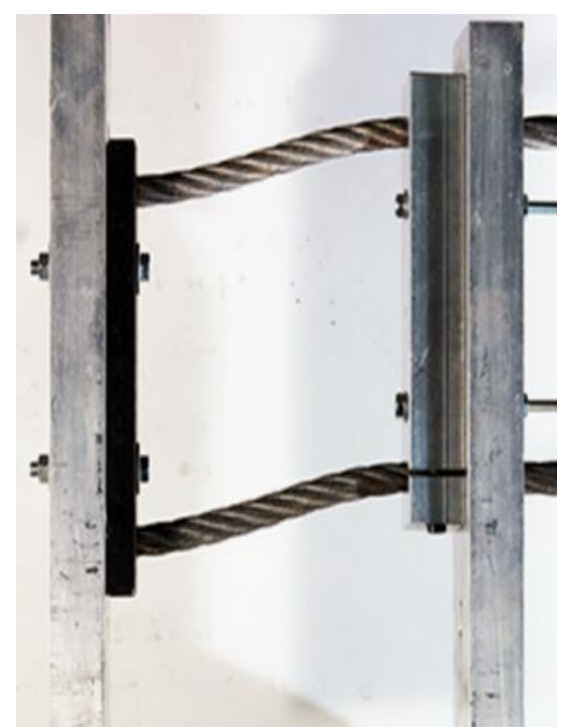

(b) Protótipo do amortecedor

Através dos experimentos, foram caracterizados os diagramas de histerese e definida uma concepção otimizada desses amortecedores para uma ampla gama de amplitudes de excitação. 
Liu et al., (2013) apresentam um modelo de otimização topológica para uma chapa de aço sujeita à ações cisalhantes com o objetivo de se melhorar sua capacidade de deformação. Eles denominaram o modelo como Shear Panel Dampers (SPD) ou simplesmente Placa de Amortecimento Cisalhante, numa tradução livre. No modelo foi analisada uma placa quadrada com dimensões de $156 \mathrm{~mm}$ de largura e $12 \mathrm{~mm}$ de espessura. A representação do modelo com as condições de contorno assim como seu modelo de deformação após a aplicação do carregamento são apresentados na Figura 2.16 .

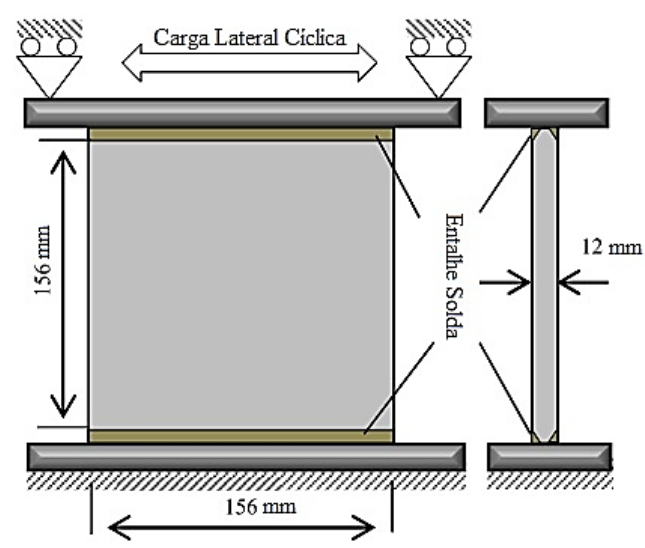

a) Formato inicial e condições de contorno

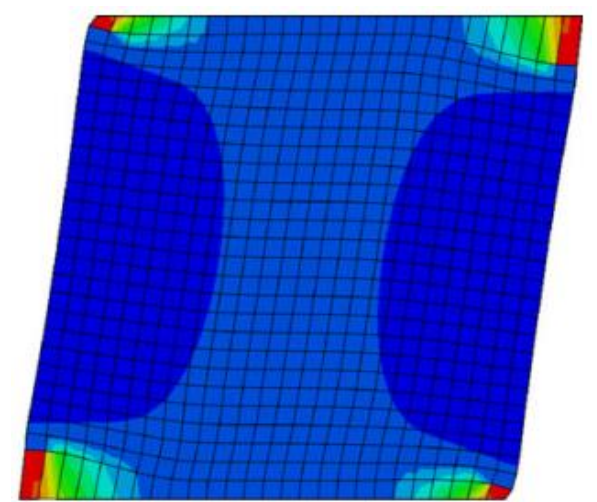

b) Modelo de deformação do SPD

Figura 2.16 - Representação do SPD. Liu et al., (2013)

Uma vez definido o modelo de carregamento e as condições de contorno, foi realizada a formulação do problema de otimização topológica em que se buscou a relação ótima entre largura $(L)$ e altura $(H)$ do modelo de forma a minimizar a flexibilidade, a otimização ficou sujeita à restrição de volume. Após convergência do modelo foi determinado o formato ideal a ser utilizada para o modelo SPD, conforme apresentado na Figura 2.17. 


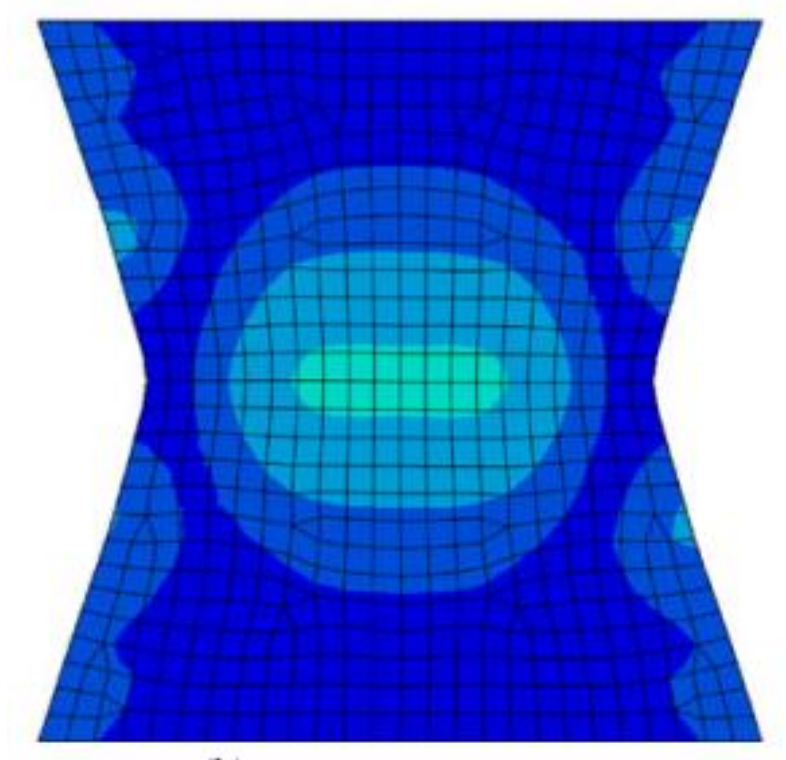

Figura 2.17 - Formato ótimo proposto para o SPD. Liu et al., (2013)

Bagheri et al., (2015) avaliaram o desempenho de amortecedores metálicos no formato "U” instalados em pórticos metálicos e os compararam com amortecedores de fricção. O detalhe de instalação do amortecedor em forma de U é apresentado na Figura 2.18.

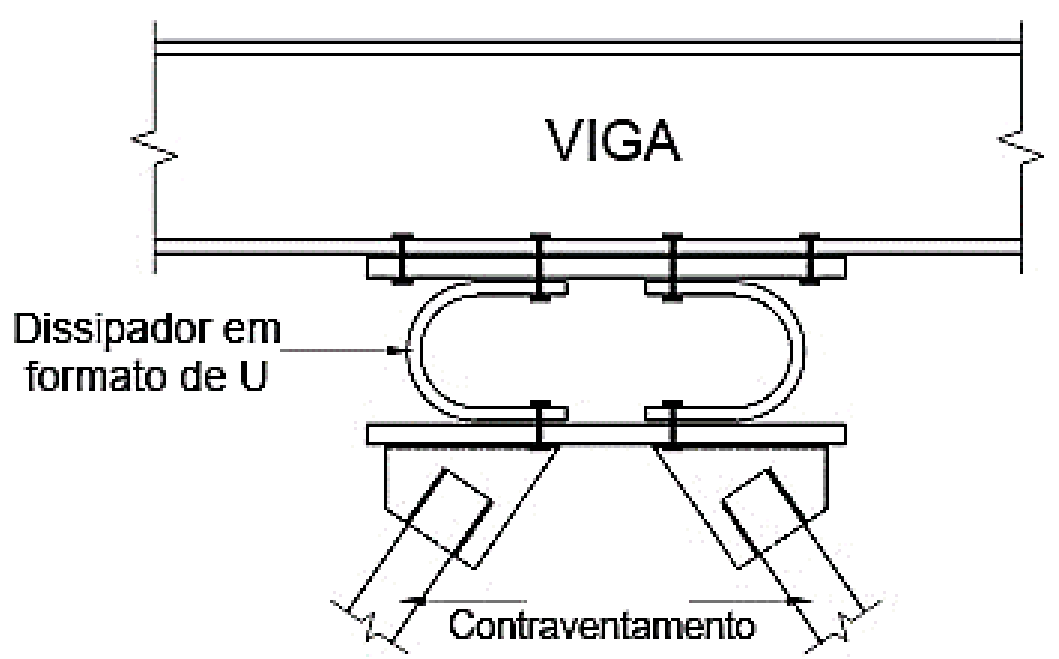

Figura 2.18 - detalhe de instalação do amortecedor em forma de U

Além disso, a fim de se suportar carregamentos biaxiais, o arranjo circular pode ser adotado, permitindo assim a dissipação de energia do dispositivo ao longo de todas as direções. A representação do arranjo uni e multiaxial é apresentada na Figura 2.19. 


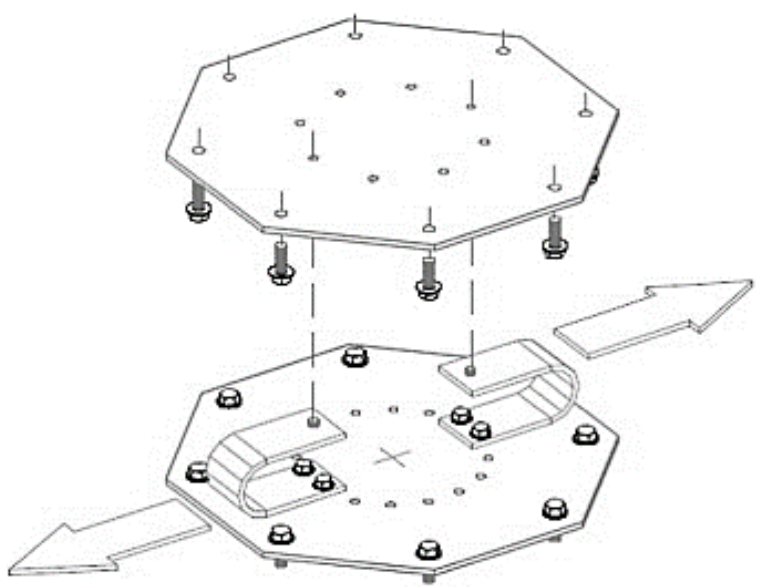

a) Uniaxial em forma de $\mathrm{U}$

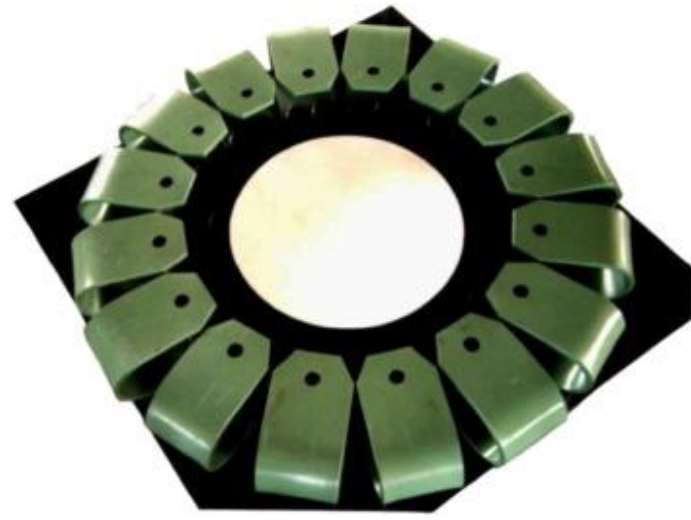

b) Multiaxial em forma de U com arranjo circular

Figura 2.19 - Arranjo direcional do dissipador metálico

Foram realizadas análises dinâmicas não lineares para quatro diferentes tipos de acelerações do solo. Os resultados demonstraram que em ambos os sistemas o comportamento não linear é transferido dos elementos estruturais para os dissipadores metálicos, mitigando ou eliminando os danos estruturais.

\subsubsection{EXEMPLOS DE APLICAÇÃO DA LITERATURA}

Com o ganho de confiabilidade no desempenho de amortecedores metálicos após análises experimentais, uma série de aplicações práticas começaram a ser implementadas. As primeiras aplicações desses amortecedores metálicos em sistemas estruturais ocorreram na Nova Zelândia e no Japão (Constantinou et. al., 1998).

O primeiro amortecedor histerético desenvolvido em laboratório foi do tipo dissipador de energia de torção para aplicação no projeto da Ponte Rangitikei localizada na Nova Zelândia (Skinner et. al., 1974). Alguns detalhes geométricos dessa obra são apresentados na Figura 2.20. 


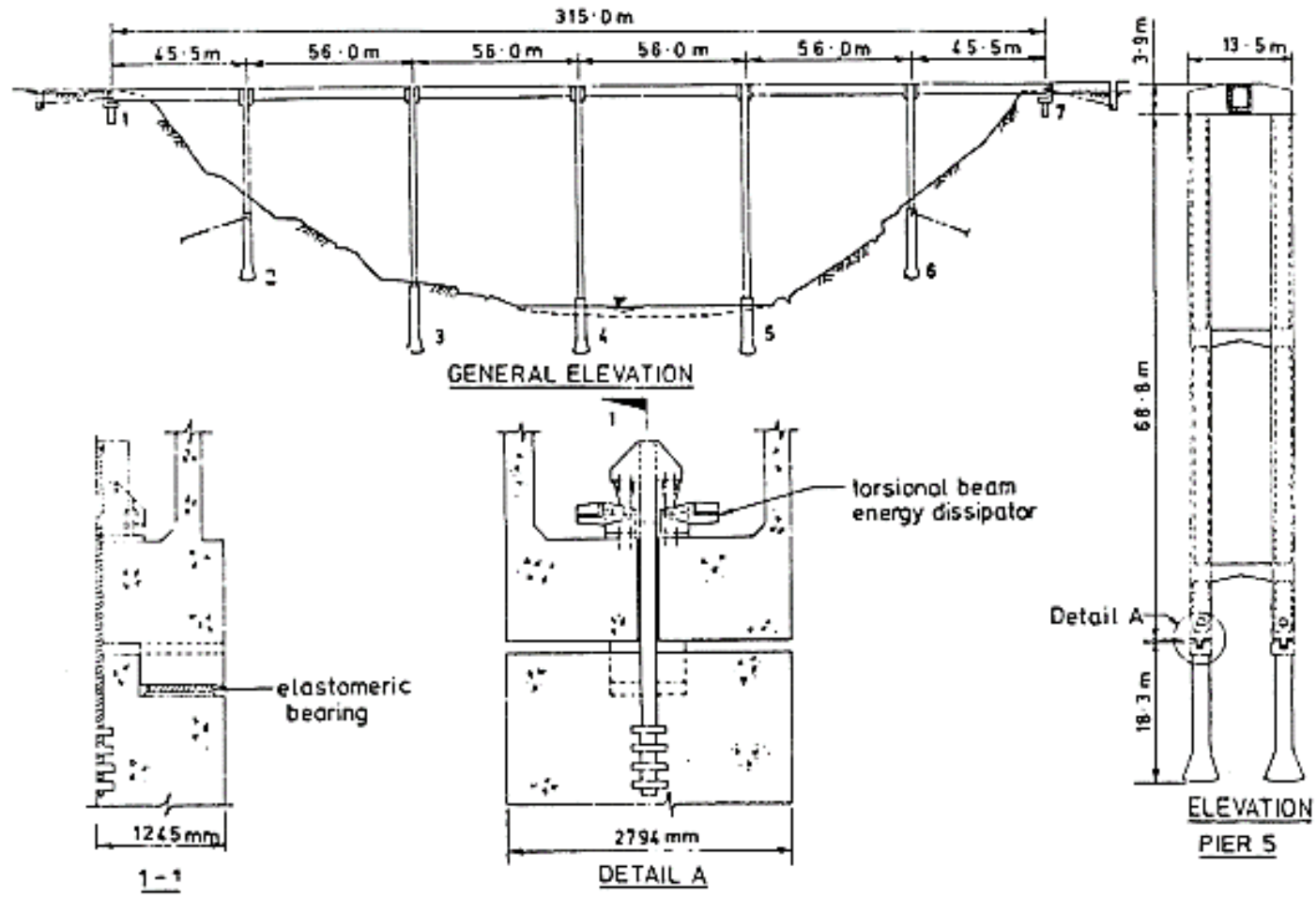

Figura 2.20 - Detalhes da ponte Rangitikei. Fonte: Skinner et. al., 1974

A Ponte Rangitikei possui três pilares de duzentos pés e dois pilares de cem pés de altura que foram projetados para resistir o movimento de suas fundações sob a ação de sismos, garantindo assim a integridade da superestrutura. Junto à base de cada um dos pilares se encontra um dissipador de energia de torção semelhante ao apresentado na Figura 2.6(b) responsável pela mitigação de energia transferida aos pilares da ponte. Na Figura 2.21 é apresentada uma foto recente da ponte.

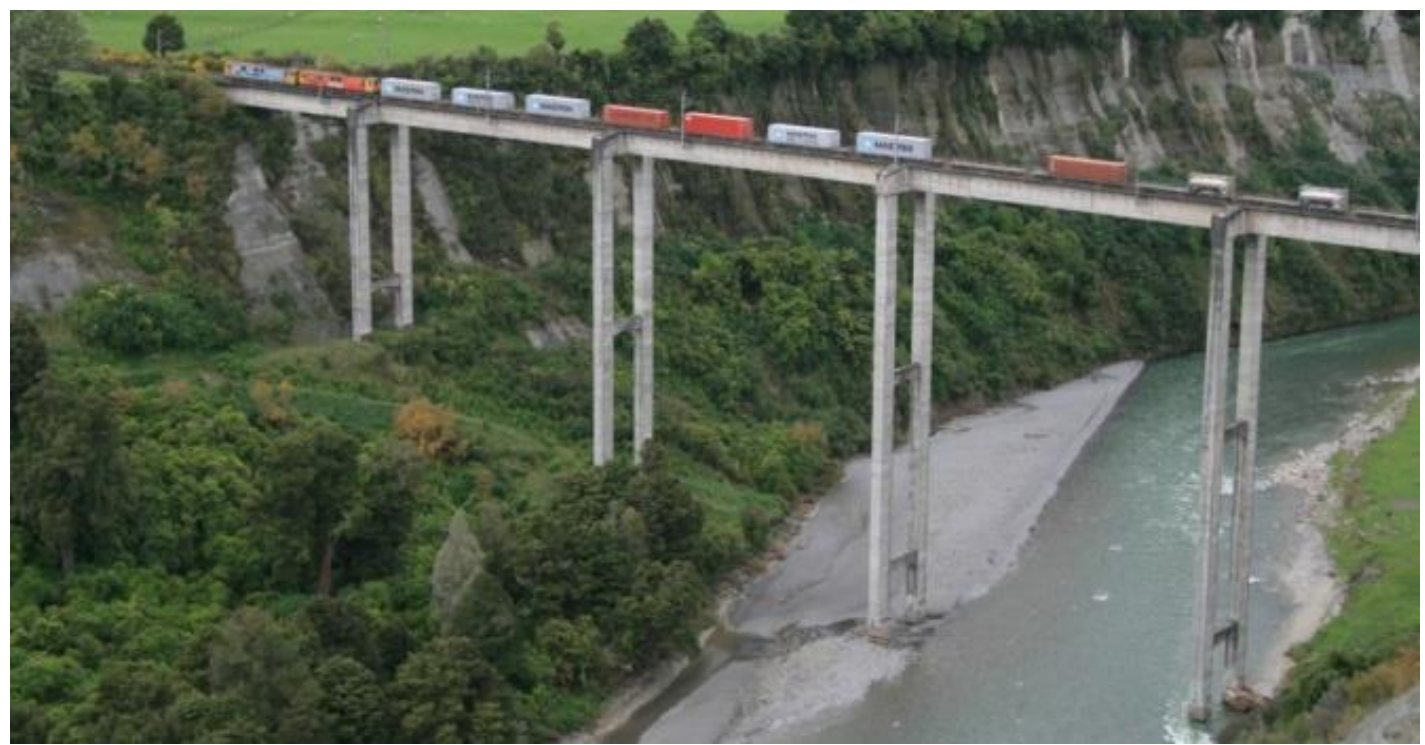

Figura 2.21 - Imagem atual da Ponte Rangitikei.

Fonte: http://www.frankship.com/enimaintrunk.html acesso em 04/08/2014 
Uma aplicação apresentada por Skinner et. al., (1983) que se tornou bastante popular foi a chaminé industrial de concreto armado, com seção transversal em formato de cruz e com trinta e cinco metros de altura, também localizada na Nova Zelândia. Essa chaminé foi projetada e construída com elevado grau de proteção às ações sísmicas permitindo a vibração da base durante grandes terremotos. A proteção se deve a um par de dissipadores metálicos instalados na sua base de forma a mitigar os efeitos das acelerações no solo. Após as verificações de cálculo manuais, realizou-se também uma análise computacional da estrutura submetendo-a à componente N-S do terremoto El Centro de 18 de maio de 1940. Como hipótese simplificadora, adotou-se a chaminé como uma estrutura bidimensional. Os deslocamentos encontrados são apresentados na Figura 2.22 e os detalhes de projeto na Figura 2.23.

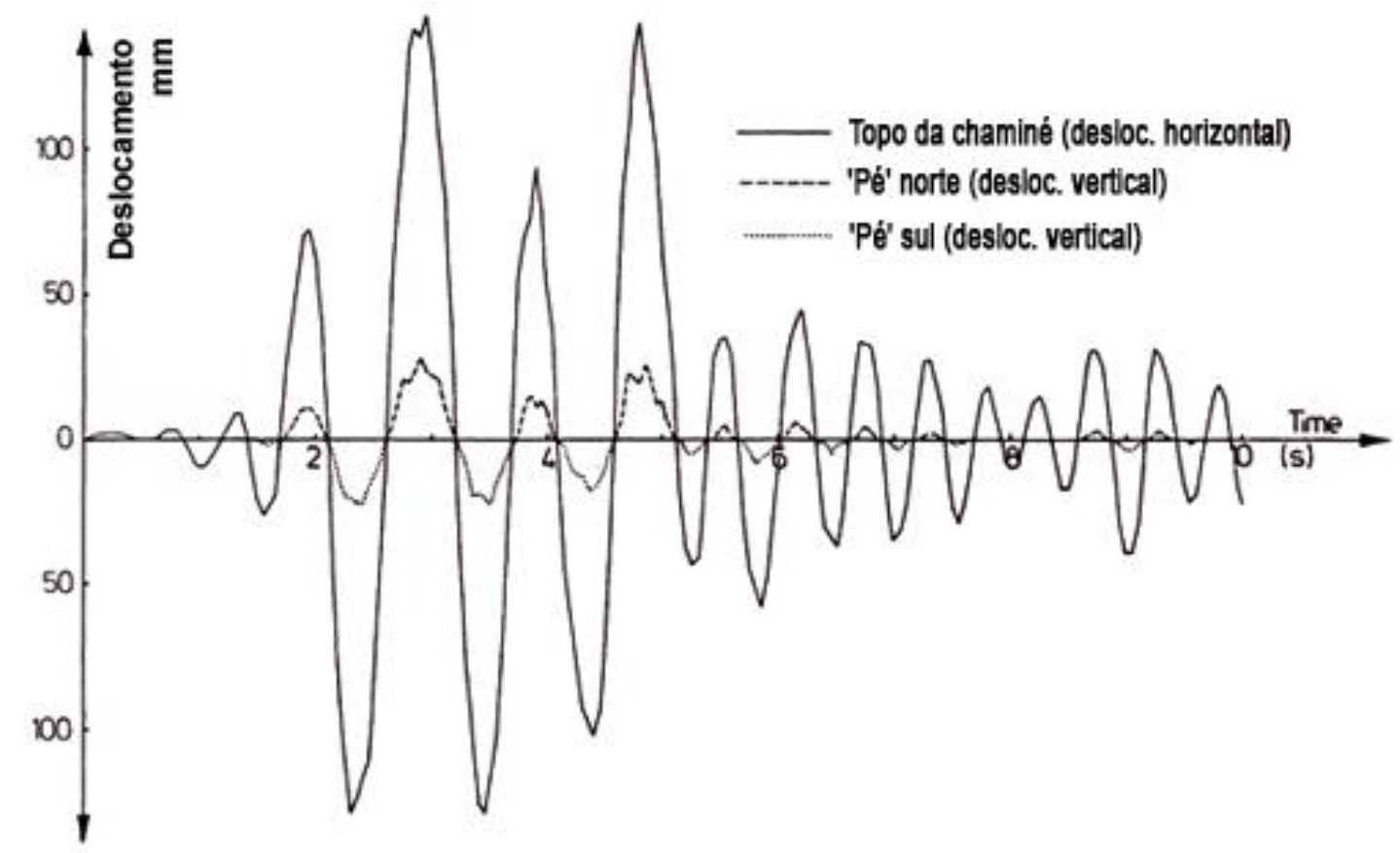

Figura 2.22 - Análise de deslocamentos da superestrutura da chaminé. Fonte: Skinner et. al., 1983 


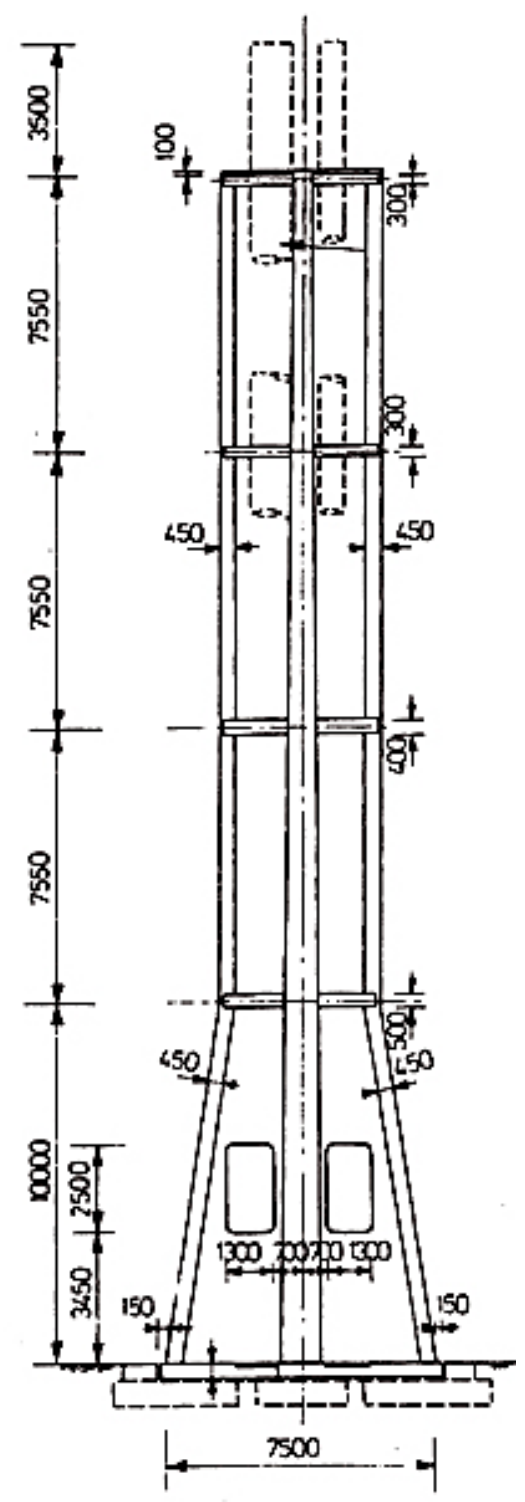

a) Perfil longitudinal da torre

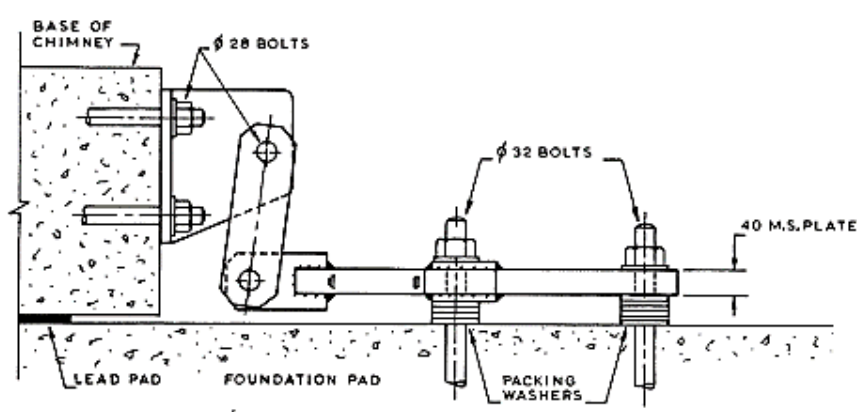

(b) Acoplamento do dissipador histerético na base da chaminé

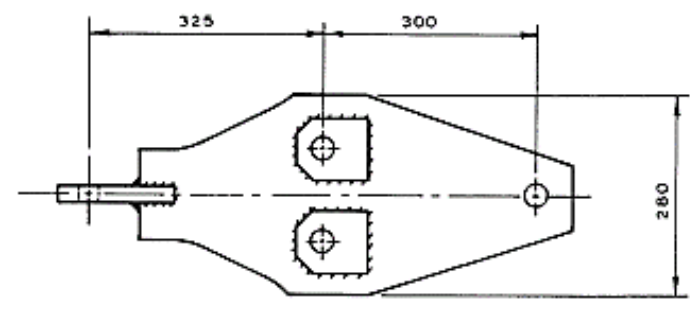

(c) Formato da placa metálica

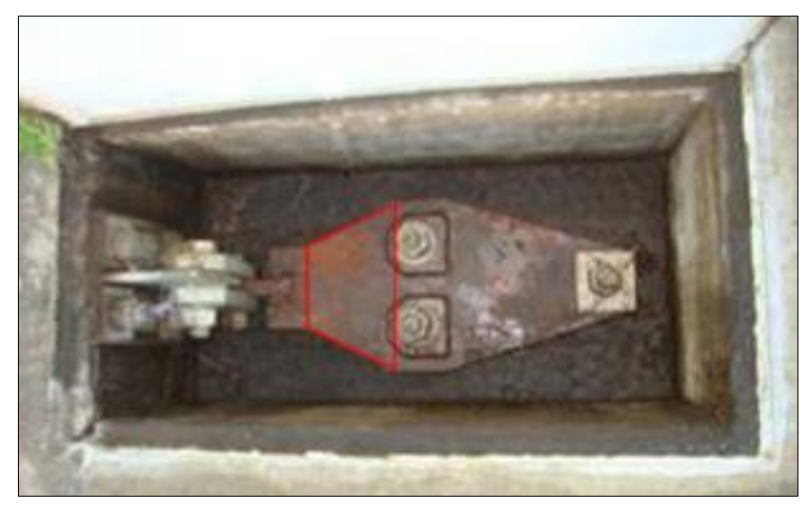

(d) Placa metálica instalada. Fonte: Sharpe et. al. 2013 Figura 2.23- Detalhe da torre de fumaça. Fonte: Skinner et. al., 1983

Nos Estados Unidos, uma utilização importante dos dissipadores metálicos é descrita por Perry et al.,(1993). Trata-se da reforma do Edifício Wells Fargo Bank localizado em São Francisco, Califórnia. A edificação é uma estrutura de concreto armado composta de dois pavimentos construída originalmente em 1967 que, após sofrer o terremoto Loma Prieta em 1989, foi parcialmente danificada. Durante a sua reforma e reabilitação, foram utilizados contraventamentos chevron e sete dispositivos ADAS foram instalados, cada um com uma força de escoamento de $150 \mathrm{Kips}(\sim 667 \mathrm{kN})$.

Tanto análises lineares quanto não lineares foram realizadas durante a realização do projeto de reforma. Por exemplo, o modelo tridimensional mostrado na Figura 2.24, foi 
utilizado para obtenção dos modos elásticos e dos resultados da análise dos espectros de resposta para a estrutura original com o programa SAP90®.
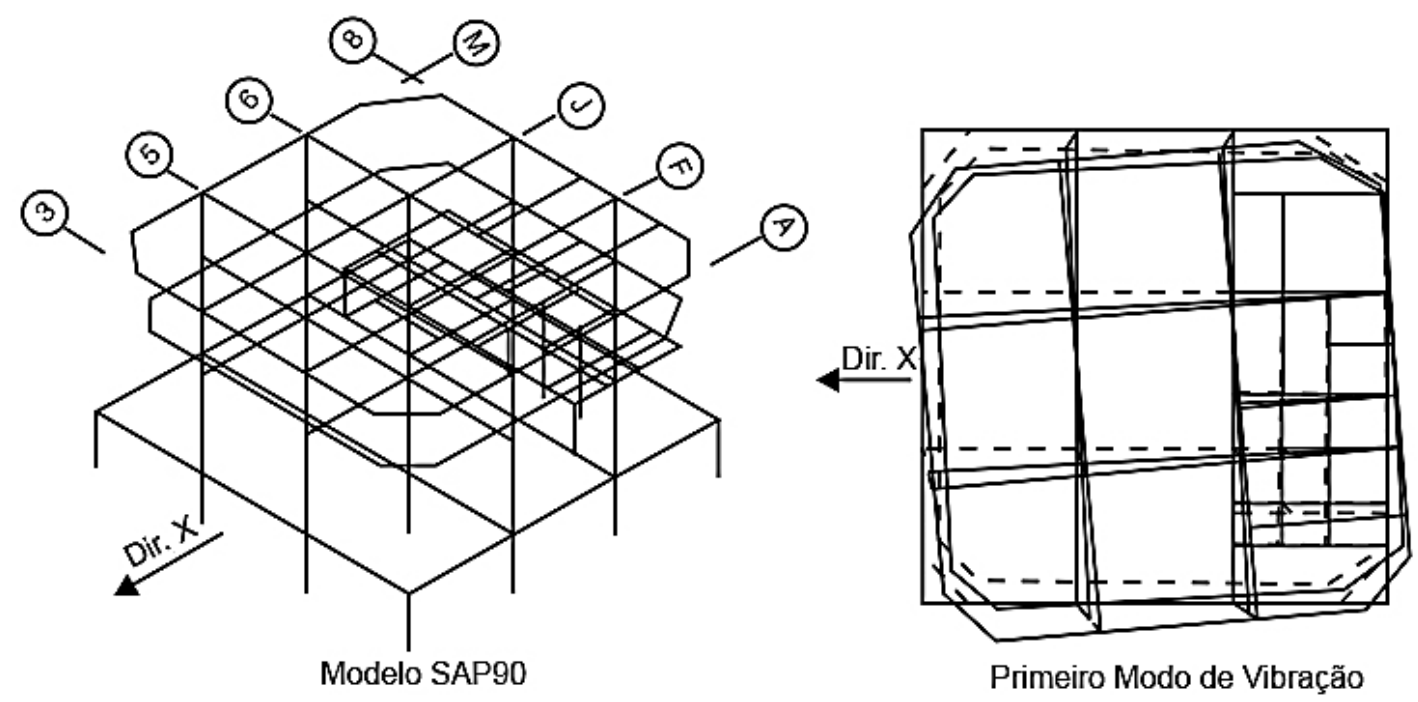

Figura 2.24 - Modelo de análise estrutural para o edifício do banco Wells Fargo. Fonte: Perry et al.,(1993), modificado.

$\mathrm{Na}$ revisão final do projeto, foram realizadas análises não lineares com o software DRAIN-2D, sendo que, os resultados numéricos indicaram que o projeto revisado era estável e confiável. A comparação da resposta obtida antes e depois da reforma é apresentada na Figura 2.25 demonstrando a redução de deslocamentos e esforços da estrutura.
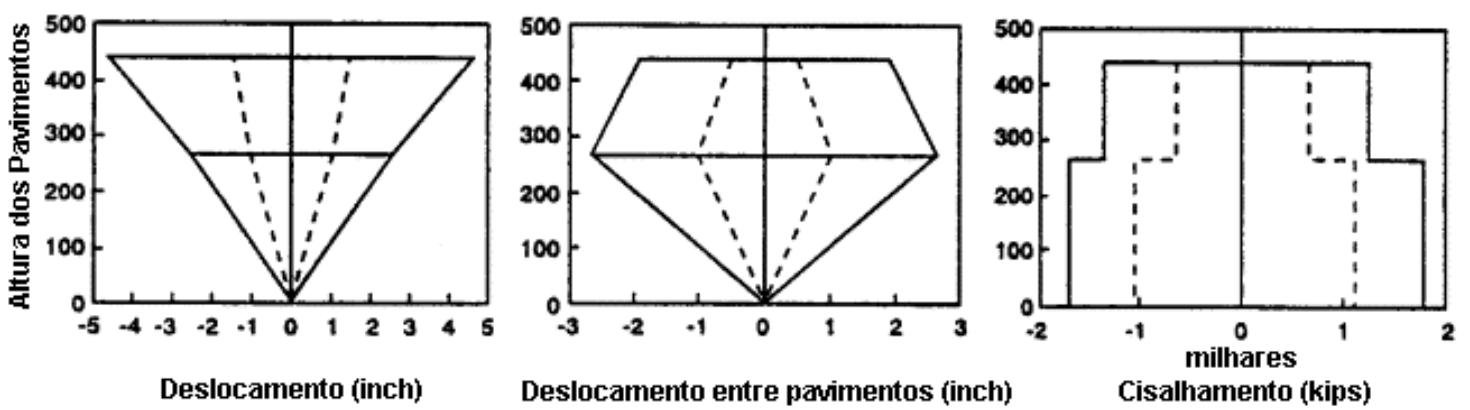

Antes da instalação do ADAS

Após a instalação do ADAS

Figura 2.25 - Avaliação numérica para o edifício do banco Wells Fargo. Perry et al.,(1993).

Tena-Colunga \& Vergara (1996) apresentam um estudo comparativo para a reforma de um edifício em aço utilizando contraventamentos diagonais ou dispositivos de dissipação de energia do tipo ADAS. O edifício estudado, localizado na Cidade do México, é um edifício de escritórios de dez pavimentos que foi danificado pela resposta 
ressonante do terremoto Michoacán em 1985. A reforma foi planejada para inibir dados estruturais e garantir que a estrutura do edifício não entrasse em ressonância.

Os estudos comparativos demostraram que uma reforma utilizando dispositivos do tipo ADAS teriam melhor performance dinâmica em relação à utilização dos contraventamentos diagonais, por outro lado, os contraventamentos garantem maior rigidez e o custo inicial de construção é bem menor. As projeções das duas propostas para a reforma da estrutura do edifício são apresentadas na Figura 2.26 e na Figura 2.27.

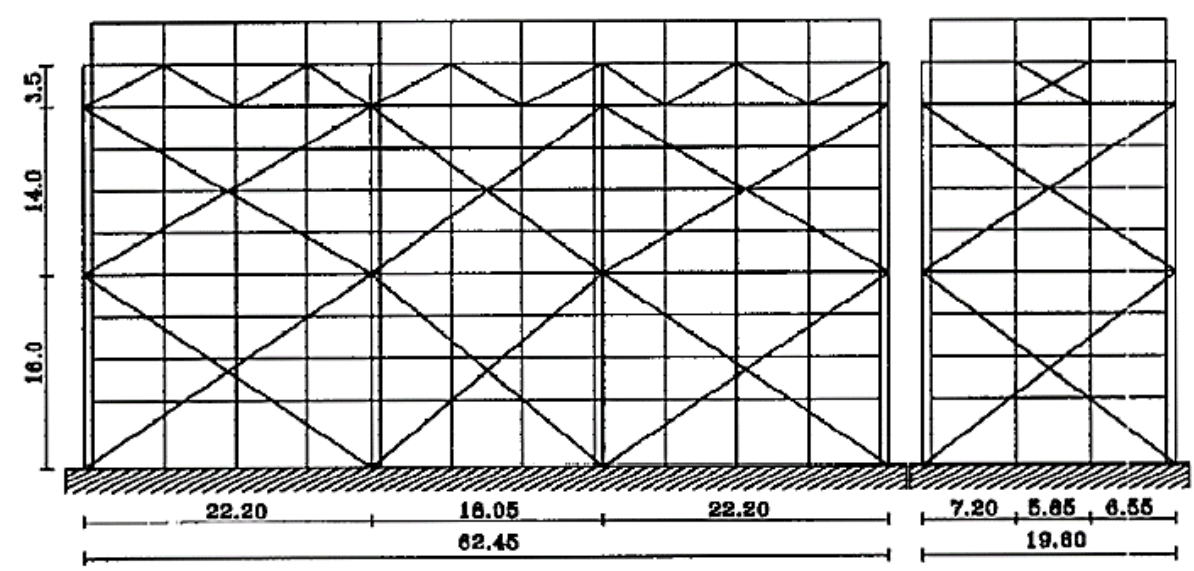

Figura 2.26- Vista do Edifício - Reforma utilizando contraventamentos diagonais. TenaColunga \& Vergara (1996)

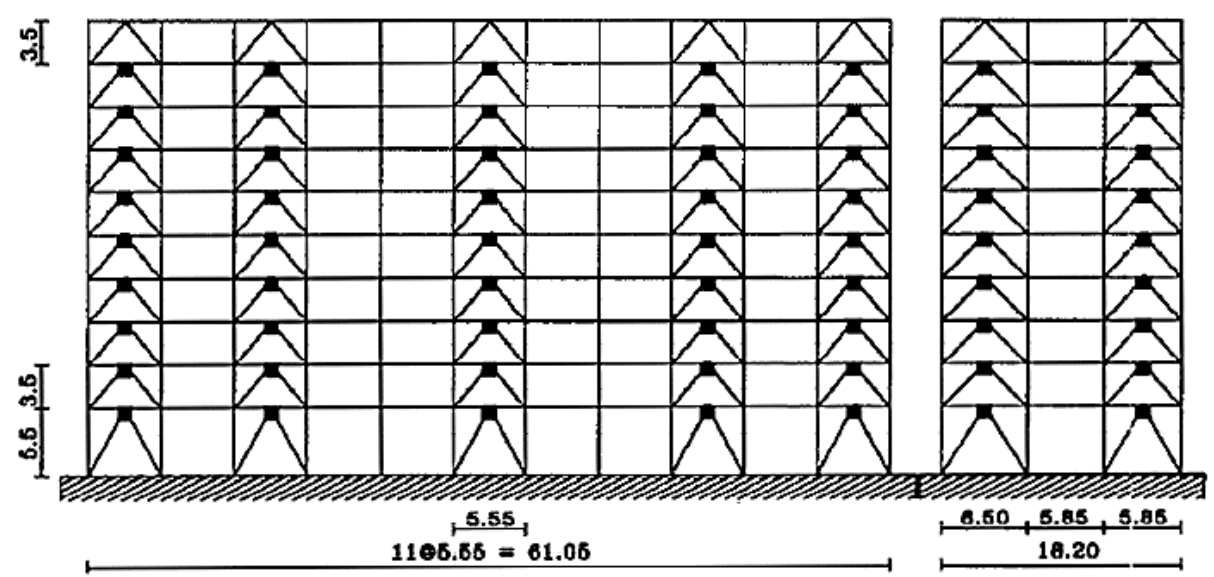

Figura 2.27 - Vista do Edifício - Reforma utilizando ADAS. Tena-Colunga \& Vergara (1996)

A análise demonstra que os dissipadores metálicos ADAS apresentam custos elevados para serem utilizados no México devido às taxas de comercialização.

No levantamento foi observado que para a reforma através de contraventamentos diagonais seriam necessárias aproximadamente 285 toneladas de aço estrutural, 
incluídos $15 \%$ de perdas devido à complexidade das conexões. Considerando um custo de US\$ $1.515,15$ por tonelada, o valor previsto inicialmente para a reforma da estrutura seria de US\$431.818,20.

Já para a reforma utilizando os dissipadores ADAS, seriam necessárias aproximadamente 145 toneladas de aço estrutural, incluindo 10\% de perda nas conexões, logo o custo inicial seria de US\$219.697,00, considerando necessidade de 162 dispositivos ADAS. A empresa que comercializa os dissipadores ADAS na Cidade do México estimou um custo de US\$ 604.480,00 referente às taxas de comercialização, fornecimento e instalação. Dessa maneira, a reforma utilizando os dissipadores metálicos totalizariam US\$ 824.177.00, um valor quase duas vezes superior em relação à opção de utilização de contraventamentos diagonais. Logo, para o proprietário da edificação, não houve dúvidas quanto à escolha, haja visto que ambas apresentam bom comportamento estrutural.

Ao final do estudo Tena-Colunga \& Vergara (1996) concluem que se o custo de utilização dos dissipadores do tipo ADAS pudessem ser reduzidos eles seriam uma alternativa bastante atrativa tanto ponto de vista técnico como econômico para a reforma de edifícios na Cidade do México.

Outro local onde se tem trabalhado intensamente no controle estrutural é na China. Lá o primeiro sistema de isolamento de base foi construído em 1993 e o primeiro sistema de dissipação de energia foi construído aproximadamente na mesma data. Em 2007 a China possuía mais de 600 sistemas de isolamento de base e cerca de 100 edifícios com dispositivos dissipadores de energia.

Peng et al., (2012) realizaram o levantamento de algumas estruturas com dispositivos de dissipação de energia na China, detalhando inclusive a forma como o conhecimento foi levado para aquele local. Uma boa contribuição prática dada por eles trata-se do fluxo de procedimentos chinês para os projetos de estruturas com dispositivos de dissipação de energia especificados a seguir:

1. Inicialmente é necessária a definição de um modelo analítico da estrutura principal sem a instalação dos dispositivos dissipadores de energia.

2. Os parâmetros de desempenho são então determinados de forma a determinar a necessidade ou não do aprimoramento da estrutura. 
3. As propriedades estruturais são calculadas, como a frequência natural, os modos de vibração, a rigidez dos pavimentos, etc.

4. Baseado na diferença entre os resultados necessários e os obtidos, os dispositivos de dissipação de energia podem ser instalados no sistema principal. Nesse passo, o tipo, a posição e as propriedades dos dispositivos são determinados.

5. A análise sísmica do edifício é realizada com os dispositivos de dissipação de energia, salienta-se que essa deve ser uma análise preliminar simplificada, que poderá ser linear ou não linear. Se todos os critérios de análise são atendidos, passa-se então ao próximo passo, caso contrário, retorna-se ao quarto passo para nova tentativa.

6. Ao final é realizada uma análise de histórico de tempo não linear e examina-se novamente se os parâmetros de desempenho são atingidos, caso positivo, continua-se com o detalhamento do projeto, caso negativo, retorna-se ao passo quatro.

O fluxograma dos processos é apresentado na Figura 2.28 a seguir:

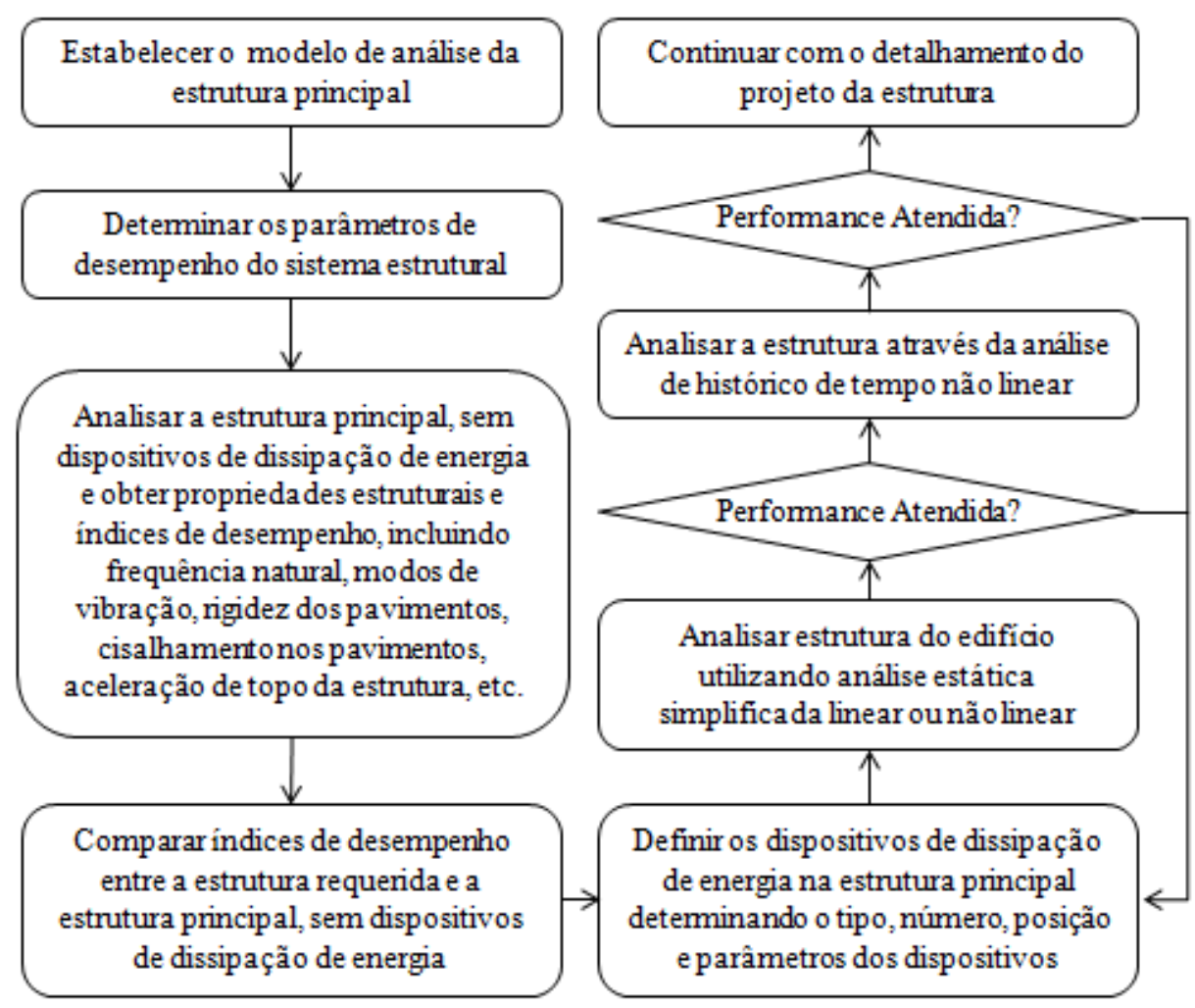

Figura 2.28 - Fluxograma para o projeto de instalação de dissipadores de energia em edifícios. Fonte: Peng et al., (2012) modificado. 
Já no Japão, Kitagawa \& Midorikawa (1997) ao estudarem as características das estruturas sismos-resistentes construídas naquele país, fizeram um grande levantamento das principais edificações, bem como do tipo de dispositivo de dissipação de energia utilizado. Os dados desse levantamento são apresentados na Tabela 2.2.

Tabela 2.2 - Estruturas típicas de controle passivo no Japão

\begin{tabular}{|c|c|c|c|c|c|c|c|c|}
\hline Edificação & $\begin{array}{l}\text { Ano de } \\
\text { Finaliz. }\end{array}$ & $\begin{array}{l}\text { Tipo de } \\
\text { Estrut. }{ }^{1}\end{array}$ & $\begin{array}{l}\text { Pav. }^{2} \\
\text { (altura) }\end{array}$ & Utilização & Local & Classificação & $\begin{array}{c}\text { Tipo de } \\
\text { Disposit. }^{3}\end{array}$ & Objetivo \\
\hline $\begin{array}{l}\text { Hitachi Head } \\
\text { Office }\end{array}$ & 1984 & S & $\begin{array}{c}+18,-3 \\
(72,6 \mathrm{~m})\end{array}$ & Escritórios & Tokyo & $\begin{array}{l}\text { Dissipação de } \\
\text { energia }\end{array}$ & HD & Terremoto \\
\hline Chiba Port Tower & 1986 & $S$ & $\begin{array}{c}- \\
(125 \mathrm{~m})\end{array}$ & Torre & Chiba & $\begin{array}{l}\text { Efeito de } \\
\text { Massa }\end{array}$ & $\begin{array}{l}\text { TMD } \\
(\mathrm{RS})\end{array}$ & $\begin{array}{l}\text { Terremoto } \\
\text { Vento }\end{array}$ \\
\hline $\begin{array}{c}\text { Yokahama } \\
\text { Marine Tower }\end{array}$ & 1987 & $S$ & $(101,3 \mathrm{~m})$ & Torre & Yokohama & $\begin{array}{l}\text { Efeito de } \\
\text { Massa }\end{array}$ & TLD & Vento \\
\hline MHS Bldg & 1988 & $\mathrm{~S}$ & $\begin{array}{c}+8,-1 \\
(26,8 \mathrm{~m})\end{array}$ & Escritórios & Tokyo & $\begin{array}{l}\text { Efeito de } \\
\text { Massa }\end{array}$ & $\begin{array}{l}\text { TMD } \\
(\mathrm{PE})\end{array}$ & $\begin{array}{l}\text { Terremoto } \\
\text { Vento }\end{array}$ \\
\hline $\begin{array}{c}\text { Sonic-City Office } \\
\text { Bldg }\end{array}$ & 1988 & $\mathrm{~S}$ & $\begin{array}{c}+31,-4 \\
(136,5 \mathrm{~m})\end{array}$ & Escritórios & Saitama & $\begin{array}{l}\text { Dissipação de } \\
\text { energia }\end{array}$ & FD & Terremoto \\
\hline Gold Tower & 1988 & $\mathrm{~S}$ & $(144 \mathrm{~m})$ & Torre & Kagawa & $\begin{array}{l}\text { Efeito de } \\
\text { Massa }\end{array}$ & TLD & Vento \\
\hline $\begin{array}{c}\text { Higashiyama Park } \\
\text { Tower }\end{array}$ & 1989 & S & $(134 \mathrm{~m})$ & Torre & Nagoya & $\begin{array}{l}\text { Efeito de } \\
\text { Massa }\end{array}$ & $\begin{array}{l}\text { TMD } \\
(\mathrm{PE})\end{array}$ & Vento \\
\hline Kajima Ki Bldg & 1989 & SRC & $\begin{array}{c}+9,-1 \\
(34,3 \mathrm{~m})\end{array}$ & Escritórios & Tokyo & $\begin{array}{l}\text { Dissipação de } \\
\text { energia }\end{array}$ & HD & Terremoto \\
\hline Fukuoka Tower & 1989 & $\mathrm{~S}$ & $(150,7 \mathrm{~m})$ & Torre & Fukuoka & $\begin{array}{l}\text { Efeito de } \\
\text { Massa }\end{array}$ & $\begin{array}{l}\text { TMD } \\
\text { (RS) }\end{array}$ & $\begin{array}{l}\text { Terremoto } \\
\text { Vento }\end{array}$ \\
\hline Asahi Beer Tower & 1989 & $S$ & $\begin{array}{c}+22,-2 \\
(94,9 \mathrm{~m})\end{array}$ & Escritórios & Tokyo & $\begin{array}{l}\text { Dissipação de } \\
\text { energia }\end{array}$ & FD & Terremoto \\
\hline Crystal Tower & 1990 & $\mathrm{~S}$ & $\begin{array}{c}+37,-2 \\
(157,0 \mathrm{~m})\end{array}$ & Escritórios & Osaka & $\begin{array}{l}\text { Efeito de } \\
\text { Massa }\end{array}$ & $\begin{array}{l}\text { TMD } \\
(\mathrm{PE})\end{array}$ & Vento \\
\hline $\begin{array}{c}\text { Fujita Corp. Head } \\
\text { Office }\end{array}$ & 1990 & S & $\begin{array}{l}+20,-4 \\
(81,2 \mathrm{~m})\end{array}$ & Escritórios & Tokyo & $\begin{array}{l}\text { Dissipação de } \\
\text { energia }\end{array}$ & LD & Terremoto \\
\hline Pipe Lab. & 1990 & $S$ & $\begin{array}{c}+12 \\
(33,8 \mathrm{~m})\end{array}$ & Laboratory & Kanagawa & $\begin{array}{l}\text { Efeito de } \\
\text { Massa }\end{array}$ & TLD & Terremoto \\
\hline $\begin{array}{c}\text { Shibaura Sea } \\
\text { Vance S-Bldg }\end{array}$ & 1991 & $S$ & $\begin{array}{c}+24,-2 \\
(97,7 \mathrm{~m})\end{array}$ & Escritórios & Tokyo & $\begin{array}{l}\text { Dissipação de } \\
\text { energia }\end{array}$ & VED & Terremoto \\
\hline $\begin{array}{c}\text { Shinyokohama } \\
\text { Prince Hotel }\end{array}$ & 1991 & S & $\begin{array}{c}+42,-3 \\
(149,3 \mathrm{~m})\end{array}$ & Hotel & Yokohama & $\begin{array}{c}\text { Efeito de } \\
\text { Massa }\end{array}$ & TLD & Vento \\
\hline $\begin{array}{c}\text { House Tembos } \\
\text { Tower }\end{array}$ & 1992 & S & $\begin{array}{c}- \\
(105,0 \mathrm{~m})\end{array}$ & Torre & Nagasaki & $\begin{array}{c}\text { Efeito de } \\
\text { Massa }\end{array}$ & $\begin{array}{l}\text { TMD } \\
\text { (MR) }\end{array}$ & Vento \\
\hline Sato Bldg & 1992 & S & $\begin{array}{c}+7,-1 \\
(20,8 \mathrm{~m})\end{array}$ & Complexo & Tokyo & $\begin{array}{c}\text { Dissipação de } \\
\text { energia }\end{array}$ & VD & Terremoto \\
\hline
\end{tabular}


Tabela 2.2 - Estruturas típicas de controle passivo no Japão

\begin{tabular}{|c|c|c|c|c|c|c|c|c|}
\hline Edificação & $\begin{array}{l}\text { Ano de } \\
\text { Finaliz. }\end{array}$ & $\begin{array}{l}\text { Tipo de } \\
\text { Estrut. }^{1}\end{array}$ & $\begin{array}{l}\text { Pav. }^{2} \\
\text { (altura) }\end{array}$ & Utilização & Local & Classificação & $\begin{array}{c}\text { Tipo de } \\
\text { Disposit. }^{3}\end{array}$ & Objetivo \\
\hline $\begin{array}{l}\text { Chiba Porside } \\
\text { Tower Bldg }\end{array}$ & 1992 & S & $\begin{array}{c}+29,-3 \\
(121,6 \mathrm{~m})\end{array}$ & Escritórios & Chiba & $\begin{array}{l}\text { Dissipação de } \\
\text { energia }\end{array}$ & VED & $\begin{array}{l}\text { Terremoto } \\
\text { Vento }\end{array}$ \\
\hline $\begin{array}{c}\text { Haneda Airport } \\
\text { Tower }\end{array}$ & 1993 & S & $\begin{array}{c}- \\
(77,6 \mathrm{~m})\end{array}$ & Torre & Tokyo & $\begin{array}{c}\text { Efeito de } \\
\text { Massa }\end{array}$ & TLD & Vento \\
\hline $\begin{array}{c}\text { Shimura 3-chome } \\
\text { Dormitory }\end{array}$ & 1993 & S & $\begin{array}{c}+10,-2 \\
(30,1 \mathrm{~m})\end{array}$ & Dormitory & Tokyo & $\begin{array}{l}\text { Dissipação de } \\
\text { energia }\end{array}$ & OD & Terremoto \\
\hline $\begin{array}{l}\text { Rokko-island } \\
\text { P\&G }\end{array}$ & 1993 & S & $\begin{array}{c}+31,-2 \\
(117,0 \mathrm{~m})\end{array}$ & Escritórios & Kobe & $\begin{array}{l}\text { Efeito de } \\
\text { Massa }\end{array}$ & $\begin{array}{l}\text { TMD } \\
(\mathrm{PE})\end{array}$ & Vento \\
\hline $\begin{array}{l}\text { Chiba City } \\
\text { Gymnasium }\end{array}$ & 1993 & S & $\begin{array}{c}+29,-3 \\
(121,6 \mathrm{~m})\end{array}$ & Escritórios & Chiba & $\begin{array}{l}\text { Dissipação de } \\
\text { energia }\end{array}$ & VED & $\begin{array}{l}\text { Terremoto } \\
\text { Vento }\end{array}$ \\
\hline $\begin{array}{c}\text { TV Shizuoka } \\
\text { Media City }\end{array}$ & 1994 & S & $\begin{array}{c}+14,-2 \\
(64,7 \mathrm{~m}) \\
\end{array}$ & Complexo & Shizuoka & $\begin{array}{c}\text { Dissipação de } \\
\text { energia }\end{array}$ & VD & Terremoto \\
\hline JAL Bldg & 1996 & $\begin{array}{c}\mathrm{SRC} \\
\mathrm{S}\end{array}$ & $\begin{array}{c}+26,-1 \\
(108,0 \mathrm{~m})\end{array}$ & Escritórios & Tokyo & $\begin{array}{l}\text { Dissipação de } \\
\text { energia }\end{array}$ & OD & $\begin{array}{l}\text { Terremoto } \\
\text { Vento }\end{array}$ \\
\hline Asuru Esaka & 1997 & $\mathrm{SRC}$ & $\begin{array}{c}+14 \\
(39,25 \mathrm{~m})\end{array}$ & Apartamentos & Osaka & $\begin{array}{l}\text { Dissipação de } \\
\text { energia }\end{array}$ & HD & Terremoto \\
\hline $\begin{array}{l}\text { Nissei Okayama } \\
\text { Shimoshakuji }\end{array}$ & 1997 & $\begin{array}{c}\mathrm{S} \\
\mathrm{CFT}\end{array}$ & $\begin{array}{c}+14,-1 \\
(55,54 \mathrm{~m})\end{array}$ & Escritórios & Okayama & $\begin{array}{l}\text { Dissipação de } \\
\text { energia }\end{array}$ & HD & Terremoto \\
\hline $\begin{array}{l}\text { Osaka Keizai } \\
\text { Univ. G-bldg }\end{array}$ & 1997 & $\begin{array}{c}\mathrm{S} \\
\mathrm{CFT}\end{array}$ & $\begin{array}{c}+7,-1 \\
(29,6 \mathrm{~m})\end{array}$ & Escola & Osaka & $\begin{array}{c}\text { Dissipação de } \\
\text { energia }\end{array}$ & HD & Terremoto \\
\hline $\begin{array}{c}\text { Saitama Koiki } \\
\text { Godo-chosha E-2 }\end{array}$ & 2000 & $\begin{array}{c}\mathrm{S} \\
\mathrm{SRC}\end{array}$ & $\begin{array}{c}+31,-2 \\
(142,7 \mathrm{~m})\end{array}$ & Escritórios & Saitama & $\begin{array}{c}\text { Dissipação de } \\
\text { energia }\end{array}$ & HD & Terremoto \\
\hline $\begin{array}{c}\text { Saitama Koiki } \\
\text { Godo-chosha H }\end{array}$ & 2000 & $\begin{array}{c}\mathrm{S} \\
\mathrm{SRC}\end{array}$ & $\begin{array}{c}+26,-3 \\
(119,4 \mathrm{~m})\end{array}$ & Escritórios & Saitama & $\begin{array}{c}\text { Dissipação de } \\
\text { energia }\end{array}$ & HD & Terremoto \\
\hline $\begin{array}{c}\text { Shi-chuo Godo- } \\
\text { chosha } 2\end{array}$ & 2000 & $\begin{array}{c}\mathrm{S} \\
\mathrm{SRC}\end{array}$ & $\begin{array}{c}+21,-4 \\
(95,05 \mathrm{~m})\end{array}$ & Escritórios & Tokyo & $\begin{array}{l}\text { Dissipação de } \\
\text { energia }\end{array}$ & $\begin{array}{l}\text { HD } \\
\text { VD }\end{array}$ & Terremoto \\
\hline $\begin{array}{c}\text { Kanto- } \\
\text { yuseikyokutou } \\
\text { Chosha }\end{array}$ & 2000 & $\begin{array}{c}\mathrm{S} \\
\mathrm{SRC}\end{array}$ & $\begin{array}{c}+28,-2 \\
(116,3 \mathrm{~m})\end{array}$ & Escritórios & Saitama & $\begin{array}{c}\text { Dissipação de } \\
\text { energia }\end{array}$ & VD & $\begin{array}{l}\text { Terremoto } \\
\text { Vento }\end{array}$ \\
\hline
\end{tabular}

${ }^{1}$ S: Estrutura de Aço, SRC: Estrutura de Concreto Armado, CFT: Estrutura de aço preenchida com concreto (compósito)

2 +: número de pavimentos acima do solo, - : Número de subsolos

${ }^{3}$ FD: Amortecedor de fricção, HD: Amortecedor histerético de aço (dissipação de energia utilizando o comportamento inelástico do aço), LD: Amortecedor Chumbo (Dissipação de energia por meio do comportamento histerético do chumbo), MR: Sistema múltiplo de rolamentos de borracha (combinação de rolamentos de borracha laminadas), OD: Amortecedor a óleo (Dissipação de energia utilizando a resistência do óleo para atravessar um orifício em um pistão), PE: Sistema pendular, RS: Sistema de molas e rolos, TLD: Amortecedor líquido sintonizado, TMD: Amortecedor de massa sintonizado, VED: Amortecedor viscoelástico, VD: Amortecedor viscoso. 


\section{FUNDAMENTOS TEÓRICOS}

\subsection{FORMULAÇÃO MATEMÁTICA DO ADAS}

A modelagem analítica dos dispositivos de dissipação de energia do tipo Added Damping and Stiffness (ADAS) é de grande importância ao estudar o comportamento das estruturas equipadas com tais dispositivos.

Devido ao formato dos dispositivos $X$ Shape, o cálculo da rigidez plástica e elástica desses dissipadores apresentam algum grau de complexidade, dessa forma, adota-se algumas simplicações de forma a facilitar a montagem das expressões algébricas. Apesar de Whittaker et. al.(1989) não apresentarem especificamente as expressões que eles utilizaram para definir os deslocamentos de escoamento, Tena-Colunga (1997) apresenta esses deslocamentos calculados a partir da dupla integração da curvatura plástica média. O deslocamento de escoamento da placa metálica é dado pela seguinte equação:

$$
\Delta_{y}{ }^{P L}=\int_{0}^{l / 2} \int_{0}^{b_{e q}} \frac{M_{p x}(z)}{E I_{x}(z)} d x d z
$$

Sendo $M_{p x}(z)$ e $I_{x}(z)$ dados por:

$$
\begin{aligned}
I_{x}(z) & =\frac{b(z) t^{3}}{12} \\
M_{p x}(z) & =\sigma_{y} \frac{b(z) t^{2}}{4}
\end{aligned}
$$

Sendo

$\Delta_{y}{ }^{P L}: \quad$ O deslocamento de escoamento da placa metálica;

$l: \quad$ Altura da placa X;

$b$ : $\quad$ Largura da placa X;

$b_{e q}: \quad$ Largura equivalente da placa X;

$M_{p x}: \quad$ Capacidade de momento plástico;

$I_{x}: \quad$ Momento de inércia da seção transversal da placa X em torno do eixo x;

$t_{p}: \quad$ Espessura da placa X;

$\sigma_{y}: \quad$ Tensão de escoamento do material. 
A representação das dimensões adotadas por Tena-Colunga (1997) são apresentadas na Figura 3.1.

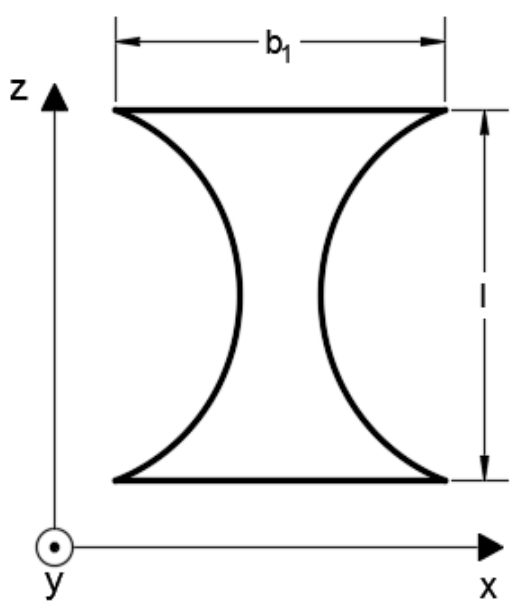

(a) Modelo idealizado tipo "Ampulheta"

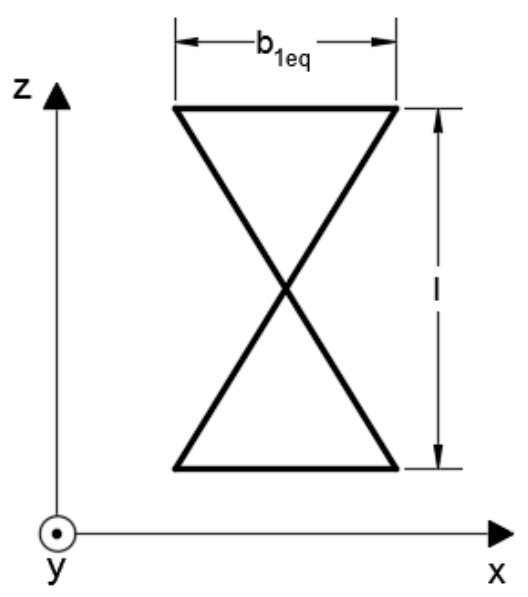

(b) Formato "X" equivalente

Figura 3.1 - Geometrias idealizadas para o dispositivo ADAS. Fonte: Tena-Colunga (1997)

Logo, o deslocamento de escoamento da placa metálica é dado por:

$$
\Delta_{y}^{P L}=\frac{3 \sigma_{y} l^{2}}{4 E t}
$$

A capacidade de cisalhamento plástico de cada placa $\mathrm{X}\left(V_{p x}{ }^{P L}\right)$ equivalente do ADAS é calculada a partir da equação de equilíbrio baseada na capacidade de momento plástico dada pela Equação 3.3:

$$
V_{p x}{ }^{P L}=\frac{2 M_{p x}}{l}=\frac{\sigma_{y} b_{e q} t^{2}}{2 l}
$$

Portanto, a rigidez de cisalhamento elástica de cada placa X é dada por:

$$
K_{P L}=\frac{V_{p x}{ }^{P L}}{\Delta_{y}{ }^{P L}}=\frac{2 E b_{e q} t^{3}}{3 l^{3}}
$$

Se adotarmos $n$ como o número de placas utilizadas em um dispositivo, a rigidez de cisalhamento elástica do ADAS é dada por: 


$$
K_{A D A S}=n \frac{2 E b_{e q} t^{3}}{3 l^{3}}
$$

Da mesma forma, Bayat e Abdollahzaden (2011) apresentam a rigidez de cisalhamento elástica de um TADAS (Triangular-plate Added Damping and Stiffness) dada pela Equação 3.8:

$$
K_{A D A S^{\Delta}}=n \frac{E b_{e q} t^{3}}{6 l^{3}}
$$

\subsection{MODELAGEM DE BOUC-WEN}

O modelo de Bouc-Wen é bastante apropriado para a simulação de uma grande variedade de comportamentos elastoplásticos devido ao seu refinamento e bom grau de precisão, sua formulação permite a variação de seus parâmetros de forma a representar diferentes tipos de relações constitutivas (Ikhouane \& Rodellar, 2007).

A reação elastoplástica do modelo se decompõe em uma componente proporcional ao modelo e outra dependente de uma variável $z$.

$$
f(t)=r k_{e} d(t)+(1-r) f_{y} z(t)
$$

Sendo, $r$ a taxa de endurecimento, $k_{e}$ e $k_{y}$ representam a rigidez elástica e plástica, respectivamente, $d(t)$ representa o deslocamento em função do tempo, $f_{y}$ corresponde à força em que se inicia o escoamento e $z$ é uma variável adimensional associada ao ciclo de histerese definida a partir da seguinte equação diferencial:

$$
\dot{z}(t)=A \dot{d}(t)-\beta z(t)|\dot{d}(t)||z(t)|^{n-1}-\gamma \dot{d}(t)|z(t)|^{n}
$$

Sendo A, $\gamma, \beta$ e $n$ quantidades adimensionais que denotam o comportamento do modelo, onde A é um fator de escala, $\beta$ e $\gamma$ parâmetros de forma e $\mathrm{n}$ um fator que regula a suavidade da transição entre a região linear e não linear. 


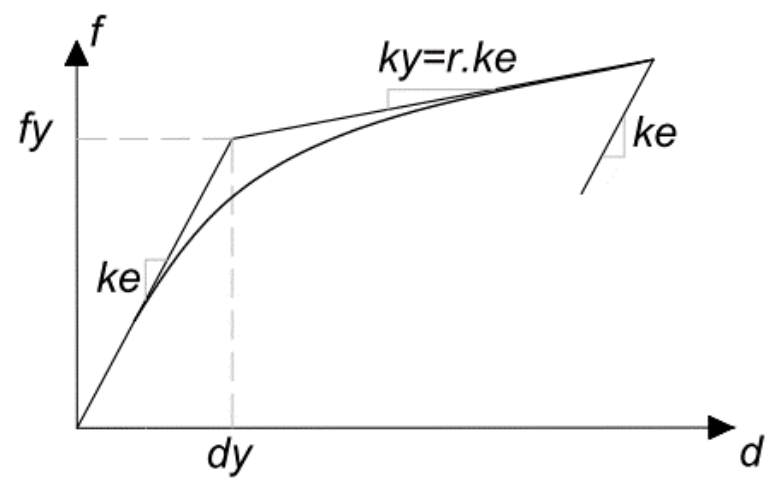

Figura 3.2 - Parâmetros para o modelo Bouc-Wen

A influência que os parâmetros $\beta$ e $\gamma$ tem sobre a variável $z$ pode ser visualizada nos gráficos da Figura 3.3, onde adota-se $A=1, r=0,5$ e $n=1$.

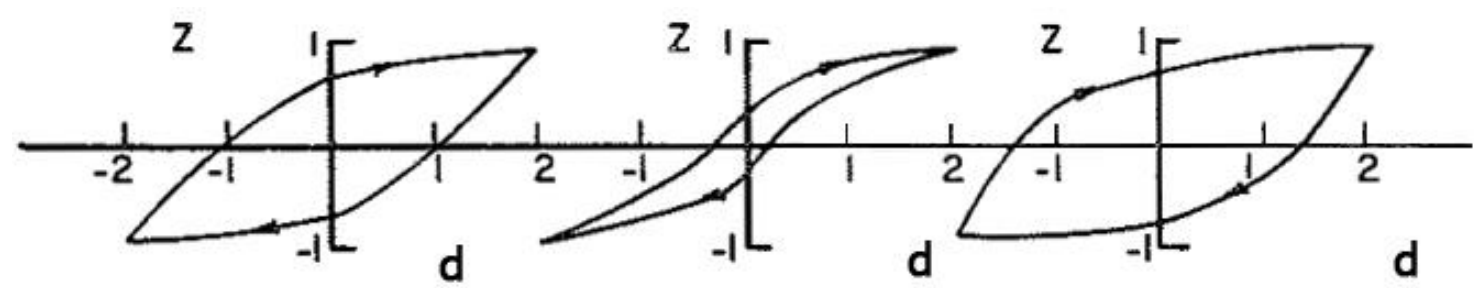

$\beta=0,5 \gamma=0,5 \quad \beta=0,1 \gamma=0,9 \quad \beta=0,9 \gamma=0,1$

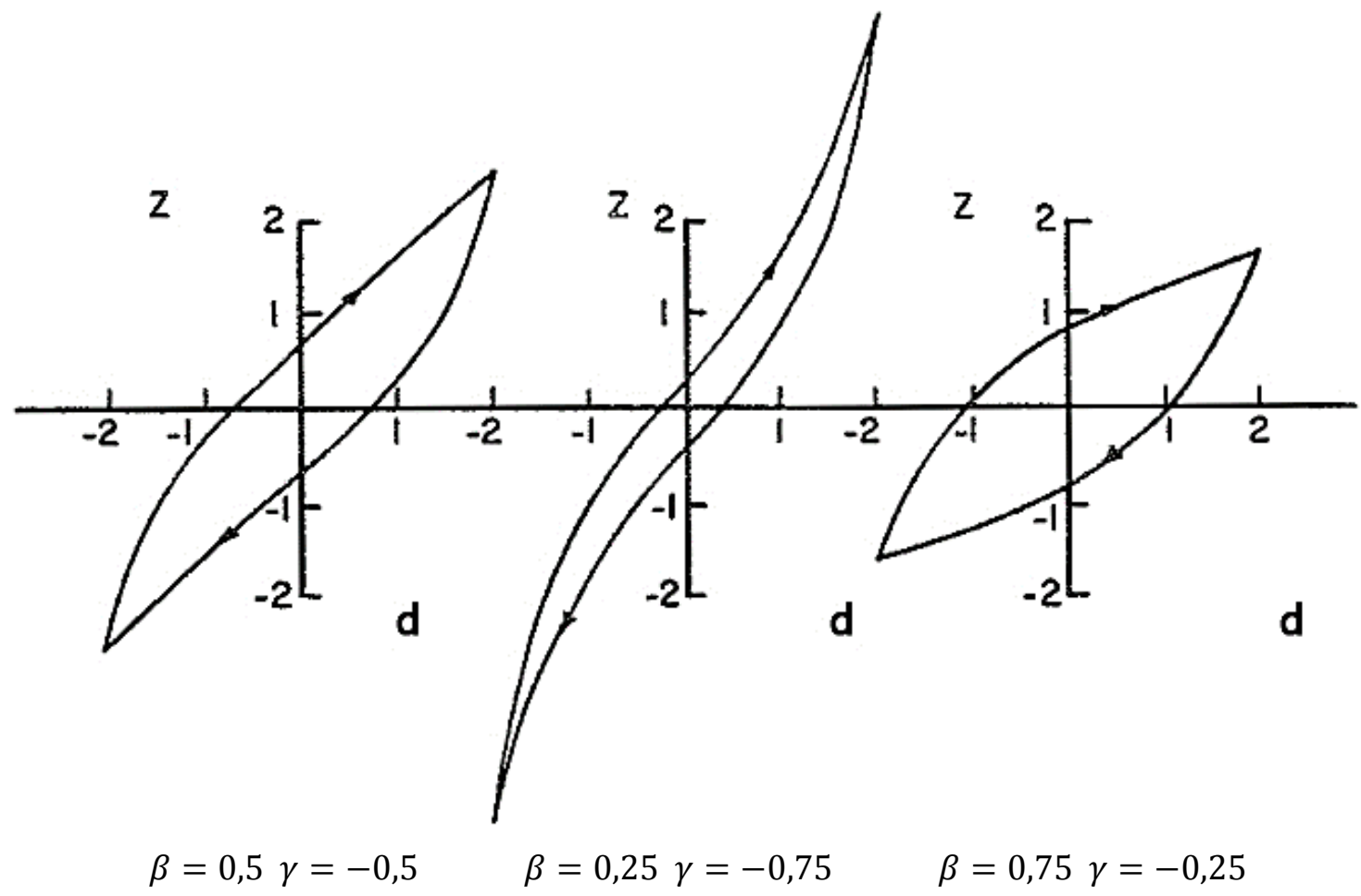

Figura 3.3 - Comportamento da variável z para distintos valores de $\beta$ e $\gamma$. Wen (1976) 
Como forma de auxílio e entendimento do algoritmo, é apresentado no "Apêndice A" a solução passo a passo para um elemento de um grau de liberdade com comportamento histerético segundo as formulações de Bouc-Wen, esse exemplo foi extraído do manual de verificação do programa computacional comercial SAP 2000® (Computer and Structures, 2009).

\subsection{OTIMIZAÇÃO}

Com a crescente concorrência entre os mercados mundiais pressionando a redução dos custos de produção e com a redução da disponibilidade de matéria prima, torna-se cada vez mais necessário que sejam desenvolvidos métodos de otimização para que os dispositivos projetados pelos engenheiros sejam econômicos e eficientes.

Segundo Rao (2009), otimização consiste em se obter a melhor solução sob determinadas circunstâncias. Dessa maneira, ao se lidar com esse tipo de problema, sempre se buscará a maximização de um benefício ou mesmo a minimização de um dano, sujeito ou não a algum tipo de restrição.

Não há um único método disponível que solucione de forma eficiente todos os problemas de otimização, portanto diferentes métodos foram desenvolvidos para resolverem os diferentes tipos de problemas de otimização. Técnicas de programação matemática, por exemplo, são apropriadas para encontrar o mínimo de uma função de várias variáveis sujeitas a algum tipo de restrição, técnicas de processo estocástico são bastante úteis para a análise de problemas de variáveis aleatórias em que a distribuição de probabilidades é conhecida e métodos estatísticos permitem analisar dados experimentais e construir modelos empíricos para a obtenção de um modelo mais preciso de representação de uma situação física real.

É importante salientar que tanto o processo de otimização, como o método de projeto convencional, são ambos iterativos, no entanto eles possuem diferenças básicas conforme apresentado na Figura 3.4.

No método de projeto convencional, pode-se observar que a atualização do modelo é baseada na experiência e intuição do projetista ou mesmo em algumas informações obtidas de uma análise anterior, já no método de projeto otimizado, a atualização é baseada em conceitos de otimização que determinam os critérios de convergência, 
tornando assim o modelo mais formal, utilizando-se de medidas de tendência para realizar as modificações no modelo.

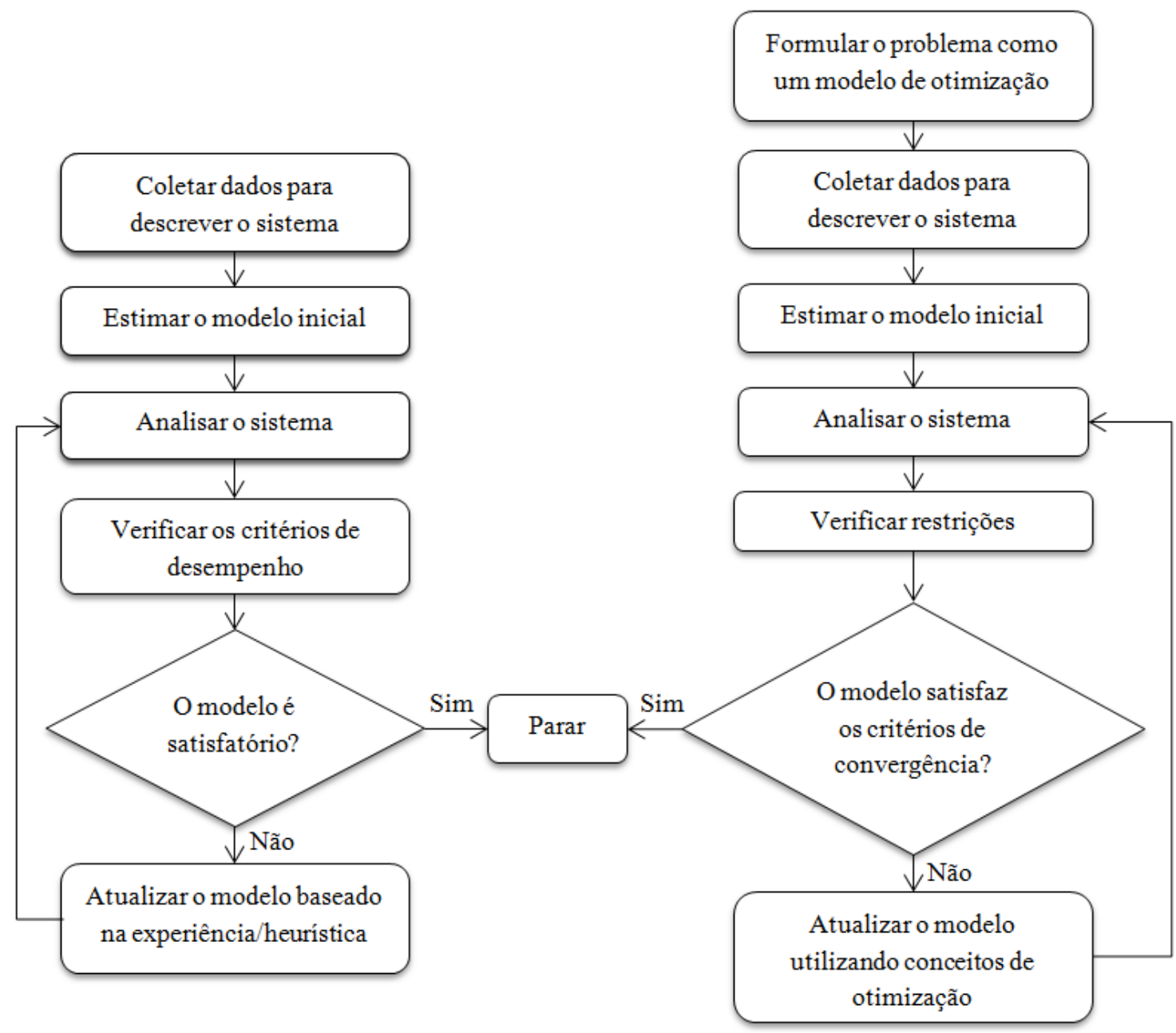

(a) método de projeto convencional

(b) método de projeto otimizado

Figura 3.4 - Comparação entre métodos de projeto. Fonte: Arora (2012), modificado.

A formulação básica de um problema de otimização é dada por:

$$
\text { Encontrar } \boldsymbol{X}=\left\{\begin{array}{c}
x_{1} \\
x_{2} \\
\vdots \\
x_{n}
\end{array}\right\} \text {, que minimiza } f(\boldsymbol{X})
$$

sujeito às seguintes restrições:

$$
\begin{gathered}
g_{j}(\boldsymbol{X}) \leq 0, \quad j=1,2,3, \ldots, m \\
l_{j}(\boldsymbol{X})=0, \quad j=1,2,3, \ldots, p
\end{gathered}
$$

sendo: 
$\boldsymbol{X}: \quad$ Vetor de dimensão $n$ chamado de vetor projeto;

$f(\boldsymbol{X})$ : Função objetivo;

$g_{j}(\boldsymbol{X}):$ Restrições de desigualdade;

$l_{j}(\boldsymbol{X}): \quad$ Restrições de igualdade.

\subsubsection{Otimização Estrutural}

Com o rápido desenvolvimento da tecnologia CAD (Computer Aided Design), de estações de trabalho com recursos gráficos e de processamento mais poderosas, as atenções se voltaram rapidamente para a otimização estrutural. Da mesma maneira, houve também um crescimento da aceitabilidade e confiabilidade das indústrias para as análises realizadas computacionalmente, como o método dos elementos finitos, de contorno e das diferenças finitas.

Por meio da otimização estrutural possibilita-se a diminuição dos custos devido à redução de uso de matéria prima decorrente da diminuição dos níveis acentuados de tensão dos componentes.

A Figura 3.5 apresenta os tipos de otimização estrutural, em (a) é mostrada a otimização paramétrica, em que a estrutura apresenta topologia e forma fixas variando as características constitutivas do material e/ou as dimensões da peça estrutural, em (b) é exibida a otimização de forma, em que a estrutura apresenta topologia fixa, variando apenas o seu formato, sem ocorrer inserção de vazios, e finalmente em (c) observa-se que os vazios foram formados no interior da viga até que todo o formato da treliça fosse determinado, caracterizando assim a otimização topológica, cuja principal característica é a inserção de vazios em um domínio fixado previamente. A formulação matemática da otimização topológica é apresentada no item 0.

Na otimização de topologia busca-se a solução ótima através da distribuição ótima de material num domínio previamente definido. Isso corresponde, em estruturas discretas, a determinar, por exemplo, o número total de barras, suas respectivas conectividades e suas propriedades geométricas. Em se tratando de estruturas contínuas, busca-se determinar a existência ou não de material em regiões do domínio, seus respectivos formatos e a conectividade entre os domínios (Pantoja, 2012). 

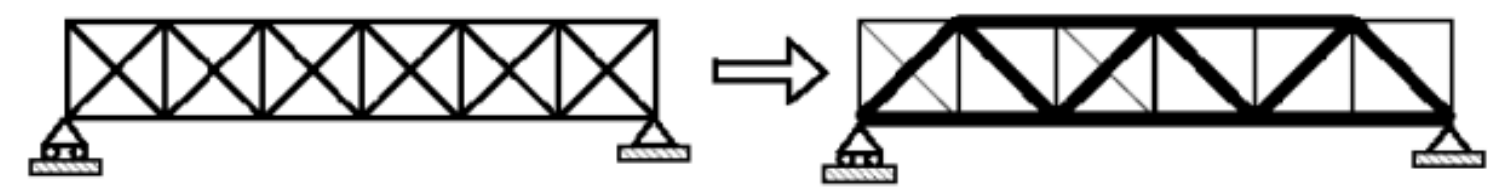

a) Otimização Paramétrica

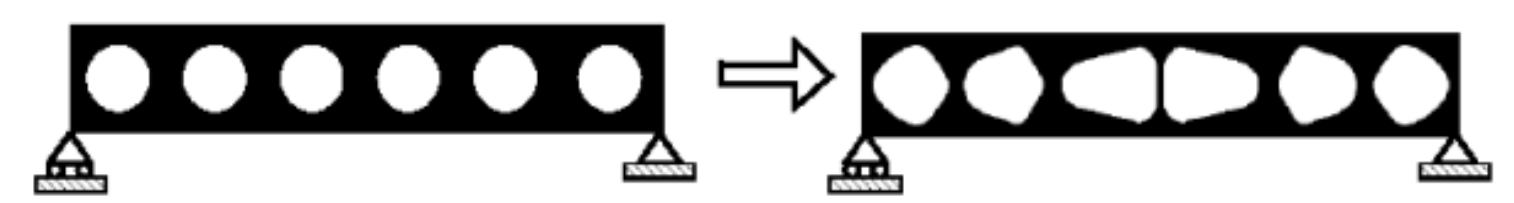

b) Otimização de forma

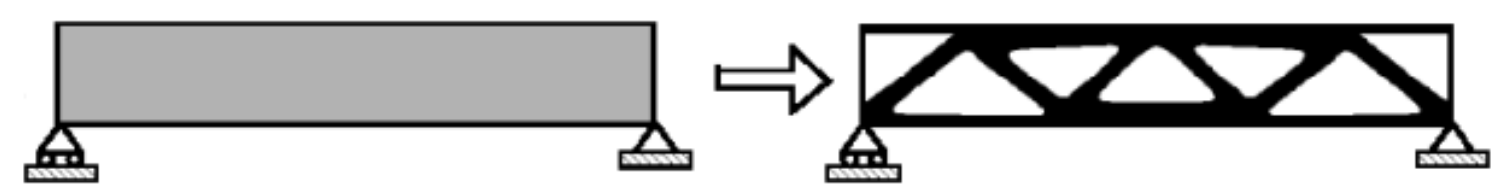

c) Otimização topológica

Figura 3.5 - Tipos de Otimização Estrutural. Fonte: Bendsøe \& Sigmund (2002)

\subsubsection{Otimização Topológica}

A otimização topológica para estruturas pode ser definida como um problema de disposição de material, cujo objetivo é encontrar uma distribuição que forme um elemento, dentro de um subconjunto ótimo $\left(\Omega^{\text {mat }}\right)$, que faça parte de um domínio de referência $(\Omega)$ em $\mathrm{R}^{2}$ ou $\mathrm{R}^{3}$. O domínio de referência $(\Omega)$, também chamado de espaço de projeto ou estrutura base é escolhido de forma a permitir a aplicação das condições de contorno, bem como do carregamento aplicado. Uma representação do modelo descrito é apresentada na Figura 3.6.

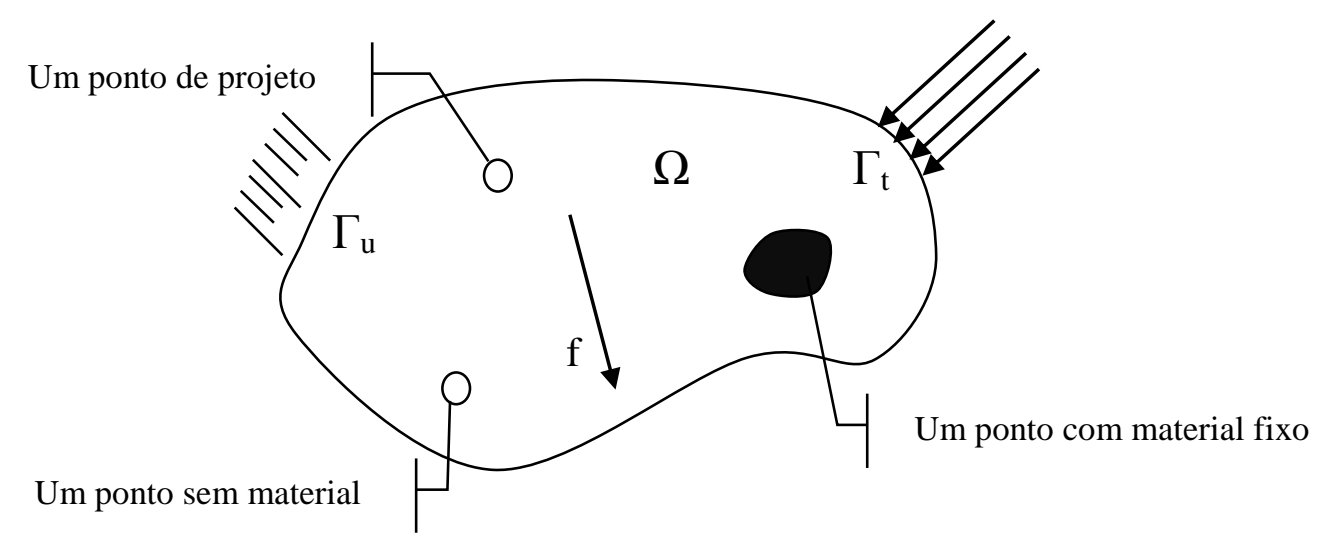

Figura 3.6 - Modelo generalizado de busca da distribuição ótima de material para um dado elemento. Sigmund \& Bendsøe, (2002) modificado) 
Dentre os problemas de otimização estrutural clássicos, podem ser citados a minimização de massa, da energia de deformação, a maximização da frequência natural crítica, a maximização da rigidez, a maximização da carga crítica de flambagem, etc.

Um dos critérios mais utilizados em problemas de otimização topológica estrutural é a minimização da energia interna de deformação com restrição sobre o volume que, em problemas lineares, é equivalente ao problema de minimização do trabalho externo. Sendo constantes os carregamentos aos quais a estrutura está submetida, minimizar o trabalho das forças externas corresponde a minimizar deslocamentos, ou seja, tornar a estrutura mais rígida (Pantoja, 2012).

\subsubsection{Maximização da Rigidez}

Para a maximização da rigidez, um dos algoritmos mais utilizados se baseia na busca da minimização da flexibilidade, tendo em vista que rigidez é inversamente proporcional à flexibilidade, minimizar a flexibilidade maximizará a rigidez.

As equações apresentadas abaixo, expressas por Bendsøe \& Sigmund (2002), definem a minimização da flexibilidade de forma matemática, sendo que a Equação 3.11 define o trabalho virtual interno de um corpo elástico no equilíbrio $u$ para um deslocamento virtual arbitrário $v$.

$$
\begin{gathered}
\alpha(u, v)=\int_{\Omega} E_{i j k l}(x) \varepsilon_{i j}(u) \varepsilon_{k l}(v) d \Omega \\
\varepsilon_{i j}(u)=\left(\frac{\partial u_{i}}{\partial x_{j}}+\frac{\partial u_{j}}{\partial x_{i}}\right)
\end{gathered}
$$

Sendo:

$$
\begin{aligned}
\alpha(u, v) & \text { Trabalho virtual interno de um corpo elástico no equilíbrio } u \text { para um } \\
& \text { deslocamento virtual arbitrário } v . \\
\varepsilon: & \text { Deformação associada ao campo } u \text { ou } v \\
u: & \text { Campo de deslocamentos na condição de equilíbrio } \\
v: & \text { Campo de deslocamentos virtuais } \\
\Omega: & \text { Domínio geométrico de referência }
\end{aligned}
$$

As forças externas realizarão um trabalho que poderá ser calculado da seguinte maneira: 


$$
l(u)=\int_{\Omega} f u d \Omega+\int_{\Gamma_{T}} t u d s
$$

Dessa maneira, a função objetivo para a minimização da flexibilidade pode ser descrita do seguinte modo:

$$
\begin{gathered}
\min _{u \in U, E}=l(u), \text { sujeito à: } \\
a_{E}(u, v)=l(v), \operatorname{para}(v \in U) \text { e }\left(E \in E_{a d}\right)
\end{gathered}
$$

Sendo:

$U: \quad$ Espaço de deslocamento cinemático admissível

$f:$ Forças internas

t: Tração

$E_{a d}: \quad$ Rigidez admissível

Ao contrário dos sistemas contínuos, ao se trabalhar com análises através do Método dos Elementos Finitos (MEF), o problema deve ser transformado para a forma de um sistema discreto padrão. Dessa maneira, assumindo uma constante $E$ para cada elemento, pode-se reescreves as Equações 3.14e 3.15 da seguinte forma:

$$
\begin{gathered}
\min \boldsymbol{f}^{T} \boldsymbol{u} \text { Sujeito à: } \\
\boldsymbol{K}\left(E_{e}\right) \boldsymbol{u}=\boldsymbol{f} \\
E_{e} \in E_{a d}
\end{gathered}
$$

Sendo:
$\boldsymbol{u}$ : Vetor deslocamento
$f$ : Vetor carregamento
$\boldsymbol{K}$ : Matriz de rigidez
$E_{e}: \quad$ Rigidez do elemento

A matriz de rigidez $\boldsymbol{K}$ depende da rigidez $E_{e}$ do elemento $e$, com $e$ variando de 1 até o número total de elementos. Podendo assim ser escrita da seguinte forma:

$$
\boldsymbol{K}=\sum_{e=1}^{N} \boldsymbol{K}_{\boldsymbol{e}}\left(E_{e}\right)
$$




\subsubsection{Disposição do Material}

Em um projeto de otimização topológica de uma estrutura, é interesse determinar a ótima localização de cada fração de material, determinando assim os pontos onde deve haver material, bem como os pontos que deve haver a falta dele. Bendsøe \& Sigmund (2002) exemplificam que, se a superfície geométrica for pensada como uma imagem renderizada, cada pixel corresponderá a um elemento dado pela discretização da malha em elementos finitos.

O objetivo é determinar o subconjunto ótimo $\left(\Omega^{\text {mat }}\right)$ de pontos com material. $\mathrm{O}$ subconjunto de $E_{a d}$ de rigidez admissível consiste naquelas que atendem às seguintes equações:

$$
\begin{gathered}
E_{i j k l}=1_{\Omega^{m a t}} E_{i j k l}^{0}, \quad 1_{\Omega^{m a t}}=\left\{\begin{array}{cc}
1 & \text { se } x \in \Omega^{\text {mat }} \\
0 & \text { se } x \in \Omega \backslash \Omega^{\text {mat }}
\end{array}\right\} \\
\int_{\Omega} 1_{\Omega^{m a t} d \Omega}=\operatorname{Vol}\left(\Omega^{\text {mat }}\right) \leq V
\end{gathered}
$$

Observa-se que a equação 3.19 formula um problema discreto do tipo [0-1], já a inequação 3.20 expressa um limite $V$ de volume total de material disponível, dessa forma a menor rigidez projetada é limitada por um volume fixo.

O problema de otimização topológica possui basicamente uma variável, que é a densidade relacionada à rigidez de cada elemento. Expressando essa rigidez $E_{i j k l}$ como um valor que depende de forma contínua da densidade do material, a sua variação irá influenciar a rigidez de cada um dos elementos discretos $E_{e}$ e a distribuição total do material. Dessa forma, como a densidade é uma variável contínua, ela precisa ser avaliada também nos valores intermediários entre 0 e 1 . Sem esse tipo de avaliação poderia não haver convergência e ainda produzir o problema do tipo "tabuleiro de xadrez" conforme apresentado na Figura 3.7. 


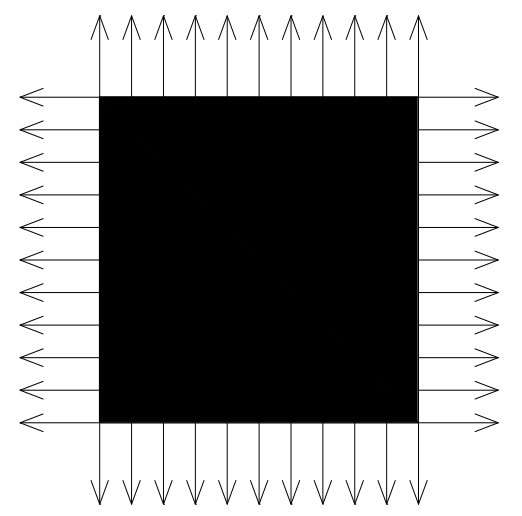

(a) modelo de projeto

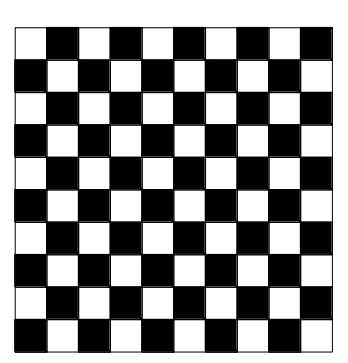

(b) solução encontrada

Figura 3.7 - Problema do tabuleiro demonstrado em uma estrutura sujeita à tensões biaxiais. (Bendsøe \& Sigmund (2002) modificado)

O requisito é que os resultados da otimização sejam praticamente de regiões com ou sem material, dessa forma, os resultados intermediários da densidade artificial devem ser penalizados. Um algoritmo que tem se mostrado bastante eficiente é o modelo SIMP (Solid Isotropic Microstructure with Penalization), também chamado de Modelo de Rigidez Proporcional Penalizada.

$$
\begin{gathered}
E_{i j k l}(x)=\rho(x)^{p} E_{i j k l}^{0}, p>1 \\
\int_{\Omega} \rho(x) d \Omega \leq V ; \quad 0 \leq \rho(x) \leq 1, \quad x \in \Omega
\end{gathered}
$$

$\mathrm{Na}$ Equação 3.21, $\rho(x)$ e $E_{i j k l}^{0}$ representam a função densidade e as propriedades de um dado material isotrópico respectivamente, dessa maneira, a equação determina a interpolação dos valores das propriedades do material entre 0 e $E_{i j k l}^{0}$.

$$
E_{i j k l}(\rho=0)=0, \quad E_{i j k l}(\rho=1)=E_{i j k l}^{0}
$$

Na prática utiliza-se um valor de $0<\rho_{\min } \leq \rho(x) \leq 1$, geralmente adota-se $\rho_{\text {min }}=$ $10^{-3}$, pois dessa forma evita-se a singularidade nas matrizes que compõem as equações de equilíbrio.

No modelo SIMP, o valor de $p>1$ garante que as densidades intermediárias sejam penalizadas, pois a rigidez obtida é pequena em relação ao volume de material utilizado. Em outras palavras, utilizar um valor de $p>1$ torna antieconômico trabalhar com densidades intermediárias na modelagem ótima. A experiência tem mostrado que nos 
problemas do tipo [0-1] em que há restrição de volume, a otimização tem apresentado melhores resultados utilizando valores de $p \geq 3$ Bendsøe \& Sigmund (2002). O gráfico da Figura 3.8 mostra a variação de $E_{i j k l}$ em função de $p$ com $E_{i j k l}^{0}$ unitário para diferentes densidades $(\rho)$. Como pode ser observado no gráfico, à medida que o valor de $p$ aumenta, torna-se cada vez menos interessante a utilização dos menores valores de densidade.

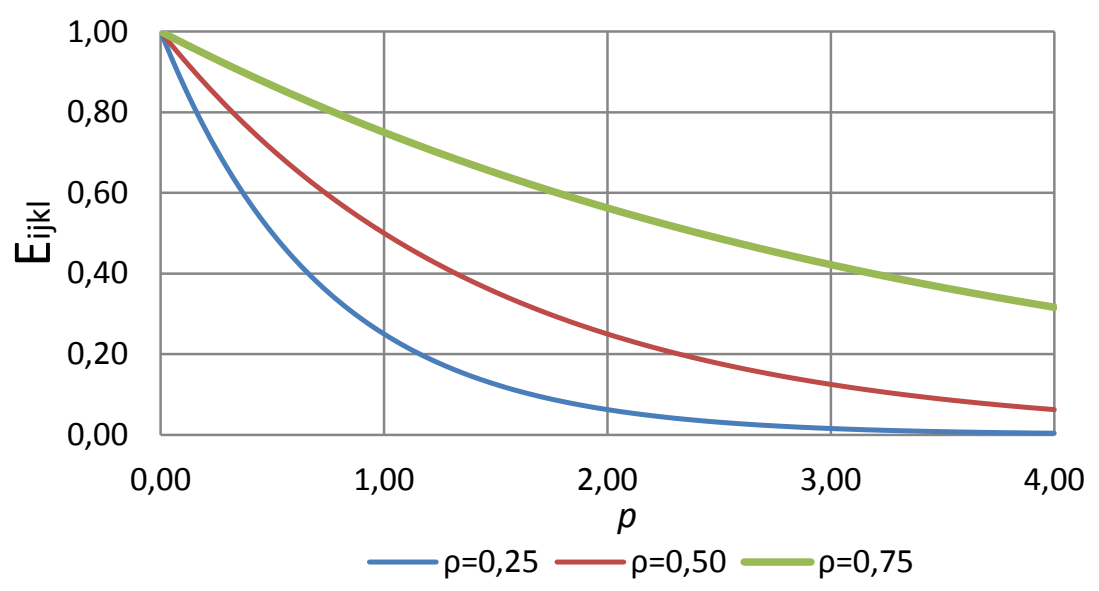

Figura 3.8 - Variação de $E_{i j k l} \operatorname{com} E_{i j k l}^{0}$ unitário para diferentes densidades

\subsubsection{Critérios de Otimização}

O problema de otimização na forma discreta é composto por um elevado número de variáveis, dessa maneira, é comum utilizar técnicas iterativas para solucionar o problema. Um método bastante utilizado, inclusive por aplicações comerciais, é o método Optimality Criteria (OC), que atualiza as variáveis utilizando um esquema heurístico.

O Lagrangiano para o problema de otimização é definido da seguinte forma:

$$
\begin{gathered}
\mathcal{L}=l(u)-\left\{a_{E}(u, \bar{u})-l(\bar{u})\right\}+\Lambda\left(\int_{\Omega} \rho(x) d \Omega-V\right)+ \\
\int_{\Omega} \lambda^{+}(x)(\rho(x)-1) d \Omega+\int_{\Omega} \lambda^{-}(x)\left(\rho_{\min }-\rho(x)\right)
\end{gathered}
$$

Sendo $\bar{u}, \Lambda, \lambda^{+}$e $\lambda^{-}$os multiplicadores de Lagrange para as várias restrições. 
De acordo com Bendsøe \& Sigmund (2002) um esquema heurístico de atualização das variáveis pode ser formulado como:

$$
\rho_{k+1}=\left\{\begin{array}{ccc}
\max \left\{(1-m) \rho_{k}, \rho_{\min }\right\} & \text { se } & \rho_{k} B_{k}{ }^{\eta} \leq \max \left\{(1-m) \rho_{k}, \rho_{\min }\right\} \\
\min \left\{(1+m) \rho_{k}, 1\right\} & \text { se } & \rho_{k} B_{k}{ }^{\eta} \geq \min \left\{(1+m) \rho_{k}, 1\right\} \\
\rho_{k} B_{k}{ }^{\eta} & \text { casocontrário }
\end{array}\right\}
$$

Na Equação $3.25 \rho_{k}$ determina o valor da densidade na iteração $k, m$ é um parâmetro de movimento e $\eta$ um coeficiente de amortecimento numérico. Os dois últimos controlam as mudanças que acontecem a cada iteração de forma a garantir uma convergência rápida e estável, um valor típico de $m$ e $\eta$, obtidos experimentalmente, são 0,2 e 0,5, respectivamente Bendsøe \& Sigmund (2002). Já $B_{k}$ é dado pela seguinte expressão:

$$
B_{k}=\Lambda_{k}{ }^{-1} p \rho(x)^{p-1} E_{i j k l}^{0} \varepsilon_{i j}\left(u_{k}\right) \varepsilon_{k l}\left(u_{k}\right)
$$

A estrutura do algoritmo de otimização se dá da seguinte forma:

$\checkmark$ Uma modelagem inicial deve ser realizada determinando uma distribuição homogênea do material;

$\checkmark$ Em seguida, para a distribuição de densidades elaborada, deve ser realizada a análise em elementos finitos, determinando as tensões e deformações do elemento;

$\checkmark$ Calcula-se então a rigidez do elemento, se não há ganho marginal em relação à iteração anterior, análise deve ser finalizada;

$\checkmark$ Se há ganho marginal, as variáveis devem ser atualizadas, e realizar um novo processo de otimização até que o critério de convergência seja atingido.

De forma a melhorar a visualização, apresenta-se na Figura 3.9 um fluxograma do processo de otimização topológica, as imagens foram geradas a partir de um algoritmo apresentado em Sigmund (2001), cujo código fonte implementado em Matlab se encontra disponível em $h t t p: / / w w w . t o p o p t . d t u . d k$. 


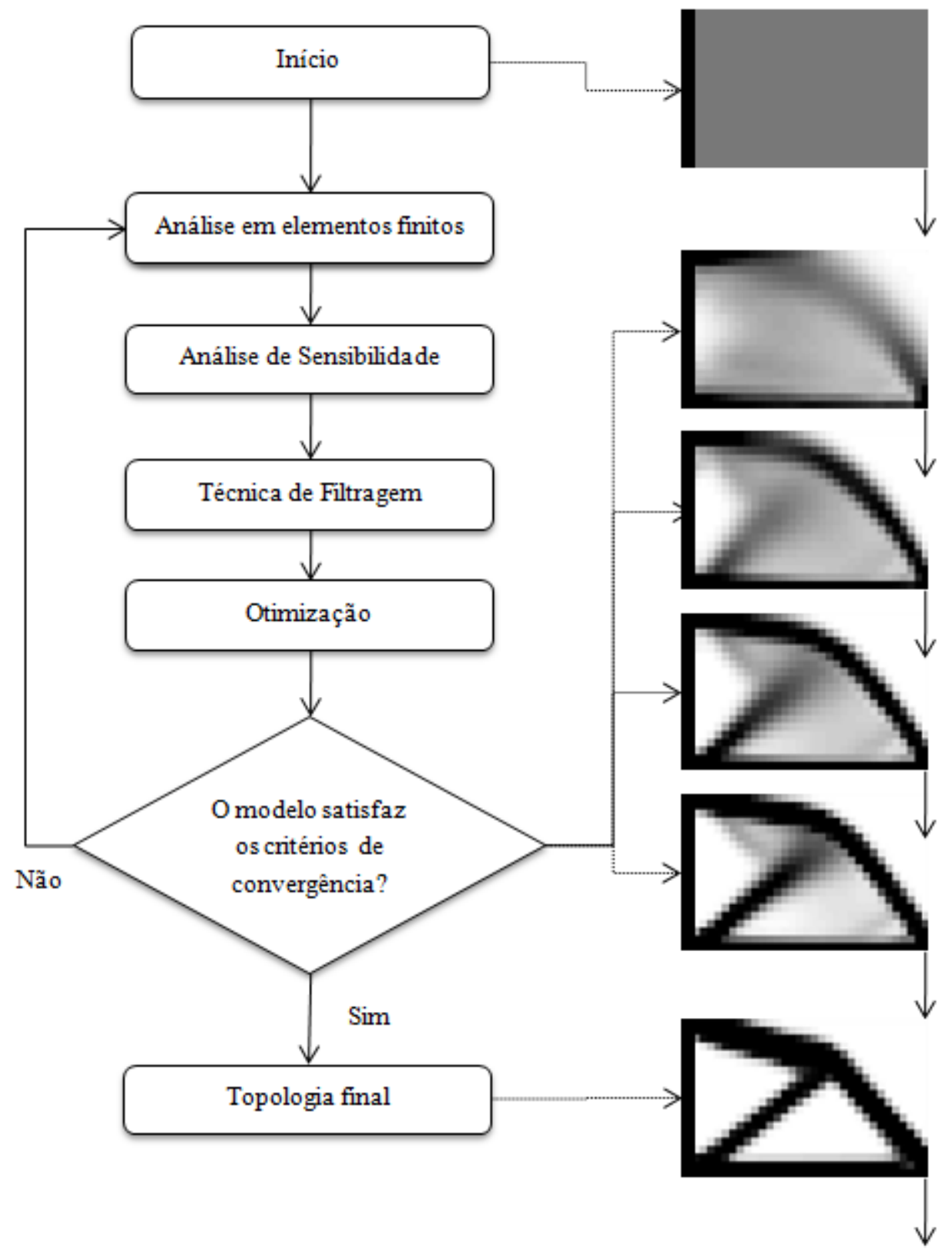

Figura 3.9 - Fluxograma de Otimização Topológica 


\section{PROPOSTA DO DISSIPADOR}

Nesse item é apresentada uma topologia proposta como alternativa para o dissipador metálico do tipo ADAS, encontrada através da otimização topológica segundo as definições apresentadas no item 0 . De forma a verificar o seu funcionamento e desempenho, são realizadas comparações entre o desempenho obtido pelo ADAS, apresentadas em trabalhos acadêmicos, com os resultados obtidos pela geometria alternativa submetida às mesmas condições dos modelos apresentados na literatura.

\subsection{TOPOLOGIA}

Como apresentado no item 2.5, Whittaker et al. (1989) investigaram o comportamento de placas paralelas no formato "X" denominadas ADAS (Added Damping and Stiffness) com o objetivo de determinar o grau de efetividade dessas placas para aplicações sísmicas em geral. O formato detalhado das placas utilizadas, bem como suas dimensões em polegadas, são apresentadas na Figura 4.1.

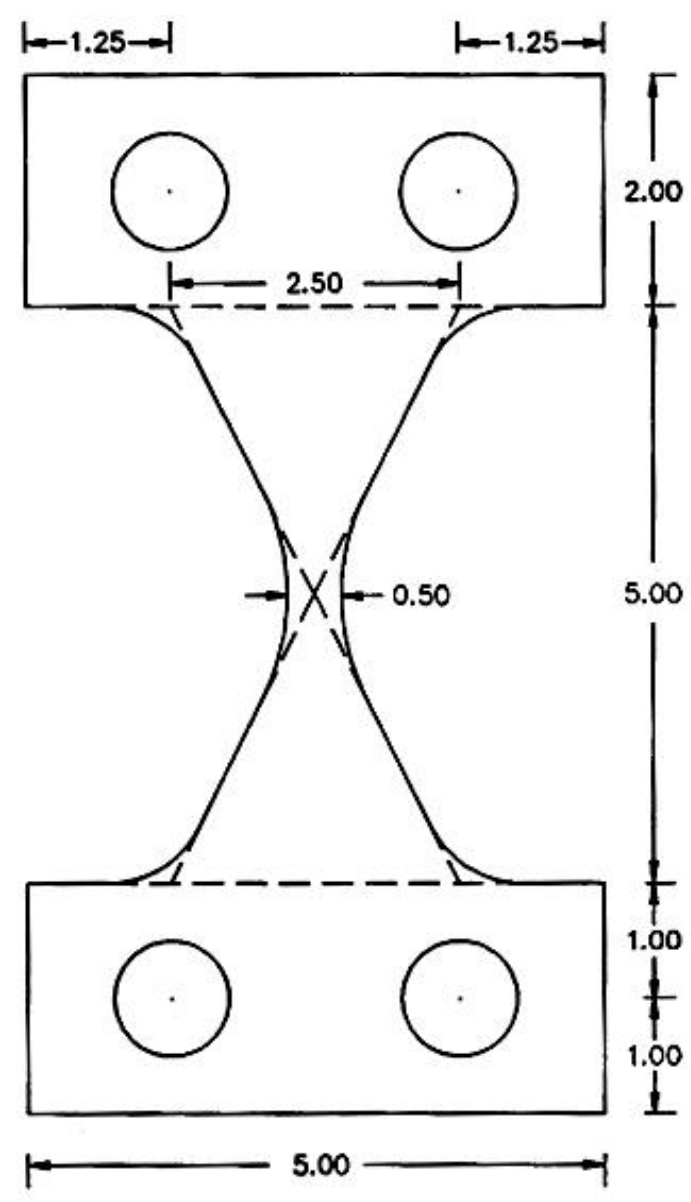

a) Vista frontal

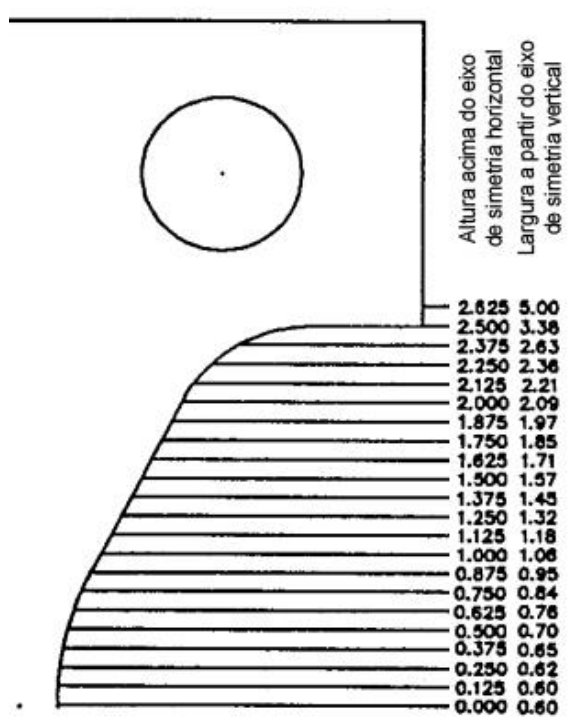

b) Detalhe canto superior direito

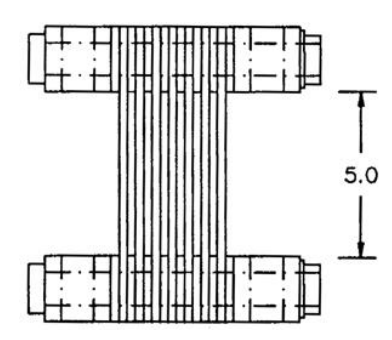

c) Vista lateral

Figura 4.1 - Dimensões do ADAS. Whittaker et. al. (1989), modificado 
No presente trabalho, buscou-se também, através da otimização topológica, a investigação do comportamento de dissipadores metálicos em que as placas tivessem uma geometria alternativa ao formato " $\mathrm{X}$ ".

Como forma de reproduzir numericamente as condições de ensaio de maneira que toda a peça se deforme com dupla curvatura em relação ao seu ponto médio e que apresente escoamento ao longo de toda sua altura, optou-se por analisar uma placa de tamanho inferior à geometria apresentada por Whittaker et. al. (1989) com configuração de restrições diferenciadas. Optou-se por engastar a estrutura na base, com carregamento aplicado no topo, semelhante a um engaste simples, para simular a dupla curvatura adotou-se um eixo de simetria em relação ao eixo horizontal e para considerar um ganho de geometria no eixo horizontal, adotou-se também um eixo de simetria vertical. Os detalhes do modelo de elementos finitos bem como a estrutura deformada após a aplicação do carregamento são apresentados na Figura 4.2.

Os seguintes valores foram adotados para a otimização: números de elementos da malha igual a 2.028 prismas $\left(\mathrm{n}_{\mathrm{elx}}=26, \mathrm{n}_{\mathrm{ely}}=3, \mathrm{n}_{\mathrm{elz}}=26\right)$ com o total de 10.720 nós, abertura de malha de 2,5mm, fração em relação ao volume inicial de $85 \%$.

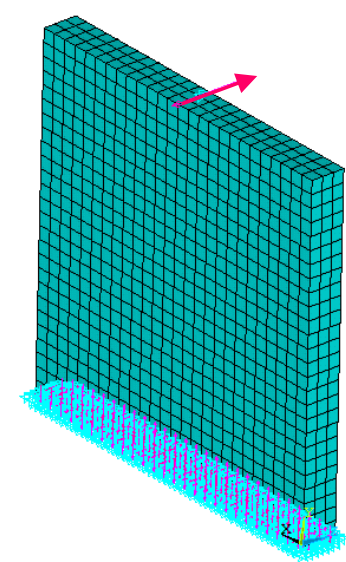

a) Aplicação do carregamento

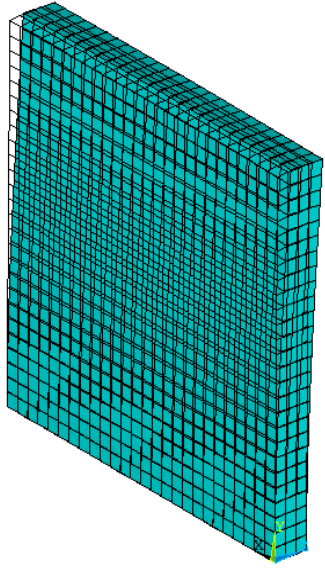

b) Estrutura deformada

Figura 4.2 -Modelo estrutural de placa metálica

Após a aplicação do carregamento, se processou o algoritmo de otimização topológica buscando uma distribuição ótima de material dentro do subconjunto da placa modelada. Conforme apresentado no item 3.3.2.2 o objetivo do algoritmo é determinar os pontos onde deve haver material, bem como os pontos onde deve haver a falta dele. Após o processamento de sucessivas iterações se obtém o modelo apresentado na Figura 4.3, 
onde, através da renderização de uma imagem, gera-se o modelo procurado pela distribuição de densidades. A densidade com valor $\rho=1$ indica que deve haver material naquele local, já os valores inferiores indicam a ausência de material na proporção considerada. Para o modelo em estudo, o valor de densidade $\rho=0,001$ foi considerado como a ausência de material.

Como o modelo obtido é bastante semelhante ao formato de uma garrafa, o mesmo foi denominado de "Bottle Shape" ou simplesmente Tipo Garrafa.

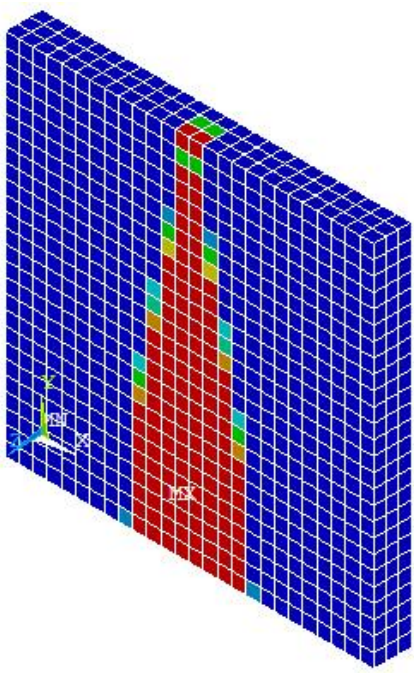

Distribuição de densidades de acordo com a discretização

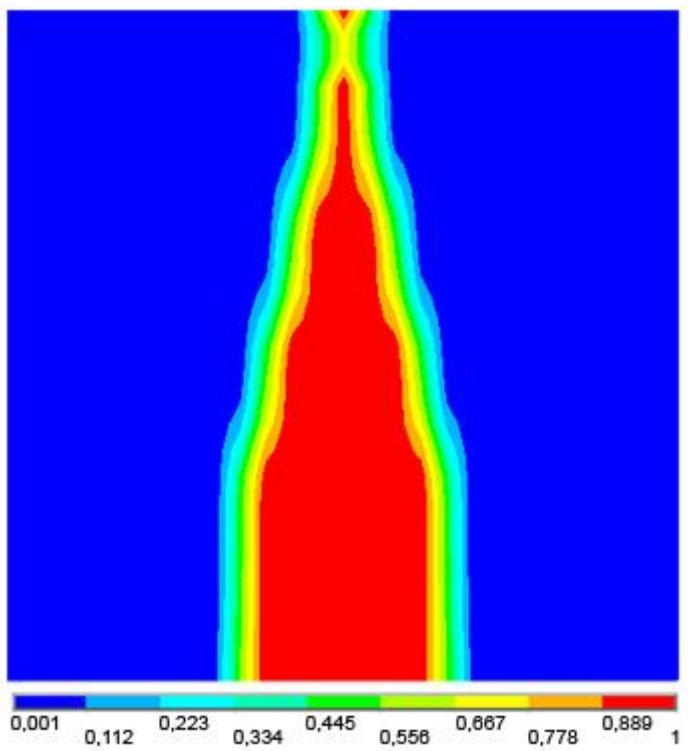

Imagem renderizada da distribuição de densidades

Figura 4.3 - Distribuição densidades para uma parte da placa

As imagens geradas a partir de alguns dos processos iterativos são apresentadas na Figura 4.4. O código utilizado, escrito na linguagem APDL (ANSYS Parametric Design Language) se encontra disponível para consulta no "Apêndice B".

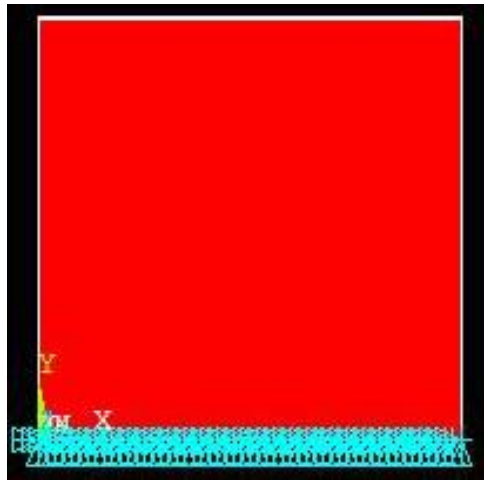

(a) processamento inicial

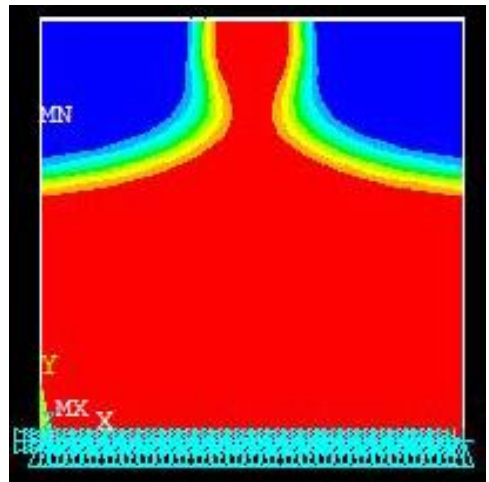

(b) iteração 01

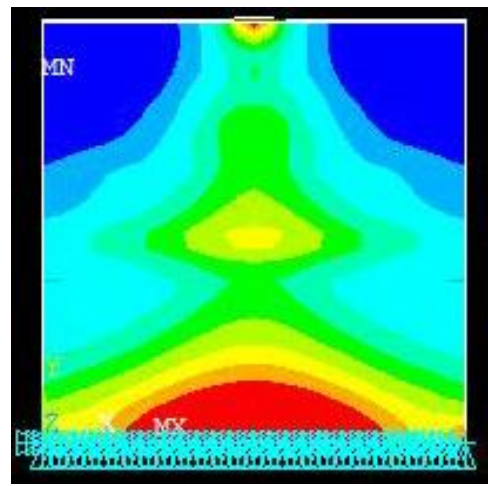

(c) iteração 03 


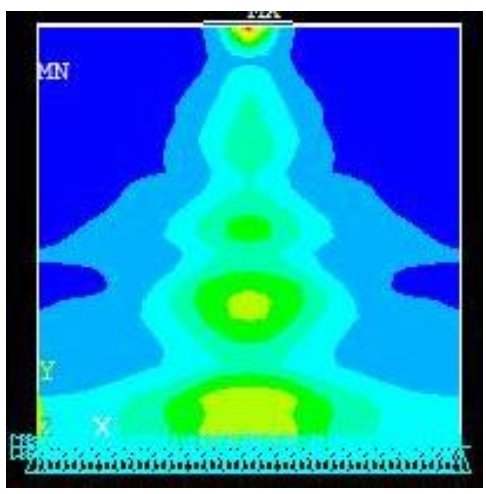

(d) iteração 05

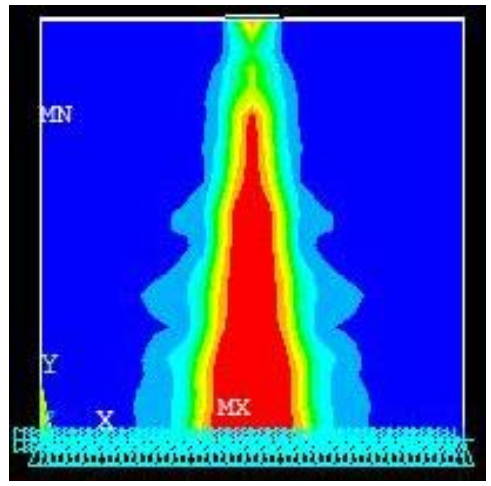

(g) iteração 12

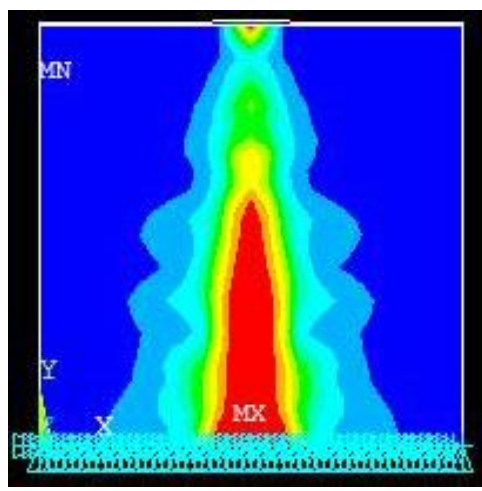

(f) iteração 09
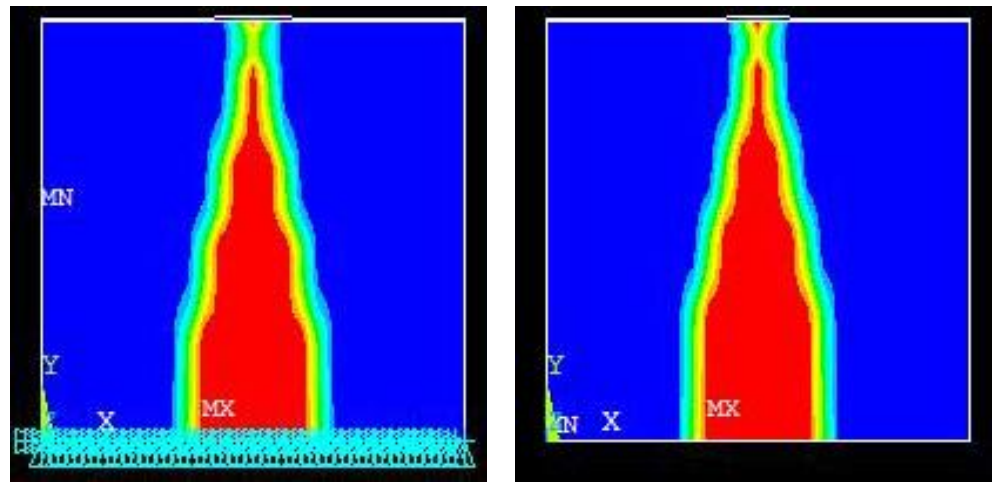

(i) iteração 29

Conforme descrito anteriormente, foram adotados para o modelo considerado, dois eixos de simetria, um horizontal que garante que a peça se deforme com dupla curvatura, e outro vertical, que permite um ganho geométrico nas dimensões da peça. Os detalhes da peça, já considerando os seus eixos de simetria são apresentados na Figura 4.5.

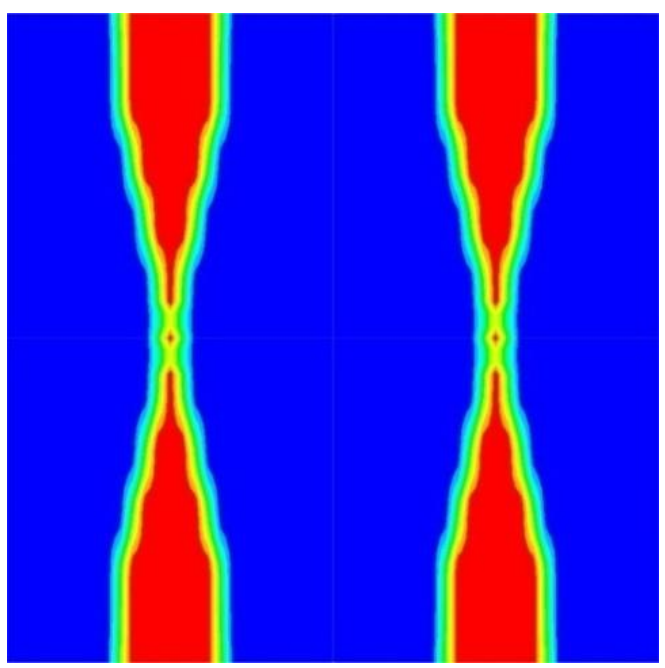

Figura 4.5 - Topologia proposta de acordo com a distribuição de densidades 
Com base no modelo de topologia obtido, foi realizada a modelagem do mesmo através de um sistema de coordenadas, permitindo assim a sua replicação ou utilização em diferentes tamanhos de escala, preservando as devidas proporções. Uma tabela com as coordenadas de cada um dos pontos é apresentada no Apêndice C, já no Apêndice D é apresentada uma rotina escrita em linguagem LISP® em que é possível realizar o desenho da forma proposta de forma automática em um programa de plataforma CAD (Computer Aided Design). A topologia representada pelo sistema de coordenadas é apresentada na Figura 4.6.

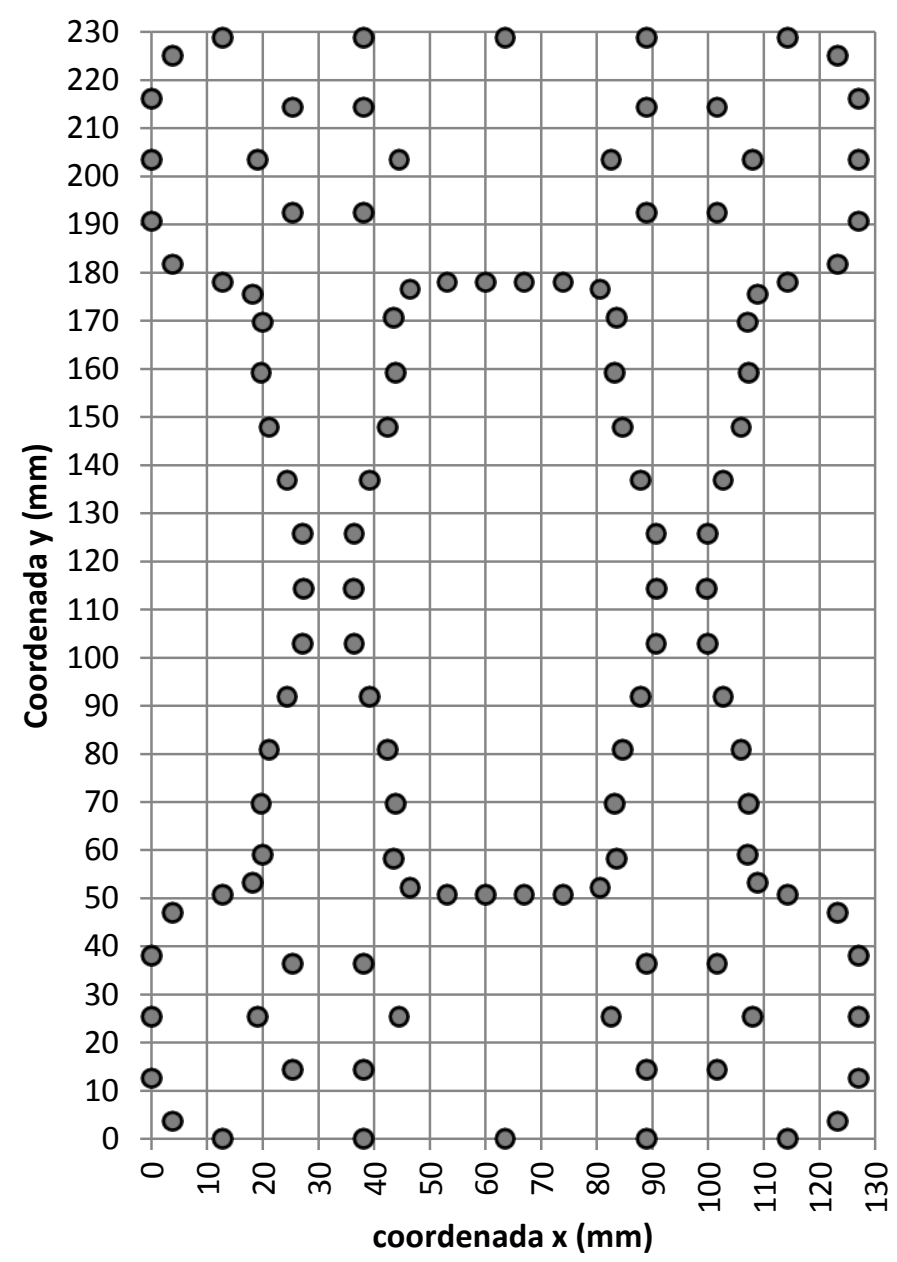

Figura 4.6 - Representação da topologia modelada através do sistema de coordenadas

A aplicação no formato " $\mathrm{X}$ " em estudo foi analisada experimentalmente por Whittaker et. al.(1989) na Universidade da Califórnia em Berkeley e posteriormente por TenaColunga (1997) ao propor um modelo matemático para os dissipadores metálicos no formato "X". 
Procedeu-se com a análise numérica de um dispositivo ADAS com quatro placas para os modelos X Shape e Bottle Shape. Os dados de projeto do ADAS no formato "X" testado numericamente estão de acordo com a notação da Figura 3.1, em que:

$$
\begin{array}{ll}
b_{1}=8,59 \mathrm{~cm} & b_{1}=3,38^{\prime \prime} \\
b_{2}=1,52 \mathrm{~cm} & b_{2}=0,6^{\prime \prime} \\
t=0,64 \mathrm{~cm} & t=0,25^{\prime \prime} \\
l=12,70 \mathrm{~cm} & l=5,0^{\prime \prime} \\
b_{1_{\text {eq }}}=6,35 \mathrm{~cm} & b_{1_{\text {eq }}}=2,5^{\prime \prime} \\
A_{\text {sup }}=152,84 \mathrm{~cm}^{2} & A_{\text {sup }}=23,69 \mathrm{pol}^{2} \\
V o l=97,06 \mathrm{~cm}^{3} & V o l=5,92 \mathrm{pol}^{3} \\
E=207.099,3 \mathrm{MPa} & E=30.000 \mathrm{Ksi}^{2}
\end{array}
$$

sendo:

$b_{1}$ : Largura de topo da placa metálica no modelo idealizado de ampulheta proposto

$b_{1}$ : por Tena-Colunga;

$b_{2}$ : Largura de centro da placa metálica no modelo idealizado de ampulheta proposto por Tena-Colunga;

$t$ : Espessura da placa;

$l:$ Altura da placa;

$b_{1}$ eq $:$ Largura equivalente do topo da placa metálica no modelo X Shape;

$A_{\text {sup }}$ : Área superficial da placa metálica;

Vol: Volume da placa;

E: Módulo de elasticidade;

A representação em elementos finitos do dissipador metálico do tipo X Shape é apresentada na Figura 4.7. Na modelagem de cada uma das placas de dissipação foi considerada uma malha retangular com abertura máxima de 5,0mm, totalizando 30.625 elementos com 92.644 nós, a limitação da abertura foi baseada em critérios de processamento da máquina utilizada. Adicionalmente foram realizadas análises com outros elementos de malha, porém não foram observadas alterações nos resuldados encontrados. 


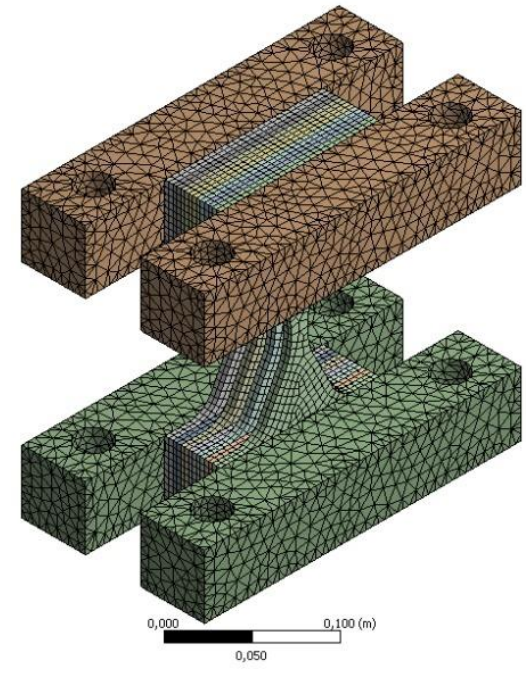

a) Perspectiva

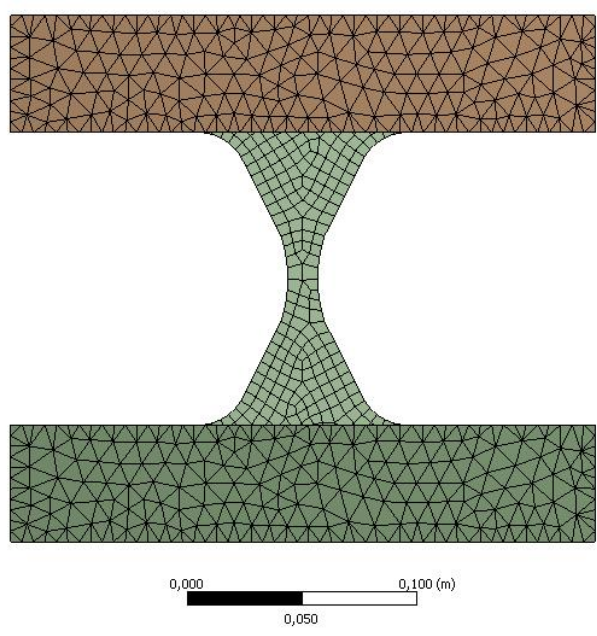

b) Vista frontal

Figura 4.7 - Modelagem em elementos finitos do dissipador metálico do tipo X Shape

Já o dissipador metálico proposto, sujeito às mesmas condições do teste em questão, possui as seguintes características.

$$
\begin{array}{ll}
t_{p}=0,64 \mathrm{~cm} & t_{p}=0,25 " \\
l=12,70 \mathrm{~cm} & l=5,0^{" \prime} \\
A_{\text {sup }}=152,42 \mathrm{~cm}^{2} & A_{\text {sup }}=23,62 \mathrm{pol}^{2} \\
V o l=96,78 \mathrm{~cm}^{3} & V o l=5,91 \mathrm{pol}^{3} \\
E=207.099,3 \mathrm{MPa} & E=30.000 \mathrm{Ksi}
\end{array}
$$

sendo:

$t_{p}:$ Espessura da placa;

l: Altura da placa;

$A_{\text {sup }}:$ Área superficial da placa metálica;

Vol: Volume da placa;

E: Módulo de elasticidade;

A modelagem em elementos finitos do dissipador metálico do tipo Bottle Shape é apresentada na Figura 4.8. Na modelagem de cada uma das placas de dissipação foi considerada uma malha retangular com abertura máxima de 5,0mm, totalizando 31.580 elementos com 97.539 nós, a limitação da abertura novamente se deu com base em critérios de processamento da máquina utilizada. 


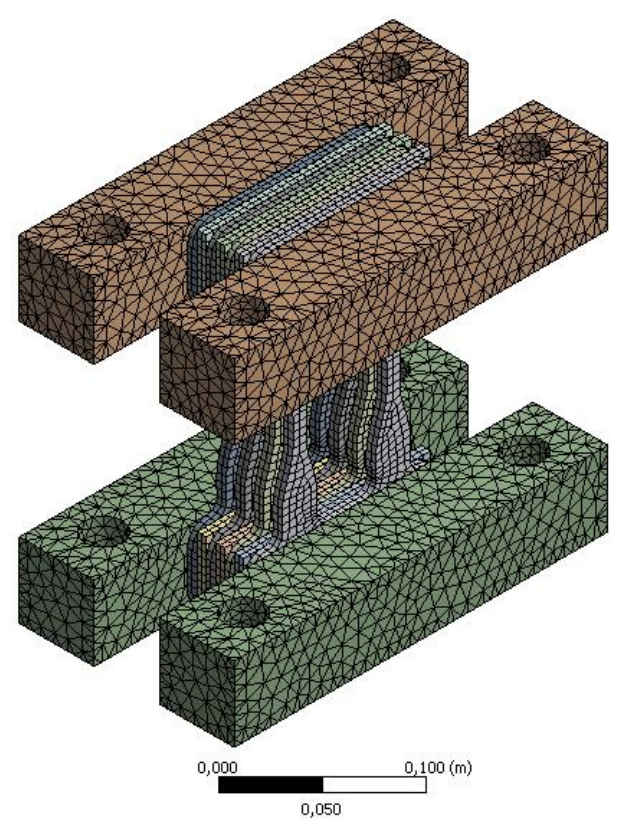

a) Com conectores

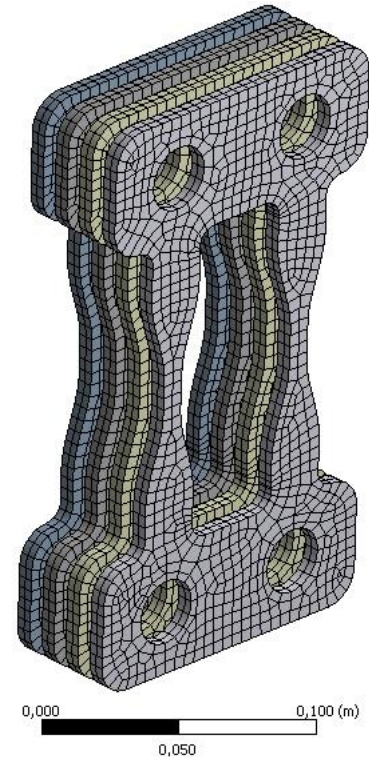

b) Sem conectores

Figura 4.8 - Modelagem em elementos finitos do dissipador metálico do tipo Bottle Shape

As dimensões geométricas do modelo estão apresentadas, através do sistema de coordenadas, na Figura 4.6 com todas as dimensões em milímetros.

Foi testado inicialmente um dispositivo ADAS com quatro placas, sendo que no modelo foi aplicado uma força cisalhante $V_{y}=11,69 k N$. Da mesma forma modelou-se um dissipador metálico do tipo Bottle Shape com a aplicação do mesmo carregamento. A representação gráfica da análise realizada é apresentada na Figura 4.9.

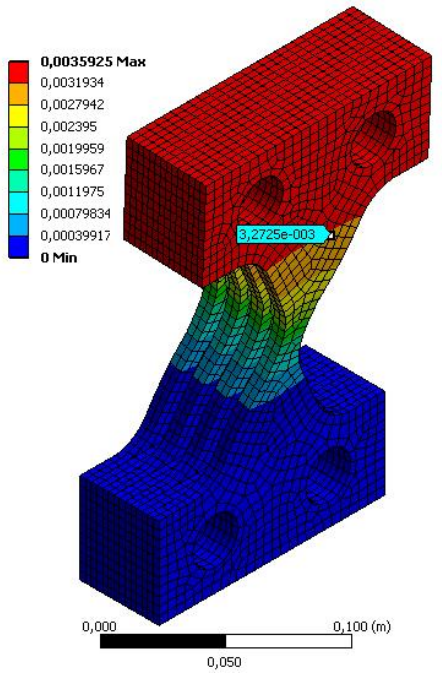

$X$ Shape

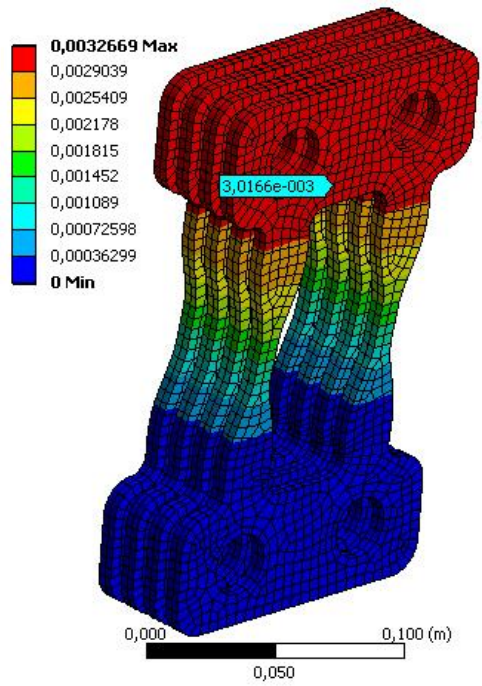

Bottle Shape

Figura 4.9 - Deslocamento dos dissipadores metálicos após a aplicação do carregamento 
Ao analisar os resultados, observou-se que, para um mesmo carregamento, o dispositivo Bootle Shape apresentou resultados bastante satisfatórios, quando se compara os deslocamentos sofridos pelas duas peças, constata-se que o desempenho do modelo proposto, relativo à rigidez elástica, é aproximadamente $8,5 \%$ superior. Cabe ressaltar ainda que ambas as peças possuem praticamente o mesmo volume de material. Os dados obtidos referentes aos deslocamentos dos dispositivos são apresentados na Tabela 4.1 .

Tabela 4.1 - Comparação da rigidez de cisalhamento elástica entres os modelos $X$

\begin{tabular}{cccccc}
\multicolumn{7}{c}{ Shape e Bottle Shape } \\
\hline Formato & $\begin{array}{c}\mathrm{N}^{\circ} \mathrm{de} \\
\text { Placas }\end{array}$ & $V_{y}(k N)$ & $\Delta_{y}\left(10^{-3} \mathrm{~cm}\right)$ & $k\left(\frac{k N}{\mathrm{~cm}}\right)$ & $\Delta_{k}(\%)$ \\
\hline X Shape & 4 & 11,69 & 327,25 & 35,72 & 0,00 \\
\hline Bottle Shape & 4 & 11,69 & 301,66 & 38,75 & 8,48
\end{tabular}

Como pode ser observado na Figura 4.10, conforme esperado, os modelos se deformaram com dupla curvatura em relação ao seu ponto médio. De forma a facilitar a visualização do atendimento desse requisito, a escala da deformação da imagem foi ampliada em cinco vezes.

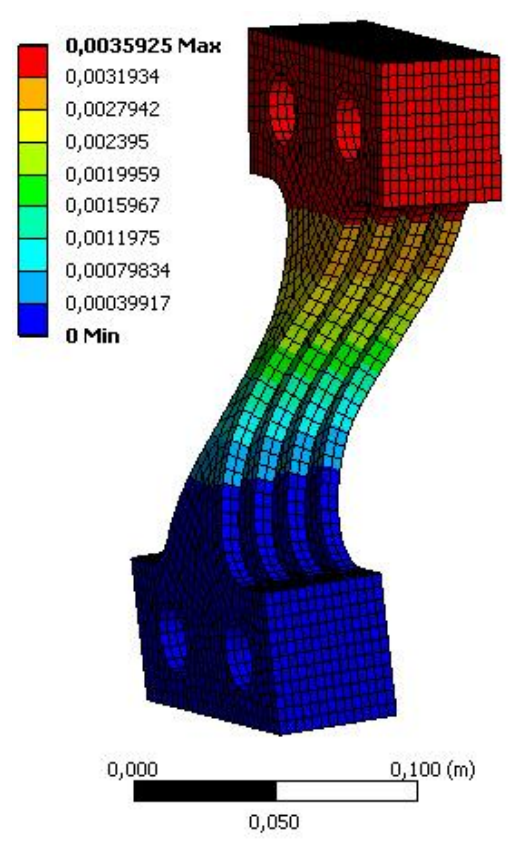

a) X Shape

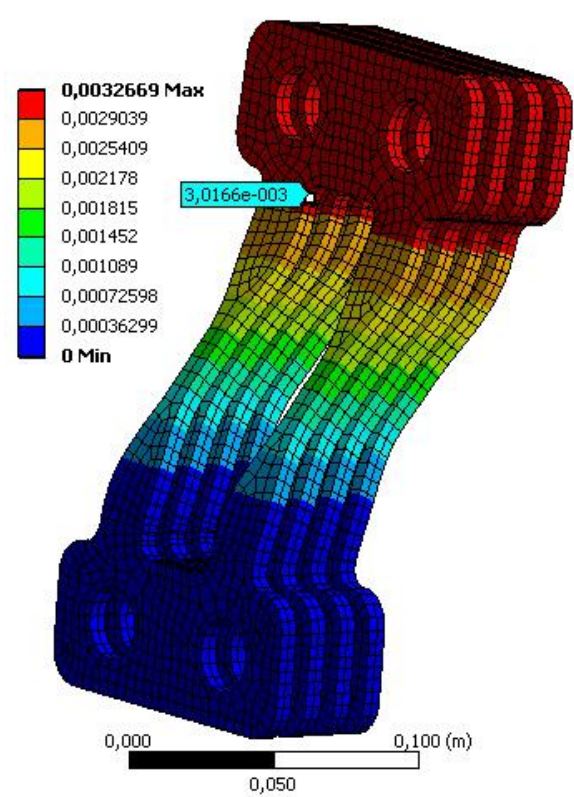

b) Bottle Shape

Figura 4.10 - Deformação em dupla curvatura dos modelos analisados (Escala: 5x) 


\subsection{ANÁLISE EXPERIMENTAL}

Partindo das investigações realizadas anteriormente, apresenta-se a seguir o estudo experimental que objetiva a validação e generalização dos resultados encontrados nas análises numéricas. Este capítulo se estrutura com a preparação das amostras de placas dissipadoras ensaiadas, a metodologia de ensaio e finalmente a apresentação dos resultados experimentais.

\subsubsection{Preparação das Placas Metálicas}

A geometria das placas metálicas foi obtida através de um sistema de corte automatizado a plasma, em que se utiliza oxigênio como gás de plasma. A automatização torna-se importante para que as peças sejam fabricadas no seu formato original com elevada precisão, evitando imperfeições geométricas e garantindo que as peças fiquem isentas de escória. Outro benefício desse tipo de corte é a dispensa do contato mecânico com a peça.

Nesse sistema, os desenhos das peças a serem cortadas, são armazenados eletronicamente em um sistema CAD, depois são transferidos para o programa Nesting (software de gerenciamento de corte) que otimiza o trabalho, garantindo um melhor aproveitamento dos materiais. Posteriormente as máquinas são operadas por CNC (Controle Numérico Computadorizado) e processam o corte de acordo com as informações recebidas diretamente do sistema CAD. Todo o processo é realizado de forma bem rápida, sem a necessidade de se fabricar matrizes. O procedimento de corte das placas apresentadas é apresentado na Figura 4.11.

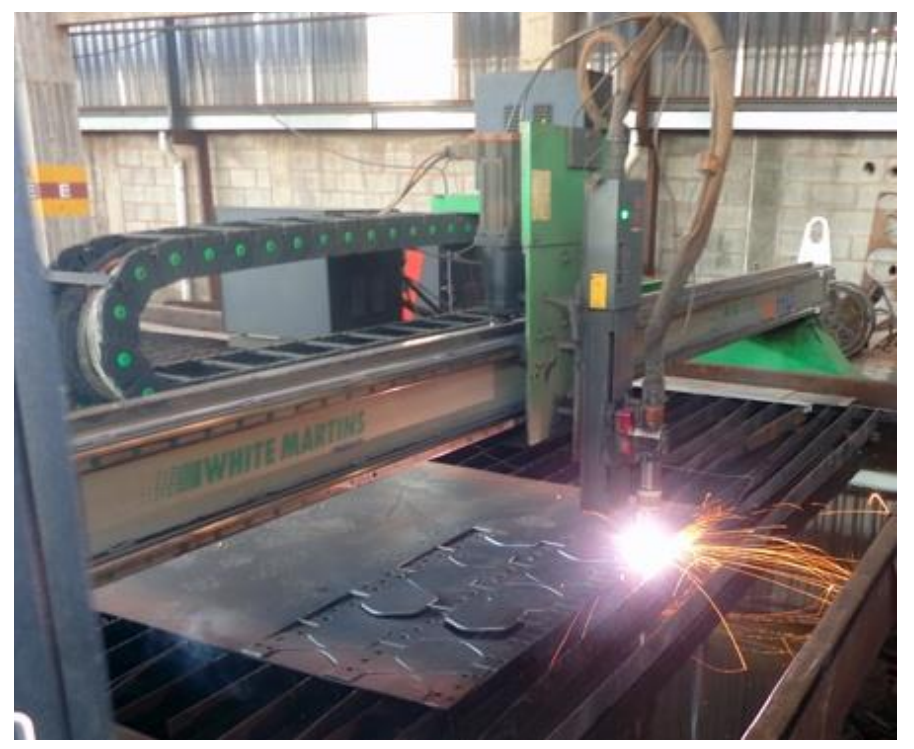

Figura 4.11 - Sistema de corte automatizado 
As placas do tipo $X$ Shape e Bottle Shape produzidas a partir do sistema de corte são apresentadas na Figura 4.12.

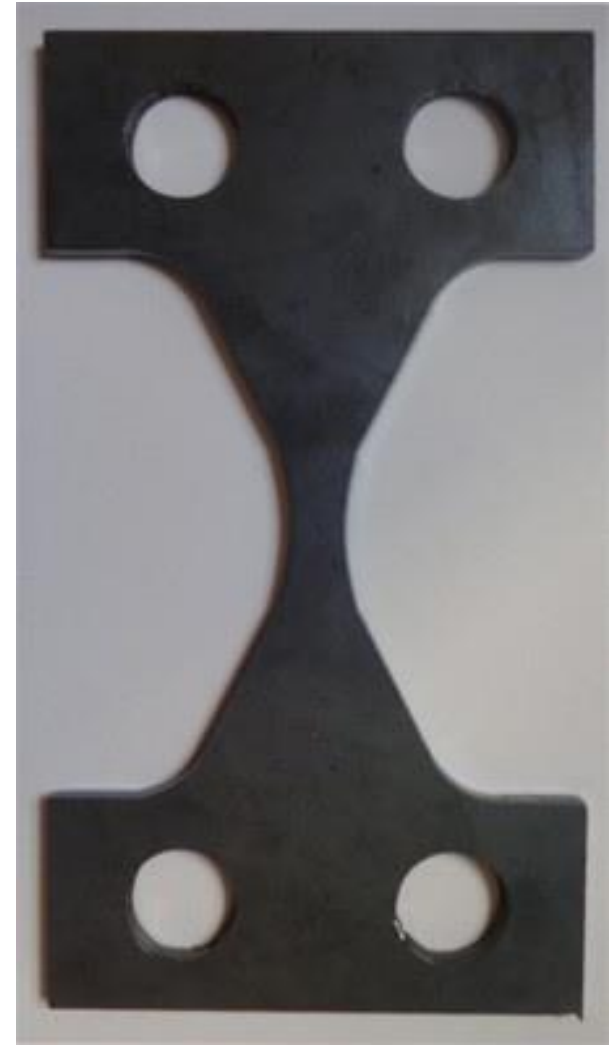

(a) - Placa do tipo $X$ Shape

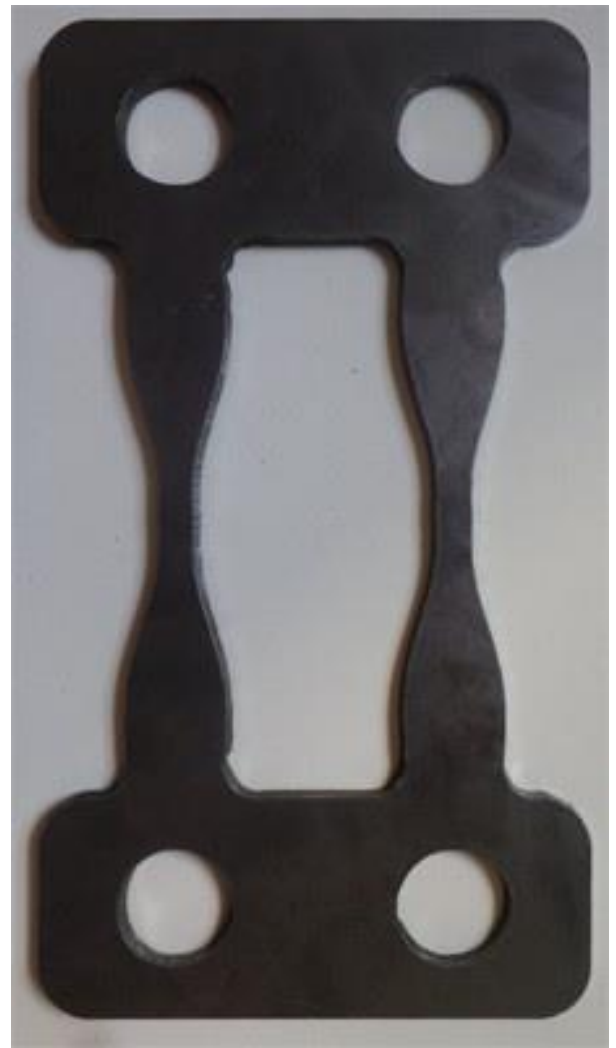

(b) - Placa do tipo Bottle Shape

Figura 4.12 - Placas submetidas ao processo de corte

\subsubsection{Metodologia de Ensaio}

Os ensaios experimentais para determinação dos diagramas de histerese foram realizados no Laboratório de Ensaios Mecânicos (SG9 - UnB). Os testes foram realizados com o acompanhamento e auxílio de técnicos e professores do Departamento de Engenharia Mecânica (ENM - UnB).

A máquina utilizada para os ensaios foi a Máquina Universal de Testes MTS 810, da MTS®. A MTS 810 proporciona uma ampla variedade de capacidades de testes, é possível a realização de ensaios com baixo, médio ou elevados níveis de carregamento, tanto para cargas estáticas como dinâmicas, tração ou compressão. Além disso, possui software específico fornecido pelo fabricante, de fácil configuração, que se ajusta bem aos diferentes tipos de carregamento, é por meio dele que são ativados e controlados as bombas e atuadores hidráulicos. As garras de fixação dos corpos de prova também são 
acionadas hidraulicamente, de maneira que se pode variar a pressão nas mesmas, utilizando um controlador na base da própria máquina. Possui ainda células de carga, que medem as forças aplicadas aos corpos de prova, com erro inferior a 1\%, em uma faixa entre $1 \mathrm{kN}$ a $100 \mathrm{kN}$ (Oliveira, 2008). A imagem do equipamento utilizado é apresentada na Figura 4.13.

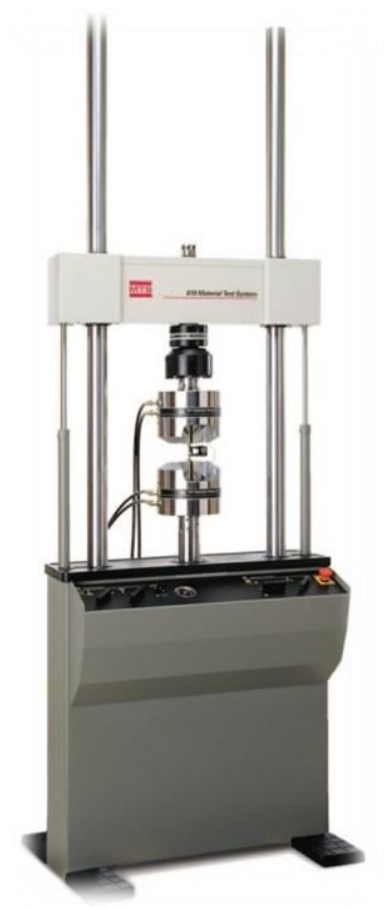

Figura 4.13 - Material Test system (MTS®) 810

Como pode ser observado no gráfico da Figura 4.14, que apresenta as possíveis configurações de carregamento em função dos deslocamentos esperados e das frequências pretendidas, a MTS 810 permite que se trabalhe em uma vasta gama de frequências de acordo com o carregamento especificado.

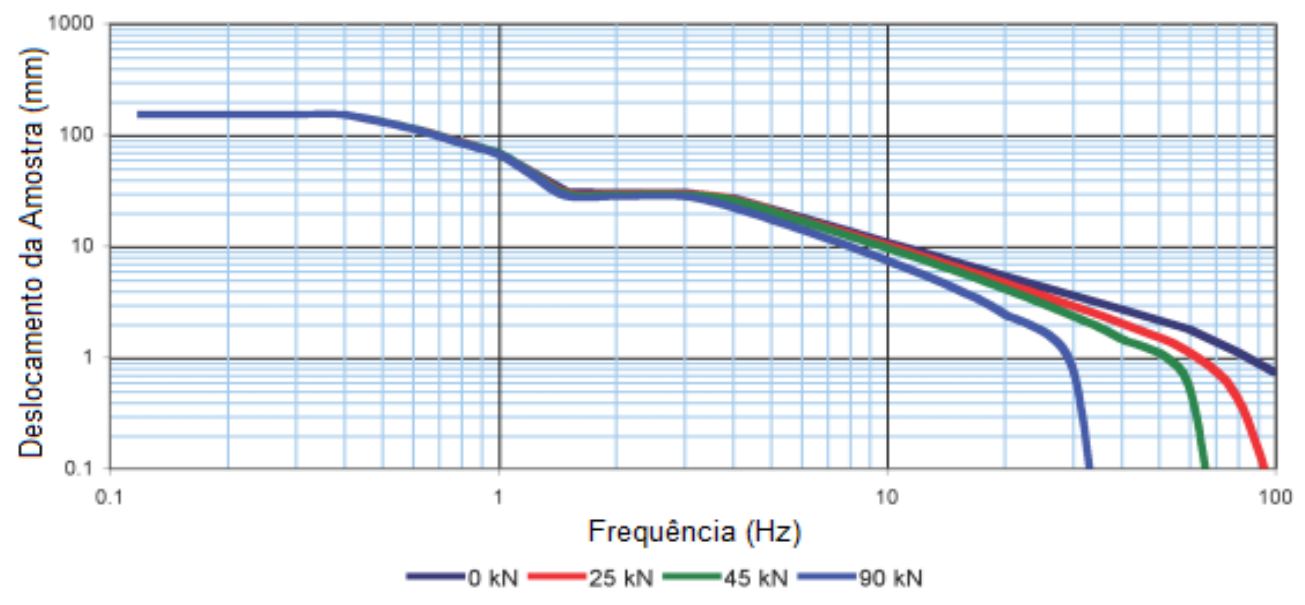

Figura 4.14 - Desempenho dinâmico do equipamento utilizado 
Como os deslocamentos esperados nos ensaios eram em torno de $20 \mathrm{~mm}$ e os carregamentos estavam situados na faixa da primeira curva, poderia se trabalhar com frequências de excitação de até cerca de $4 \mathrm{~Hz}$, no entanto, por questões de controle e segurança dos operadores, optou-se por realizar a maioria dos ensaios com frequência de $0.1 \mathrm{~Hz}$, que é a frequência mínima de operação do equipamento.

Para a realização dos ensaios das placas metálicas é necessário que haja o engastamento em uma das extremidades e que o carregamento seja aplicado na outra, que possui as rotações restritas e um dos deslocamentos livre. No entanto tem-se a limitação da MTS® que somente aplica cargas de tração e compressão no eixo vertical, além disso não pode sofrer ações excêntricas em relação ao seu eixo de atuação pois não é dimensionada para suportar esse tipo de carregamento.

De forma a contornar essas restrições e tornar possível o ensaio, foram realizadas algumas mudanças em relação ao modelo proposto, foi adotado um eixo de simetria em relação às placas modeladas e o carregamento foi aplicado ao centro desse eixo, além disso foram acoplados dois suportes verticais, que funcionam como apoios, para que se engastasse ambas as extremidades, ademais a furação dos apoios foi modificada para se adequar à furação dos suportes verticais. Logo, pelo princípio da superposição dos efeitos, o resultado de cada placa ensaiada corresponde ao comportamento de duas placas originais superpostas, não deixando de ponderar que essa consideração é uma simplificação, tendo em vista que as solicitações fogem do regime elástico e os deslocamentos são suficientemente grandes (cerca de 20 vezes menores que a menor dimensão). Os eixos de simetria, assim como a representação esquemática tridimensional da configuração utilizada para fixação das placas e aplicação de carregamentos, são apresentados, respectivamente, na Figura 4.15 e Figura 4.16. 


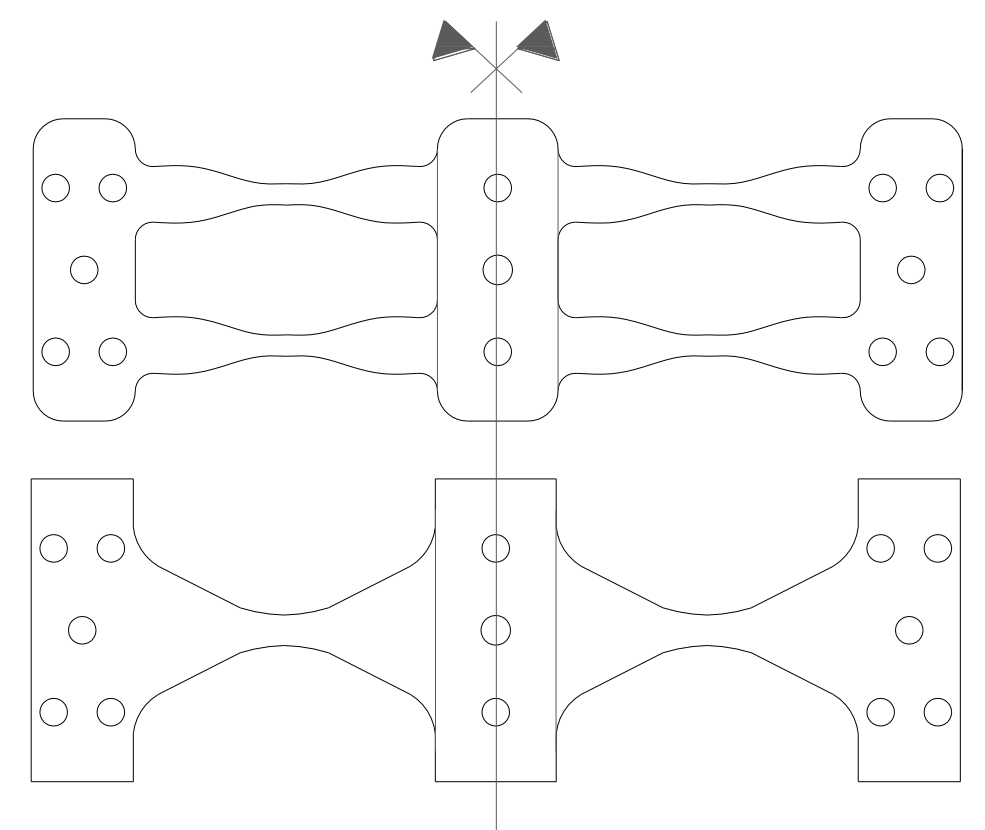

Figura 4.15 - Representação de eixo de simetria adotado

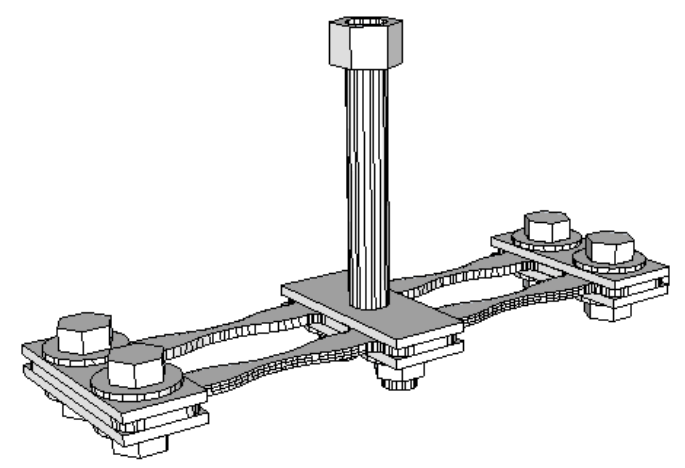

a) Configuração inicial

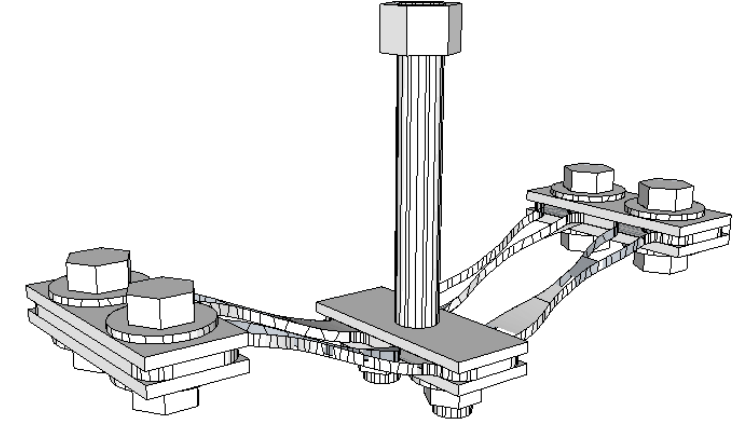

b) Configuração após aplicação do carregamento

Figura 4.16 - Representação esquemática tridimensional do sistema de fixação e aplicação de carregamento.

O procedimento detalhado de fixação do corpo de prova a ser ensaiado na MTS 810 se deu da seguinte forma:

a) Foram fixados dois suportes verticais na base do mecanismo de atuação de forma que o Corpo de Prova (C.P.) pudesse ser preso no topo destes;

b) A fixação do corpo de prova no suporte foi realizada com a utilização de 10 parafusos e quatro chapas, sendo cinco parafusos e duas chapas de cada lado, colocadas em ambas as extremidades do modelo. Tal configuração foi adotada para que se garantisse o engastamento do C.P nos pontos de fixação; 
c) Na parte central, onde fica o atuador, foram utilizados mais dois parafusos com arruelas e porcas sextavadas e duas chapas para garantir a distribuição uniforme do carregamento sobre o C.P.;

d) Foi utilizado um parafuso central sem cabeça para fixação do corpo de prova à garra do atuador.

A adaptação dos suportes à MTS 810 é apresentada na Figura 4.17.

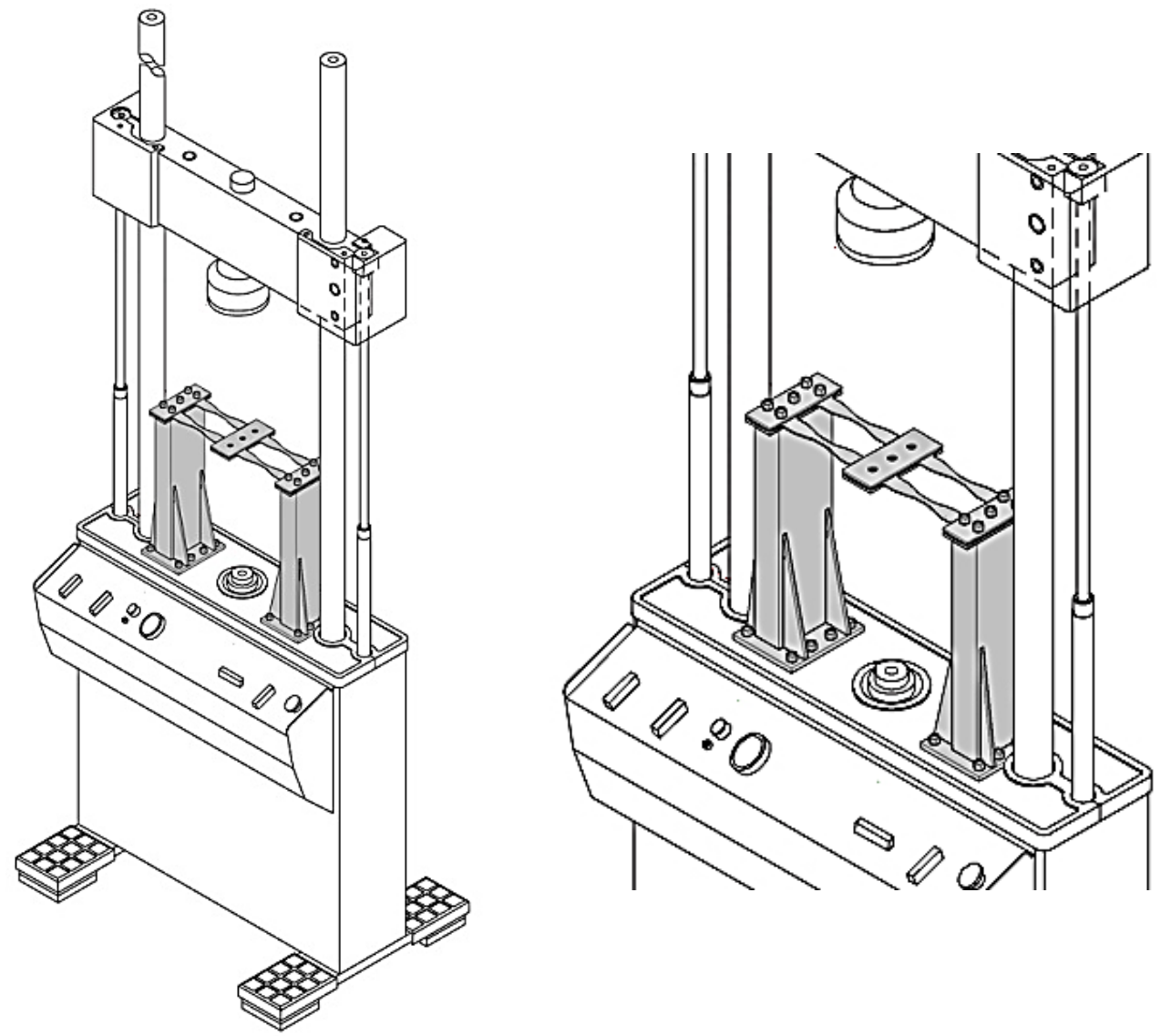

Figura 4.17 - MTS® com fixação de suporte.

As placas do tipo $X$ Shape e Bottle Shape, fabricadas a partir do sistema de corte automatizado e adaptadas ao sistema de ensaio, são apresentadas na Figura 4.18. 


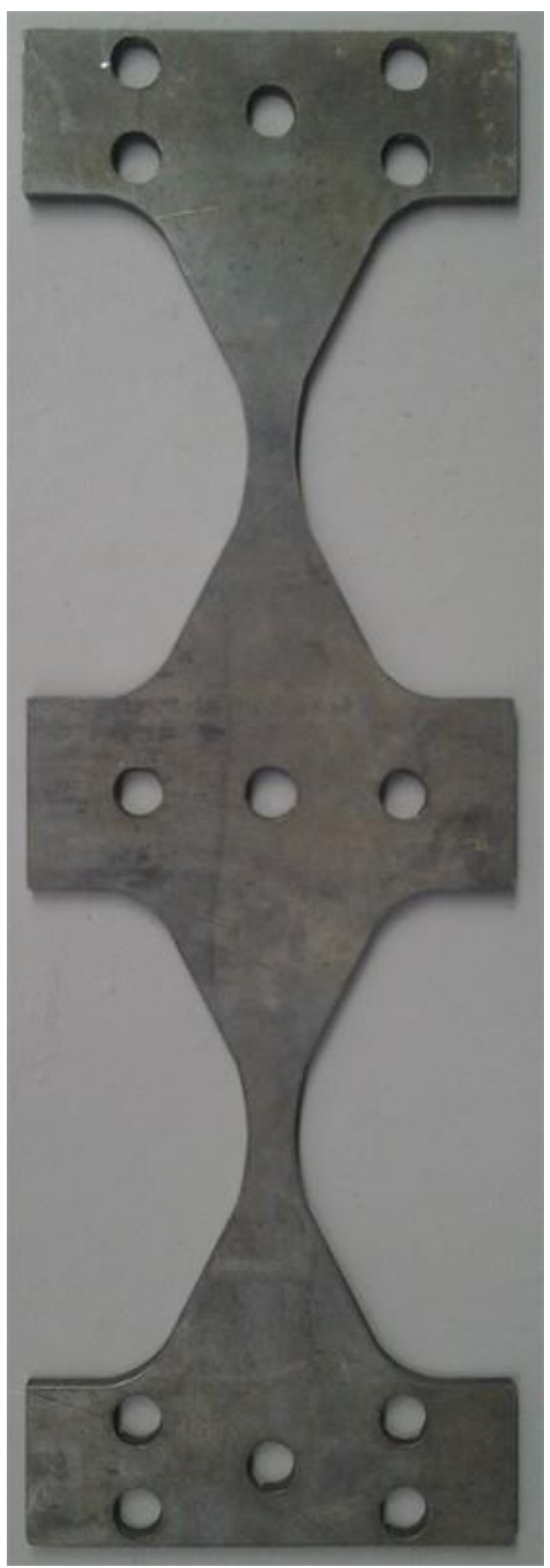

(a) - Placa adaptada do tipo $X$ Shape

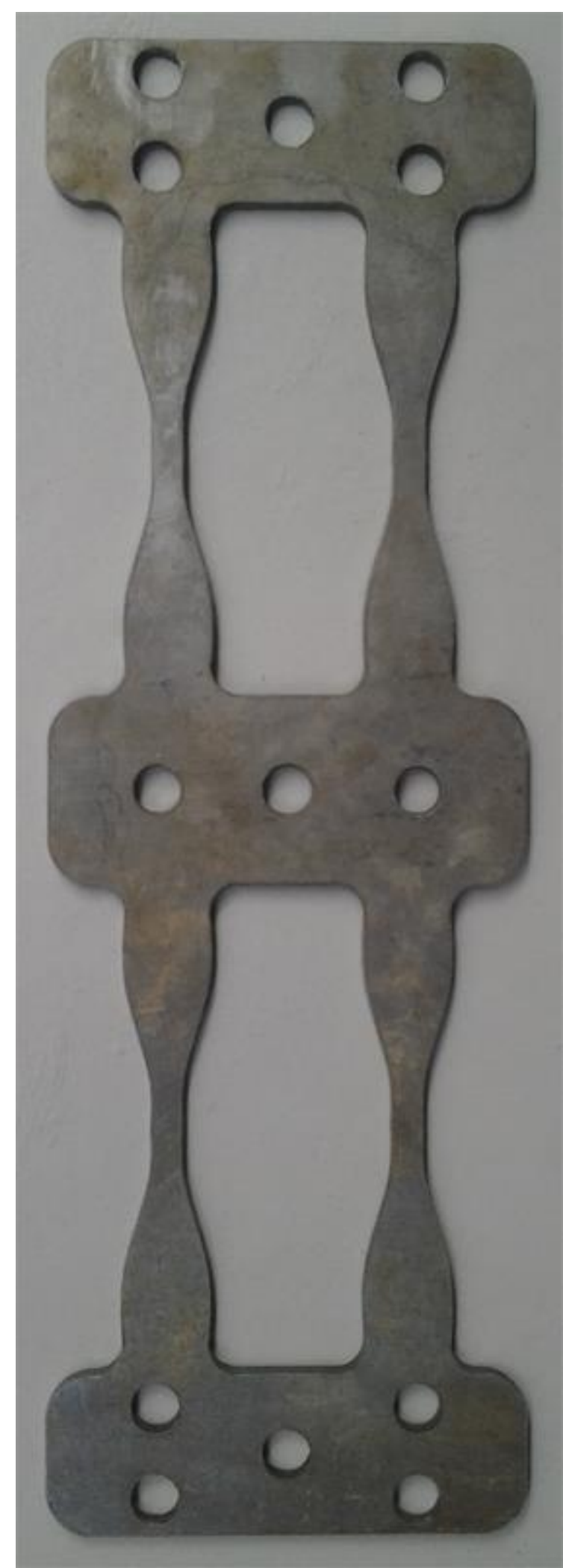

(b) - Placa adaptada do tipo Bottle Shape Figura 4.18 - Modelos de placas ensaidas

As dimensões das peças utilizadas para os ensaios são apresentadas na Figura 4.19. Utilizou-se uma espessura constante de $5 \mathrm{~mm}$ para todas as placas, a escolha de tal dimensão para a espessura se deu em função da grande disponibilidade comercial para 
sua aquisição e por se adequar às análises numéricas realizadas. O material utilizado para confecção das placas foi o aço estrutural ASTM A36, que é classificado como um aço carbono de média resistência mecânica.

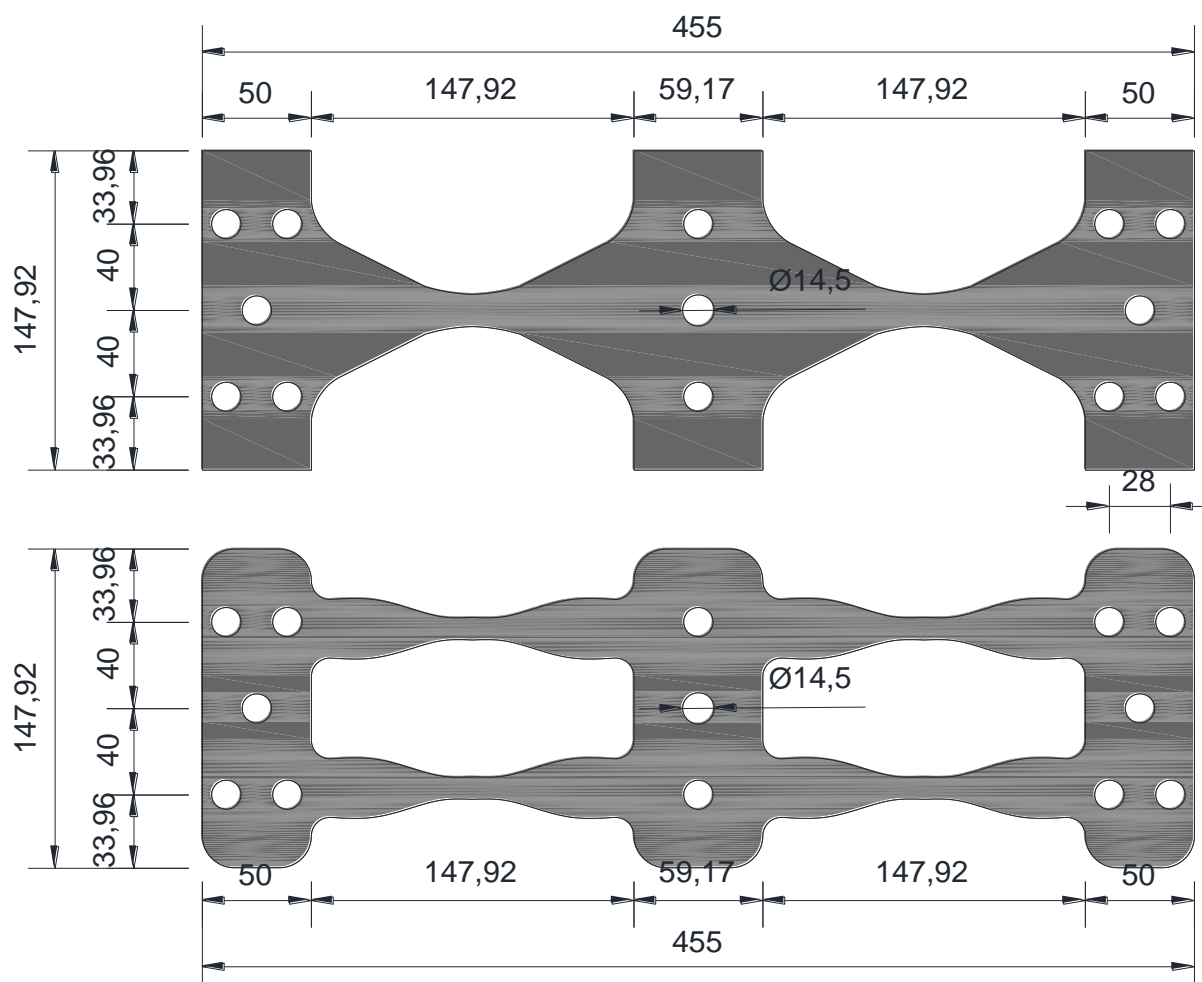

Figura 4.19 - Dimensões das placas ensaiadas (unidade: mm)

As imagens do sistema de ensaio para as placas do tipo $X$ Shape e Bottle Shape são apresentadas na Figura 4.20.

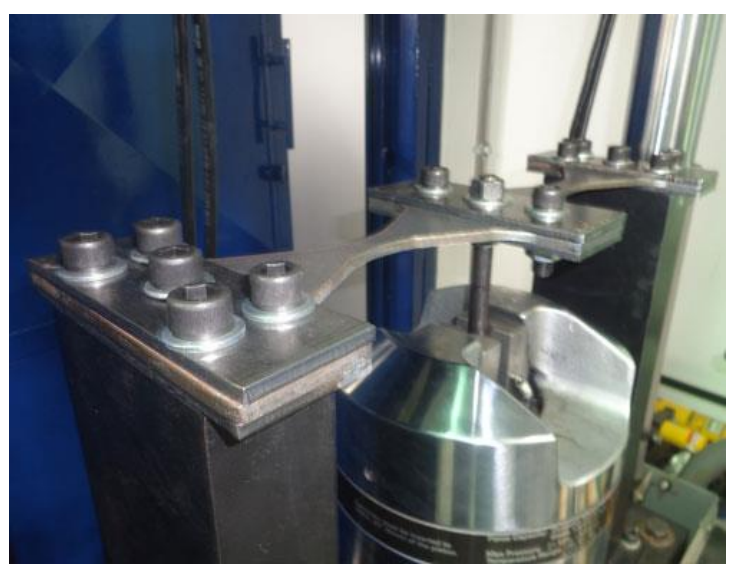

a) Ensaio de placa $X$ Shape

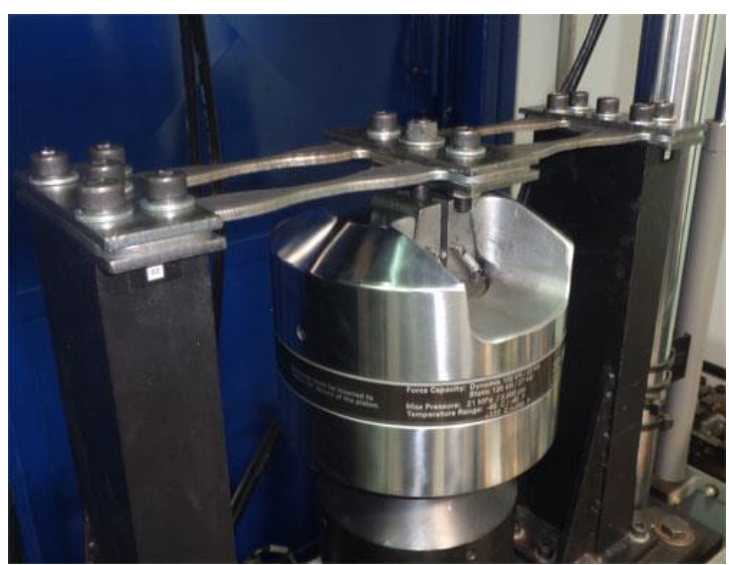

b) Ensaio de placa Bottle Shape

Figura 4.20 - Placas ensaiadas

Ao serem instaladas no suporte, as placas ficam engastadas em ambos os extremos, impedidas assim as rotações. Observa-se que ambos os modelos, X Shape e Bottle Shape se deformaram com dupla curvatura em relação ao seu ponto médio, 
apresentando assim escoamento ao longo de toda a altura. Os detalhes da deformação são apresentados na Figura 4.21.

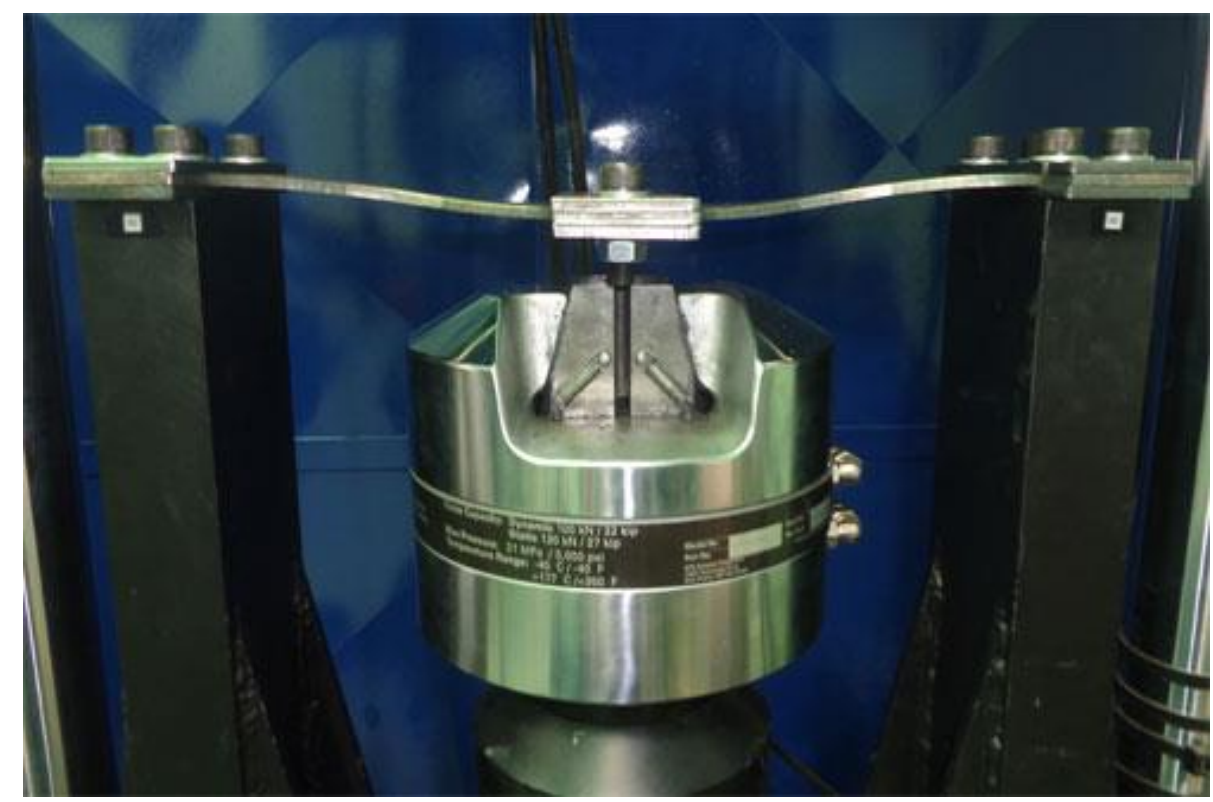

Figura 4.21 - Deformação em dupla curvatura do modelo

Para a realização dos ensaios conecta-se todo o sistema hidráulico da MTS 810 a um computador que possuiu um software específico para o gerenciamento dos carregamentos aplicados assim como para a apresentação dos deslocamentos obtidos. Os detalhes do sistema de ensaio e aquisição de dados são apresentados na Figura 4.22

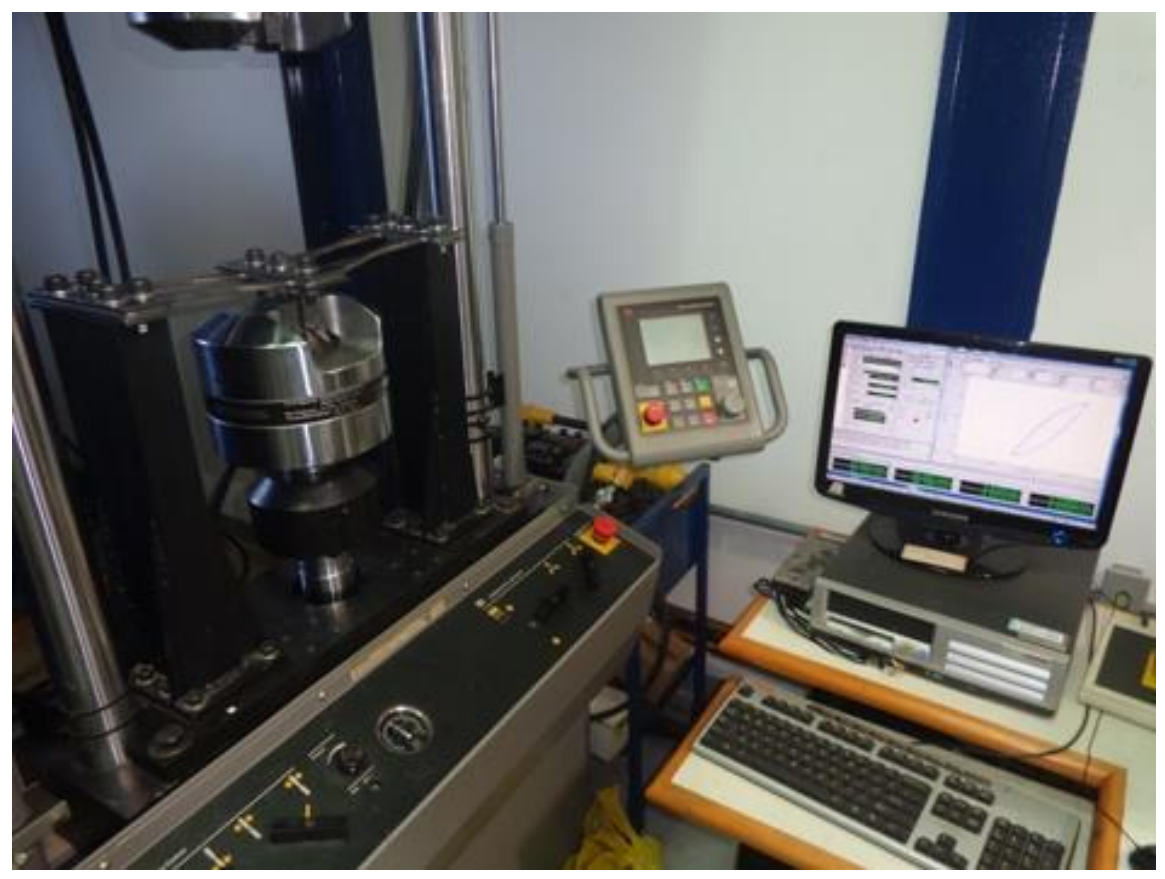

Figura 4.22 - Sistema de ensaio e aquisição de dados 
Os deslocamentos das placas submetidas ao ensaio são coletados pela própria MTS 810 que possui um sensor LVDT (Linear Variable Differential Transformer) responsável pela obtenção desses dados.

O gerenciamento dos carregamentos, assim como a obtenção dos resultados, se deu com a aplicação Station Manager fornecida pelo próprio fabricante da MTS 810. O software é responsável pelo controle da atuação das bombas hidráulicas, encarregadas pela aplicação das forças de atuação. Com base em um arquivo de configuração específica (*.cfg), podem ser criados conjuntos de parâmetros para testes ou grupos de testes de acordo com a necessidade do ensaio. Uma vez realizado o ensaio, os dados podem ser facilmente exportados para arquivos com extensões diversas. $\mathrm{O}$ ambiente de trabalho do software é apresentado na Figura 4.23.

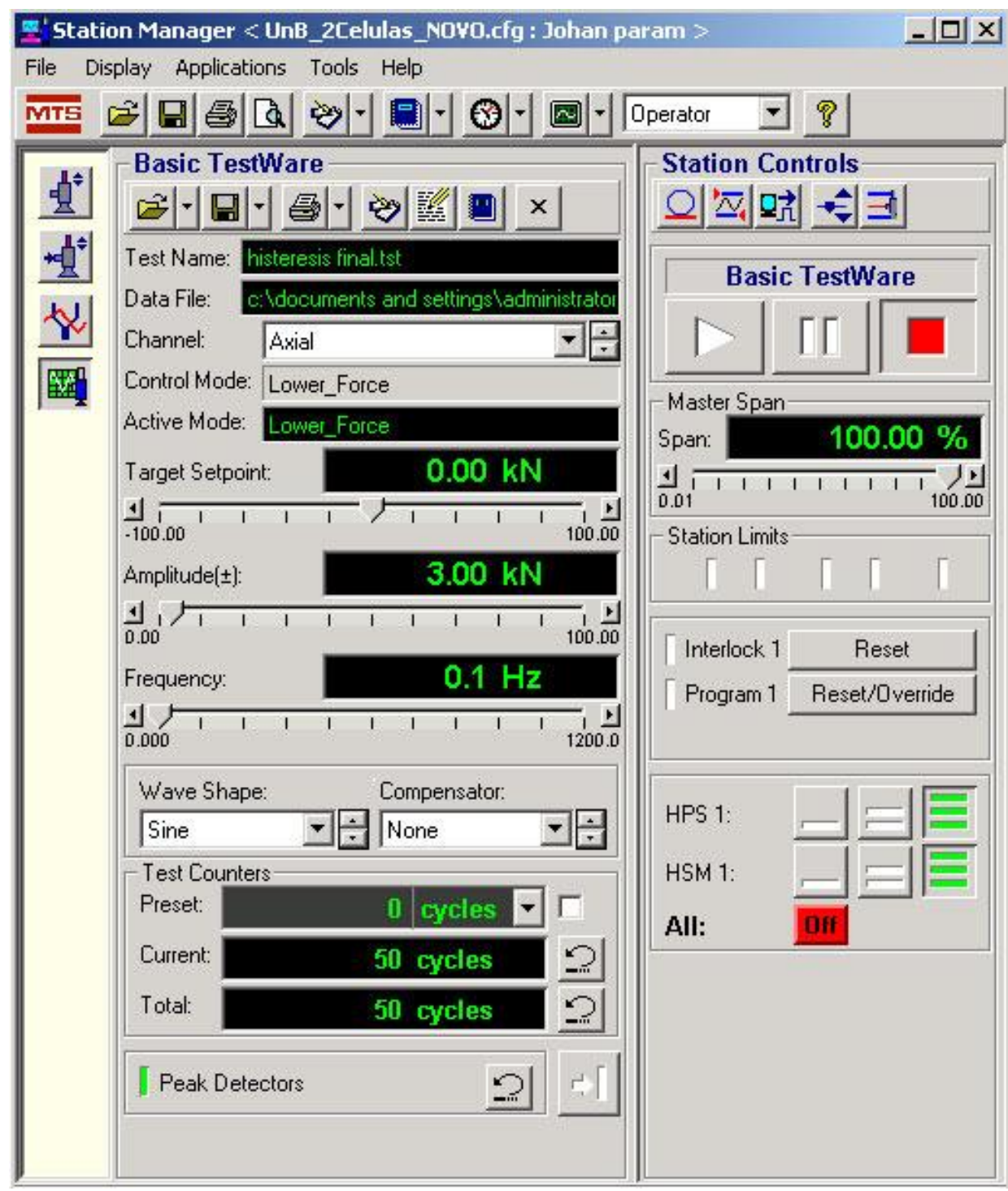

Figura 4.23 - Tela principal do software Station Mananger da MTS. 
Maiores detalhes quanto ao funcionamento do software podem ser encontrados no site do fabricante (MTS Systems, 2015). Como pode ser observado é possível o controle da amplitude e frequência de excitação, o formato do carregamento, bem como dos dispositivos de segurança.

Com base na metodologia de ensaio e uso de software foi realizada a análise experimental. As imagens das placas ensaiadas do tipo X Shape e Bottle Shape são apresentadas, respectivamente, na Figura 4.24 e na Figura 4.25.

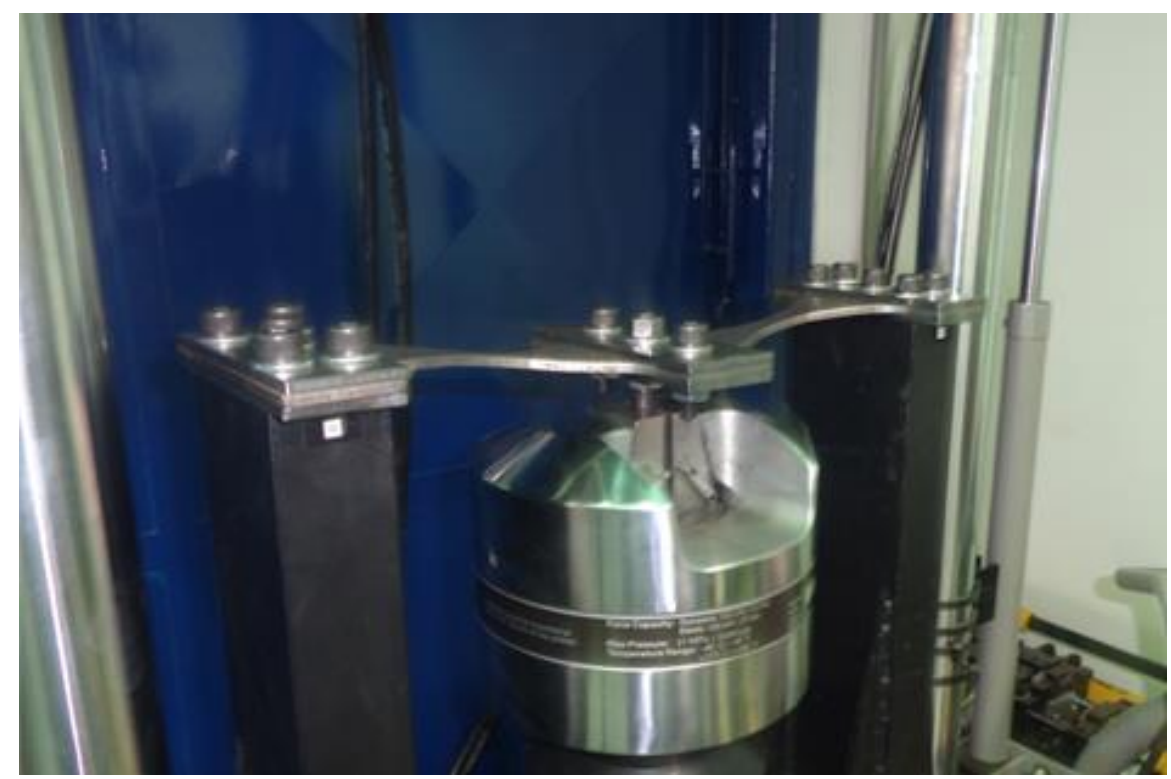

Figura 4.24 - Ensaio de Placa do Tipo X Shape

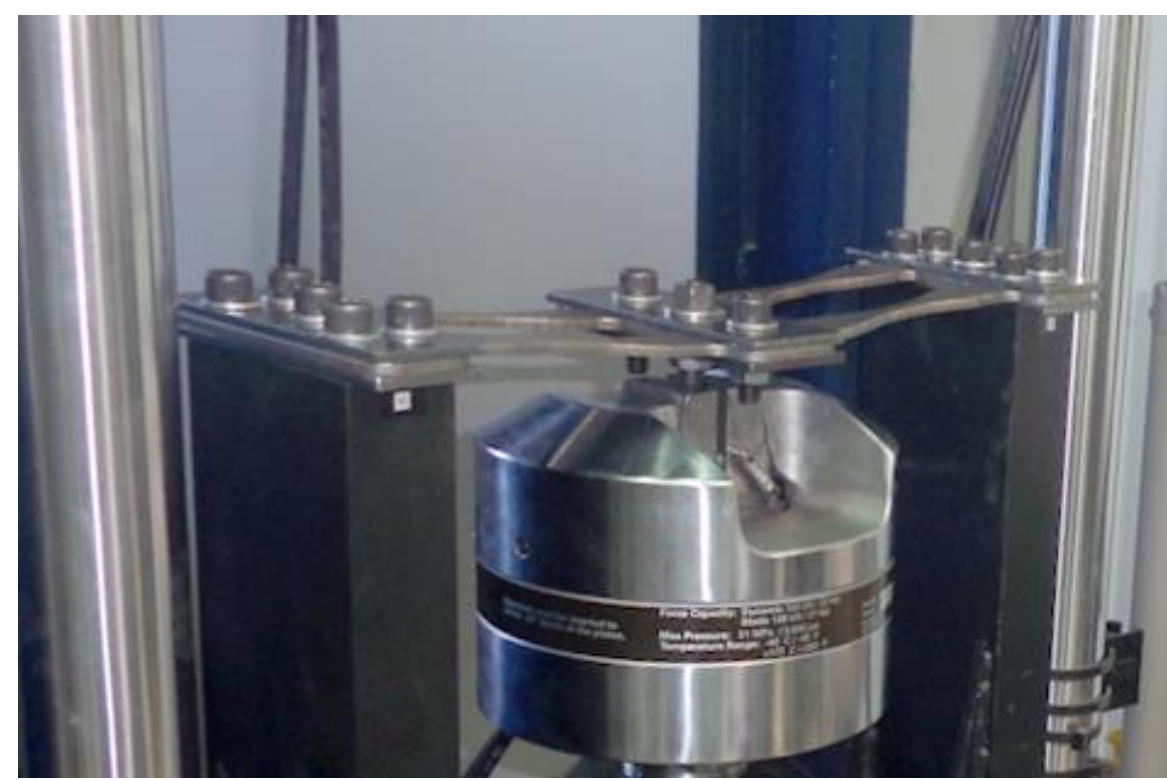

Figura 4.25 - Ensaio de Placa do Tipo Bottle Shape 


\subsubsection{Resultados Experimentais}

Os testes foram realizados para diferentes tipos de carregamento, sendo que para cada carregamento foram ensaiados os dissipadores metálicos do tipo $X$ Shape e Bottle Shape, tornado assim possível a comparação dos resultados. Para cada um dos ensaios executados, as variáveis controladas foram os carregamentos e as frequências de excitação, obtendo-se os deslocamentos como variável de saída.

Ensaiou-se inicialmente um corpo de prova do tipo $X$ Shape com carregamentos lineares incrementais até o limite de $4,0 \mathrm{kN}$, adotando-se uma razão de $5 \mathrm{kN}$ por minuto como taxa de carregamento. A evolução dos deslocamentos do modelo, quando submetido a uma força triangular com amplitudes crescentes, é apresentado na Figura 4.26.

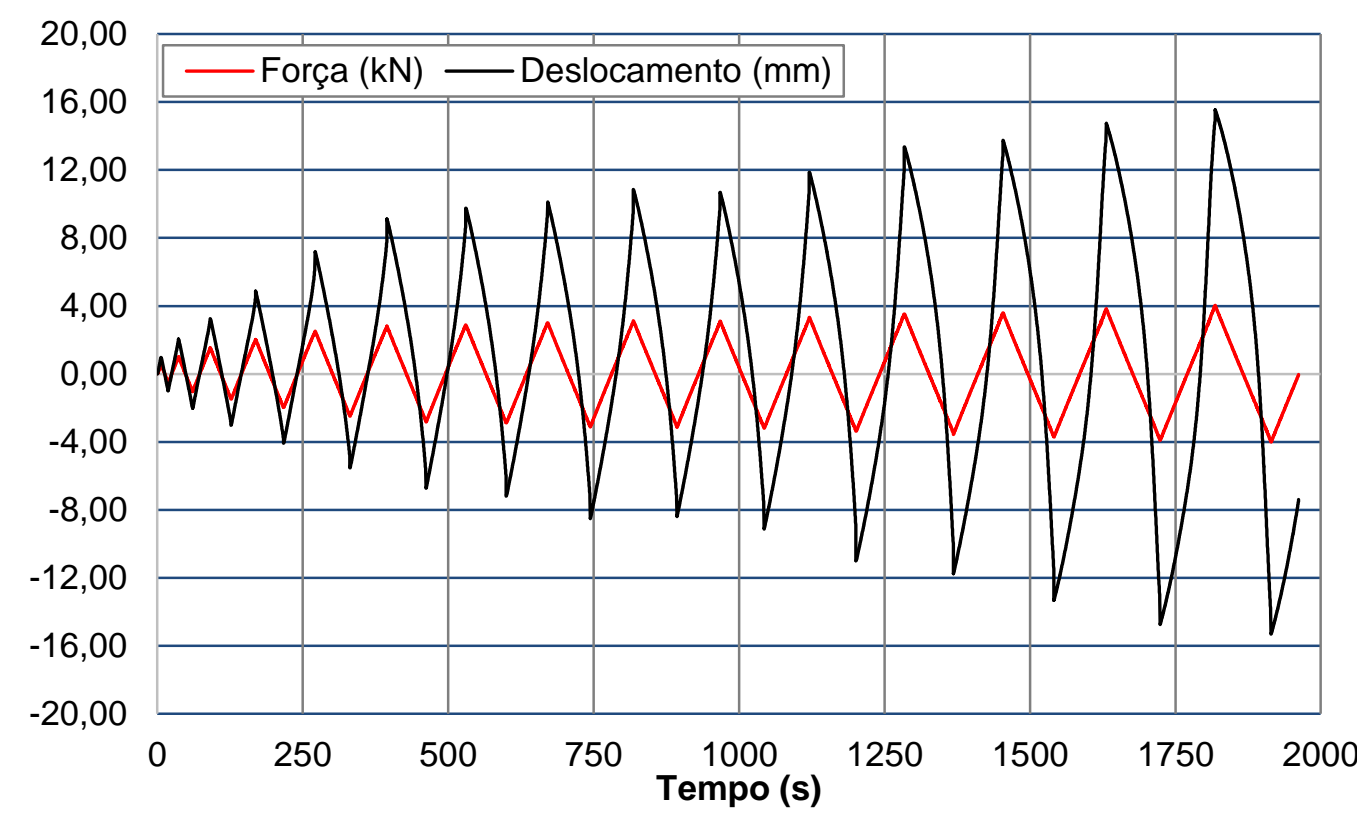

Figura 4.26 - Carregamento triangular crescente aplicado ao modelo $X$ Shape com histórico de deslocamentos

O software Station Manager, utilizado para o controle dos carregamentos, não contempla o módulo que automatiza a aplicação de carregamentos crescentes incrementais, dessa forma, ao término de cada ciclo de carregamento foi iniciado manualmente um novo ciclo a partir do anterior.

A partir do carregamento aplicado e da obtenção do histórico de deslocamentos, elaborou-se o gráfico de histerese, apresentado na Figura 4.27. 


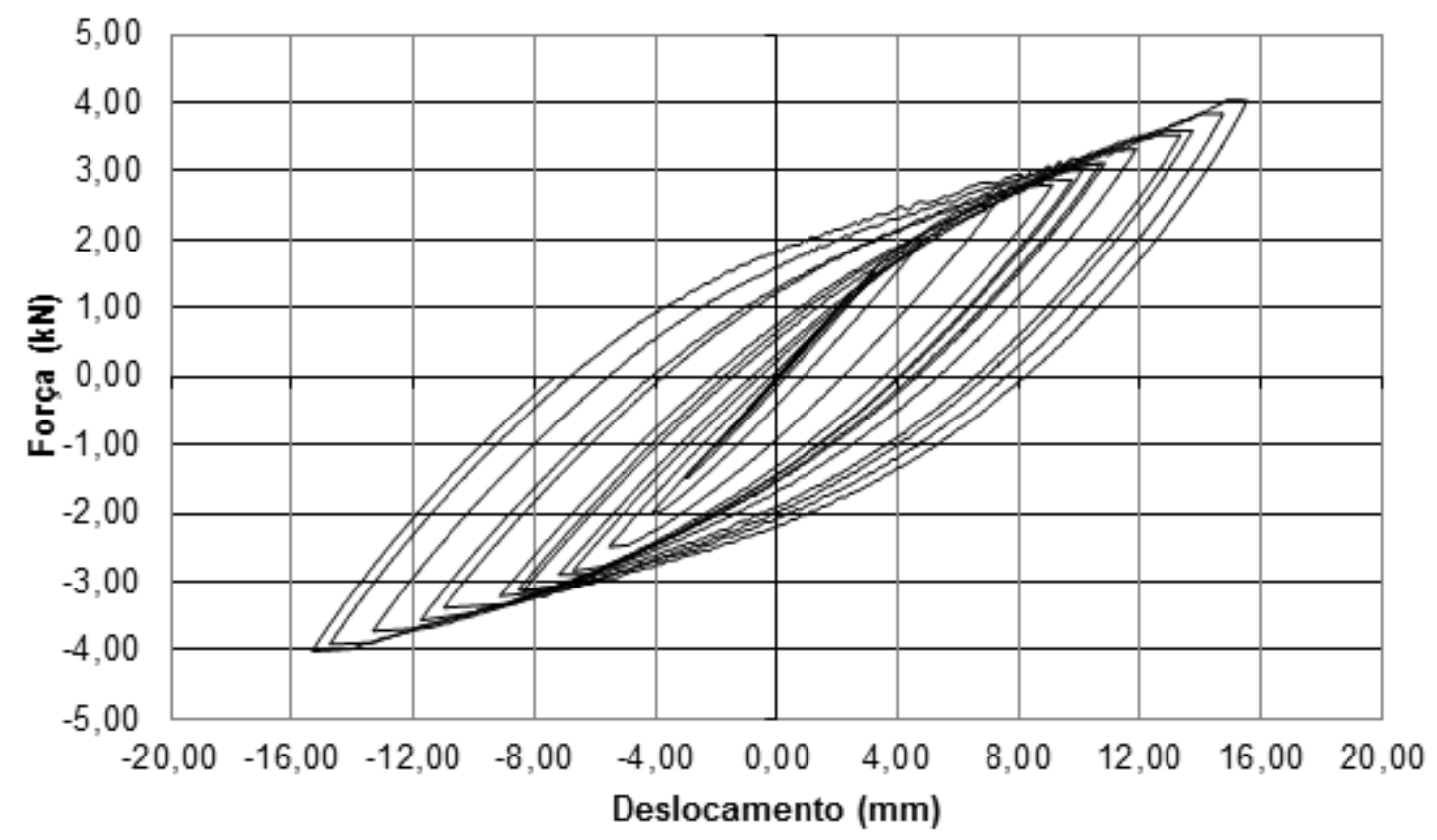

Figura 4.27 - Carregamento triangular crescente aplicado ao modelo $X$ Shape

Em seguida, com o objetivo de comparar o desempenho dos dois modelos, aplicou-se carregamento semelhante ao modelo Bottle Shape. Da mesma forma, foi utilizado carregamento triangular incremental como variável de entrada, obtendo-se o deslocamento como variável de saída. O histórico de deslocamentos relacionados com a aplicação das forças é apresentado na Figura 4.28.

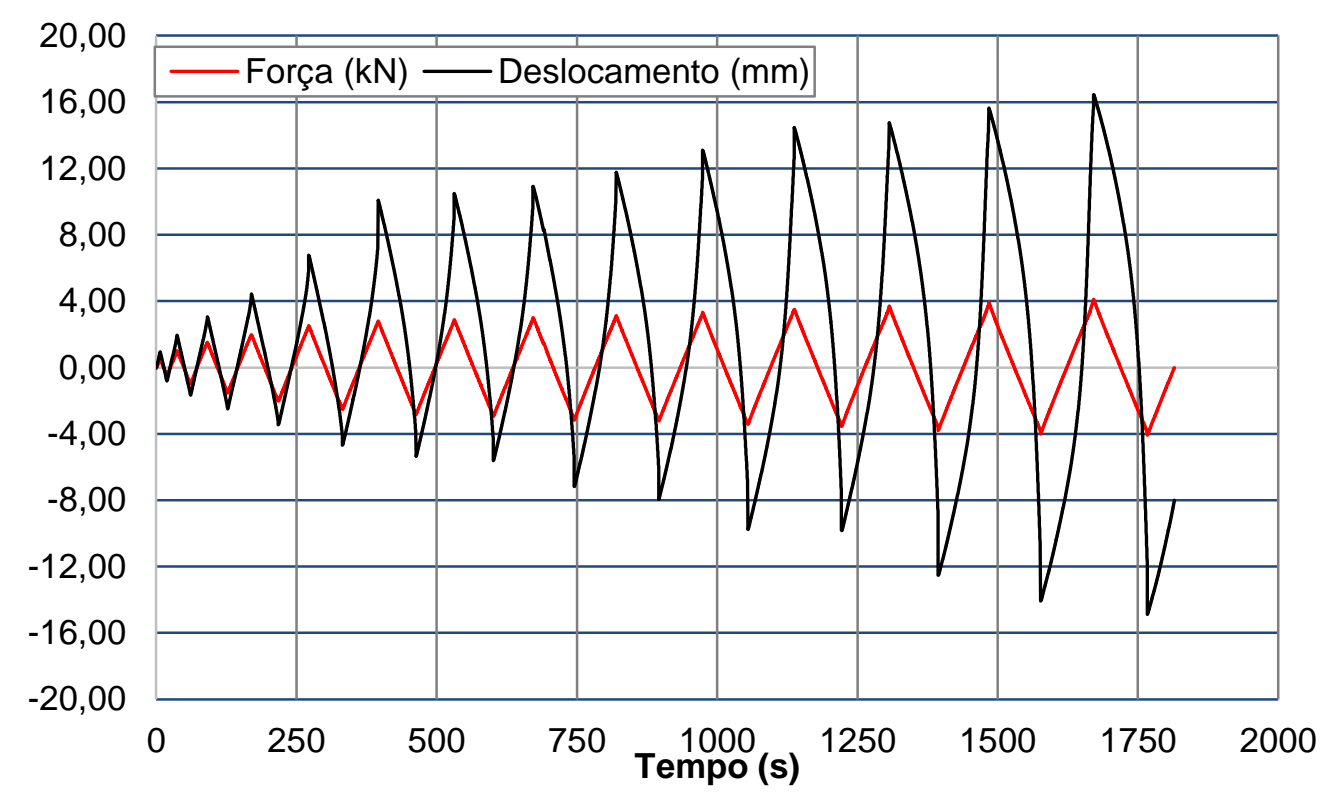

Figura 4.28 - Carregamento triangular crescente aplicado ao modelo Bottle Shape com histórico de deslocamentos

De igual modo, com base nos dados de aplicação de força e verificação de deslocamentos, elaborou-se o diagrama de histerese, apresentado na Figura 4.29. 


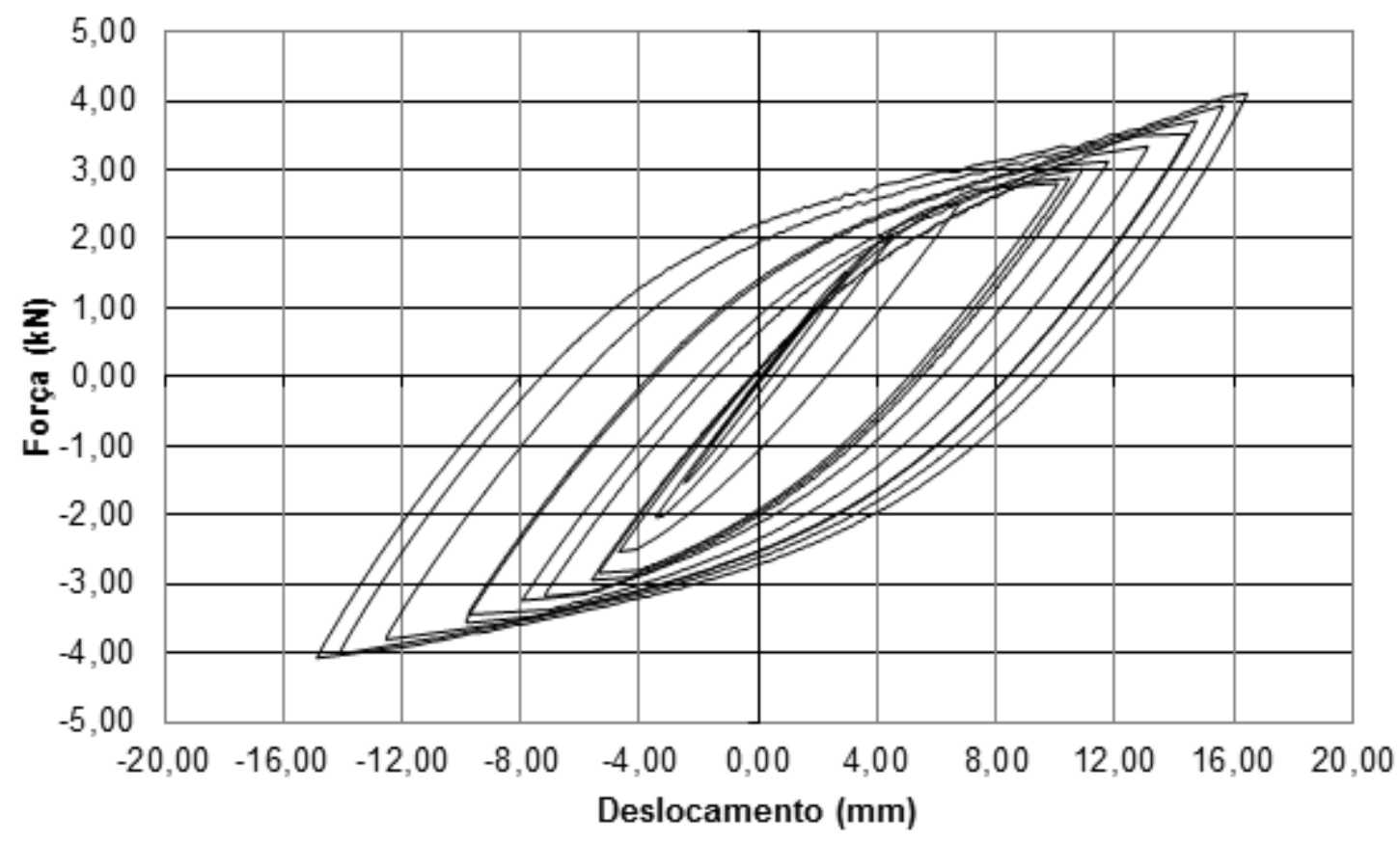

Figura 4.29 - Histerese do modelo Bottle Shape

O comportamento dos modelos $X$ Shape e Bottle Shape, quando submetidos a um carregamento triangular, é bastante semelhante, havendo apenas pequenas diferenças entre os deslocamentos, com o formato de diagramas de histerese muito parecidos. Se adotarmos como padrão de referência para comparação o valor quadrático médio (RMS) dos deslocamentos, observa-se que a diferença entre os modelos é de apenas 3,253\%, sendo que, para esta análise o modelo Bottle Shape apresentou valores mais elevados. Os dados utilizados para a comparação são apresentados na Tabela 4.2.

Tabela 4.2 - Comparação entre modelos quando submetidos a um carregamento triangular

\begin{tabular}{ccc}
\hline Modelo & $\begin{array}{l}\text { RMS } \\
(\mathrm{mm})\end{array}$ & $\begin{array}{c}\Delta \\
(\%)\end{array}$ \\
\hline X Shape & 6,702 & - \\
Bottle Shape & 6,920 & $3,253 \%$ \\
\hline
\end{tabular}

Verifica-se ainda que, baseado no formato das curvas, os modelos de histerese de ambos corpos de prova são bastante semelhantes aos modelos numéricos apresentados no item 5.2.1, corroborando assim as análises numérica e experimental.

Em seguida foram realizadas análises com carregamentos periódicos no formato senoidal, com variação das amplitudes. Nesse modo de análise as variáveis controladas foram as amplitudes das forças aplicadas, assim como a frequência de excitação. 
Inicialmente ensaiou um corpo de prova do tipo X Shape, os dados da força, bem como os respectivos deslocamentos são apresentados na Figura 4.30.

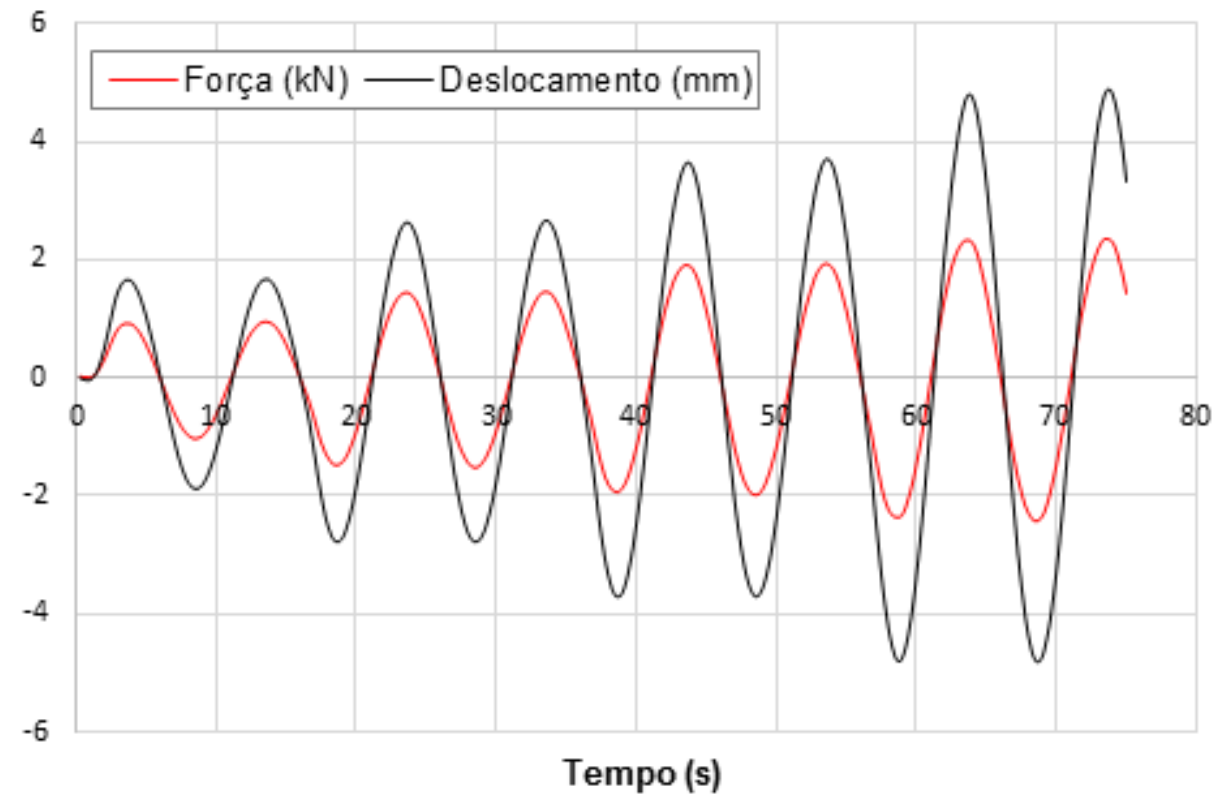

Figura 4.30 - Carregamento Harmônico Crescente aplicado ao modelo X Shape com histórico de deslocamentos

Para o experimento realizado, adotou-se um incremento das amplitudes de 0,5 $\mathrm{kN}$ a cada dois ciclos, com uma frequência de $0,1 \mathrm{~Hz}$. A partir do carregamento aplicado e da obtenção do histórico de deslocamentos, elaborou-se o gráfico de histerese, apresentado na Figura 4.31.

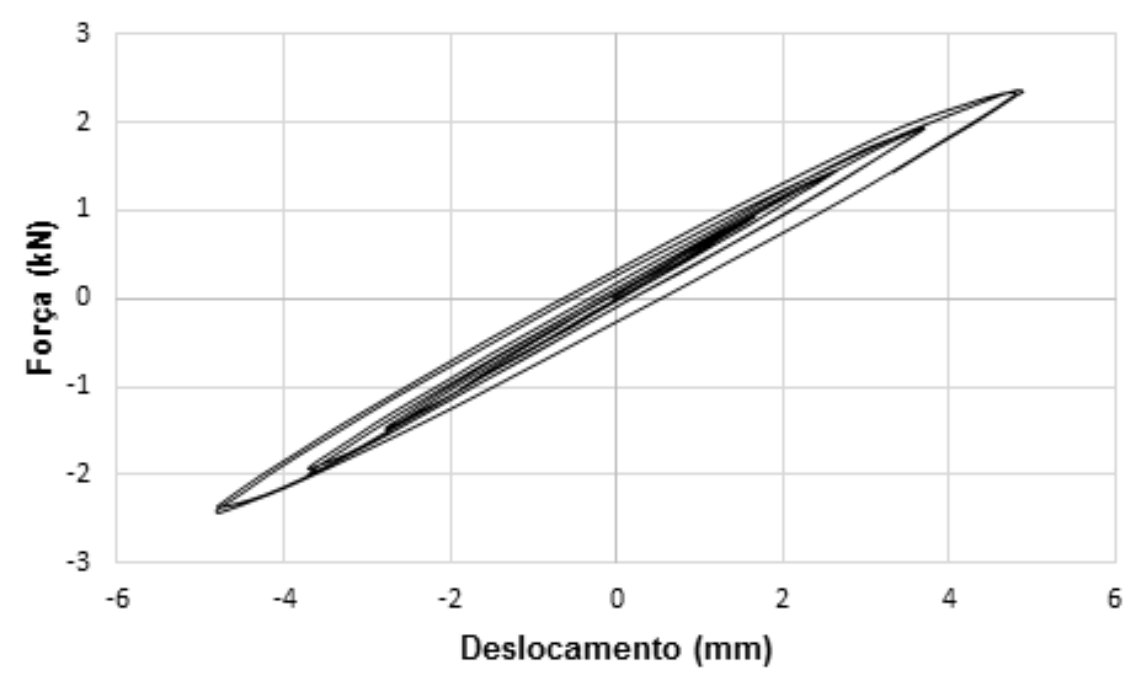

Figura 4.31 - Histerese $X$ Shape

Em seguida, repetiu-se o carregamento, considerando a mesma excitação, frequência e amplitudes, aplicados ao modelo Bottle Shape. O histórico de deslocamentos relacionados com a atuação dos carregamentos é exibido na Figura 4.32. 


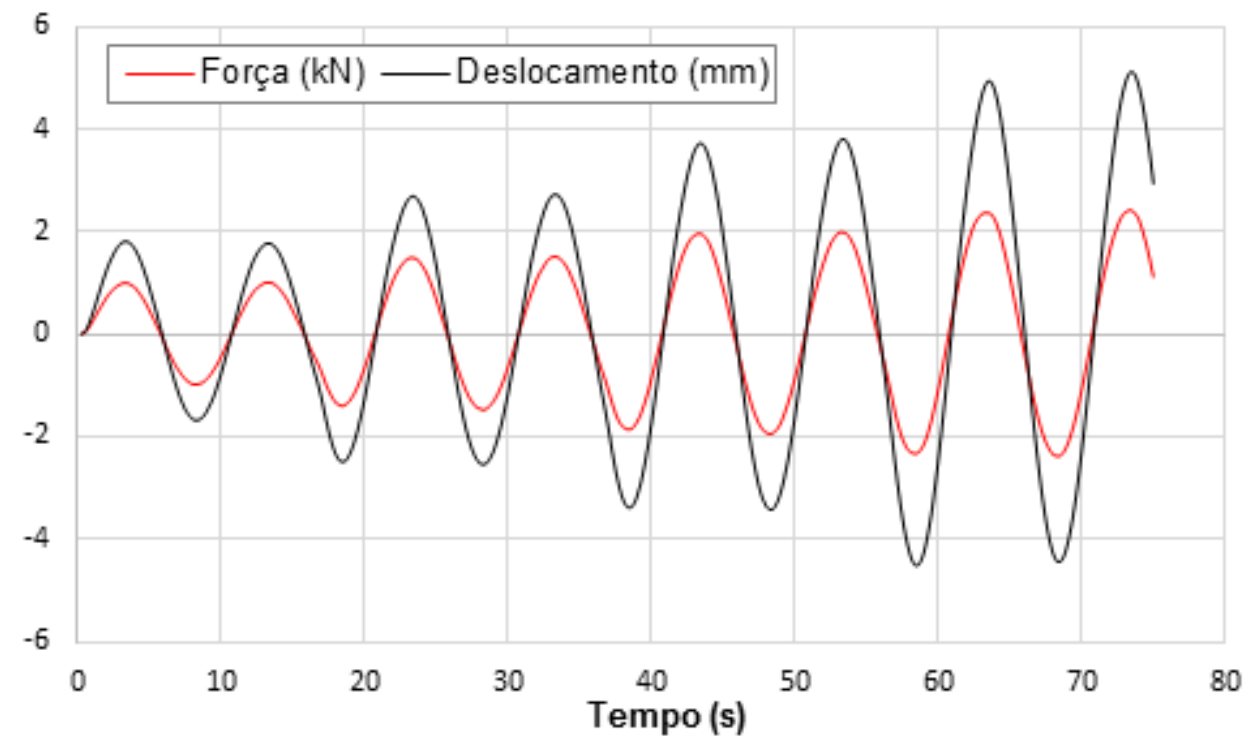

Figura 4.32 - Carregamento Harmônico Crescente aplicado ao modelo Bottle Shape com histórico de deslocamentos

O diagrama de histerese, relacionando as forças e deslocamentos, é apresentado na Figura 4.33.

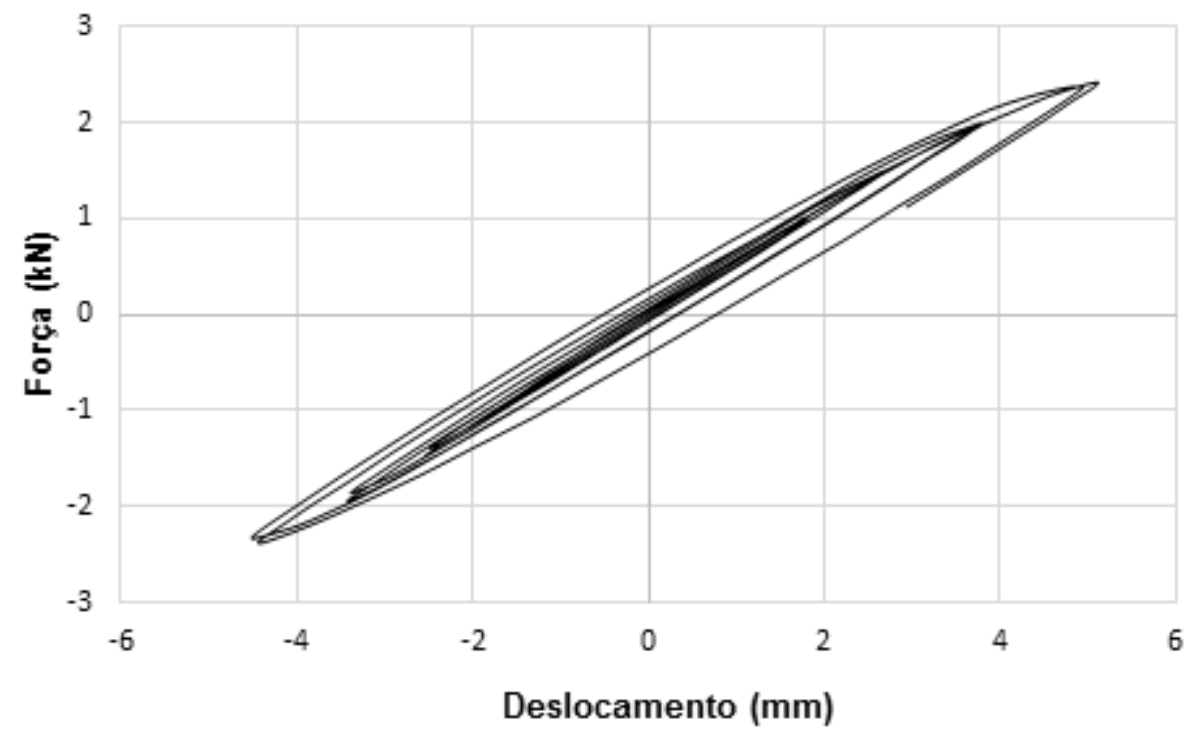

Figura 4.33 - Histerese Bottle Shape

Adotando como padrão de referência para comparação o valor quadrático médio (RMS) dos deslocamentos, observa-se que a diferença entre os modelos é de apenas 2,075\%, sendo que, para esta análise o modelo $X$ Shape apresentou valores mais elevados. Os dados utilizados para a comparação são apresentados na Tabela 4.3. 
Tabela 4.3 - Comparação entre modelos quando submetidos a um carregamento senoidal crescente

\begin{tabular}{ccc}
\hline Modelo & $\begin{array}{c}\text { RMS } \\
(\mathrm{mm})\end{array}$ & $\begin{array}{c}\Delta \\
(\%)\end{array}$ \\
\hline X Shape & 2,460 & 2,075 \\
Bottle Shape & 2,410 & - \\
\hline
\end{tabular}

Em seguida analisaram-se novos corpos de prova submetidos a um carregamento harmônico senoidal constante. Nesse caso adotou-se uma amplitude constante de carga de 3,0 kN. Os gráficos relativos à evolução dos deslocamentos a partir da aplicação do carregamento, assim como o diagrama de histerese, referentes ao modelo $X$ Shape, são apresentadas, respectivamente, na Figura 4.34 e na Figura 4.35.

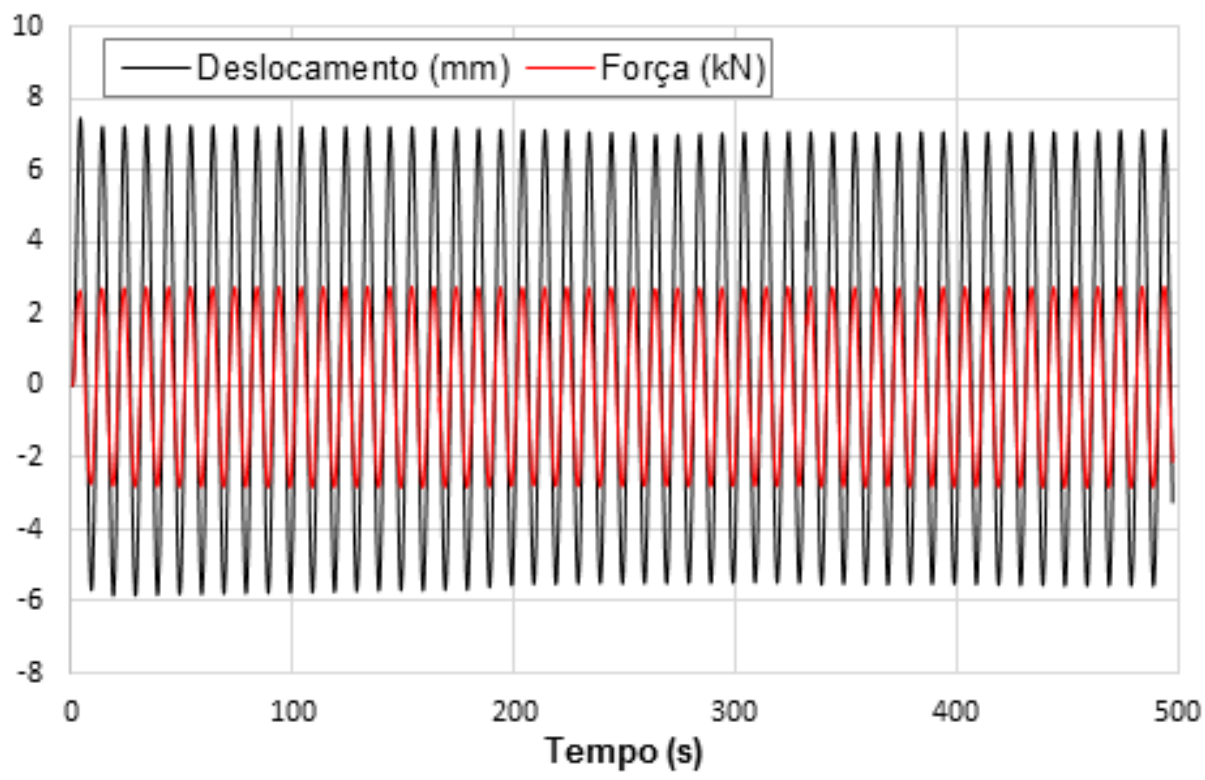

Figura 4.34 - Carregamento harmônico com amplitude constante aplicado ao modelo $X$ Shape com histórico de deslocamentos 


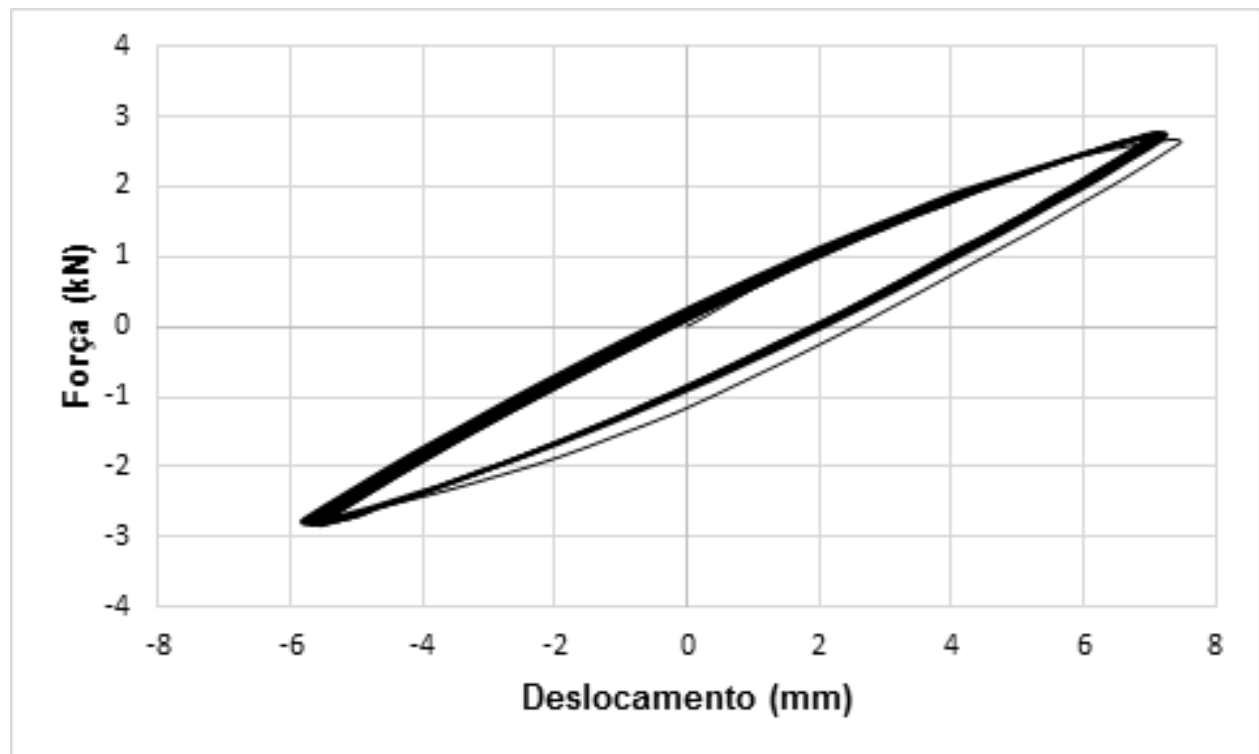

Figura 4.35 - Histerese X Shape

De igual modo, repetiu-se o carregamento, considerando a mesma excitação, frequência e amplitude, aplicados ao modelo Bottle Shape. O histórico de deslocamentos relacionado com a atuação do carregamento, assim como o diagrama de histerese, são exibidos, respectivamente, na Figura 4.36 e na Figura 4.37.

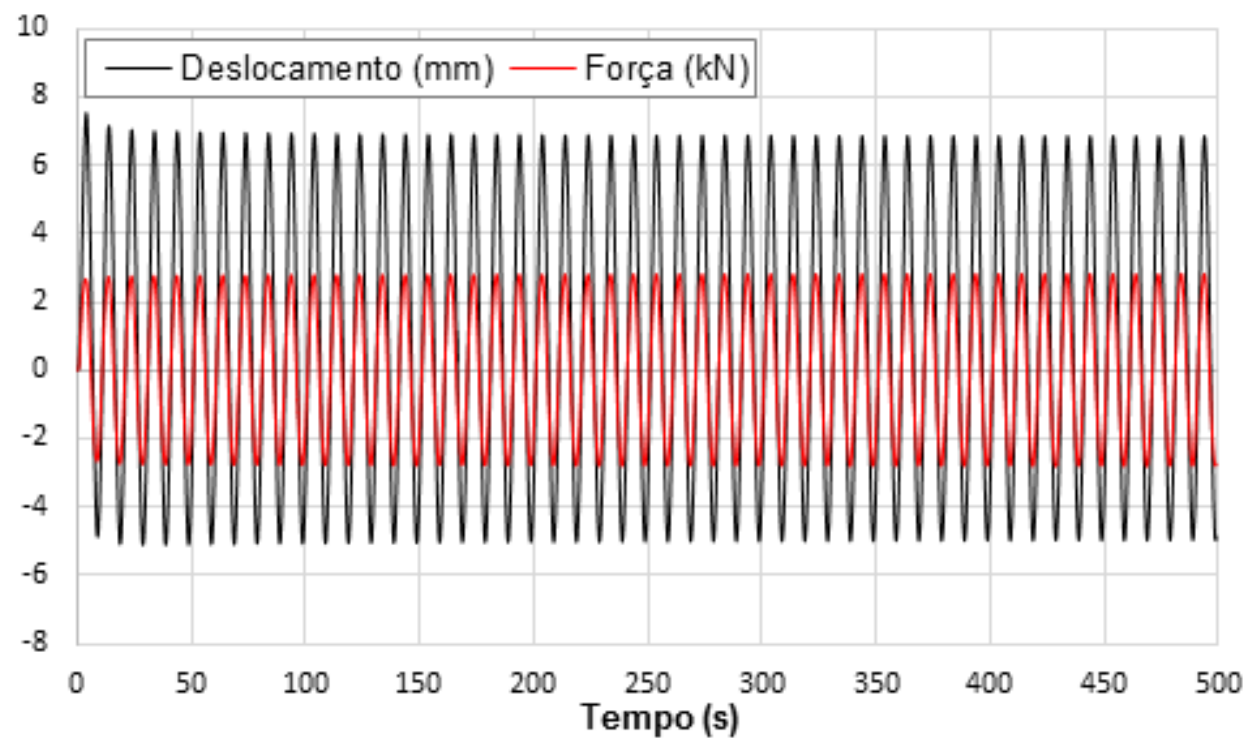

Figura 4.36 - Carregamento harmônico com amplitude constante aplicado ao modelo Bottle Shape com histórico de deslocamentos 


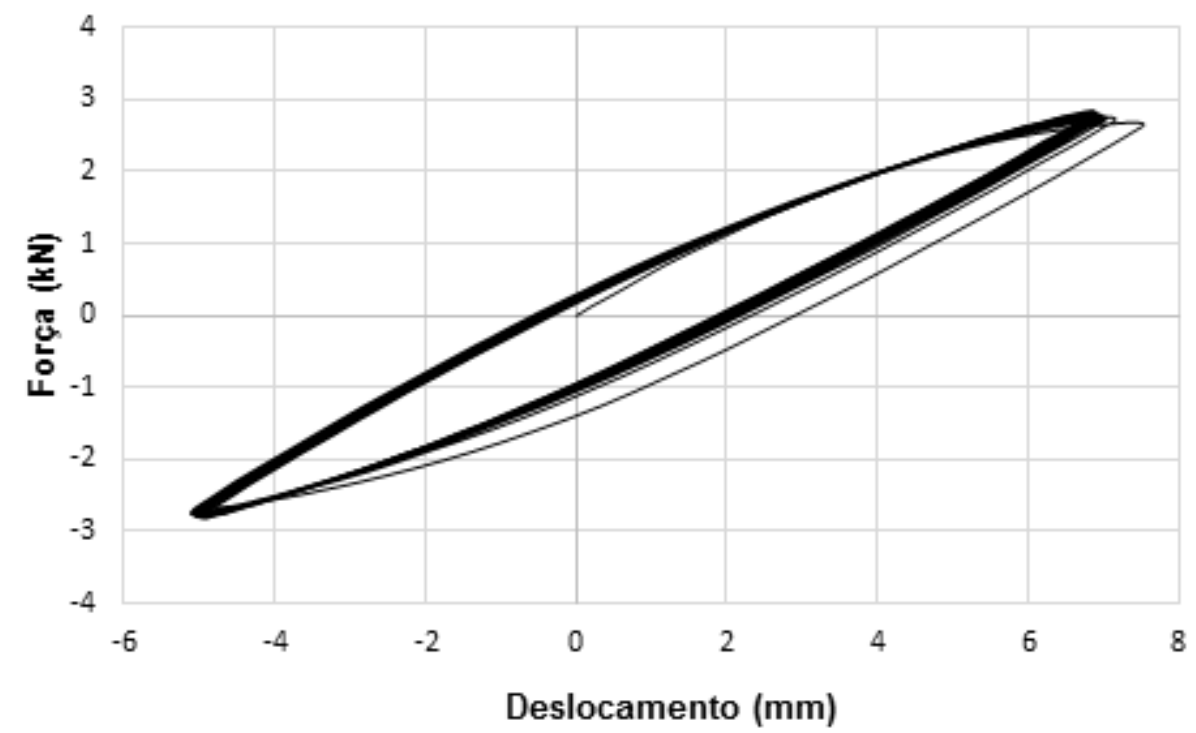

Figura 4.37 - Histerese Bottle Shape

O comportamento dos modelos $X$ Shape e Bottle Shape, quando submetidos a um carregamento harmônico constante, é mais uma vez bastante parecido, havendo apenas pequenas diferenças entre os deslocamentos, com o formato de diagramas de histerese semelhantes. Ao adotar como padrão de referência para comparação o valor quadrático médio (RMS) dos deslocamentos, observa-se que a diferença entre os modelos é de $6,678 \%$, com o modelo $X$ Shape apresentando maiores valores de deslocamentos. Os valores de RMS encontrados são apresentados na Tabela 4.4.

Tabela 4.4 - Comparação entre modelos quando submetidos a um carregamento senoidal constante

\begin{tabular}{ccc}
\hline Modelo & $\begin{array}{l}\text { RMS } \\
(\mathrm{mm})\end{array}$ & $\begin{array}{c}\Delta \\
(\%)\end{array}$ \\
\hline X Shape & 4,505 & 6,678 \\
Bottle Shape & 4,223 & - \\
\hline
\end{tabular}

Finalmente de modo a detalhar o diagrama de histerese do modelo Bottle Shape foi realizado um ensaio aplicando um carregamento harmônico senoidal com amplitudes crescentes, sendo que a amplitude máxima de carregamento é de $3,5 \mathrm{kN}$. 


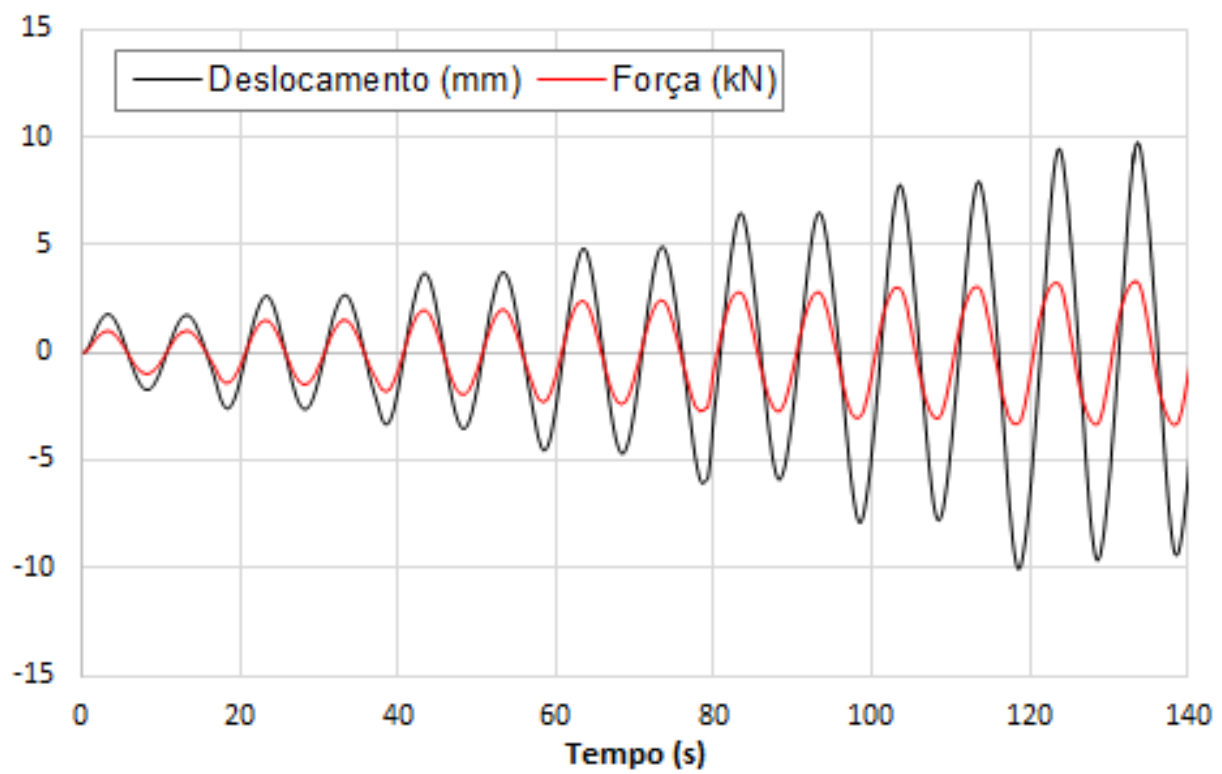

Figura 4.38 - Carregamento senoidal crescente aplicado ao modelo Bottle Shape com histórico de deslocamentos

O modelo demonstrou comportamento estável com ciclos de histerese bem definidos como pode ser observado na Figura 4.39.

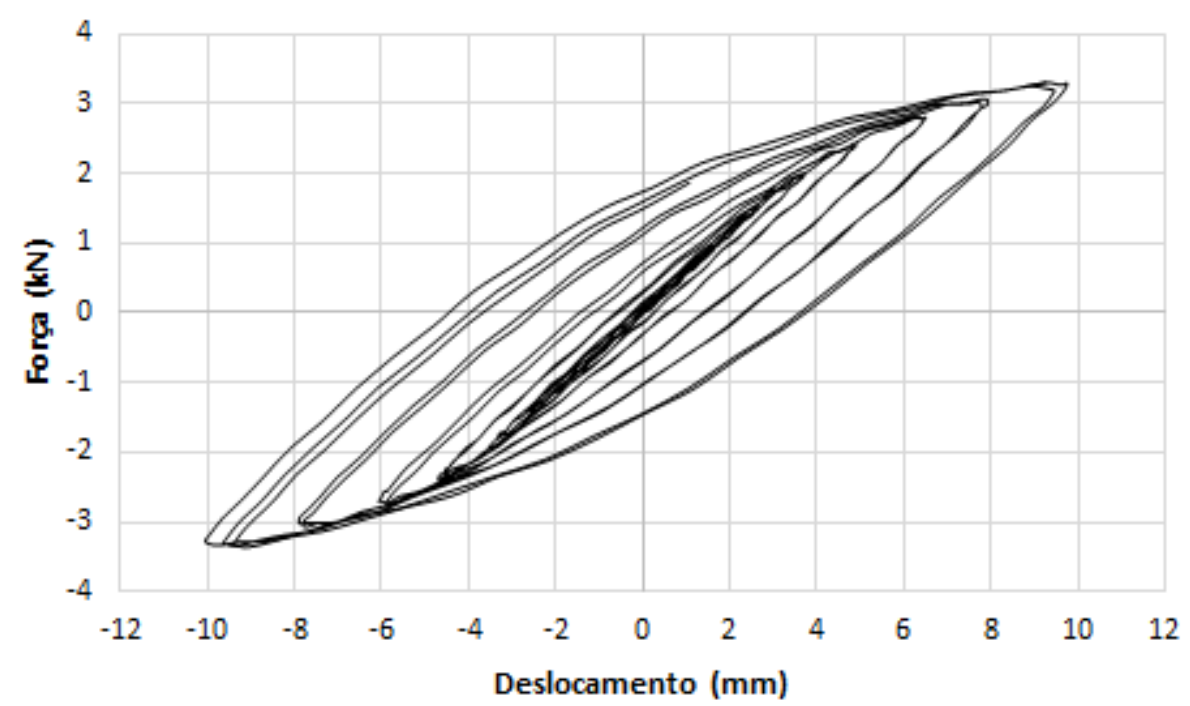

Figura 4.39 - Histerese Bottle Shape

Através das análises realizadas foi possível a determinação das propriedades físicas dos dissipadores necessárias à análise numérica. Com base nas curvas força versus deslocamento obtidas nos ensaios dos dissipadores, foram determinados os parâmetros do modelo de Bouc-Wen específicos dos dissipadores X Shape e Bottle Shape, conforme definições do item 3.2 e da Figura 3.2. 
Os dados necessários ao modelo foram extraídos das fases de carregamento iniciais dos ensaios realizados para os modelos X Shape e Bottle Shape. Na Figura 4.40 e na Figura 4.41 são apresentadas as curvas de carregamento dos corpos de prova relativas às fases elástica e plástica, incluindo as retas tangenciais de ambas as fases, dos modelos $X$ Shape e Bottle Shape, respectivamente.

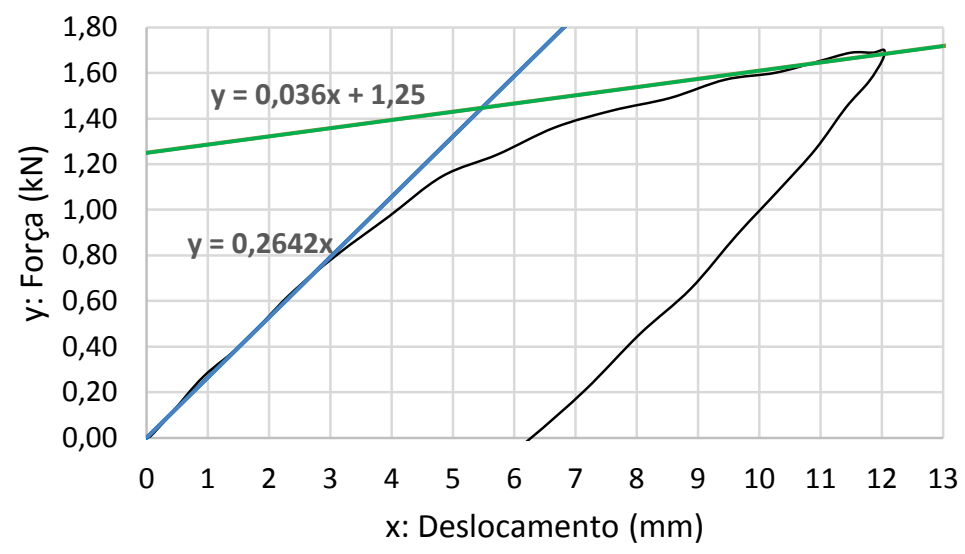

Figura 4.40 - Fase inicial de carregamento do modelo $X$ Shape

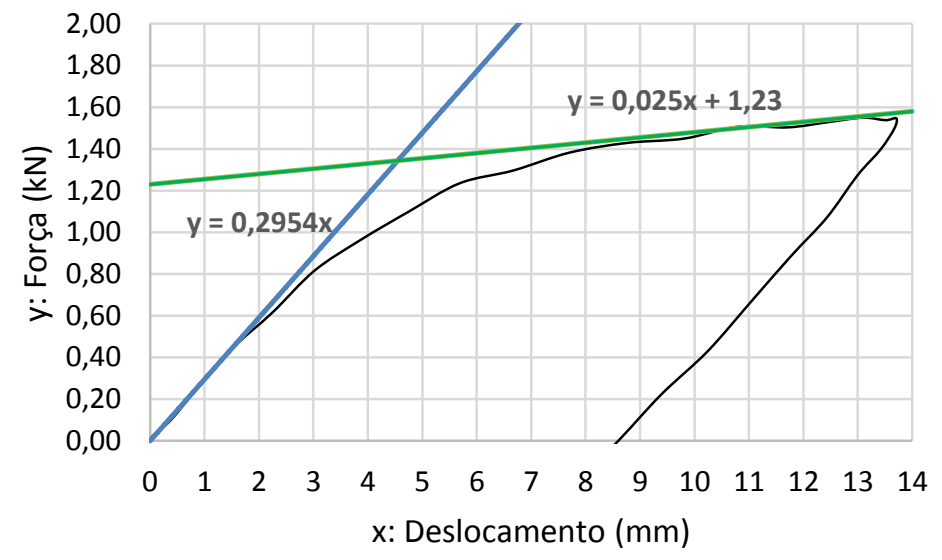

Figura 4.41 - Fase inicial de carregamento do modelo Bottle Shape

A partir das curvas apresentadas é possível extrair as variáveis necessárias ao modelo de Bouc-Wen, conforme apresentado na Tabela 4.5. Os dados foram consolidados com base no comportamento de uma única placa simples. 
Tabela 4.5 - Variáveis encontradas para o modelo de Bouc-Wen relativa aos dissipadores

\begin{tabular}{cc}
\hline X Shape & Bottle Shape \\
\hline$d_{y}=5,478 \mathrm{~mm}$ & $d_{y}=4,549 \mathrm{~mm}$ \\
$f_{y}=1,447 \mathrm{kN}$ & $f_{y}=1,344 \mathrm{kN}$ \\
$k_{y}=0,036 \mathrm{kN} / \mathrm{mm}$ & $k_{y}=0,025 \mathrm{kN} / \mathrm{mm}$ \\
$k_{e}=0,264 \mathrm{kN} / \mathrm{mm}$ & $k_{e}=0,295 \mathrm{kN} / \mathrm{mm}$ \\
$k_{e}=264.200,00 \mathrm{~N} / \mathrm{m}$ & $k_{e}=295.400,00 \mathrm{~N} / \mathrm{m}$ \\
$r=0,136$ & $r=0,085$ \\
\hline
\end{tabular}

Os dados experimentais obtidos a partir dos ensaios em laboratório foram confrontados com uma análise computacional modelada em elementos finitos para a verificação da compatibilidade entre a rigidez elástica obtida a partir do modelo numérico com a obtida a partir do modelo experimental. Os resultados demonstram excelente aproximação entre modelo físico e numérico computacional, com diferenças de aproximadamente 3,5\%, a comparação entre essas análises é apresentada na Tabela 4.6.

Tabela 4.6 - Comparação entre modelo numérico e experimental

\begin{tabular}{cccc}
\hline $\begin{array}{c}\text { Rigidez Elástica } \\
(\mathrm{kN} / \mathrm{mm})\end{array}$ & $\begin{array}{c}\text { Modelo } \\
\text { Numérico }\end{array}$ & $\begin{array}{c}\text { Modelo } \\
\text { Experimental }\end{array}$ & $\Delta(\%)$ \\
\hline X Shape & 0,255 & 0,264 & $3,529 \%$ \\
Bottle Shape & 0,305 & 0,295 & $3,390 \%$ \\
\hline
\end{tabular}

Na modelagem em elementos finitos da placa do tipo Bottle Shape foi utilizada uma malha retangular com 2.708 elementos, totalizando 17.004 nós, já na modelagem da placa do tipo $X$ Shape foi utilizada uma malha do mesmo formato com 2.398 elementos que totalizam 14.968 nós.

Com base nas variáveis encontradas em laboratório para o modelo de Bouc-Wen relativas aos dissipadores, mais uma vez foi avaliado numericamente o comportamento histerético dos dissipadores metálicos DM\#1, DM\#2 e DM\#3, conforme nomenclatura apresentada na Figura 5.3. Os dados encontrados para os dissipadores $X$ Shape foram consolidados nos diagramas de histerese apresentados na Figura 4.42, Figura 4.43 e Figura 4.44, relativos aos dissipadores DM\#3, DM\#2 e DM\#1, respectivamente. 


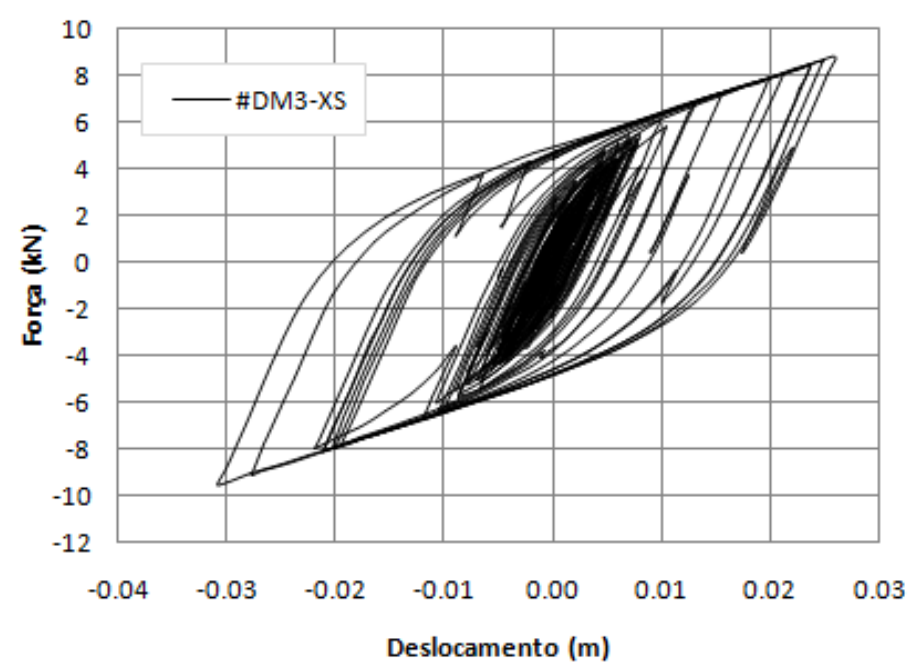

Figura 4.42 - Comportamento histerético do dissipador metálico DM\#3 do tipo X Shape quando a estrutura é submetida à excitação sísmica

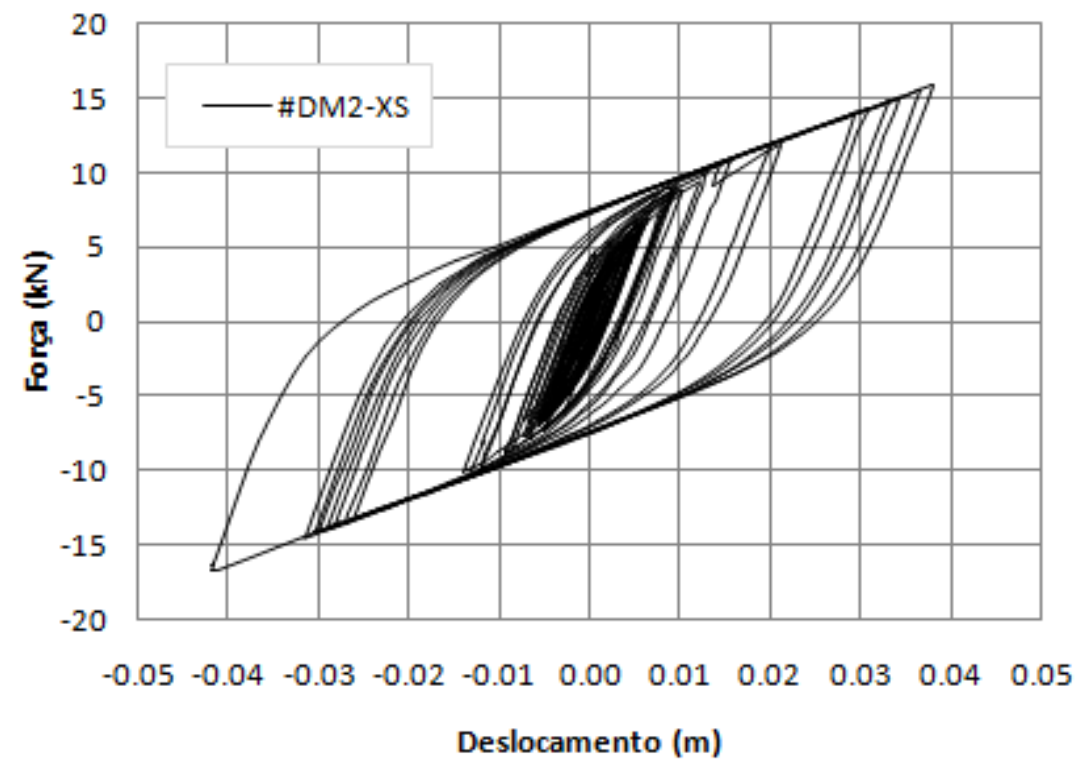

Figura 4.43 - Comportamento histerético do dissipador metálico DM\#2 do tipo X Shape quando a estrutura é submetida à excitação sísmica 


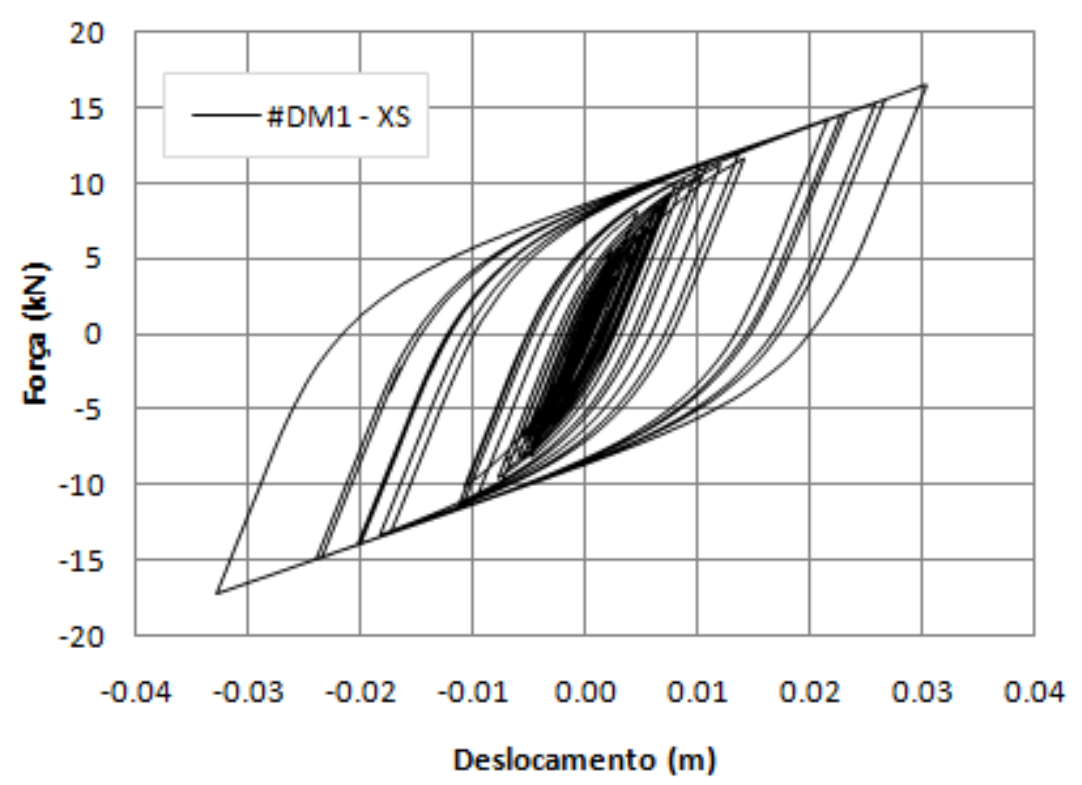

Figura 4.44 - Comportamento histerético do dissipador metálico DM\#1 do tipo X Shape quando a estrutura é submetida à excitação sísmica

Os dados encontrados para os dissipadores Bottle Shape foram consolidados nos diagramas de histerese apresentados na Figura 4.45, Figura 4.46 e Figura 4.47 relativos, respectivamente, aos dissipadores DM\#3, DM\#2 e DM\#1.

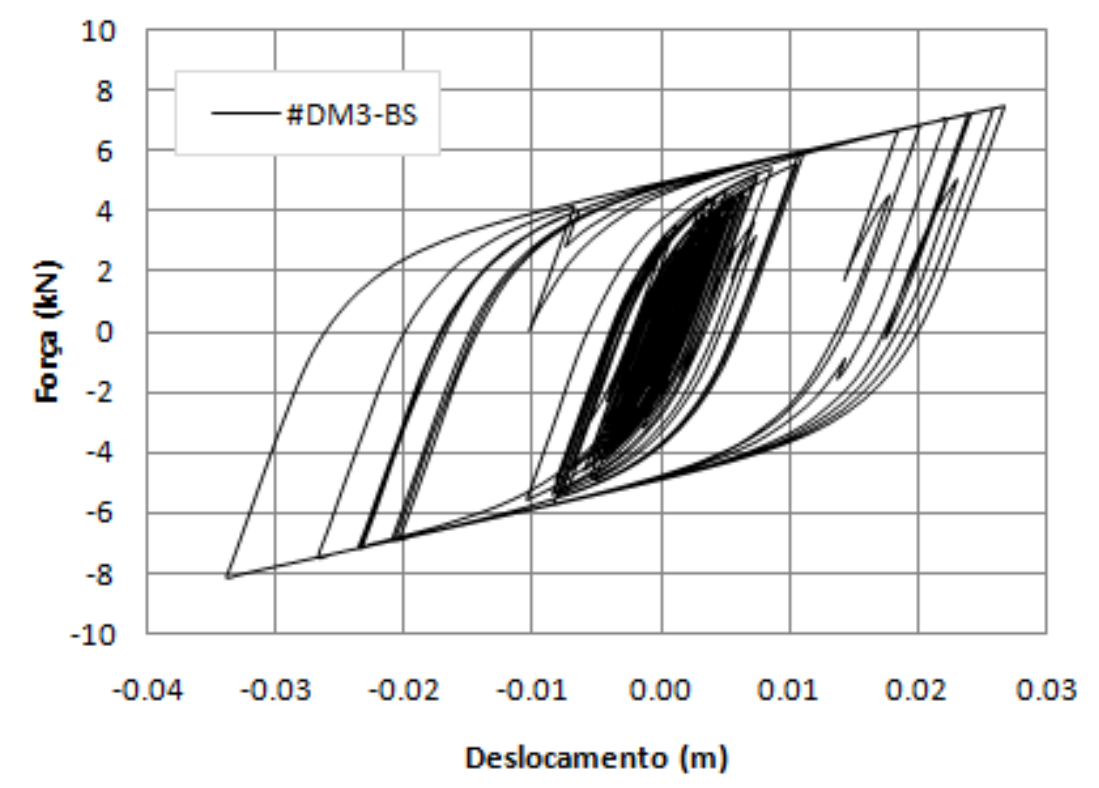

Figura 4.45 - Comportamento histerético do dissipador metálico DM\#3 do tipo Bottle Shape quando a estrutura é submetida à excitação sísmica 


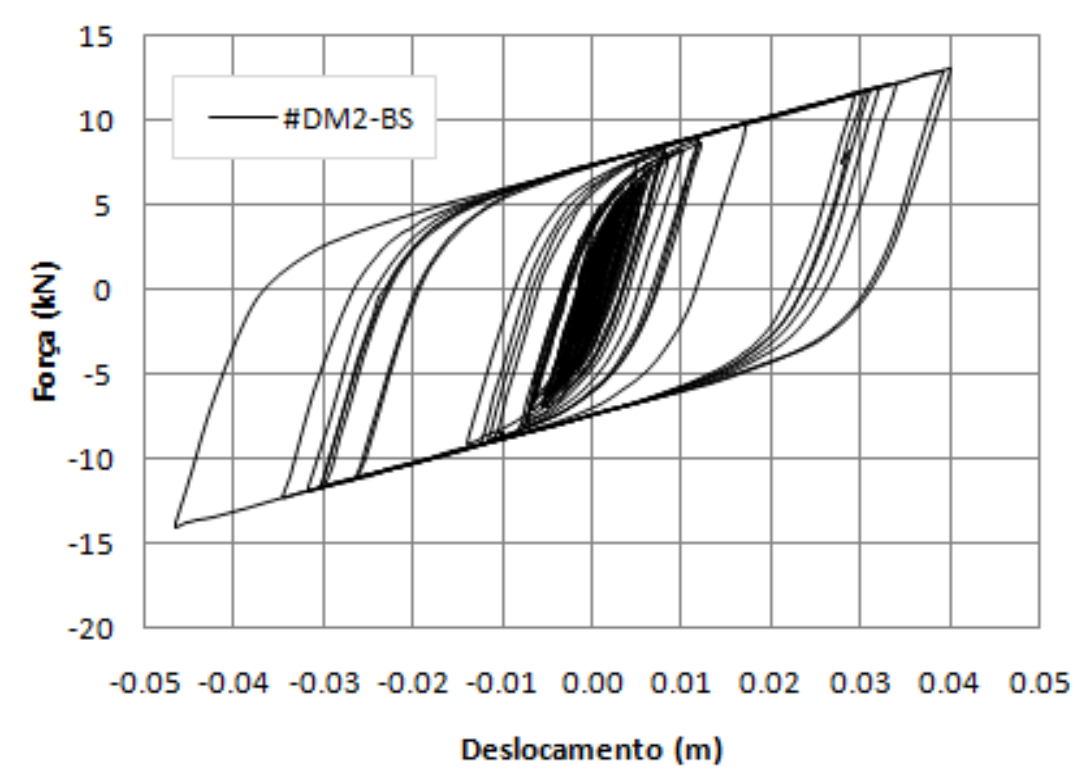

Figura 4.46 - Comportamento histerético do dissipador metálico DM\#2 do tipo Bottle Shape quando a estrutura é submetida à excitação sísmica

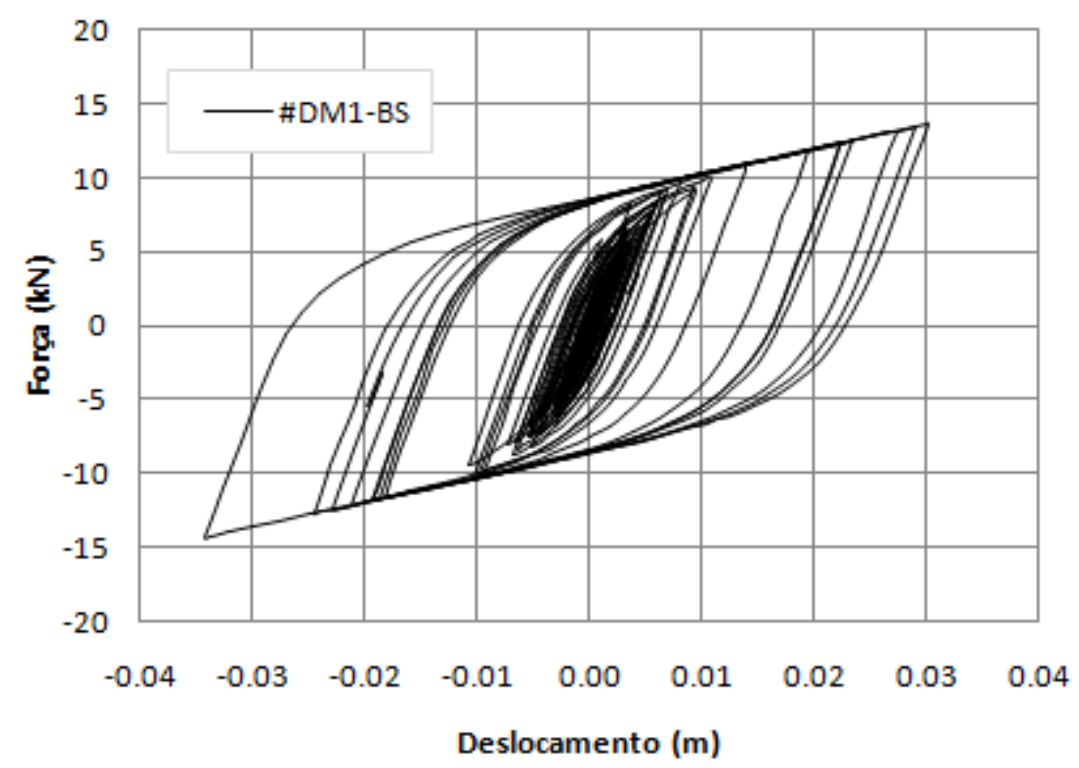

Figura 4.47 - Comportamento histerético do dissipador metálico DM\#1 do tipo Bottle Shape quando a estrutura é submetida à excitação sísmica

Nos itens 5.2 e 0 da análise numérica são apresentados os diagramas de histerese obtidos a partir da simulação computacional, observa-se que ao comparar os diagramas baseados em dados experimentais e numéricos eles se apresentaram semelhantes, demonstrando assim a equivalência entre os modelos analisados. 


\section{ANÁLISE NUMÉRICA}

Após a modelagem da topologia Bottle Shape e da avaliação de sua rigidez elástica, compara-se também o comportamento desse modelo com o X Shape incorporados em modelos estruturais completos, em que se submete a estrutura a uma excitação sísmica utilizando cada um dos dispositivos.

\subsection{EXCITAÇÃO SÍSMICA}

O modelo em estudo foi submetido à excitação sísmica correspondente ao registrado no terremoto El Centro 1940 relativa à componente norte sul do registro de aceleração, os dados foram normalizados para uma aceleração máxima de projeto de $0,33 \mathrm{~g}$. Os registros das acelerações em função do tempo são apresentados na Figura 5.1.

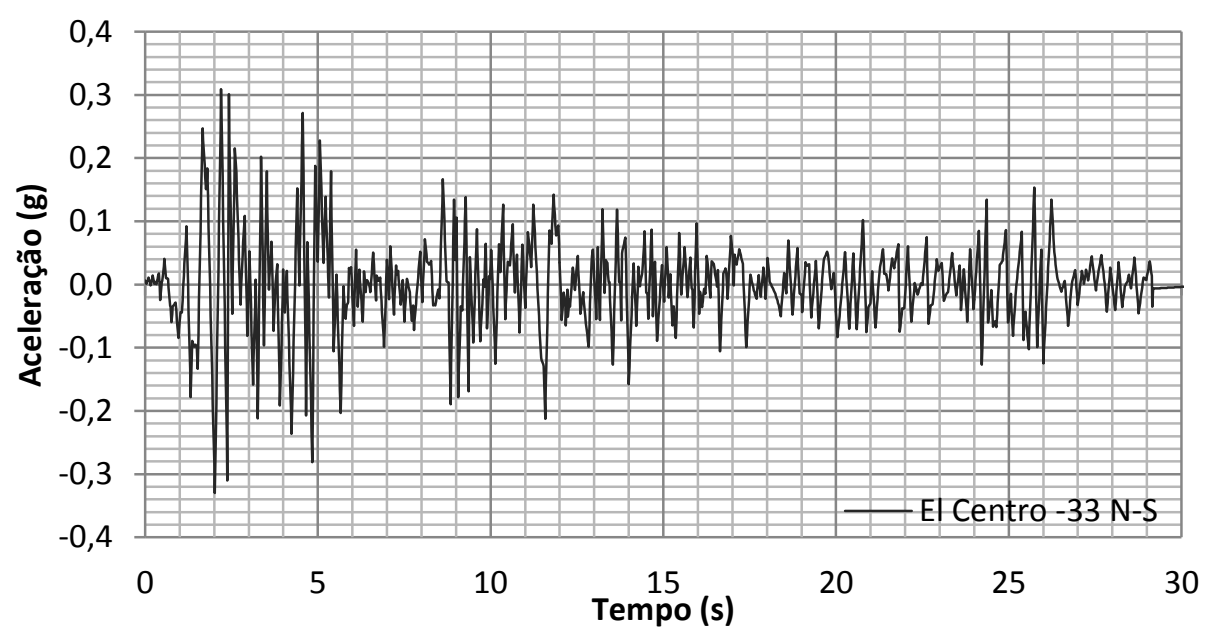

Figura 5.1 - Acelerograma El Centro $33 \mathrm{~N}-\mathrm{S}$

De igual forma, apresenta-se na Figura 5.2 o espectro de potência desse acelerograma.

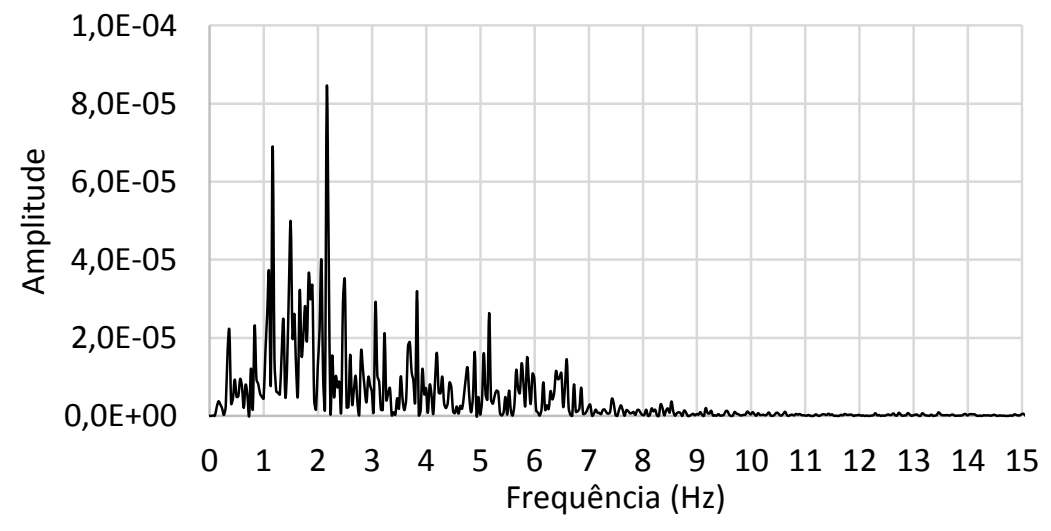

Figura 5.2 - Espectro de Potência do Acelerograma 


\subsection{SISTEMA ESTRUTURAL I}

O primeiro pórtico plano analisado, denominado Sistema Estrutural I, foi o mesmo utilizado por Tena-Colunga (1997), que realizou a modelagem numérica do comportamento do dissipador metálico, e também por Chalco (2014), que trabalhou na implementação de um modelo computacional do comportamento histerético não linear do dispositivo ADAS, as dimensões do pórtico são apresentadas na Figura 5.3.

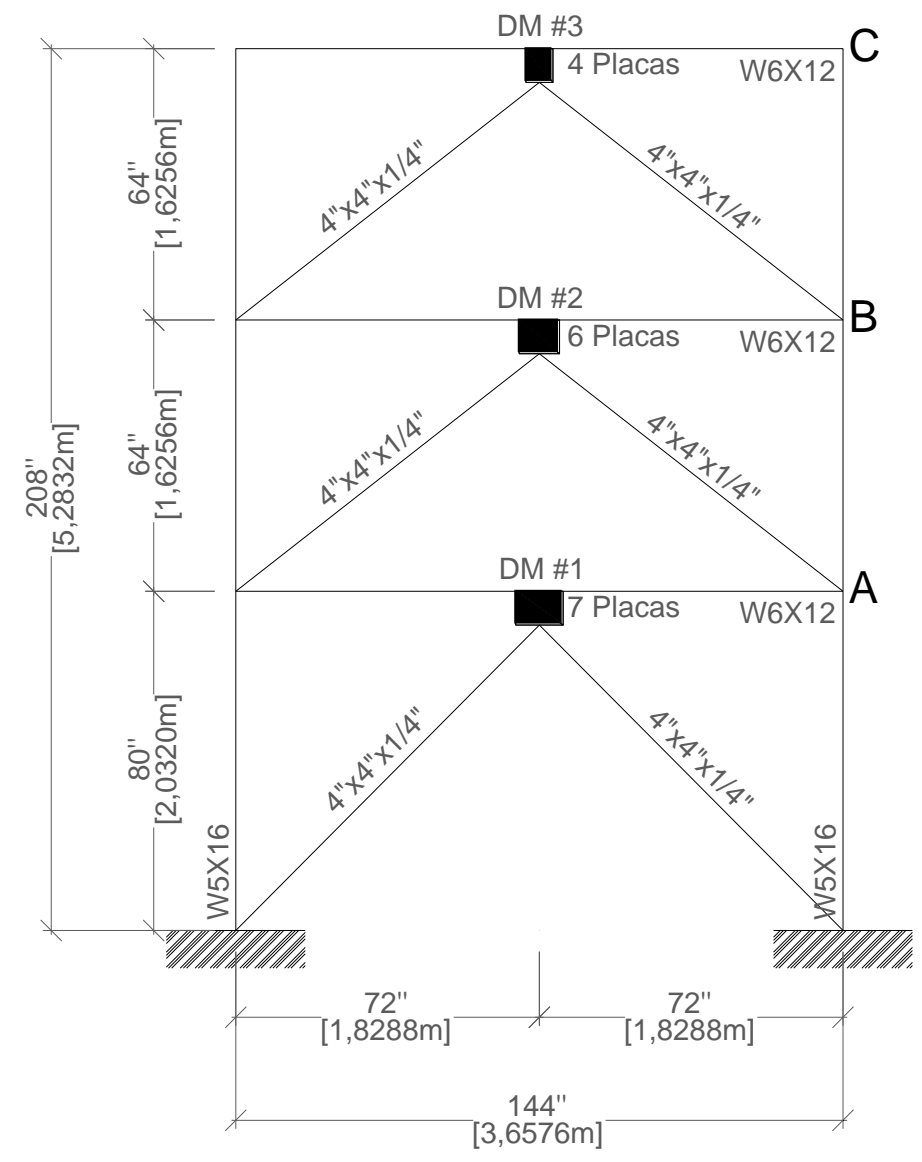

Figura 5.3 - Pórtico Plano de 03 andares com amortecedores histeréticos instalados (Sistema Estrutural I)

As propriedades dos elementos estruturais do pórtico plano analisado são apresentadas na Tabela 5.1.

Tabela 5.1 - Propriedades dos elementos estruturais do pórtico plano analisado. Fonte: Whittaker et. al. (1989)

\begin{tabular}{ccccc}
\hline Elementos/Propriedades & $\begin{array}{c}\text { Área } \\
\left(\mathrm{in}^{2}\right)\end{array}$ & $\begin{array}{c}\text { Área } \\
\left(\mathrm{cm}^{2}\right)\end{array}$ & $\begin{array}{c}\mathrm{I} \\
\left(\mathrm{in}^{4}\right)\end{array}$ & $\begin{array}{c}\mathrm{I} \\
\left(\mathrm{cm}^{4}\right)\end{array}$ \\
\hline Viga - $(W 6 \times 12)$ & 3,54 & 22,84 & 21,7 & 903,22 \\
\hline Pilar - $(W 5 \times 16)$ & 4,70 & 30,32 & 21,3 & 886,57 \\
\hline $\begin{array}{c}\text { Contraventamento } \\
(4 \times 4 \times 1 / 4 ")\end{array}$ & 3,59 & 23,16 & - & - \\
\hline
\end{tabular}


Os parâmetros relativos à rigidez de cisalhamento elástica dos dissipadores metálicos estão de acordo com os parâmetros definidos em Whittaker et. al. (1989) e descritos na Tabela 4.5, respeitando a Equação 3.7 no que se refere ao número de placas utilizadas em um de sistema de dissipação no cálculo da rigidez.

Tabela 5.2 - Rigidez elástica aplicada aos modelos

\begin{tabular}{ccc}
\hline \multirow{2}{*}{$\mathrm{N}^{\circ}$ de Placas } & \multicolumn{2}{c}{ Rigidez Elástica $(\mathrm{kN} / \mathrm{cm})$} \\
\cline { 2 - 3 } & $X$ Shape & Bottle Shape \\
\hline 4 & 10,57 & 11,82 \\
\hline 6 & 15,85 & 17,72 \\
\hline 7 & 18,49 & 20,68 \\
\hline
\end{tabular}

Além disso, uma rigidez pós-escoamento de $5 \%$ da rigidez elástica foi considerada para os dissipadores metálicos, valor semelhante ao adotado por Tena-Colunga (1997) em seu estudo. Os pilares, vigas e contraventamentos possuem elevada resistência em relação aos dissipadores metálicos, garantindo assim que o comportamento não linear seja concentrado nos mecanismos de dissipação de energia. As frequências naturais dos três modos de vibração são apresentadas na Tabela 5.3.

\begin{tabular}{ccc}
\multicolumn{3}{c}{ Tabela 5.3 - Modos de vibração do Sistema Estrutural I } \\
\hline \multirow{2}{*}{ Modo } & Período (s) & Frequências Naturais (Hz) \\
\hline 1 & 0.659 & 1.518 \\
\hline 2 & 0.222 & 4.513 \\
\hline 3 & 0.127 & 7.887 \\
\hline
\end{tabular}

A representação gráfica desses modos de vibração é apresentada na Figura 5.4.

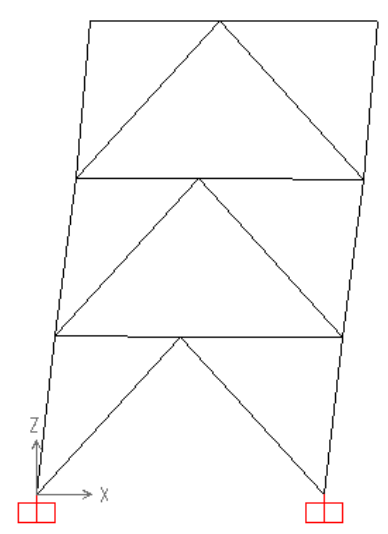

a) Primeiro modo de vibração

Figura 5.4 - Representação gráfica dos modos de vibração

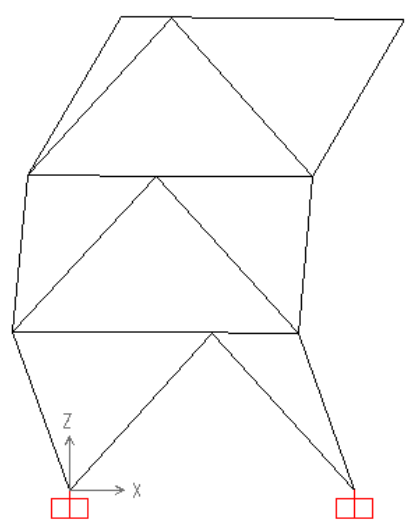

b) Segundo modo de vibração

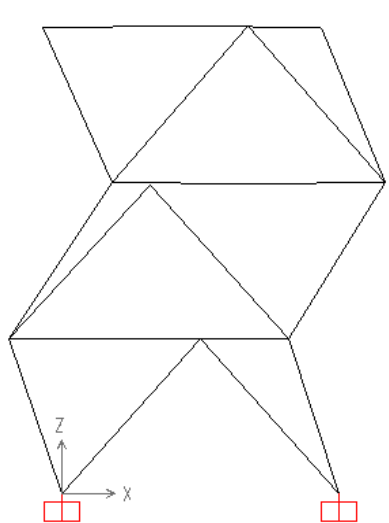

c) Terceiro modo de vibração 


\subsubsection{Apresentação e comparação dos resultados}

Os resultados da análise do sistema estrutural submetido à excitação sísmica são apresentados a seguir, foram avaliados os deslocamentos da estrutura nos pontos A, B, C, DM\#1, DM\#2 e DM\#3 conforme nomenclatura apresentada na Figura 5.3. Da mesma forma foram avaliadas as forças atuantes nos dissipadores metálicos DM\#1, DM\#2 e DM\#3.

Inicialmente avaliou-se os deslocamentos da estrutura equipada com os dissipadores metálicos do tipo Bottle Shape e $X$ Shape para os nós A, B e C e os comparou com a estrutura sem nenhum tipo de controle. Como se pode observar na Tabela 5.4, que mostra os dados de deslocamento de maneira resumida, na Figura 5.5, na Figura 5.6 e na Figura 5.7, que apresenta esses deslocamentos de forma gráfica, houve expressivo ganho na redução dos descolamentos com variação de 308,39\% a 1.399,44\%.

Tabela 5.4 - Comparação entre deslocamentos do pórtico plano

\begin{tabular}{|c|c|c|c|c|c|c|}
\hline \multicolumn{2}{|c|}{ Deslocamentos } & $\begin{array}{l}\text { Sem Controle } \\
\text { (m) }\end{array}$ & $\begin{array}{l}\text { X Shape } \\
\text { (m) }\end{array}$ & $\begin{array}{l}\text { Bottle Shape } \\
\text { (m) }\end{array}$ & $\begin{array}{l}\Delta(\%) \\
(1) /(2)\end{array}$ & $\begin{array}{l}\Delta(\%) \\
(1) /(3)\end{array}$ \\
\hline \multirow{3}{*}{ Nó C } & & (1) & (2) & (3) & (4) & (5) \\
\hline & RMS* & 0,18048 & 0,01242 & 0,01204 & $1.353,29 \%$ & $1.399,44 \%$ \\
\hline & Máximo & 0,30128 & 0,07377 & 0,07203 & $308,39 \%$ & $318,25 \%$ \\
\hline \multirow{2}{*}{ Nó B } & RMS & 0,12880 & 0,00905 & 0,00880 & $1.322,60 \%$ & $1.363,27 \%$ \\
\hline & Máximo & 0,22139 & 0,04884 & 0,04766 & $353,32 \%$ & $364,49 \%$ \\
\hline \multirow{2}{*}{ Nó A } & RMS & 0,05344 & 0,00401 & 0,00391 & $1.232,47 \%$ & $1.266,39 \%$ \\
\hline & Máximo & 0,09216 & 0,02027 & 0,01950 & $354,58 \%$ & $372,55 \%$ \\
\hline
\end{tabular}

*RMS: Root Mean Square

Os gráficos de deslocamento em função do tempo para a estrutura equipada com dissipadores do tipo X Shape, Bottle Shape e Sem Controle, para os nós C, B e A, são apresentados na Figura 5.5, Figura 5.6 e Figura 5.7, respectivamente. 




Figura 5.5 - Comparação de deslocamentos no nó C para estrutura com e sem controle

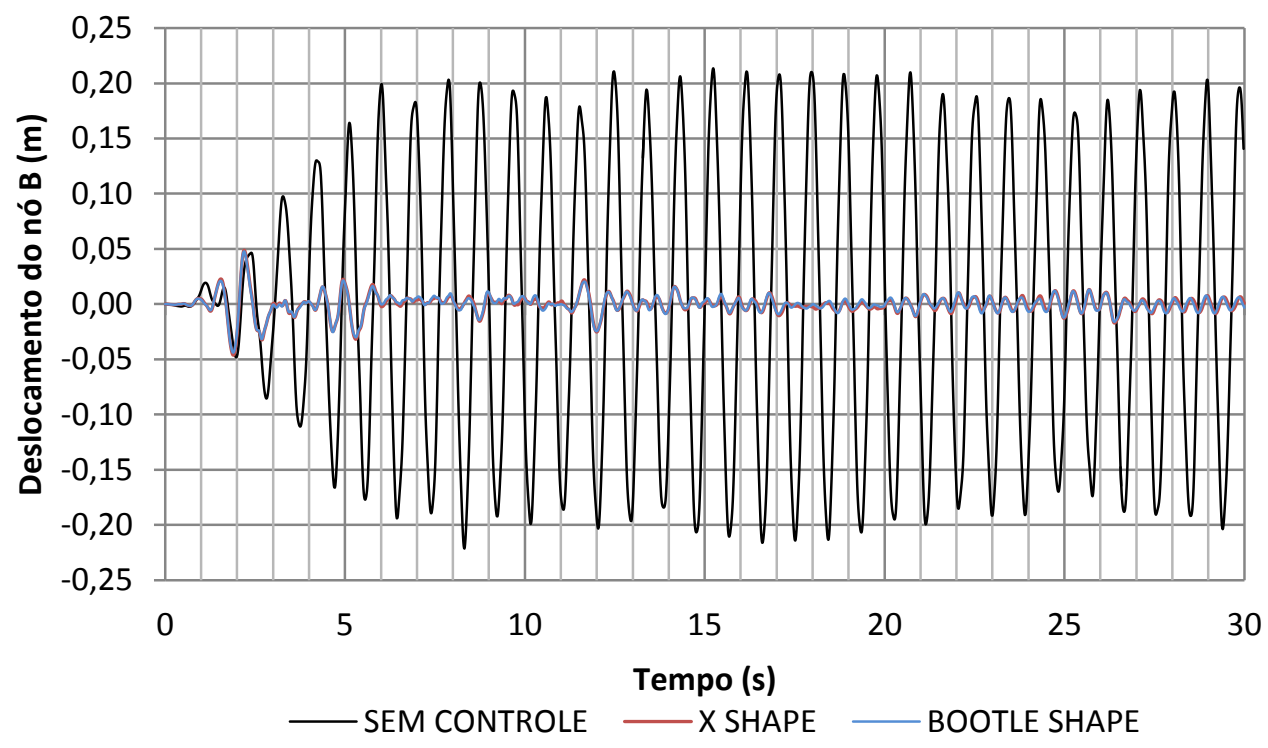

Figura 5.6 - Comparação de deslocamentos no nó B para estrutura com e sem controle 


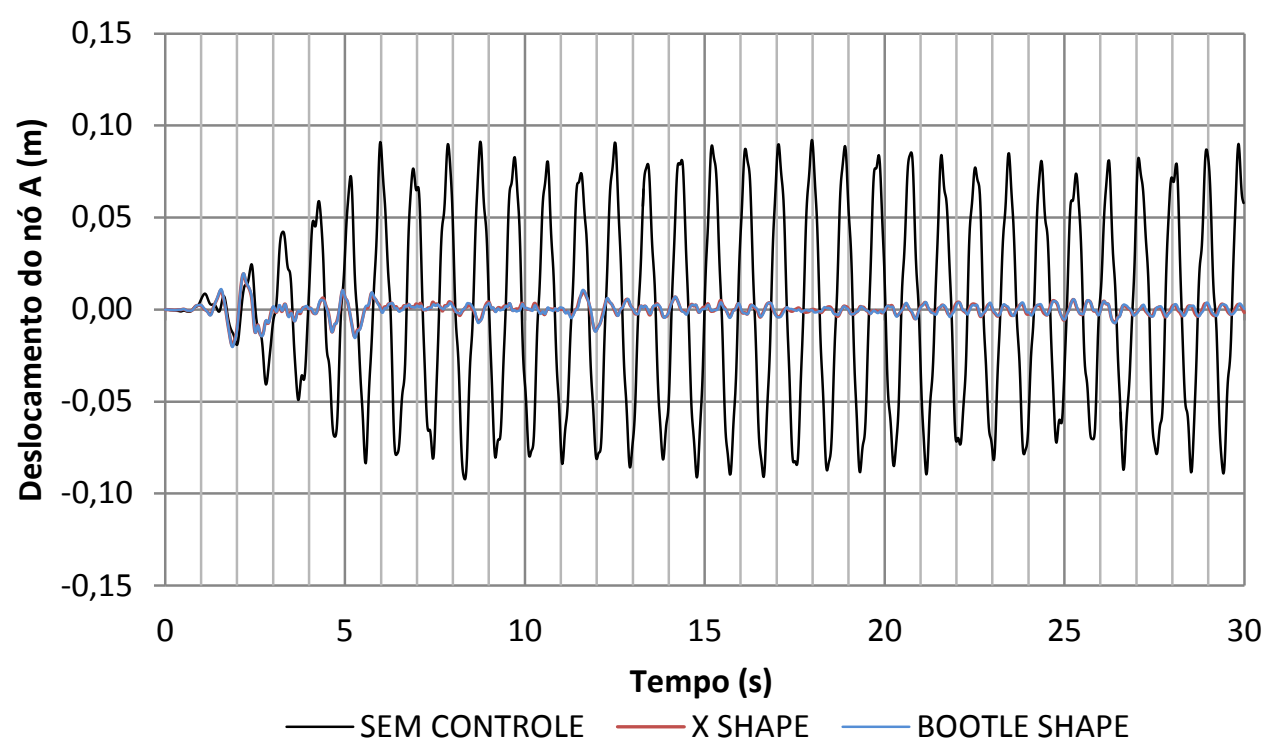

Figura 5.7 - Comparação de deslocamentos no nó A para estrutura com e sem controle

Uma análise de deslocamentos apresentados pela estrutura nos pontos A, B, C, DM\#1, DM\#2 e DM\#3 demonstra que a estrutura equipada com os dissipadores metálicos do tipo Bottle Shape apresenta comportamento muito semelhante à estrutura equipada com os dissipadores metálicos do tipo $X$ Shape. Cabe observar que apesar do comportamento semelhante das duas estruturas, a equipada com os dissipadores Bottle Shape apresentou um RMS médio 3,19\% inferior para os 06 pontos analisados, demonstrando maior estabilidade.

Os deslocamentos dos pontos A, B e C são apresentados no gráfico da Figura 5.8 para a estrutura equipada com dos dispositivos do tipo $X$ Shape e na Figura 5.9 para a estrutura equipada com os dispositivos do tipo Bottle Shape.

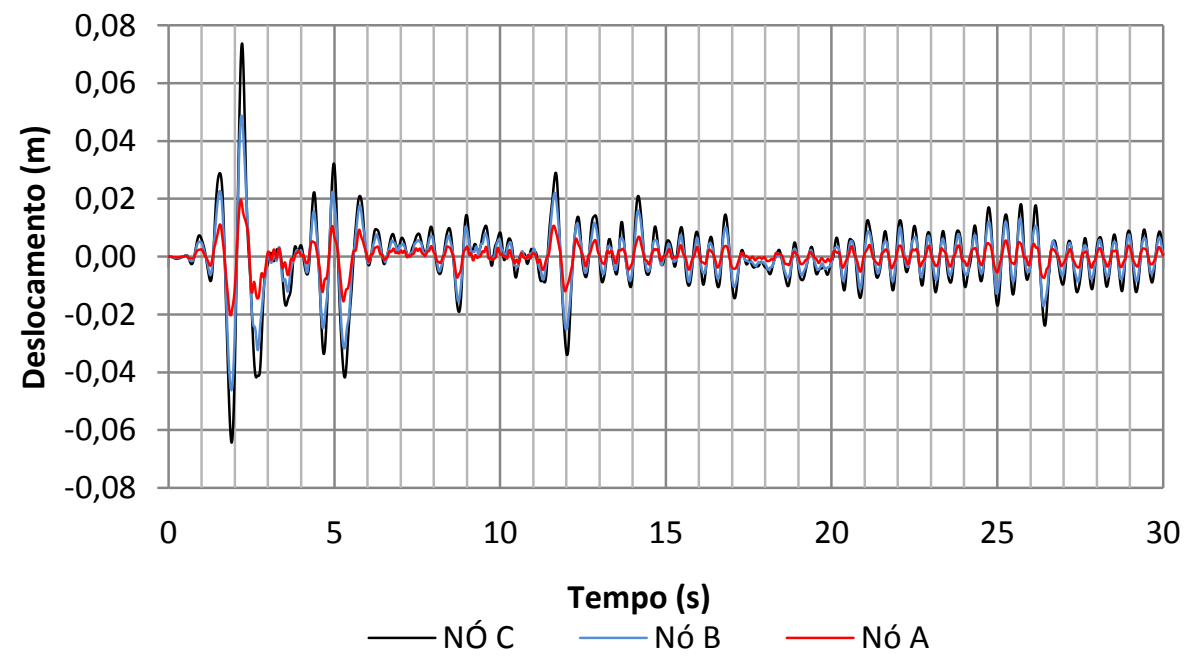

Figura 5.8 - Comparação de deslocamentos da estrutura equipada com o dispositivo $X$ Shape quando a mesma é submetida à excitação sísmica 


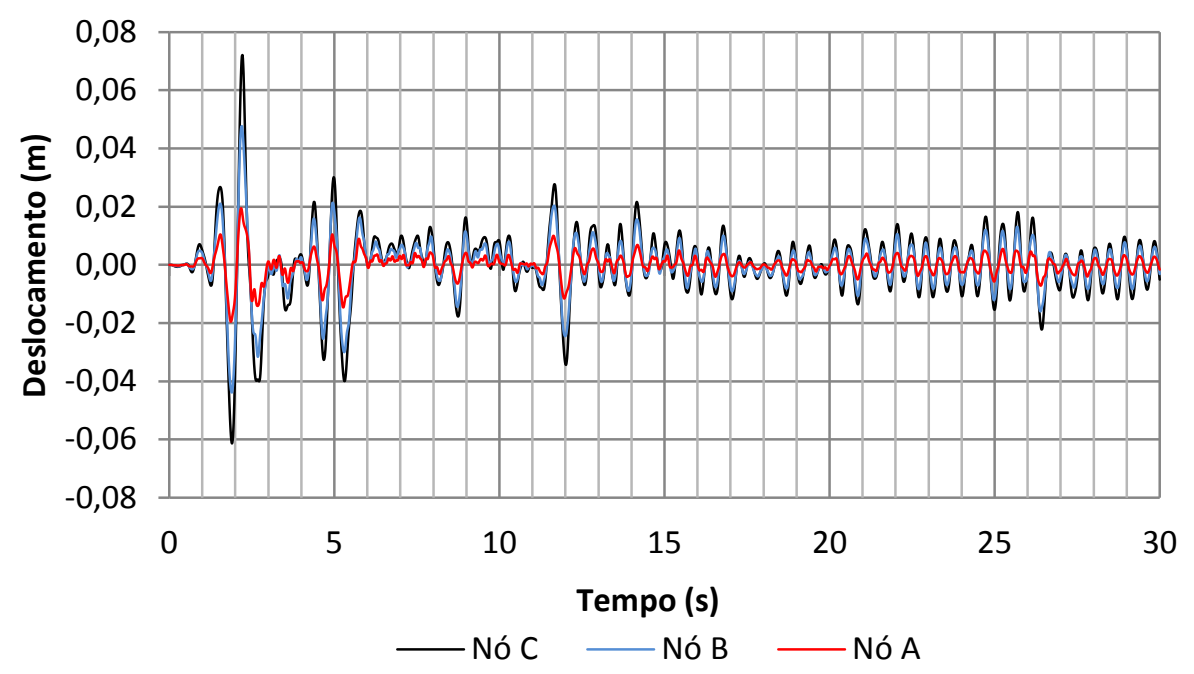

Figura 5.9 - Comparação de deslocamentos da estrutura equipada com o dispositivo Bottle Shape quando a mesma é submetida à excitação sísmica

Os dados relativos aos deslocamentos absolutos máximos dos pontos analisados do pórtico plano são apresentados na Tabela 5.5. Ao analisar os dados, pode-se observar que a diferença entre os deslocamentos absolutos máximos analisados varia de $0,41 \%$ a $3,95 \%$, sendo essa diferença mais acentuada nos nós inferiores.

Tabela 5.5 - Comparação entre deslocamentos absolutos máximos de pontos do pórtico plano

\begin{tabular}{cccc}
\hline & $\begin{array}{c}\text { X Shape } \\
(\mathrm{m})\end{array}$ & $\begin{array}{c}\text { Bottle Shape } \\
(\mathrm{m})\end{array}$ & $\begin{array}{c}\Delta \\
(\%)\end{array}$ \\
\hline Nó C & 0,07377 & 0,07203 & $2,41 \%$ \\
\hline Nó B & 0,04884 & 0,04766 & $2,46 \%$ \\
\hline Nó A & 0,02027 & 0,01950 & $3,95 \%$ \\
\hline DM\#3 & 0,02559 & 0,02548 & $0,41 \%$ \\
\hline DM\#2 & 0,02967 & 0,02868 & $3,44 \%$ \\
\hline DM\#1 & 0,02009 & 0,01933 & $3,95 \%$ \\
\hline
\end{tabular}

Além dos deslocamentos absolutos máximos, analisou-se também o valor quadrático médio dos deslocamentos da estrutura, que estão sintetizados na Tabela 5.6. Da mesma maneira obteve-se um desempenho superior para a estrutura equipada com os dispositivos do tipo Bottle Shape com a redução de descolamentos variando entre 2,55\% e $4,55 \%$ para os pontos analisados. Neste caso a diferença entre os dois modelos foi mais acentuada para os nós localizados na parte superior da estrutura. 
Tabela 5.6 - Comparação entre RMS dos deslocamentos absolutos do pórtico plano

\begin{tabular}{lccc}
\hline & $\begin{array}{c}\text { X Shape } \\
(\mathrm{m})\end{array}$ & $\begin{array}{c}\text { Bottle Shape } \\
(\mathrm{m})\end{array}$ & $\begin{array}{c}\Delta \\
(\%)\end{array}$ \\
\hline Nó C & 0.01242 & 0.01204 & $3.18 \%$ \\
\hline Nó B & 0.00905 & 0.00880 & $2.86 \%$ \\
\hline Nó A & 0.00401 & 0.00391 & $2.55 \%$ \\
\hline DM\#3 & 0.00352 & 0.00337 & $4.55 \%$ \\
\hline DM\#2 & 0.00505 & 0.00488 & $3.44 \%$ \\
\hline DM\#1 & 0.00395 & 0.00385 & $2.59 \%$ \\
\hline
\end{tabular}

Uma vez observados os deslocamentos da estrutura, partiu-se para a análise das solicitações nos dissipadores metálicos \#DM1, \#DM2 e \#DM3.

Para a realização da análise das solicitações nos dissipadores metálicos foram montadas as curvas de histerese para cada um dos dissipadores. Na Figura 5.10 é apresentada a curva histerética do dissipador metálico denominado DM\#3 no formato $X$ Shape e na Figura 5.11 é apresentada a curva histerética do DM\#3 no formato Bottle Shape.

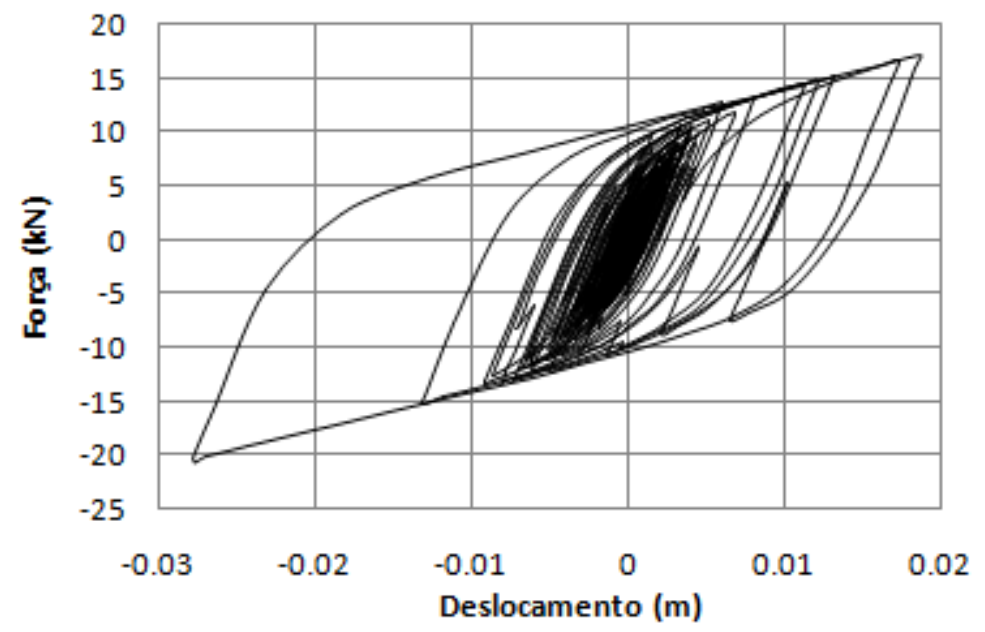

Figura 5.10 - Comportamento histerético do dissipador metálico DM\#3 do tipo X Shape quando a estrutura é submetida à excitação sísmica 


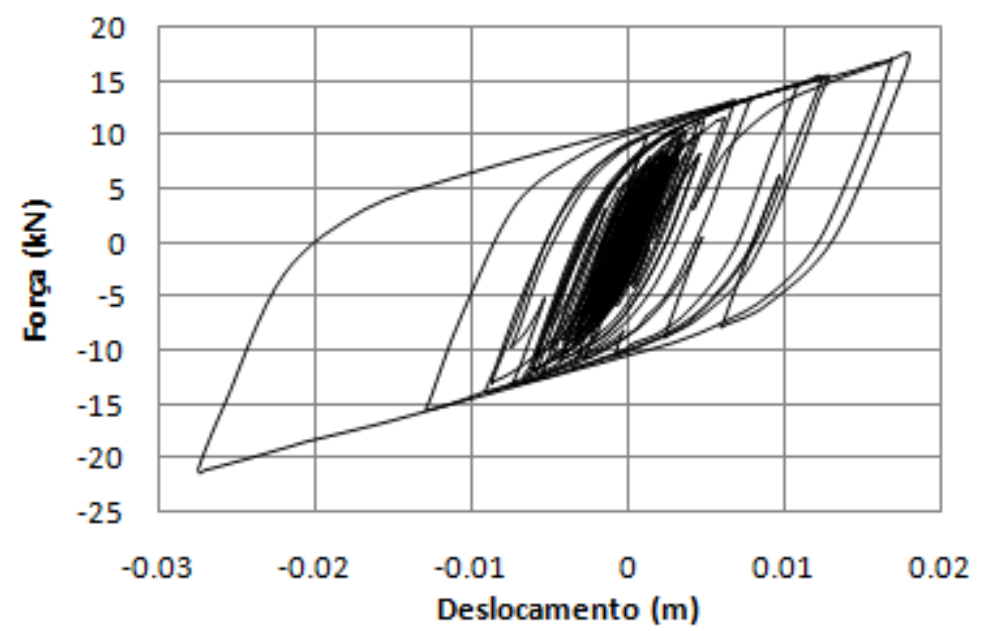

Figura 5.11 - Comportamento histerético do dissipador metálico DM\#3 do tipo Bottle Shape quando a estrutura é submetida à excitação sísmica

Ao analisar as curvas de histerese apresentadas nas figuras, observa-se que as mesmas são bastante semelhantes. Uma análise aponta que as forças absolutas máximas absorvidas pelos dissipadores metálicos do tipo $X$ Shape são inferiores às absorvidas pelos dispositivos do tipo Bottle Shape, com diferenças variando de 1,08\% a 2,32\%, conforme apresentado na Tabela 5.7. Observa-se que, conforme esperado, os dissipadores metálicos localizados na parte inferior do pórtico são os mais solicitados, necessitando, portanto, de maior rigidez, fato que justifica a adoção de um maior número de dissipadores metálicos na estrutura à medida que a mesma se aproxima da base.

Tabela 5.7 - Comparação entre forças absolutas máximas atuantes nos dissipadores metálicos

\begin{tabular}{lccc}
\hline & $\begin{array}{c}\text { X Shape } \\
(\mathrm{kN})\end{array}$ & $\begin{array}{c}\text { Bottle Shape } \\
(\mathrm{kN})\end{array}$ & $\begin{array}{c}\Delta \\
(\%)\end{array}$ \\
\hline $\mathrm{DM} \# 3$ & 15,68500 & 16,05700 & $2,32 \%$ \\
\hline $\mathrm{DM} \# 2$ & 24,59900 & 24,99500 & $1,58 \%$ \\
\hline $\mathrm{DM} \# 1$ & 25,71900 & 26,00000 & $1,08 \%$ \\
\hline
\end{tabular}

Além das forças absolutas máximas, analisou-se também o valor quadrático médio das forças atuantes em cada um dos dissipadores metálicos. Ao analisar os dados da Tabela 5.8, observa-se que o desempenho médio do dissipador metálico do tipo X Shape é inferior ao dispositivo Bottle Shape no caso analisado, com diferenças de dissipação de forças variando de $1,80 \%$ a $3,11 \%$. 
Tabela 5.8 - Comparação entre RMS das forças atuantes nos dissipadores metálicos

\begin{tabular}{lccc}
\hline & $\begin{array}{c}\text { X Shape } \\
(\mathrm{kN})\end{array}$ & $\begin{array}{c}\text { Bottle Shape } \\
(\mathrm{kN})\end{array}$ & $\begin{array}{c}\Delta \\
(\%)\end{array}$ \\
\hline $\mathrm{DM} \# 3$ & 7.28619 & 7.41945 & $1.80 \%$ \\
\hline $\mathrm{DM} 2$ & 12.19355 & 12.40621 & $1.71 \%$ \\
\hline $\mathrm{DM} \# 1$ & 12.98995 & 13.40705 & $3.11 \%$ \\
\hline
\end{tabular}

As curvas de histerese dos dissipadores metálicos DM\#2 e DM\#3 tanto para a estrutura equipada com dispositivos do tipo $X$ Shape como para a estrutura equipada com dispositivos do tipo Bottle Shape são apresentadas a partir da Figura 5.12 até a Figura 5.15 .

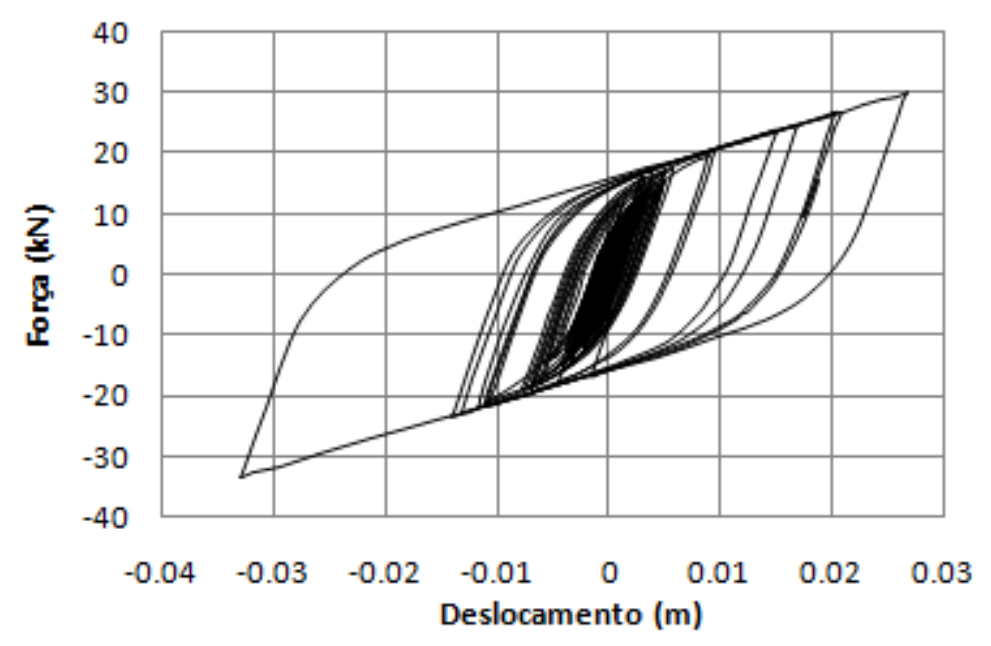

Figura 5.12 - Comportamento histerético do dissipador metálico DM\#2 do tipo X Shape quando a estrutura é submetida à excitação sísmica

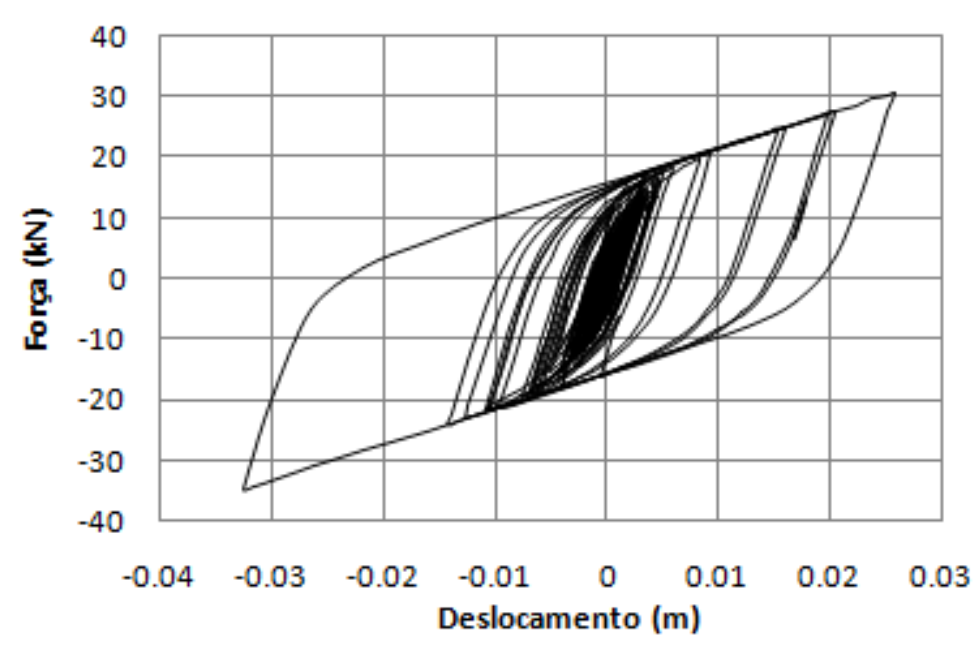

Figura 5.13 - Comportamento histerético do dissipador metálico DM\#2 do tipo Bottle Shape quando a estrutura é submetida à excitação sísmica 


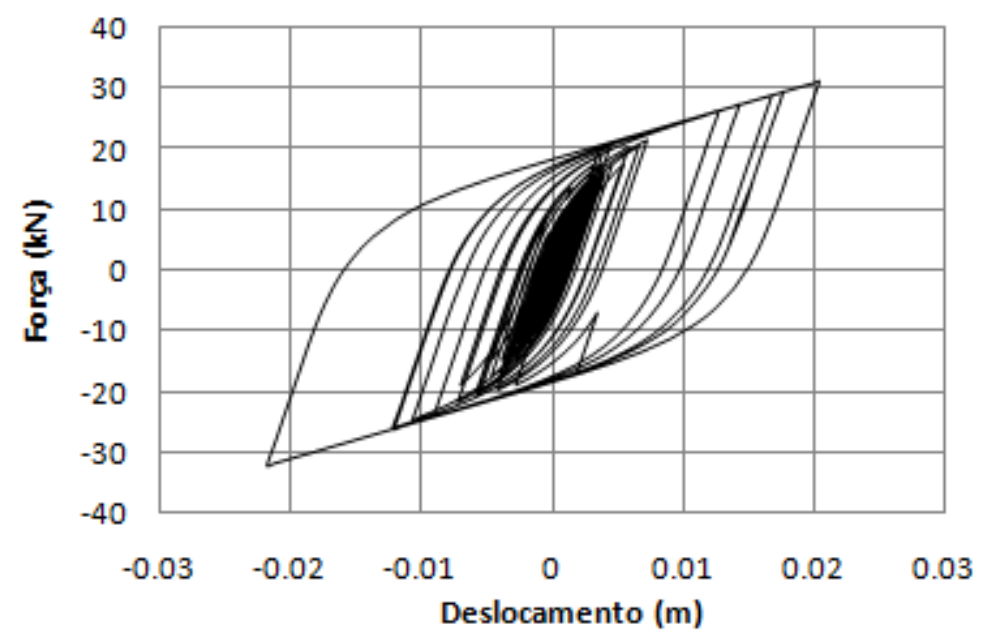

Figura 5.14 - Comportamento histerético do dissipador metálico DM\#1 do tipo X Shape quando a estrutura é submetida à excitação sísmica

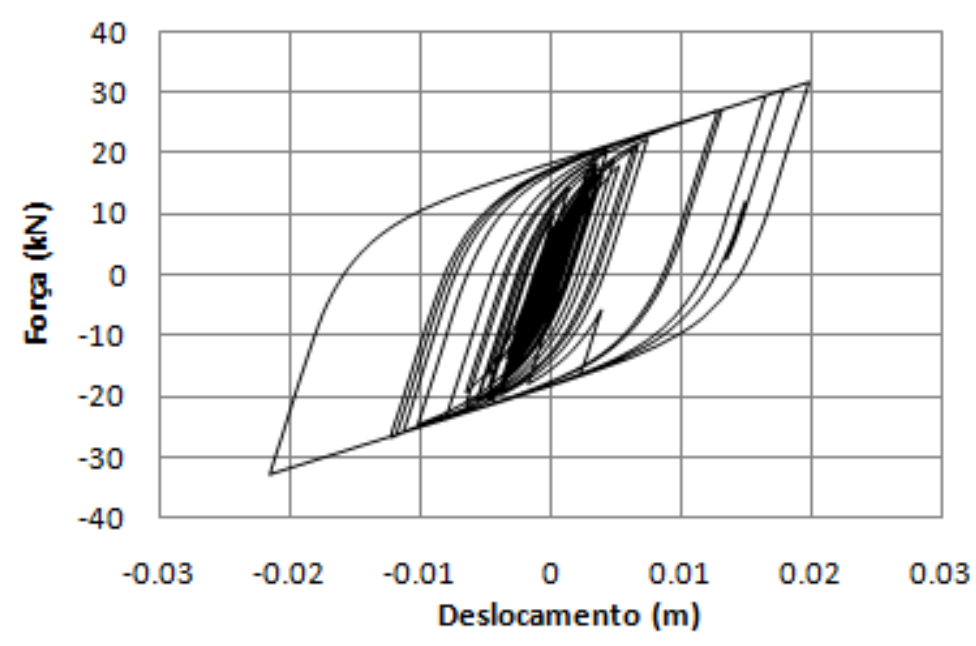

Figura 5.15 - Comportamento histerético do dissipador metálico DM\#1 do tipo Bottle Shape quando a estrutura é submetida à excitação sísmica

\subsection{SISTEMA ESTRUTURAL II}

O segundo pórtico plano analisado, denominado Sistema Estrutural II, foi uma extensão do sistema do Sistema Estrutural I, em que foi considerada uma estrutura com as mesmas características da primeira, com a adição de um maior número de pavimentos. Conforme representação da Figura 5.16, foram considerados 10 pavimentos, totalizando uma altura de $16,66 \mathrm{~m}$ para o pórtico estrutural. As propriedades dos elementos estruturais são as mesmas descritas na Tabela 5.1. 


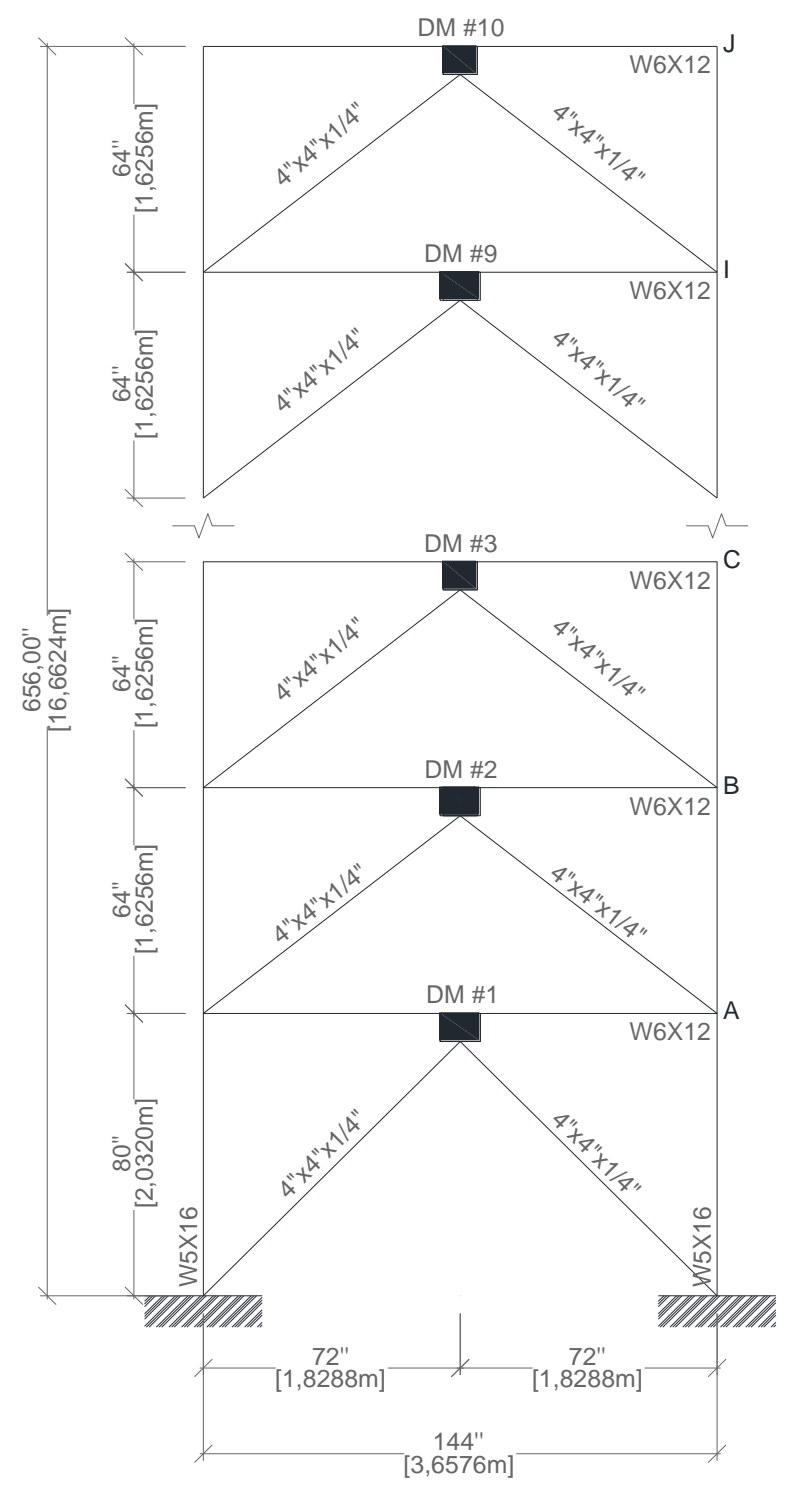

Figura 5.16 - Pórtico Plano com amortecedores histeréticos instalados (Sistema Estrutural II) As características relacionadas à rigidez elástica dos dissipadores metálicos, foram novamente utilizados com base nos parâmetros definidos em laboratório e definidos na Tabela 4.5, respeitando a Equação 3.7 no que se refere ao número de placas utilizadas em um de sistema de dissipação no cálculo da rigidez. Os dados relativos à rigidez são apresentados na Tabela 5.9.

Tabela 5.9 - Rigidez elástica aplicada aos modelos

\begin{tabular}{ccc}
\hline \multirow{2}{*}{$\mathrm{N}^{\circ}$ de Placas } & \multicolumn{2}{c}{ Rigidez Elástica $(\mathrm{kN} / \mathrm{cm})$} \\
\cline { 2 - 3 } & $X$ Shape & Bottle Shape \\
\hline 3 & 7,93 & 8,86 \\
\hline 5 & 13,21 & 17,77 \\
\hline 7 & 18,49 & 20,68 \\
\hline 10 & 26,42 & 29,54 \\
\hline 12 & 31,70 & 35,45 \\
\hline
\end{tabular}


As frequências naturais dos dez modos de vibração desse sistema estrutural são apresentadas na Tabela 5.10.

\begin{tabular}{ccc}
\multicolumn{2}{c}{ Tabela 5.10 - Modos de vibração do Sistema Estrutural II } \\
\hline \multirow{2}{*}{ Modo } & Período (s) & Frequências Naturais (Hz) \\
& & \\
1 & 2,370 & 0,422 \\
\hline 2 & 0,774 & 1,292 \\
\hline 3 & 0,447 & 2,236 \\
\hline 4 & 0,312 & 3,202 \\
\hline 5 & 0,236 & 4,238 \\
\hline 6 & 0,187 & 5,336 \\
\hline 7 & 0,155 & 6,464 \\
\hline 8 & 0,133 & 7,515 \\
\hline 9 & 0,120 & 8,358 \\
\hline 10 & 0,113 & 8,876
\end{tabular}

A representação gráfica dos seus seis primeiros modos de vibração é apresentada na Figura 5.17

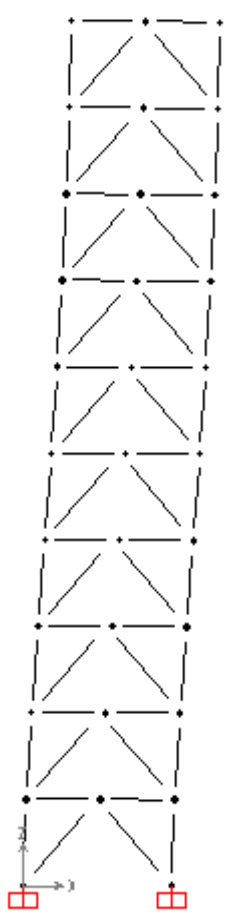

a) Primeiro modo de
vibração

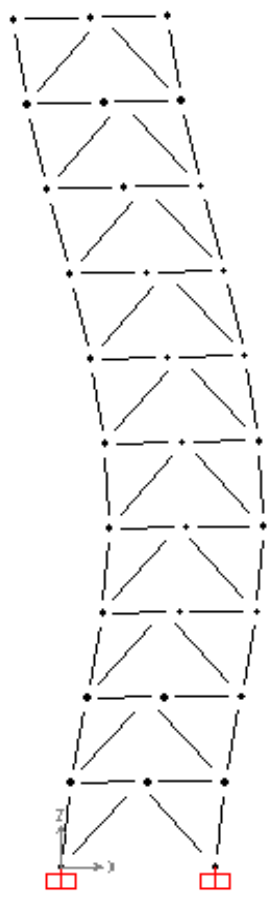

b) Segundo modo de vibração

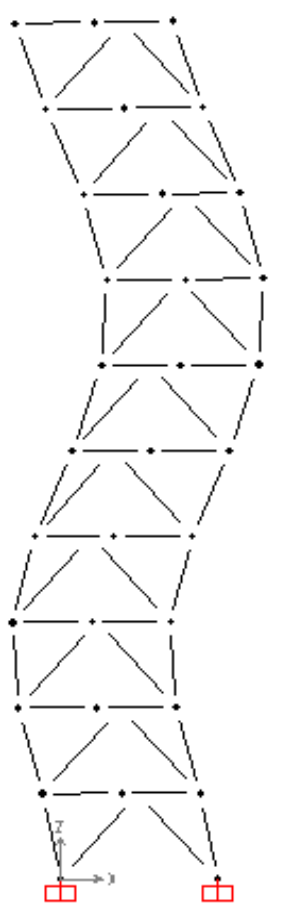

c) Terceiro modo de vibração 


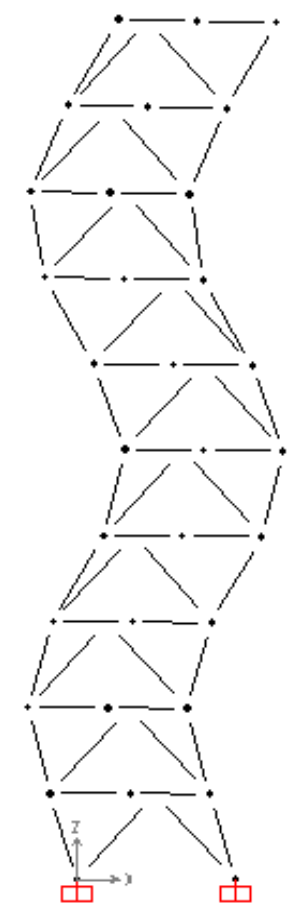

d) Quarto modo de vibração

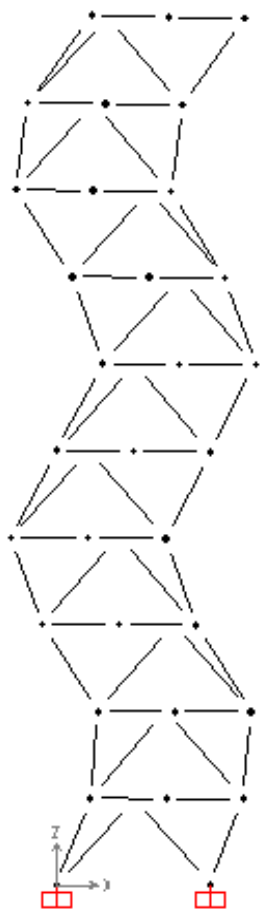

e) Quinto modo de vibração

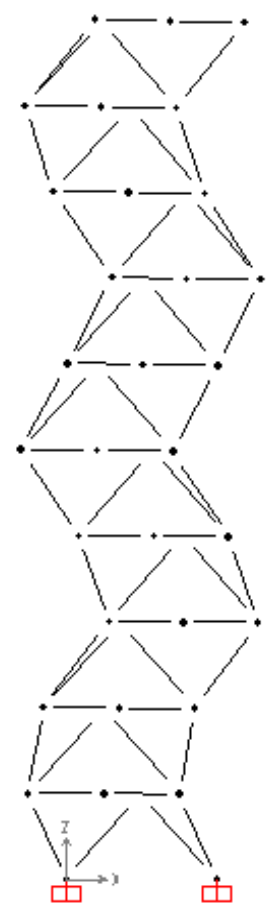

f) Sexto modo de vibração

Figura 5.17 - Representação gráfica dos seis primeiros modos de vibração

Para o Sistema Estrutural II foram adotadas duas configurações distintas para os dissipadores, uma denominada 60/40, em que os dissipadores metálicos DM\#1 e DM\#2 recebem, respectivamente, $60 \%$ e $40 \%$ da rigidez utilizada no primeiro exemplo, que totalizavam 17 placas de dissipação, e outra 70/30, em que os dissipadores metálicos DM\#1 e DM\#2 recebem, respectivamente, $70 \%$ e $30 \%$ da rigidez relativa à 17 placas dissipadoras. Para os demais pavimentos (03-10) foram utilizadas três placas de dissipação em ambas as configurações. O detalhamento da configuração é apresentado na Tabela 5.11 conforme nomenclatura da Figura 5.16.

Tabela 5.11 - Configurações de dissipadores para o Sistema Estrutural II

\begin{tabular}{|c|c|c|c|c|}
\hline \multirow{2}{*}{ Configuração } & \multirow{2}{*}{$\begin{array}{l}\mathrm{N}^{\circ} \mathrm{de} \\
\text { Placas }\end{array}$} & \multirow{2}{*}{$\begin{array}{l}\text { Ponto de } \\
\text { Aplicação }\end{array}$} & \multicolumn{2}{|c|}{ Rigidez Elástica $(\mathrm{kN} / \mathrm{cm})$} \\
\hline & & & X Shape & Bottle Shape \\
\hline \multirow{3}{*}{$60 / 40$} & 10 & DM\#1 & 26,42 & 29,54 \\
\hline & 7 & DM\#2 & 18,49 & 20,68 \\
\hline & 3 & DM\#3 a DM\#10 & 7,93 & 8,86 \\
\hline \multirow{3}{*}{$70 / 30$} & 12 & DM\#1 & 31,70 & 35,45 \\
\hline & 5 & DM\#2 & 13,21 & 14,77 \\
\hline & 3 & DM\#3 a DM\#10 & 7,93 & 8,86 \\
\hline
\end{tabular}


Quanto às acelerações, o modelo em estudo também foi submetido à excitação sísmica correspondente ao registrado no terremoto El Centro 1940, conforme definições apresentadas no item 5.1.

\subsubsection{Configuração 60/40}

Para a configuração 60/40 avaliou-se os deslocamentos da estrutura equipada com os dissipadores metálicos do tipo Bottle Shape e X Shape para os nós A, E e J e os comparou com a estrutura sem nenhum tipo de controle. Tal escolha de nós se deu de forma que se obtivessem os deslocamentos da estrutura próximo à base (Nó A), mais ao centro (Nó E) e no topo (Nó J). A definição das posições dos nós é apresentada na Figura 5.16.

Como se pode observar na Tabela 5.12, que mostra os dados de maneira resumida, foram comparados os valores de deslocamentos máximos absolutos (|Máx|) e também o valor médio (RMS) dos pontos analisados.

Baseados nos dados obtidos, pode-se afirmar que houve ganho expressivo na redução dos deslocamentos quando se compara a estrutura sem controle com a estrutura equipada com os dissipadores metálicos, com diferenças de valores máximos de deslocamentos entre $21,29 \%$ e $93,68 \%$ e diferenças de valores RMS variando entre $29,64 \%$ e $60,52 \%$.

Tabela 5.12 - Comparação entre deslocamentos para diferentes pontos da estrutura

\begin{tabular}{ccccccc}
\hline \multirow{2}{*}{$\mid$ Máx $\mid$} & Nó & $\begin{array}{c}X \text { Shape } \\
(1)\end{array}$ & $\begin{array}{c}\text { Bottle Shape } \\
(2)\end{array}$ & $\begin{array}{c}\text { Sem Controle } \\
(3)\end{array}$ & $\begin{array}{c}\Delta \%(3) /(1) \\
(4)\end{array}$ & $\begin{array}{c}\Delta \%(3) /(2) \\
(5)\end{array}$ \\
\hline & $\mathrm{A}$ & 0,033 & 0,032 & 0,061 & $84,43 \%$ & $93,68 \%$ \\
\cline { 2 - 7 } & $\mathrm{E}$ & 0,257 & 0,248 & 0,317 & $23,13 \%$ & $27,74 \%$ \\
\cline { 2 - 7 } & $\mathrm{J}$ & 0,450 & 0,430 & 0,546 & $21,29 \%$ & $27,13 \%$ \\
\hline \multirow{3}{*}{ RMS } & $\mathrm{A}$ & 0,015 & 0,014 & 0,022 & $49,63 \%$ & $60,52 \%$ \\
\cline { 2 - 7 } & $\mathrm{E}$ & 0,122 & 0,113 & 0,161 & $31,79 \%$ & $42,51 \%$ \\
\cline { 2 - 7 } & $\mathrm{J}$ & 0,200 & 0,185 & 0,259 & $29,64 \%$ & $40,50 \%$ \\
\hline
\end{tabular}

Observa-se ainda que ambos os dissipadores, $X$ Shape e Bottle Shape, tiverem bom desempenho na redução dos deslocamentos. O histórico de deslocamento para os nós A, E e J são apresentados na Figura 5.18, na Figura 5.19 e na Figura 5.20, respectivamente. 


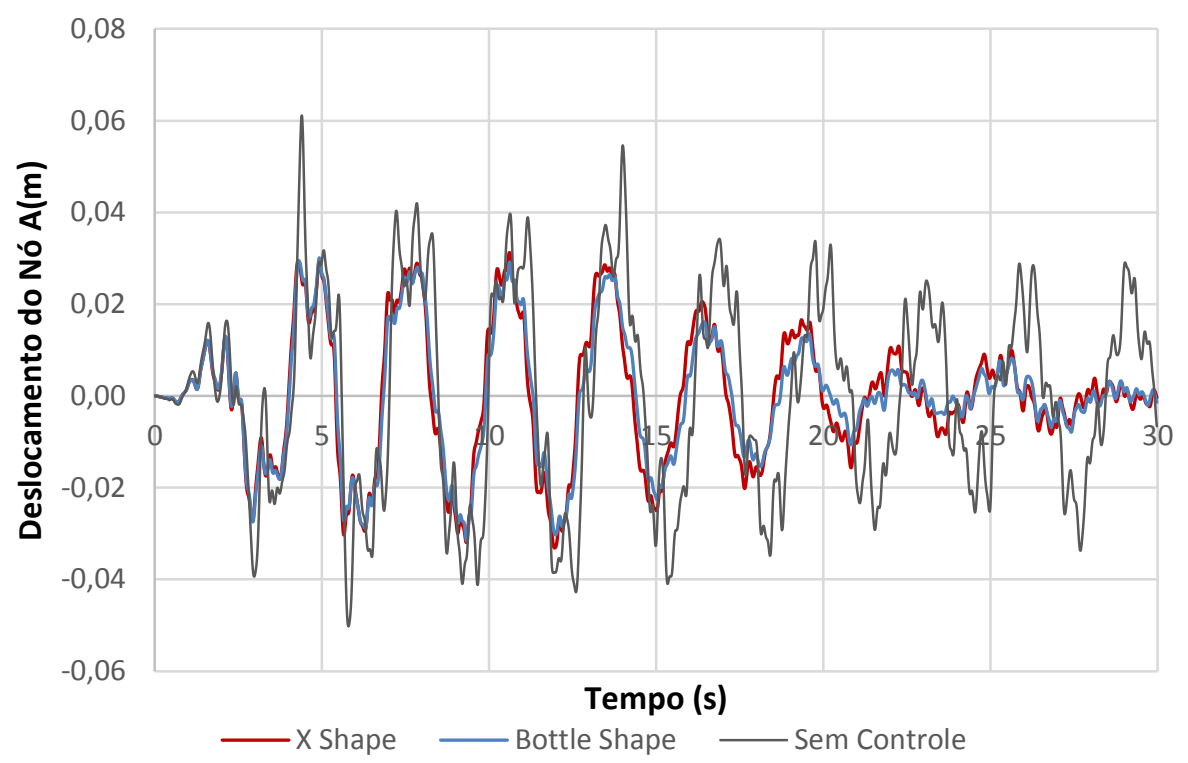

Figura 5.18 - Histórico de deslocamentos do nó A. Unid.: m

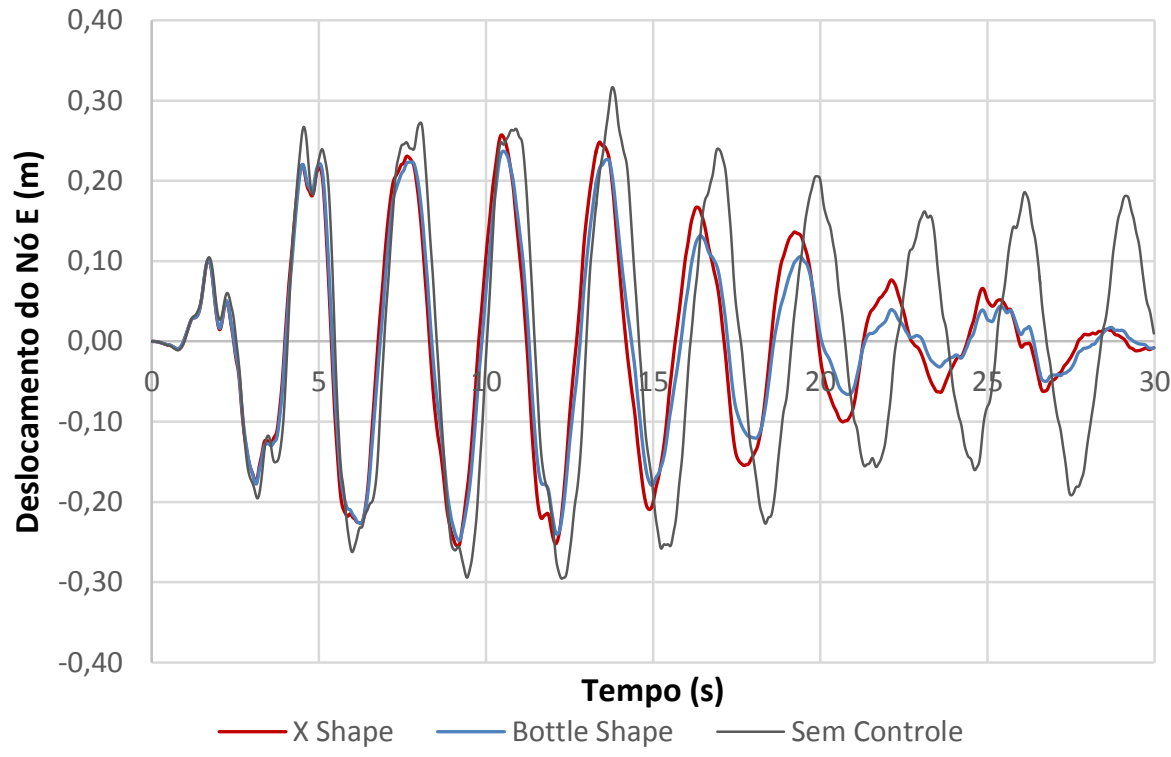

Figura 5.19 - Histórico de deslocamentos do nó B. Unid.: m 


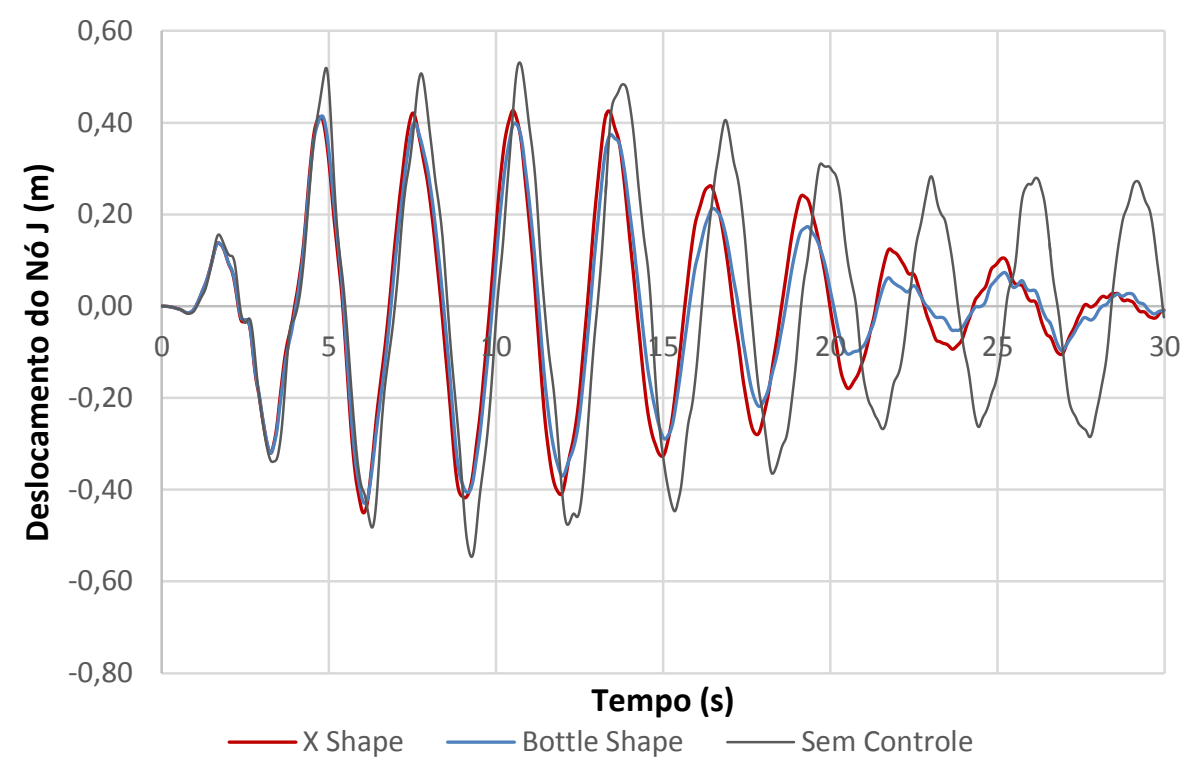

Figura 5.20 - Histórico de deslocamentos do nó C. Unid.: m

De igual modo foram levantados os deslocamentos máximos sofridos pelos dissipadores metálicos instalados ao longo da estrutura. Foram coletados os dados relativos aos descolamentos máximos (|Máx|) e médios (RMS) para os pontos DM\#1, DM\#2, DM\#3, DM\#5 e DM\#10, esses dados são apresentados de forma agrupada na Tabela 5.13.

Tabela 5.13 - Comparação entre deslocamentos (m) sofridos pelos dissipadores para diferentes pontos da estrutura

\begin{tabular}{cccc}
\hline \multirow{2}{*}{ Nó } & $\begin{array}{c}\text { X Shape } \\
(1)\end{array}$ & $\begin{array}{c}\text { Bottle Shape } \\
\text { (2) }\end{array}$ \\
\hline \multirow{3}{*}{$\mid$ Máx $\mid$} & DM\#1 & 0,033 & 0,031 \\
\cline { 2 - 4 } & DM\#2 & 0,052 & 0,050 \\
\cline { 2 - 4 } & DM\#5 & 0,059 & 0,055 \\
\cline { 2 - 4 } & DM\#10 & 0,028 & 0,029 \\
\hline \multirow{3}{*}{ RMS } & DM\#1 & 0,015 & 0,014 \\
\hline & DM\#2 & 0,025 & 0,023 \\
\hline & DM\#5 & 0,025 & 0,023 \\
\hline & DM\#10 & 0,007 & 0,006 \\
\hline
\end{tabular}

Observa-se que ambos os modelos, $X$ Shape e Bottle Shape apresentam comportamento semelhante quando se utiliza os deslocamentos como padrão de comparação, havendo uma diferença de apenas 6,45\% entre deslocamentos máximos e de 7,14\% entre valores médios (RMS) para o dissipador DM\#1, que, conforme Tabela 5.14, foi o mais solicitado. 
Uma vez observados os deslocamentos da estrutura, partiu-se para a análise das solicitações nos dissipadores metálicos \#DM1, \#DM2, \#DM3, \#DM5 e \#DM10, partindo do ponto mais próximo à base até o topo da estrutura analisada. Os dados são apresentados de forma resumida na Tabela 5.14 e de forma detalhada nos gráficos de histerese, para ambos os modelos, na Figura 5.21.

Tabela 5.14 - Comparação entre forças $(\mathrm{kN})$ aplicadas aos dissipadores para diferentes pontos da estrutura.

\begin{tabular}{cccc}
\hline \multirow{2}{*}{ Nó } & $\begin{array}{c}\text { X Shape } \\
(1)\end{array}$ & $\begin{array}{c}\text { Bottle Shape } \\
(2)\end{array}$ \\
\hline \multirow{3}{*}{$\mid$ Máx $\mid$} & DM\#1 & 23,836 & 19,677 \\
\cline { 2 - 4 } & DM\#2 & 21,510 & 17,136 \\
\cline { 2 - 4 } & DM\#5 & 10,079 & 7,814 \\
\cline { 2 - 4 } & DM\#10 & 6,709 & 5,855 \\
\hline \multirow{3}{*}{ RMS } & DM\#1 & 11,320 & 9,831 \\
\hline & DM\#2 & 10,455 & 8,566 \\
\hline & DM\#5 & 4,341 & 3,544 \\
\hline & DM\#10 & 2,492 & 2,273 \\
\hline
\end{tabular}

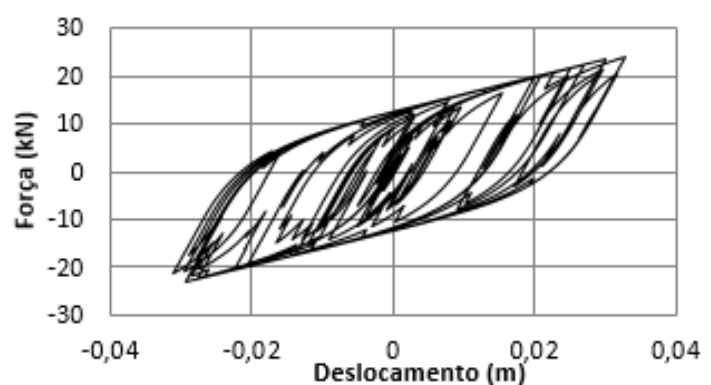

a) DM\#1 do tipo $X$ Shape

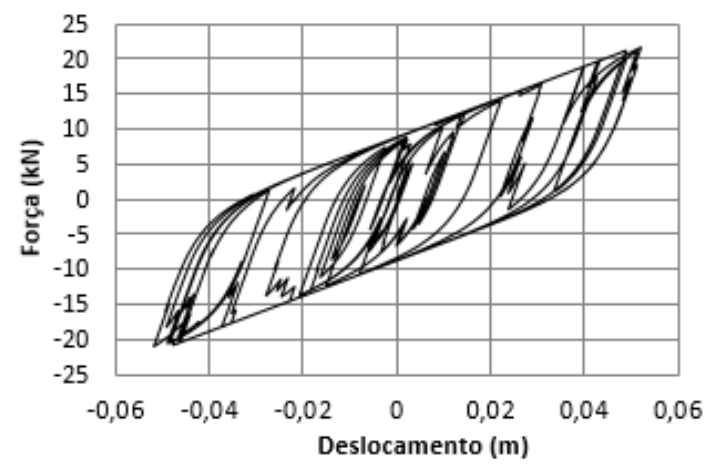

c) DM\#2 do tipo $X$ Shape

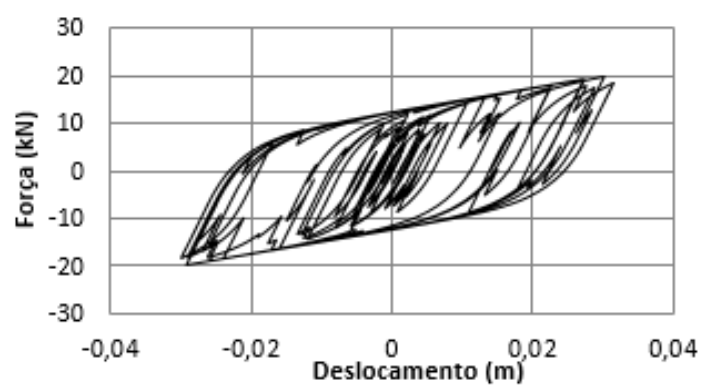

b) DM\#1 do tipo Bottle Shape

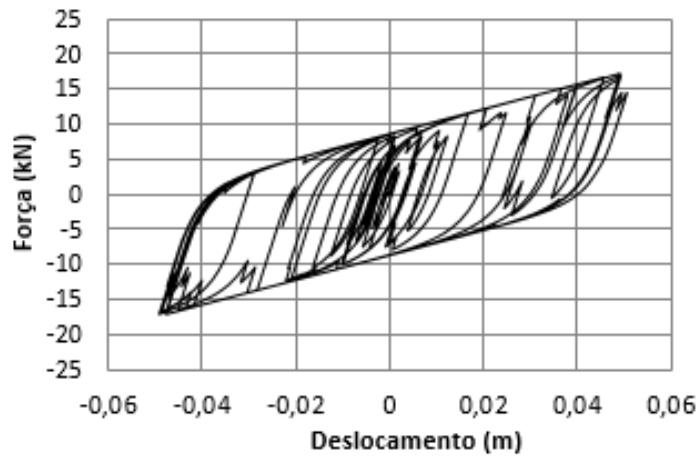

d) DM\#2 do tipo Bottle Shape 


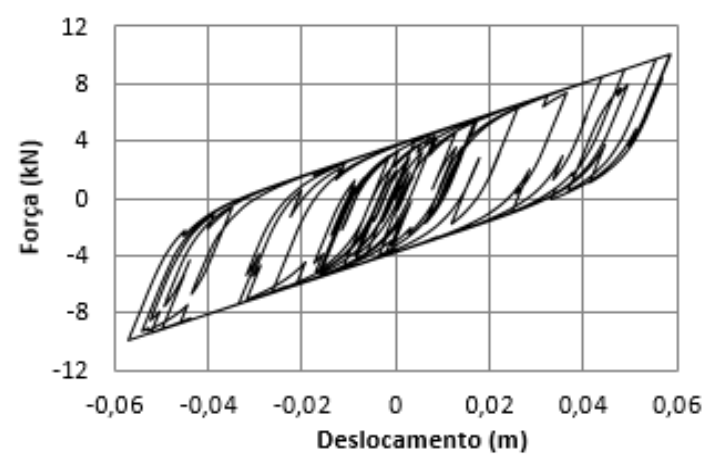

e) DM\#5 do tipo $X$ Shape

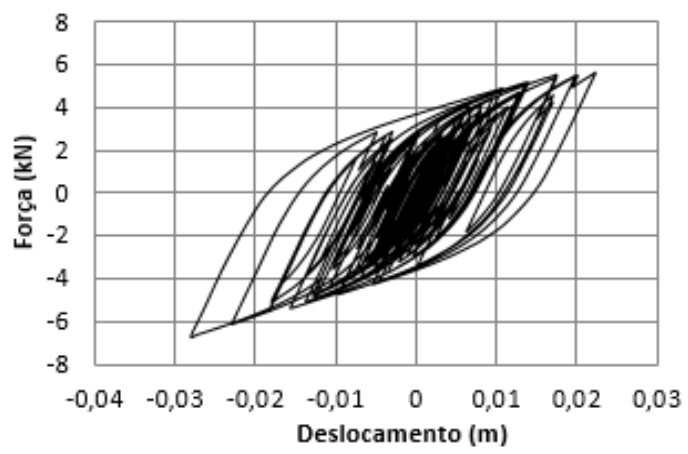

g) DM\#10 do tipo $X$ Shape

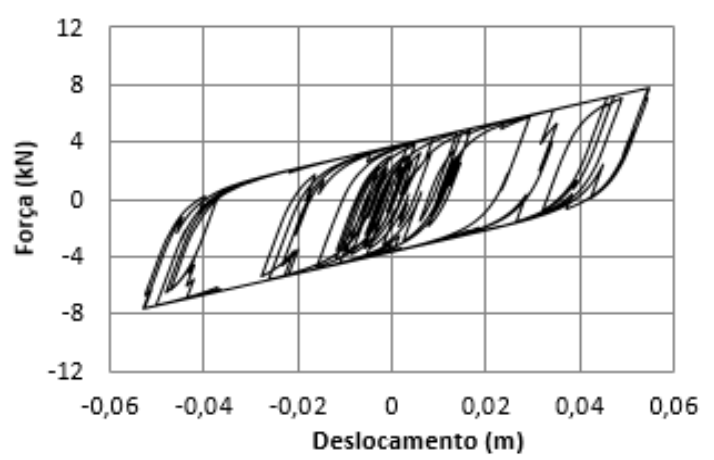

f) DM\#5 do tipo Bottle Shape

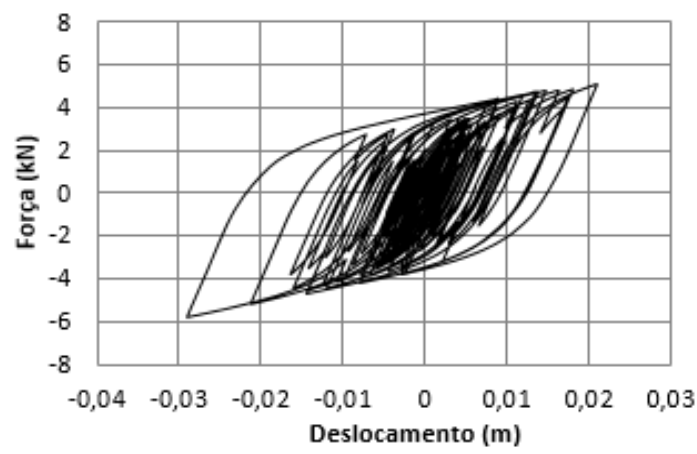

h) DM\#10 do tipo Bottle Shape

Figura 5.21 - Comportamento histerético dos dissipadores metálicos quando a estrutura é submetida à excitação sísmica (configuração 60/40)

Ao analisar as curvas de histerese apresentadas nas figuras, observa-se que o formato das mesmas é bastante semelhante. Uma análise aponta que as forças absolutas máximas absorvidas pelos dissipadores metálicos do tipo Bottle Shape são inferiores às absorvidas pelos dispositivos do tipo $X$ Shape. Observa-se mais uma vez que, conforme esperado, os dissipadores metálicos localizados na parte inferior do pórtico são os mais solicitados, necessitando, portanto, de maior rigidez, fato que justifica a adoção de um maior número de dissipadores metálicos na estrutura à medida que a mesma se aproxima da base.

\subsubsection{Configuração 70/30}

Para a configuração 70/30 avaliou-se novamente os deslocamentos da estrutura equipada com os dissipadores metálicos do tipo Bottle Shape e $X$ Shape para os nós A, E e J e os comparou com a estrutura sem nenhum tipo de controle. Tal escolha de nós mais uma vez se deu de forma que se obtivesse os deslocamentos da estrutura próximo à 
base (Nó A), mais ao centro (Nó E) e no topo (Nó J). A definição das posições dos nós é apresentada na Figura 5.16.

Como se pode observar na Tabela 5.15, que mostra os dados de maneira resumida, na Figura 5.18, na Figura 5.19 e na Figura 5.20, houve expressivo ganho na redução dos descolamentos quando se compara a estrutura sem controle com a equipada com os dissipadores metálicos.

Tabela 5.15 - Comparação entre deslocamentos para diferentes pontos da estrutura

\begin{tabular}{ccccccc}
\hline \multirow{2}{*}{$\mid$ Náx } & Nó & $\begin{array}{c}X \text { Shape } \\
(1)\end{array}$ & $\begin{array}{c}\text { Bottle Shape } \\
(2)\end{array}$ & $\begin{array}{c}\text { Sem Controle } \\
(3)\end{array}$ & $\begin{array}{c}\Delta \%(3) /(1) \\
(4)\end{array}$ & $\begin{array}{c}\Delta \%(3) /(2) \\
(5)\end{array}$ \\
\hline & $\mathrm{A}$ & 0,028 & 0,031 & 0,061 & $117,30 \%$ & $95,47 \%$ \\
\cline { 2 - 7 } & $\mathrm{E}$ & 0,209 & 0,252 & 0,317 & $51,34 \%$ & $25,47 \%$ \\
\cline { 2 - 7 } & $\mathrm{J}$ & 0,479 & 0,431 & 0,546 & $14,13 \%$ & $26,83 \%$ \\
\hline \multirow{3}{*}{$\mathrm{RMS}$} & $\mathrm{A}$ & 0,009 & 0,014 & 0,022 & $137,57 \%$ & $61,36 \%$ \\
\cline { 2 - 7 } & $\mathrm{E}$ & 0,086 & 0,115 & 0,161 & $85,69 \%$ & $40,02 \%$ \\
\cline { 2 - 7 } & $\mathrm{J}$ & 0,171 & 0,187 & 0,259 & $51,38 \%$ & $38,40 \%$ \\
\hline
\end{tabular}

Os dados demonstram que, ao comparar os deslocamentos da estrutura sem controle com a equipada com os dissipadores, houve diferença de valores máximos de deslocamentos entre $14,13 \%$ e $117,30 \%$ e diferenças de valores RMS variando entre $38,40 \%$ e 137,57\%. Esses valores, comparados aos apresentados aos da Tabela 5.12 demonstram que de forma geral a configuração 70/30 apresentou melhores resultados, pois com um mesmo número de dissipadores, porém em posições distintas, foram observados menores deslocamentos. Uma comparação mais detalhada dessa mudança de posição dos dissipadores é apresentada no item 5.3.3.

Ambos os dissipadores, $X$ Shape e Bottle Shape, tiverem bom desempenho na redução dos deslocamentos. O histórico de deslocamento para os nós A, E e J são apresentados na Figura 5.22, na Figura 5.23 e na Figura 5.24, respectivamente. 


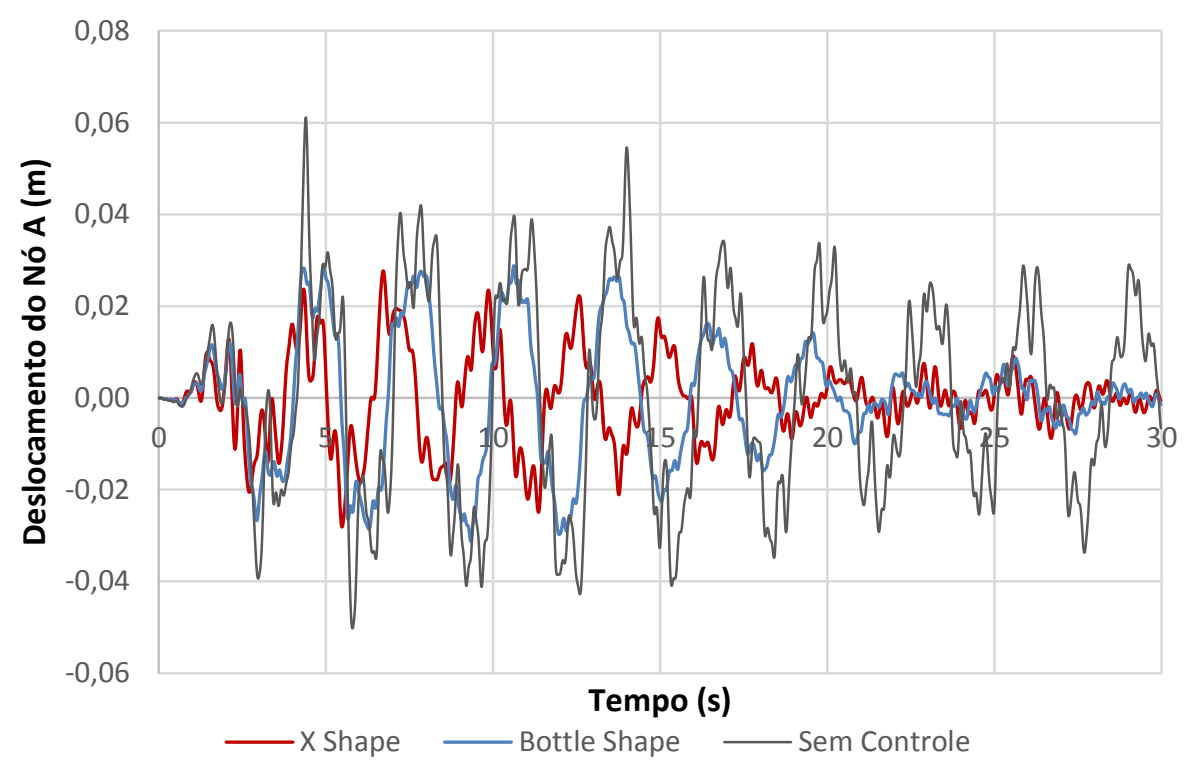

Figura 5.22 - Histórico de deslocamentos do nó A.

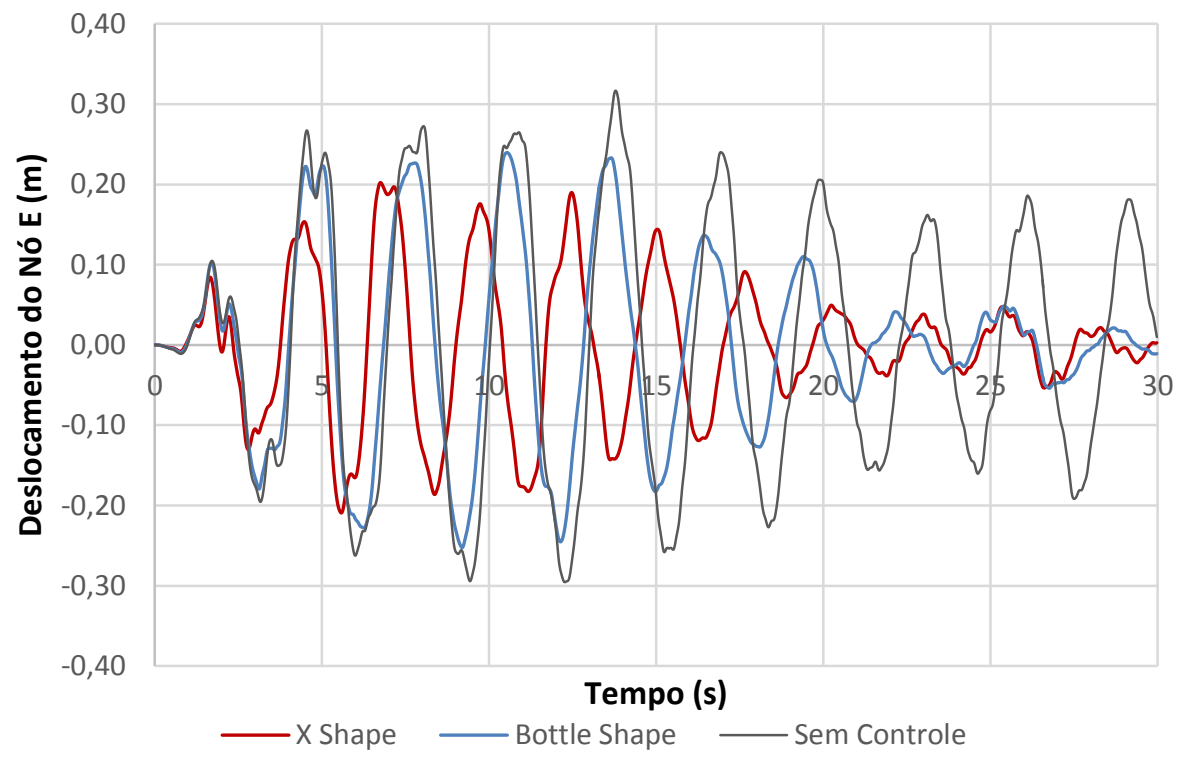

Figura 5.23 - Histórico de deslocamentos do nó E. 


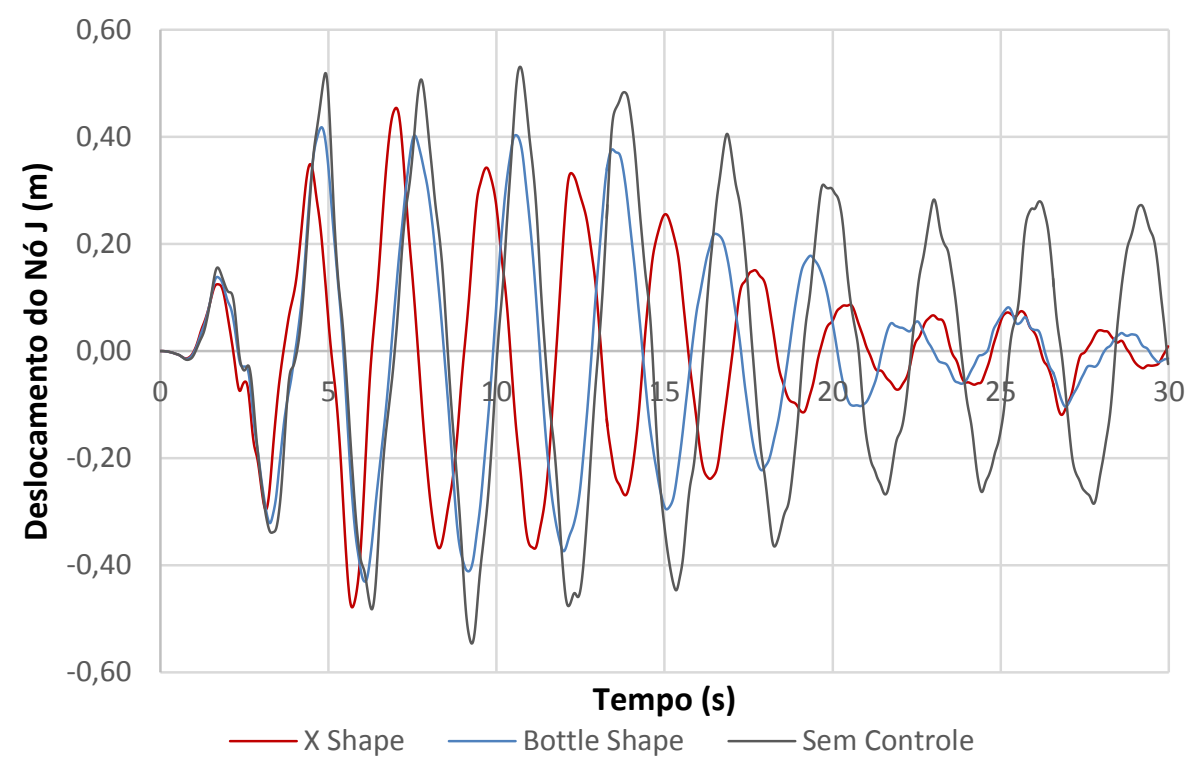

Figura 5.24 - Histórico de deslocamentos do nó J.

Mais uma vez foram levantados os deslocamentos sofridos pelos dissipadores metálicos instalados ao longo da estrutura. Foram coletados os dados relativos aos descolamentos máximos (|Máx|) e médios (RMS) para os pontos DM\#1, DM\#2, DM\#3, DM\#5 e DM\#10, esses dados são apresentados de forma agrupada na Tabela 5.16.

Tabela 5.16 - Comparação entre deslocamentos (m) sofridos pelos dissipadores para diferentes pontos da estrutura

\begin{tabular}{cccc}
\hline \multirow{2}{*}{ Nó } & $\begin{array}{c}\text { X Shape } \\
(1)\end{array}$ & $\begin{array}{c}\text { Bottle Shape } \\
(2)\end{array}$ \\
\hline \multirow{3}{*}{$\mid$ Máx $\mid$} & DM\#1 & 0,028 & 0,031 \\
\cline { 2 - 4 } & DM\#2 & 0,055 & 0,052 \\
\cline { 2 - 4 } & DM\#5 & 0,069 & 0,055 \\
\cline { 2 - 4 } & DM\#10 & 0,031 & 0,029 \\
\hline \multirow{3}{*}{ RMS } & DM\#1 & 0,009 & 0,013 \\
\hline & DM\#2 & 0,026 & 0,024 \\
\hline & DM\#5 & 0,026 & 0,023 \\
\cline { 2 - 4 } & DM\#10 & 0,008 & 0,006 \\
\hline
\end{tabular}

Os dados demonstram pequena variação entre os modelos, demonstrando, mais uma vez, que ambos os dispositivos apresentam bom desempenho.

Nessa configuração os dissipadores DM\#1 responderam por maiores valores de carregamento, especialmente quando se trata de comparar os carregamentos máximos absolutos aplicados aos dissipadores. Tais comparações são apresentadas de forma resumida na Tabela 5.17. 
Tabela 5.17 - Comparação entre forças $(\mathrm{kN})$ aplicadas aos dissipadores para diferentes pontos da estrutura

\begin{tabular}{cccc}
\hline \multirow{2}{*}{ Nó } & $\begin{array}{c}\text { X Shape } \\
(1)\end{array}$ & $\begin{array}{c}\text { Bottle Shape } \\
(2)\end{array}$ \\
\hline \multirow{3}{*}{$\mid$ Máx $\mid$} & DM\#1 & 26,838 & 23,493 \\
\cline { 2 - 4 } & DM\#2 & 15,957 & 12,435 \\
\cline { 2 - 4 } & DM\#5 & 11,192 & 7,817 \\
\cline { 2 - 4 } & DM\#10 & 7,094 & 5,858 \\
\hline \multirow{3}{*}{ RMS } & DM\#1 & 10,728 & 11,776 \\
\hline & DM\#2 & 7,685 & 6,244 \\
\hline & DM\#5 & 4,467 & 3,573 \\
\hline & DM\#10 & 2,678 & 2,250 \\
\hline
\end{tabular}

Os detalhes da atuação dessas forças relacionadas aos seus respectivos deslocamentos, são apresentados nos gráficos de histerese da Figura 5.25.

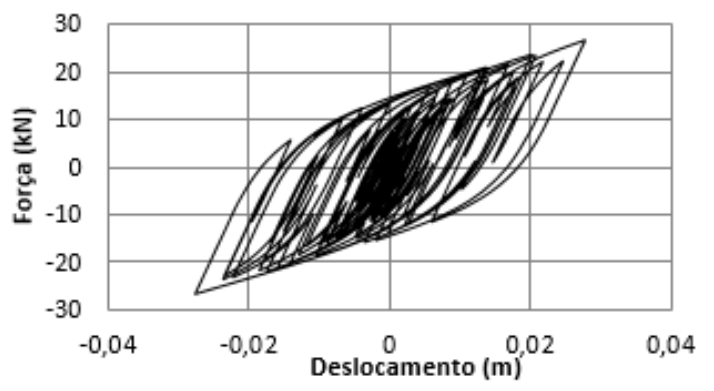

a) DM\#1 do tipo $X$ Shape

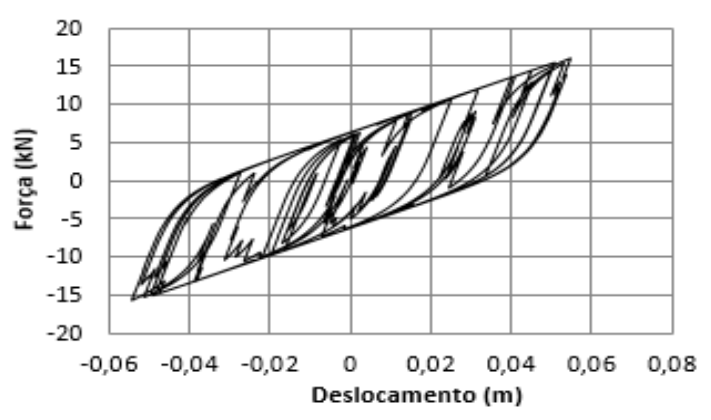

c) DM\#2 do tipo $X$ Shape

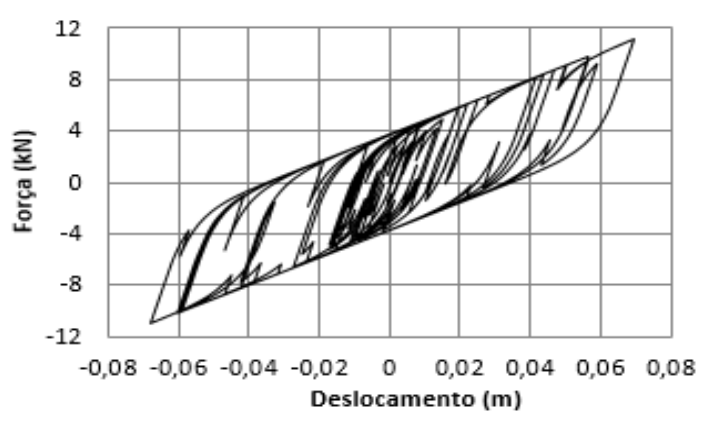

e) DM\#5 do tipo $X$ Shape

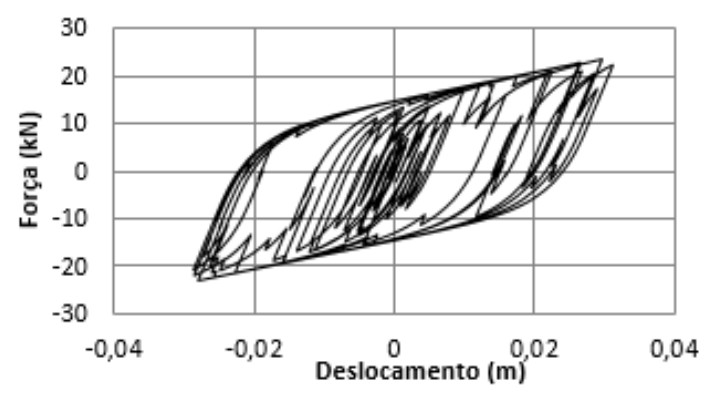

b) DM\#1 do tipo Bottle Shape

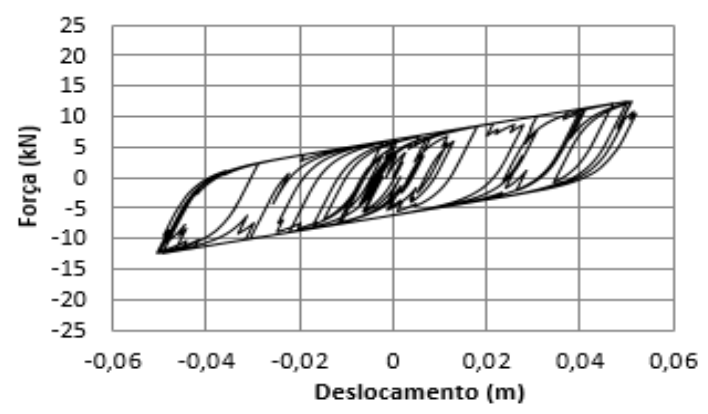

d) DM\#2 do tipo Bottle Shape

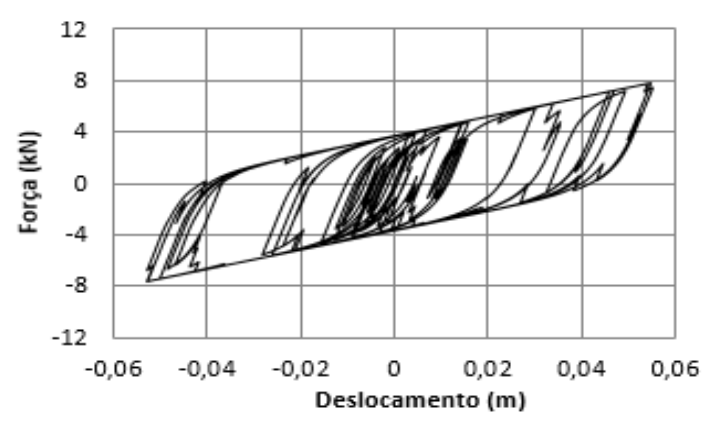

f) DM\#5 do tipo Bottle Shape 


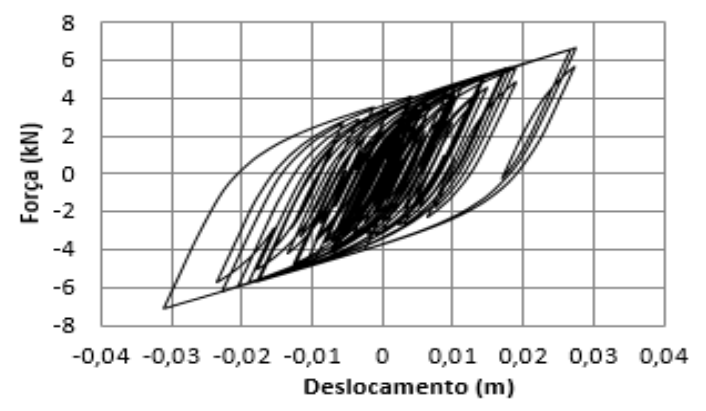

g) DM\#10 do tipo $X$ Shape

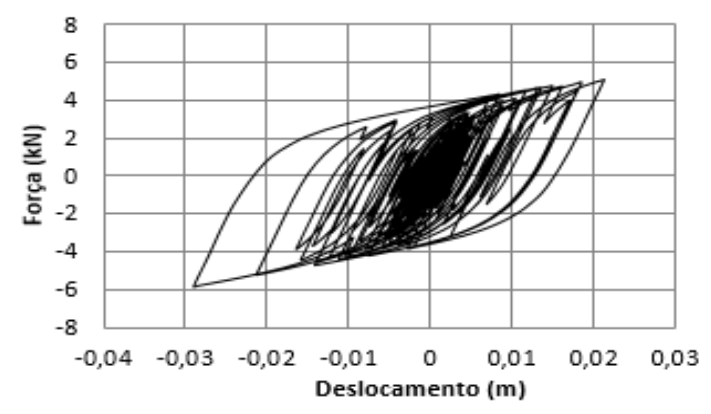

h) DM\#10 do tipo Bottle Shape

Figura 5.25 - Comportamento histerético dos dissipadores metálicos quando a estrutura é submetida à excitação sísmica (configuração 70/30)

Ao analisar os diagramas de histerese dos dissipadores $X$ Shape e Bottle Shape instalados ao longo da estrutura, constata-se que os modelos apresentam desempenho semelhante, com ciclos de histerese bem definidos e bem parecidos, demonstrando similaridade quanto ao comportamento das duas peças. Repara-se ainda que em ambas as peças, para os diferentes pontos analisadas, a dissipação não se dá como deveria, uma vez que os ciclos de histerese não estão plenamente desenvolvidos. Tal situação indica que a distribuição dos dissipadores não é completamente satisfatória, pois não extrai a máxima capacidade de dissipação dos dispositivos histeréticos.

Essa análise indica a necessidade de uma investigação mais aprofundada quanto ao valor ótimo do número e das posições desses dissipadores, análise essa que extrapola os objetivos desse trabalho, mas que cabe uma verificação ainda que simplificada.

\subsubsection{Influência da posição dos dissipadores}

Na realização das análises do Sistema Estrutural II, conforme descrito no item 0, foram adotadas duas configurações distintas denominadas 60/40 e 70/30 que consideram a mudança das posições dos dissipadores. Durante a avaliação dos resultados para essas duas configurações observou-se que, apesar de ambas se valerem do mesmo número de placas metálicas para o sistema estrutural, elas apresentaram considerável diferença de resultados devido à mudança de posições dessas placas.

Nesse sentido, buscou-se realizar uma comparação para essas duas configurações distintas, não objetivando confrontar o desempenho entre dissipadores, mas a influência das posições das placas metálicas para um mesmo dispositivo. 
Devido à sua ampla aceitação já consagrada no mercado, optou-se por realizar as análises com dispositivos do tipo $X$ Shape, comparando-se para nós A, E e J, os deslocamentos da estrutura para as duas configurações analisadas (60/40 e 70/30). Os dados são apresentados na Tabela 5.18 .

Tabela 5.18 - Comparação entre deslocamentos apresentados pela estrutura com a variação das posições dos dissipadores

\begin{tabular}{|c|c|c|c|c|}
\hline & Nó & Configuração & Deslocamento $(\mathrm{m})$ & $\Delta_{\text {maior/menor }}$ \\
\hline \multirow{6}{*}{ |Máx| } & \multirow{2}{*}{ A } & $60 / 40$ & 0.450 & \multirow{2}{*}{$6.277 \%$} \\
\hline & & $70 / 30$ & 0.479 & \\
\hline & \multirow{2}{*}{$\mathrm{E}$} & $60 / 40$ & 0.257 & \multirow{2}{*}{$22.907 \%$} \\
\hline & & $70 / 30$ & 0.209 & \\
\hline & \multirow{2}{*}{$\mathrm{J}$} & $60 / 40$ & 0.033 & \multirow{2}{*}{$17.821 \%$} \\
\hline & & $70 / 30$ & 0.028 & \\
\hline \multirow{6}{*}{ RMS } & \multirow{2}{*}{ A } & $60 / 40$ & 0.200 & \multirow{2}{*}{$16.769 \%$} \\
\hline & & $70 / 30$ & 0.171 & \\
\hline & \multirow{2}{*}{$\mathrm{E}$} & $60 / 40$ & 0.122 & \multirow{2}{*}{$40.900 \%$} \\
\hline & & $70 / 30$ & 0.086 & \\
\hline & \multirow{2}{*}{$\mathrm{J}$} & $60 / 40$ & 0.015 & \multirow{2}{*}{$58.769 \%$} \\
\hline & & $70 / 30$ & 0.009 & \\
\hline
\end{tabular}

Os dados demonstram que a configuração 70/30, apesar de utilizar no sistema estrutural o mesmo número de placas dissipadoras da configuração 60/40, apresentou melhores resultados de deslocamentos máximos absolutos na maioria dos pontos analisados e melhores resultados de valores médios (RMS) de deslocamentos em todas as análises.

Uma análise da variação entre o maior e menor deslocamento para um mesmo nó, apresenta valores que ficam entre $6.277 \%$ e $22.907 \%$, sendo que a configuração 60/40 apresentou maiores valores de deslocamentos máximo absolutos para os nós E e J, e maiores valores de RMS para todos os nós analisados.

O histórico de deslocamentos para os nós A, E e J são apresentados respectivamente na Figura 5.26, Figura 5.27 e Figura 5.28. 


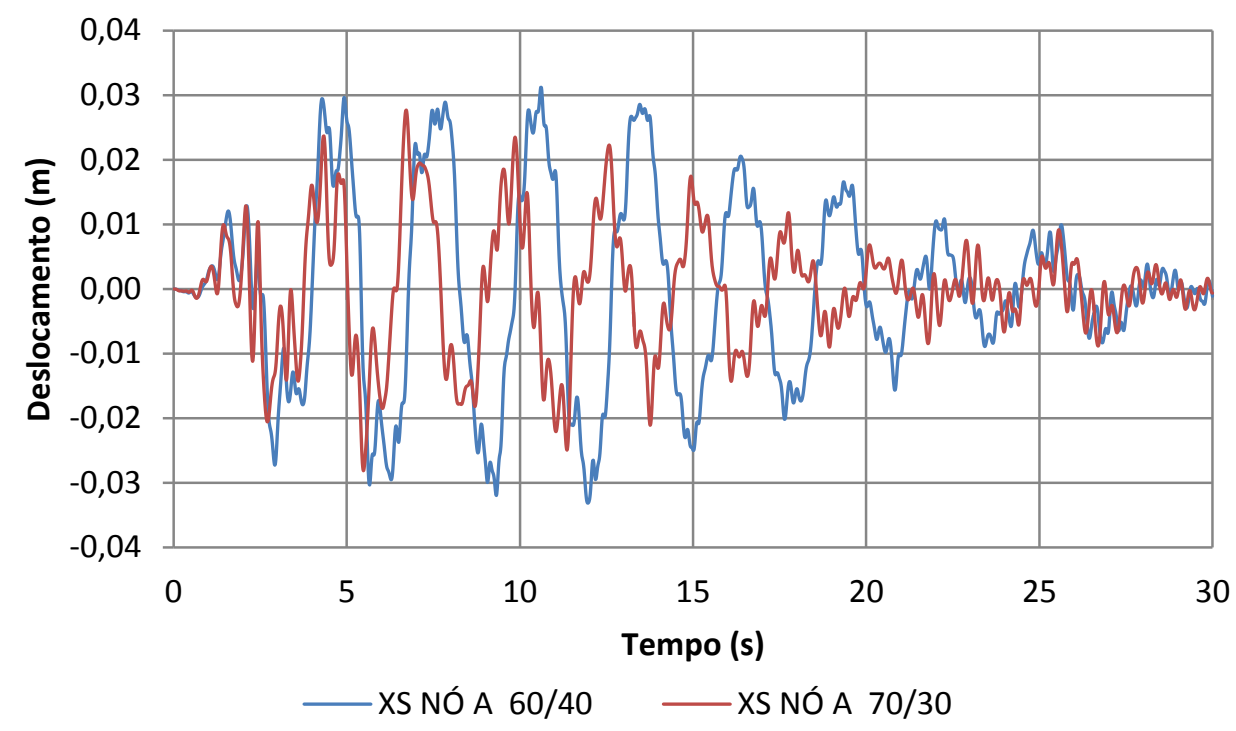

Figura 5.26 - Comparação entre deslocamentos apresentados pelo nó A com a variação das posições dos dissipadores

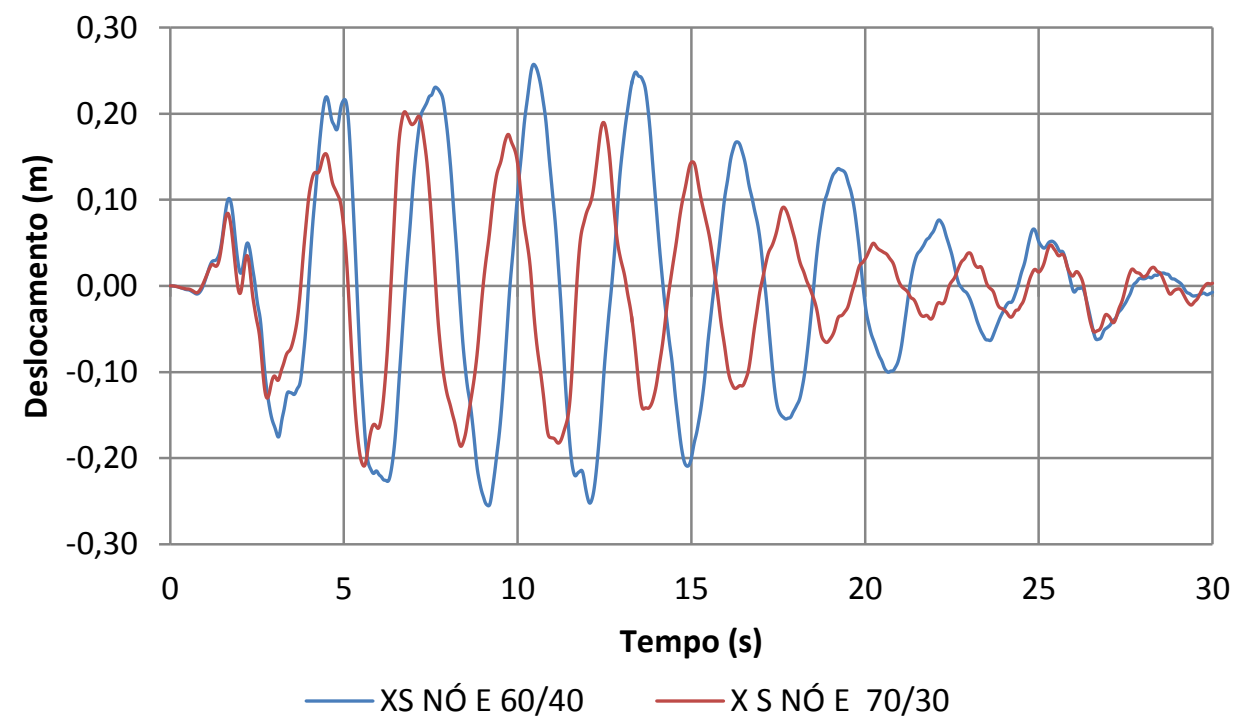

Figura 5.27 - Comparação entre deslocamentos apresentados pelo nó E com a variação das posições dos dissipadores 


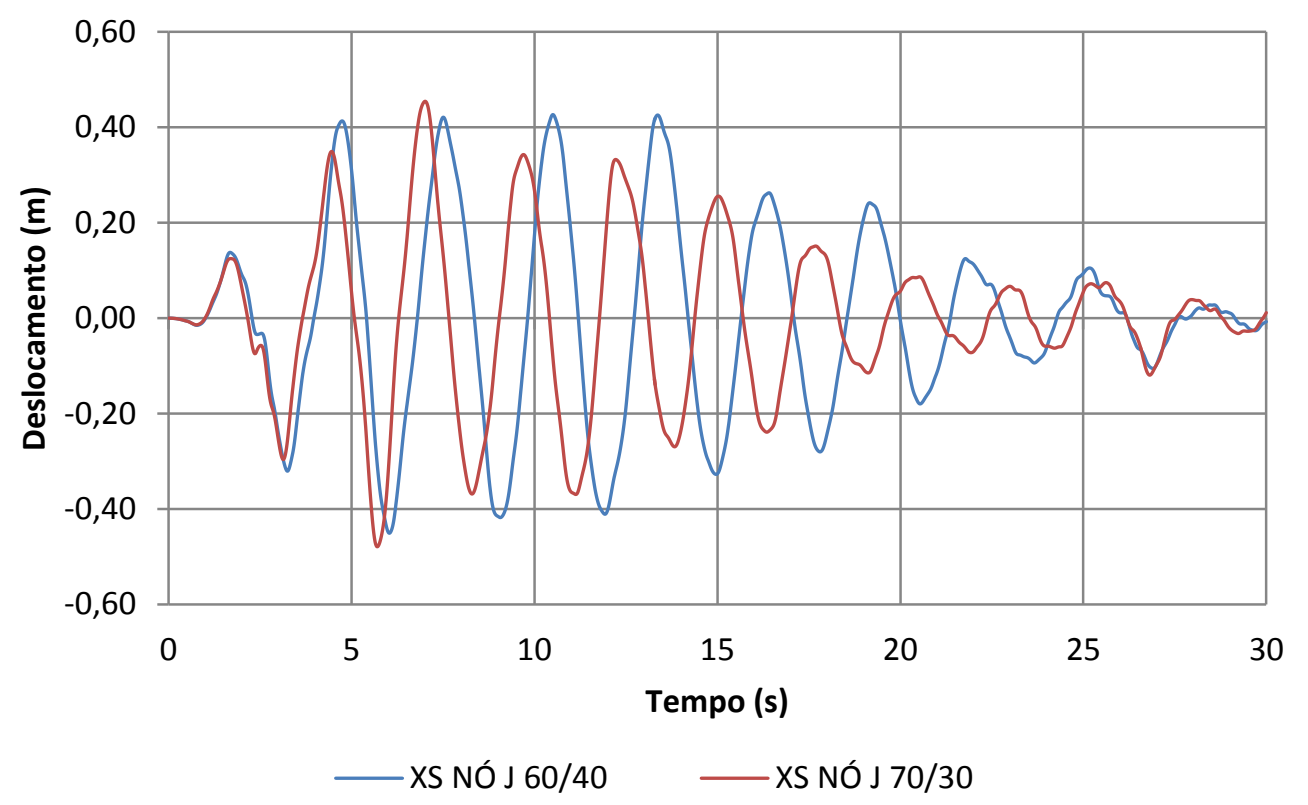

Figura 5.28 - Comparação entre deslocamentos apresentados pelo nó J com a variação das posições dos dissipadores

Acredita-se que como a configuração $70 / 30$ cria uma rigidez mais elevada próxima à base da estrutura, que por sua vez está mais próxima e sujeita à ação do sismo, implicando de certa forma, numa maior isolação da base da estrutura em relação ao sistema principal.

Cabe considerar que tais conclusões são embasadas em uma análise simples, que não leva em consideração o número ótimo de dissipadores necessários à essa estrutura, ou a posição ótima de instalação de cada um deles. Observa-se que, apesar da análise otimizada quanto ao número ou as posições dos dissipadores não ser objetivo desse trabalho, pode-se concluir que essas duas variáveis exercem grande influência sobre o desempenho do sistema estrutural, tendo em vista que é grande a diferença entre os deslocamentos analisados ao se alterar as posições dos dissipadores. 


\section{CONFIABILIDADE ESTRUTURAL}

A confiabilidade estrutural é uma ferramenta que permite ao engenheiro considerar as incertezas nas variáveis de seu projeto através das distribuições reais de probabilidade das mesmas e obter, entre outros resultados, a probabilidade de falha da estrutura. Esta informação pode ser de fundamental importância na tomada de decisões que envolvam a segurança da estrutura. Existem várias aplicações práticas da confiabilidade estrutural e entre elas podemos citar: calibrações de normas de projeto, reanálise de estruturas existentes, revisão de planos de inspeções, avaliação de segurança de novas concepções estruturais e na escolha de alternativas de projeto (Sagrilo \& Lima, 2002).

As estruturas existentes apresentam desgastes devido ao uso, tais como: acidentes, corrosão, trincas, etc. Por outro lado, devido à redundância estrutural e certas circunstâncias de projeto, a falha (ou o desgaste) de um elemento não significa a falha da estrutura como um todo. Usando confiabilidade é possível avaliar a segurança global da estrutura como um todo e com isto então, somente tomar algumas decisões emergenciais quando o nível da probabilidade de falha for menor que um determinado nível (Sagrilo \& Lima, 2002).

Obter a probabilidade de falha de sistemas estruturais levando-se em consideração as incertezas é o objetivo principal dos métodos de análise de confiabilidade. Pode-se entender como falha o não atendimento da estrutura aos objetivos para os quais ela foi concebida. Uma vez que um cenário de falha ocorre, prejuízos tanto da ordem material como de segurança podem acontecer. Uma vez que sempre existe o risco de falha, um controle para mantê-lo dentro de um nível aceitável, de acordo com critérios de segurança e economia, é imprescindível (Pantoja, 2012).

A confiabilidade de um sistema estrutural pode ser entendida como a probabilidade desse sistema não falhar quando o mesmo estiver desempenhando os objetivos do seu dimensionamento, logo a confiabilidade é dada pelo complemento da probabilidade de falha.

$$
C=1-P_{f}
$$

Sendo $C$ a confiabilidade e $P_{f}$ a probabilidade de falha do sistema estrutural. A falha é definida como a incapacidade do sistema funcionar conforme foi projetado. 
De maneira geral, a confiabilidade estrutural pode ser expressa quantitativamente por:

$$
P_{f}=\int_{\Omega_{F}} p_{x}(x) d x
$$

Sendo $\Omega_{F}$ o domínio de falha caracterizado pela região em que a equação de estado limite apresenta valores menores que zero e $p_{x}(x)$ a função de densidade de probabilidade de ligação da variável aleatória básica $x$. Os conceitos de probabilidade e funções de probabilidade são definidos nos item 6.3.

\subsection{PROBABILIDADE E FUNÇÕES DE PROBABILIDADE}

Se vários experimentos de um determinado fenômeno são exatamente iguais, o fenômeno é chamado determinístico. Por outro lado, se estes experimentos não forem idênticos o fenômeno é chamado de aleatório ou randômico. No último caso, a cada experimento está associado um número real de probabilidade de ocorrência de um determinado evento relacionado ao fenômeno em observação. Intuitivamente pode-se avaliar que: (a) a probabilidade está relacionada com a frequência de ocorrência do evento ao longo de uma sequência grande de experimentos; (b) ela deve estar situada entre 0 e 1 e (c) a soma da probabilidade de todos os possíveis resultados do fenômeno deve ser igual a 1 (Sagrilo \& Lima, 2002).

Segundo Yoriyaz (2010), uma variável aleatória $(x)$ tem uma distribuição discreta se ela assumir apenas valores distintos $x_{1}, x_{2}, \ldots$, cujo conjunto pode ser finito ou infinito. Uma variável aleatória $(x)$ tem uma distribuição contínua se ela pode assumir qualquer valor entre os limites $x_{1}$ e $x_{2}$ e a probabilidade desta variável estar neste intervalo, $P\left(x_{1}<x<x_{2}\right)$ é dada pela seguinte integral:

$$
P\left(x_{1}<x<x_{2}\right)=\int_{x_{1}}^{x_{2}} p_{x}(x) d x
$$

A função $p_{x}(x)$ é chamada de função densidade de probabilidade de $x$, tal que:

- A função densidade de probabilidade descreve um processo físico; 
- A simulação é feita pela amostragem dessas funções a partir da utilização de números aleatórios;

- Obtêm-se valores médios e respectivos desvios padrões após várias simulações.

A função $p_{x}(x)$ é normalizada, tal que:

$$
\int_{-\infty}^{+\infty} p_{x}(x) d x=1,00
$$

A Equação 6.4 significa que a probabilidade de ocorrer o fenômeno no intervalo que a função densidade de probabilidade está definida é igual a 1,00.

Para uma função de distribuição acumulada, considera-se uma variável aleatória associada a um evento $(E)$. Podemos definir a função a Função Distribuição Acumulativa, $F(x)$, como sendo a probabilidade que $x$ assuma um valor que é menor ou igual a $E$, tal que, $F(x)=P(x<E)$.

A Tabela 6.1, extraída de Kalos (1986), apresenta algumas funções de distribuição contínua de probabilidade.

Tabela 6.1 - Algumas funções de distribuição contínua de probabilidade. Fonte: Kalos (1986)

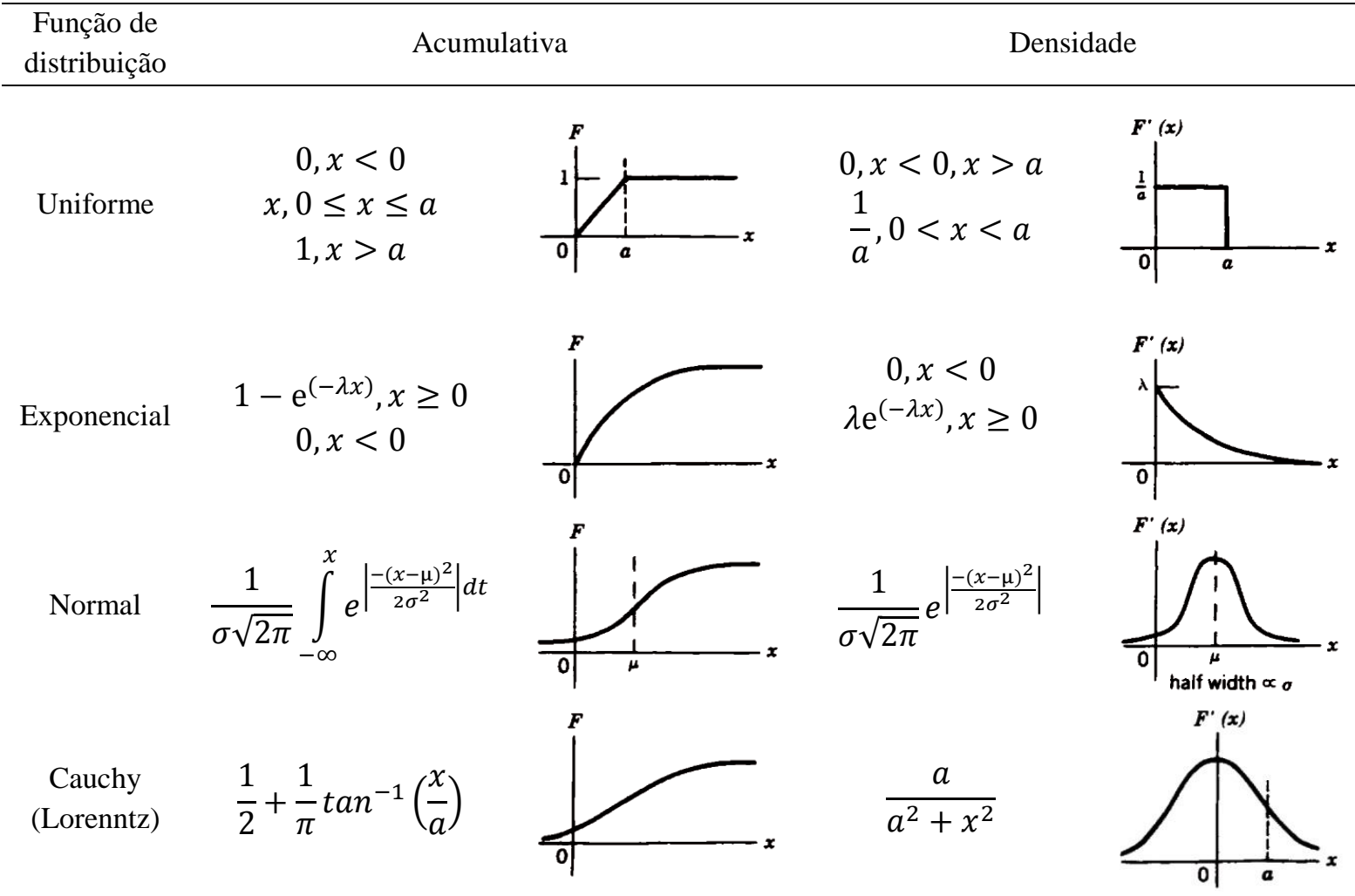




\section{2 ÍNDICE DE CONFIABILIDADE}

O problema básico de análise de confiabilidade é definido a partir de um sistema de duas variáveis $(R, S)$ descritas pelas suas distribuições de probabilidade e parâmetros estatísticos. Considerando a Equação 6.5 a probabilidade de falha pode ser definida como a probabilidade de ocorrência de uma ação $S$ superior a uma resistência $R$, conforme as expressões:

$$
\begin{gathered}
P_{f}=P(R \leq S) \\
P_{f}=P(R-S \leq 0)
\end{gathered}
$$

Outro modo de se definir a probabilidade de violação do estado limite se dá a partir da função de falha $G(R, S)$ :

$$
P_{f}=P[G(R, S) \leq 0]
$$

A função de densidade conjunta $f_{R S}(R, S)$ pode ser definida de forma semelhante ao tratamento dado às funções de densidade de probabilidade com somente uma variável aleatória:

$$
P_{f}=P(R-S \leq 0)=\int_{\Omega_{F}} f_{R S}(R, S) d R d S
$$

Uma vez que as variáveis $R$ e $S$ são variáveis não correlacionadas a função de densidade conjunta $f_{R S}(R, S)$ pode ser escrita na seguinte forma:

$$
P_{f}=P(R-S \leq 0)=\int_{-\infty}^{\infty} \int_{-\infty}^{S} f_{R}(R) f_{S}(S) d R d S
$$

O problema básico de confiabilidade estrutural é resolvido a partir da definição da margem de segurança representada por uma variável normal $Z$ (Souza, 2011), obtida pela expressão:

$$
Z=R-S
$$

Sendo $Z$ uma variável normal de valor esperado (média) $E(Z)$ e variância $E\left[\left(z-\mu_{z}\right)^{2}\right]$, obtida a partir de $R$ e $S$. 
A Figura 6.1 mostra a função densidade de probabilidade da margem de segurança onde são relacionados o índice de confiabilidade $\beta$ e a probabilidade de falha $P_{f}$. Com base na análise da figura, observa-se que um aumento de $\beta$ provoca o deslocamento do gráfico da distribuição de probabilidade para a direita, reduzindo assim a área da probabilidade de falha que se encontra hachurada.

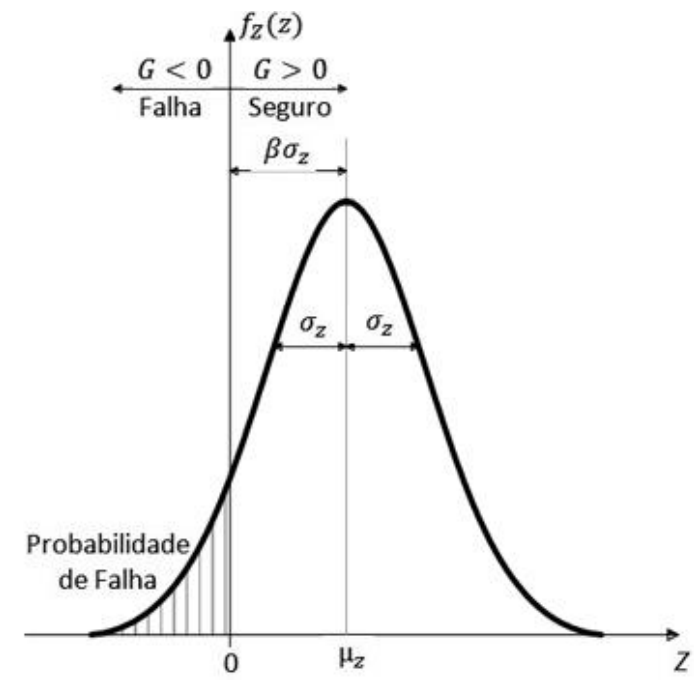

Figura 6.1 - Distribuição da margem de segurança. Melchers (1987)

Ainda na Figura 6.1 pode se observar que:

$$
\begin{gathered}
\mu_{Z}-\beta \sigma_{Z}=0 \\
\beta=\frac{\mu_{Z}}{\sigma_{Z}} \\
\beta=\frac{\mu_{R}-\mu_{S}}{\sqrt{\sigma_{R}^{2}-\sigma_{S}^{2}}}
\end{gathered}
$$

Para a função de distribuição normal de $\mathrm{Z}$ é possível criar uma variável auxiliar reduzida, dessa forma tem se:

$$
\begin{gathered}
f_{z}(z)=\frac{1}{\sigma \sqrt{2 \pi}} e^{\left[\frac{-\left(z-\mu_{z}\right)^{2}}{2 \sigma^{2}}\right]} \\
y=\frac{z-\mu_{z}}{\sigma_{z}}
\end{gathered}
$$

Substituindo a variável auxiliar reduzida na Equação 6.14 obtém-se a função densidade normal padrão de probabilidade, cuja média e desvio padrão são 0 e 1, respectivamente.

$$
f_{y}(y)=\phi(y)=\frac{1}{\sqrt{2 \pi}} e^{\left[-\frac{1}{2} y^{2}\right]}
$$


A função distribuição cumulativa normal padrão $\Phi(y)$ é calculada por:

$$
\Phi(y)=\int_{-\infty}^{y} f_{y}(y) d y
$$

$\log 0$

$$
P_{f}=P(R-S \leq 0)=P(Z \leq 0)=\Phi(y)=\int_{-\infty}^{y} f_{y}(y) d y
$$

No ponto onde $\mathrm{Z}=0$, limite entre o domínio de segurança e o domínio de falha, tem-se:

$$
y=\frac{0-\mu_{z}}{\sigma_{z}}=\frac{-\mu_{z}}{\sigma_{z}}=-\beta
$$

No espaço normalizado, a medida da probabilidade de falha corresponde à distância entre a origem da distribuição y normalizada e a região de falha, denominada índice de confiabilidade $\beta$. Dessa forma, a expressão para cálculo da probabilidade de falha fica:

$$
P_{f}=\int_{-\infty}^{-\beta} f_{y}(y) d y=\Phi\left(\frac{-\mu_{z}}{\sigma_{z}}\right)=\Phi(-\beta)
$$

A Figura 6.2 mostra a relação entre o índice de confiabilidade e a probabilidade de falha.

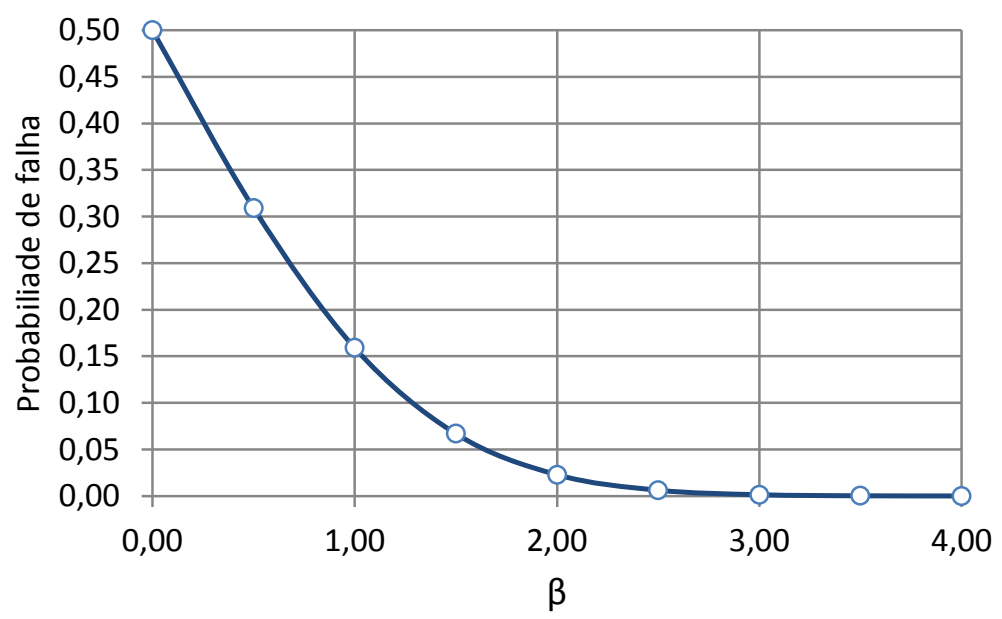

Figura 6.2 - Relação entre $\beta$ e $P_{f}$. Souza (2011)

Os valores que mostram a relação entre o índice de confiabilidade e a probabilidade de falha da Figura 6.2 são apresentados na Tabela 6.2. 


\begin{tabular}{cc} 
Tabela 6.2 - Relação entre $\beta$ e $P_{f}$. Souza (2011) \\
\hline Índice de Confiabilidade $\beta$ & Probabilidade de Falha $P_{f}$ \\
\hline 0,00 & 0,50 \\
0,50 & 0,31 \\
1,00 & 0,16 \\
1,50 & 0,07 \\
2,00 & 0,02 \\
2,50 & 0,01 \\
3,00 & 0,00 \\
3,50 & 0,00 \\
4,00 & 0,00 \\
\hline
\end{tabular}

\subsection{ESTADO LIMITE}

Os requisitos básicos de sistemas estruturais podem ser equacionados na forma de estados limites. O não atendimento de um requisito de serviço ou de segurança representa um estado indesejável da estrutura (Beck, 2004).

Dado um evento qualquer pertencente a um espaço generalizado, existe uma função de desempenho $G(x)$ associada a um operador matemático. A região caracterizada pelo domínio de falha, onde todos os pontos não atendam parcial ou integralmente os requisitos de segurança é representada por $G(x)<0$. A região caracterizada pelo domínio de segurança é representada por $G(x)>0$. A fronteira entre essas duas regiões onde $G(x)=0$ constitui o estado limite.

De forma geral a função $G(x)$ pode ser representada de acordo com a Equação 6.21, em que a variável $R$ é a parcela referente às resistências e a variável $S$ é a parcela referente às solicitações, sendo que cada uma das parcelas, $R$ ou $S$ pode ser desdobrada em inúmeras outras parcelas, quantas forem necessárias para melhor avaliação do problema em análise.

$$
G(x)=R-S
$$

As regiões que representam o domínio de falha, o domínio de segurança e o estado limite desses domínios são representados na Figura 6.3. 


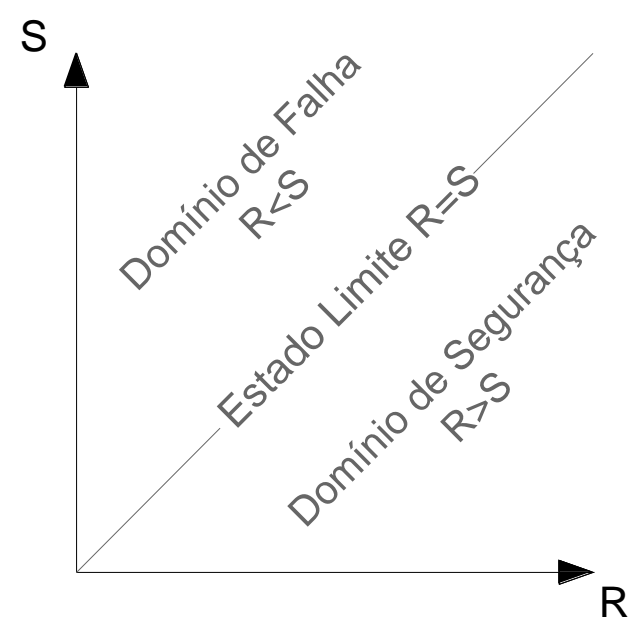

Figura 6.3 - Definição dos domínios de falha, segurança e estado limite para uma análise de confiabilidade

\subsection{EQUAÇÃO DE ESTADO LIMITE}

A ABNT NBR 15421:2006, Projeto de Estruturas Resistentes a Sismos, fixa os requisitos exigíveis para verificação da segurança das estruturas usuais da construção civil relativamente às ações de sismos e os critérios de quantificação destas ações e das resistências a serem consideradas no projeto das estruturas de edificações, relativamente a estas ações, quaisquer que sejam sua classe e destino.

Em seu item 8.10 essa norma apresenta as limitações para os deslocamentos relativos entre elevações, sendo que esses deslocamentos $\Delta_{x}$ são limitados aos valores máximos definidos na Tabela 6.3. A variável $h_{s x}$ é a distância entre as duas elevações correspondentes.

Tabela 6.3 - Limitação para deslocamentos relativos de um pavimento $\Delta_{x}$.

\begin{tabular}{ccc}
\hline \multicolumn{3}{c}{ Categoria de utilização } \\
\hline I & II & III \\
\hline $0,020 h_{s x}$ & $0,015 h_{s x}$ & $0,010 h_{s x}$ \\
\hline
\end{tabular}

Para cada estrutura deve ser definida uma categoria de utilização conforme a Tabela 6.4. Observar que as estruturas necessárias ao acesso às estruturas de categoria II ou III também devem ser categorizadas como tal. Caso uma estrutura contenha áreas de ocupação de mais de uma categoria, a categoria mais alta deve ser considerada na análise realizada. 
Tabela 6.4 - Definição das categorias de utilização. ABNT NBR 15421:2006

\begin{tabular}{|c|c|}
\hline $\begin{array}{l}\text { Categ. de } \\
\text { Utilização }\end{array}$ & Natureza da Ocupação \\
\hline $\mathrm{I}$ & Todas as estruturas não classificadas como de categoria II ou III \\
\hline II & $\begin{array}{l}\text { Estruturas de importância substancial para a preservação da vida humana no } \\
\text { caso de ruptura, incluindo, mas não estando limitadas às seguintes: } \\
\text { - Estruturas em que haja reunião de mais de } 300 \text { pessoas em uma única } \\
\text { área } \\
\text { - Estruturas para escolas primárias ou secundárias com mais de } 250 \\
\text { ocupantes } \\
\text { - Estruturas para escolas superiores ou para educação de adultos com } \\
\text { mais de } 500 \text { ocupantes } \\
\text { - Instituições de saúde para mais de } 50 \text { pacientes, mas sem instalações de } \\
\text { tratamento de emergência ou para cirurgias } \\
\text { - Instituições penitenciárias } \\
\text { - Quaisquer outras estruturas com mais de } 5000 \text { ocupantes } \\
\text { Instalações de geração de energia, de tratamento de água potável, de } \\
\text { tratamento de esgotos e outras instalações de utilidade pública não } \\
\text { classificadas como de categoria III. } \\
\text { - Instalações contendo substâncias químicas ou tóxicas cujo } \\
\text { extravasamento possa ser perigoso para a população, não classificadas } \\
\text { como de categoria III. }\end{array}$ \\
\hline III & $\begin{array}{l}\text { Estruturas definidas como essenciais, incluindo, mas não estando limitadas às } \\
\text { seguintes: } \\
\text { - Instituições de saúde com instalações de tratamento de emergência ou } \\
\text { para cirurgias } \\
\text { - Prédios de bombeiros, de instituições de salvamento e policiais e } \\
\text { garagens para veículos de emergência. } \\
\text { - Centros de coordenação, comunicação e operação de emergência e } \\
\text { outras instalações necessárias para resposta em emergência } \\
\text { - Instalações de geração de energia e outras instalações necessárias para } \\
\text { a manutenção em funcionamento das estruturas classificadas como de } \\
\text { categoria III } \\
\text { - Torres de controle de aeroportos, centros de controle de tráfego aéreo e } \\
\text { hangares de aviões de emergência } \\
\text { - Estações de tratamento de água necessárias para a manutenção de } \\
\text { fornecimento de água para o combate ao fogo } \\
\text { - Estruturas com funções críticas para a Defesa Nacional } \\
\text { - Instalações contendo substâncias químicas ou tóxicas consideradas } \\
\text { altamente perigosas, conforme classificação de autoridade } \\
\text { governamental designada para tal. }\end{array}$ \\
\hline
\end{tabular}

Para a análise de confiabilidade, optou-se em analisar o pórtico plano do Sistema Estrutural I, apresentado em 5.2. Como o pórtico não se enquadra nas categorias II ou III o valor limite para os deslocamentos relativos é determinado por $0,020 * h_{s x}$, 
conforme Tabela 6.3, portanto a equação de estado limite fica definida da seguinte forma:

$$
G(x)=0,020 * h_{s x}-r(x)
$$

Sendo $r(x)$ o deslocamento relativo horizontal em função de todas as variáveis do problema analisado.

Dado que no pórtico exemplo analisado, apresentado na Figura 5.3, $h_{s x}=5,2832 \mathrm{~m}$, a equação de estado limite fica definida da seguinte forma:

$$
G(x)=0,032512-r(x) \quad(m)
$$

\subsection{MÉTODO DE CÁLCULO DA PROBABILIDADE DE FALHA}

Através de métodos de análise de confiabilidade busca-se a obtenção da probabilidade de falha dos sistemas estruturais. Para problemas reais, onde existem inúmeras variáveis e com distribuições diversas, essa análise torna-se bastante complexa.

A integral apresentada pela Equação 6.7 não possui uma solução analítica para a maioria dos casos práticos. Além disso, em problemas usuais de engenharia, a maioria das variáveis aleatórias é correlacionada, assim como as distribuições são complexas, fazendo com que a integração exata da probabilidade de falha se torne praticamente impossível. A solução para o problema pode então ser a adoção de métodos de simulação ou de métodos aproximados onde a probabilidade de falha é obtida através de índices de confiabilidade.

Conforme Sagrilo (1994) muitos métodos foram desenvolvidos para realizar análises de confiabilidade. Esses métodos em geral podem ser divididos em quatro categorias:

$\checkmark$ Métodos de Integração Numérica;

$\checkmark$ Métodos de Simulação ou Técnicas de Monte Carlo;

$\checkmark$ Métodos Analíticos Form e Sorm;

$\checkmark$ Métodos Mistos ou Híbridos;

No método analítico FORM (First Order Reliability Method), utilizado nesse trabalho, as variáveis básicas do problema no espaço original $X$, que podem estar correlacionadas ou não, são transformadas em variáveis normais padrão, num espaço normalizado $Y$. A 
função de desempenho associada, $G(X)$, é descrita em função das variáveis $Y$ como $G(Y)$. Procura-se então o ponto $Y^{*}$, denominado ponto de projeto ou ponto mais provável de falha e a distância deste ponto até a origem é chamado de índice de confiabilidade $\beta$ dado por:

$$
\beta=\left|Y^{*}\right|
$$

Na Figura 6.4 é apresentada a representação gráfica do método FORM no espaço original e no espaço normal padrão.

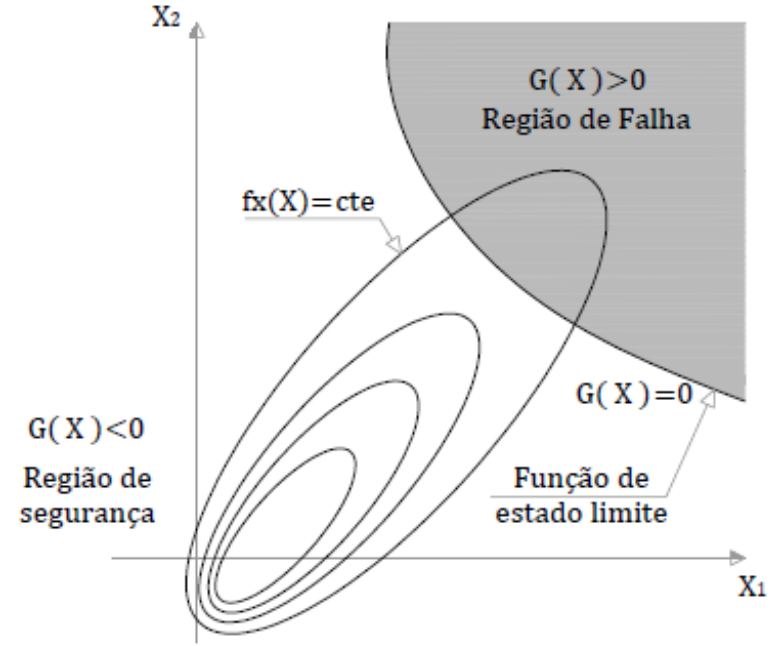

a) Espaço Original

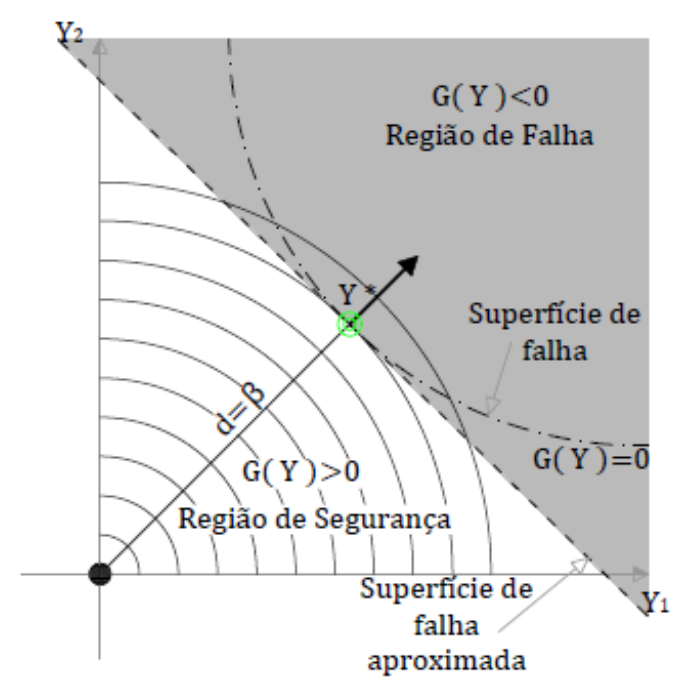

b) Espaço Normal Padrão

Figura 6.4 - Representação gráfica do método FORM

Os principais desafios no método FORM são a transformação das variáveis aleatórias do espaço original para o espaço normal padrão e encontrar o ponto sobre a superfície de falha mais próximo à origem. O processo de transformação das variáveis, bem como da determinação do ponto de falha, podem ser encontradas com algoritmos detalhados em Sagrilo (1994) e em Pantoja (2012).

\subsection{ANÁLISE DE CONFIABILIDADE}

Um sistema estrutural, por melhor que tenha sido projetado e construído, não está livre de falhar em algum momento. Muitos são os fatores que podem influenciar no processo de falha, tais como fatores climáticos, agressividade local, problemas de execução, carregamentos não considerados, falta de manutenção, etc. 
No desenvolvimento dos projetos um aspecto tão importante quanto a funcionalidade de uma estrutura é a sua segurança, e para sua determinação se requer o conhecimento de todas as variáveis envolvidas. No entanto, o conhecimento dessas variáveis não é pleno e quase sempre estão associadas a algum grau de incerteza.

As estruturas concebidas pelos engenheiros são projetadas seguindo coeficientes de segurança determinados por normas específicas para que elas se comportem de forma segura frente aos carregamentos atuantes.

Realizou-se uma análise de confiabilidade para o pórtico apresentado na Figura 5.3. De modo a se obter uma comparação entre o modelo proposto e o já amplamente utilizado, realizou-se uma análise específica considerando as características de cada um dos modelos.

\subsubsection{Interface de programação de aplicações (API)}

Para a realização da análise e obtenção dos resultados relativos à confiabilidade $(\beta) \mathrm{e}$ probabilidade de falha $\left(P_{f}\right)$, foi utilizado o programa Ferum (Finite Element Reliability Using Matlab), um open-source Matlab® toolbox cujo desenvolvimento foi iniciado em 1999 sob a liderança de Armen Der Kiureghian na Universidade da Califórnia em Berkeley (UCB). O propósito geral do código confiabilidade estrutural foi desenvolvido e mantido pela Terje Haukaas, com as contribuições de muitos pesquisadores da UCB (Bourinet, 2010).

Paralelamente foi desenvolvida uma rotina, também escrita em Matlab® para que houvesse a possibilidade de sincronizar o programa de obtenção da probabilidade de falha (FERUM), com a análise estrutural realizada pelo programa de elementos finitos SAP2000®. Essa comunicação entre programas foi possível graças à utilização de rotinas do tipo API - Application Programming Interface, ou simplesmente Interface de Programação de Aplicações, que são rotinas e padrões estabelecidos por um software para a utilização das suas funcionalidades por aplicativos que não se destinam a modificar a sua implementação, mas apenas a utilização dos seus serviços.

Dessa forma, a partir do Matlab® são gerados arquivos do tipo $\$ 2 \mathrm{k}$ ou s2k, que se tratam de arquivos de texto que o software SAP2000® é capaz de importar, com os dados das variáveis aleatórias fornecidos segundo suas respectivas distribuições de 
probabilidade, tornando assim possível a realização de centenas ou milhares de análises de forma iterativa sem o preenchimento manual dos dados. Um fluxograma da interface entre Ferum e o modelo de elementos finitos é apresentada na Figura 6.5.

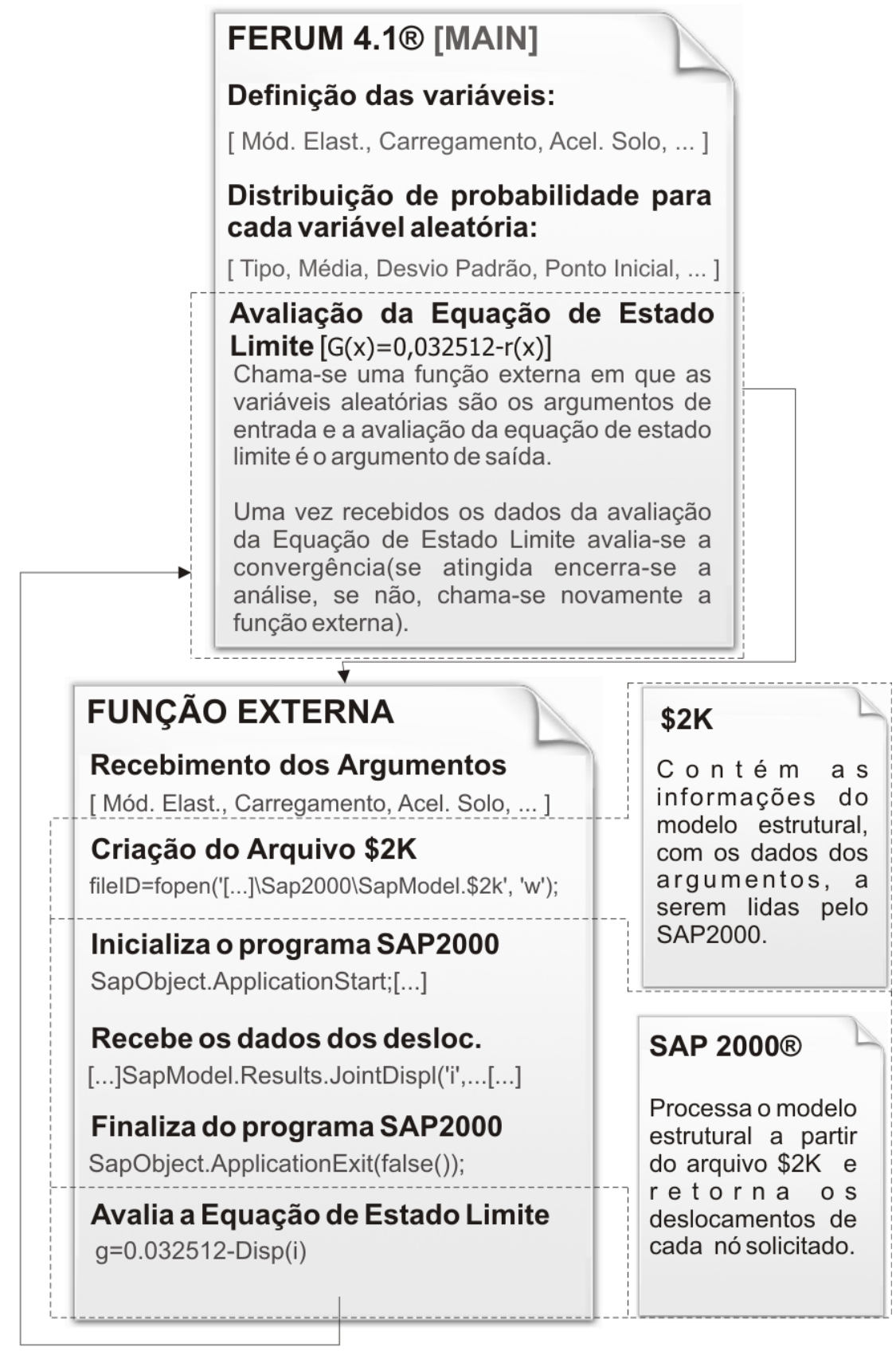

Figura 6.5 - Fluxograma API Matlab® SAP2000®

\subsubsection{Dados e resultados}

Quanto à distribuição estatística das variáveis, foram considerados os dados apresentados na Tabela 6.5, em que os valores adotados para as variáveis aleatórias 
foram baseados em Haldar \& Mahadevan (2000), para representar as incertezas relativas ao modelo analisado.

Tabela 6.5 - Descrição das variáveis aleatórias

\begin{tabular}{ccccc}
\hline Variável & Unidade & Valor Médio & $\begin{array}{c}\text { Coeficiente } \\
\text { de Variação }\end{array}$ & Distribuição \\
\hline Módulo de Elast. & $\mathrm{GPa}$ & 200 & 0,06 & Normal \\
Carregamento & $\mathrm{N} / \mathrm{m}^{3}$ & $78 \mathrm{E} 3$ & 0,10 & Normal \\
Aceleração Solo & $\mathrm{m} / \mathrm{s}^{2}$ & 3,24 & 1,38 & $\begin{array}{c}\text { Tipo I } \\
\text { (Gumbel) }\end{array}$ \\
\hline
\end{tabular}

A variação do carregamento se deu com a alteração do peso específico do material, alterando assim o seu peso próprio. $\mathrm{O}$ valor de $3,24 \mathrm{~m} / \mathrm{s}^{2}$ corresponde à aceleração máxima de projeto normalizada em 0,33 unidades de $\mathrm{g}$.

Após processamento das análises segundo a distribuição da variáveis apresentadas na Tabela 6.5, foram obtidos os seguintes resultados.

Tabela 6.6 - Comparação da probabilidade de falha para os modelos analisados

\begin{tabular}{cccc}
\hline Modelo & $\beta$ & $P_{f}$ & $\begin{array}{c}\text { Proporcionalidade } \\
\text { da } P_{f}\end{array}$ \\
\hline Bottle Shape & 0.4990 & 0.3089 & - \\
$X$ Shape & 0.4937 & 0.3108 & $0.61 \%$ \\
Sem Controle & 0.2541 & 0.3997 & $29.39 \%$ \\
\hline
\end{tabular}

Observa-se que ambos os modelos, Bottle Shape e X Shape, apresentam baixa probabilidade de falha com valores bastante similares, já a probabilidade de falha do modelo estrutural Sem Controle relativa aos modelos controlados aumenta em cerca de $30 \%$. Salienta-se que a probabilidade de falha $P_{f}$ encontrada está vinculada com a probabilidade do modelo adotado, considerando as incertezas das variáveis analisadas, de superar o deslocamento máximo dado pela equação de estado limite, que na prática é um estado limite de serviço dado pela ABNT NBR 15421:2006 Projeto de Estruturas Resistentes a Sismos. A superação dos deslocamentos dessas estruturas em relação ao estado limite considerado, ainda que aconteça, não necessariamente representará o colapso da mesma.

Uma análise de sensibilidade das variáveis utilizadas, que trata do grau de influência dessa variável sobre a variação dos resultados da equação de estado limite, demonstra que a variável aceleração é preponderante sobre as demais, até mesmo porque seu coeficiente de variação é consideravelmente superior, dessa forma realizou-se uma 
análise da probabilidade de falha da estrutura em função da variação dessa aceleração. A variação de $\beta$ em função da variação da amplitude de $g$ é apresentada na Figura 6.6.

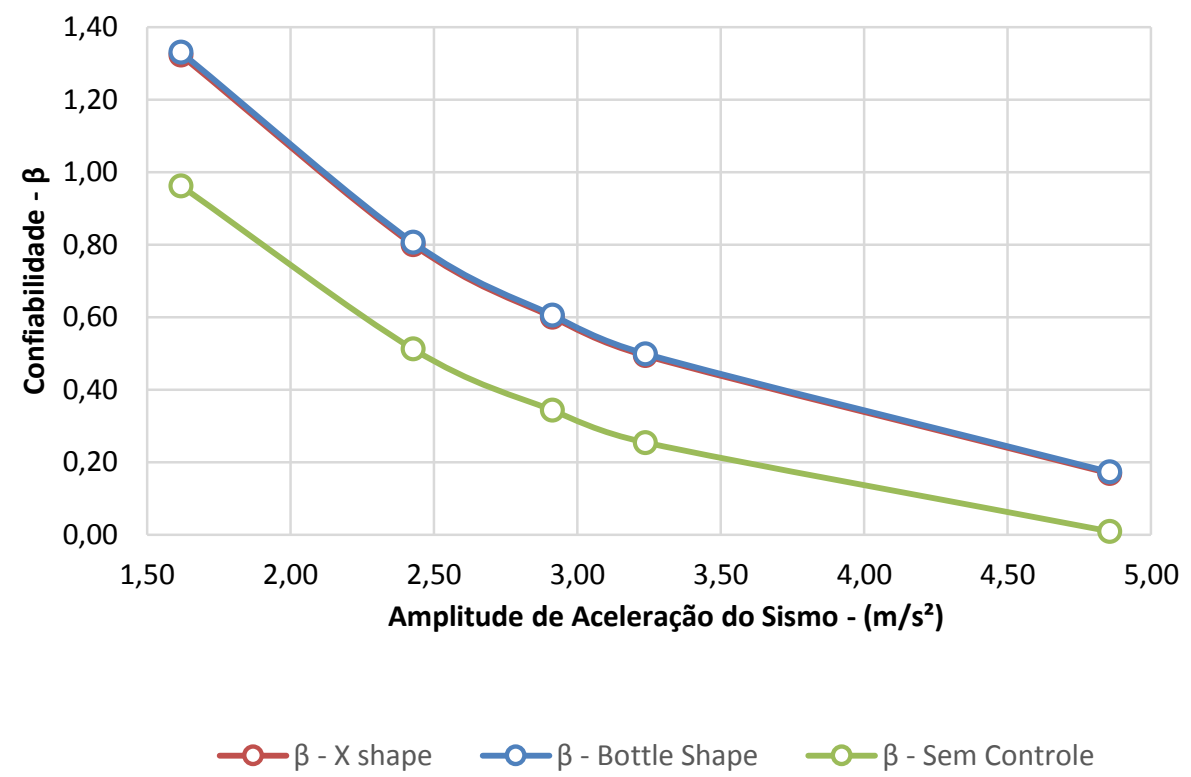

Figura 6.6 - Valores de confiabilidade e probabilidade de falha em função da variação da aceleração na base do pórtico estrutural

Observa-se que as curvas relativas aos modelos Bottle Shape e $X$ Shape estão praticamente sobrepostas, demonstrando que os modelos se comportam de forma semelhante no que tange à confiabilidade. Os dados utilizados para a elaboração das figuras acima são apresentados de forma sintetizada na Tabela 6.7.

Tabela 6.7 - Valores de confiabilidade e probabilidade de falha em função da variação da aceleração na base do pórtico estrutural

\begin{tabular}{ccccccc}
\hline \multirow{2}{*}{$\begin{array}{c}\text { Aceleração } \\
\mathrm{m} / \mathrm{s}^{2}\end{array}$} & \multicolumn{3}{c}{ Confiabilidade $\beta$} & \multicolumn{3}{c}{ Probabilidade de Falha } \\
\cline { 2 - 7 } & $\begin{array}{c}\text { Bottle } \\
\text { Shape }\end{array}$ & X Shape & $\begin{array}{c}\text { Sem } \\
\text { Controle }\end{array}$ & $\begin{array}{c}\text { Bottle } \\
\text { Shape }\end{array}$ & X Shape & $\begin{array}{c}\text { Sem } \\
\text { Controle }\end{array}$ \\
\cline { 2 - 7 } 1,62 & 1,3308 & 1,3227 & 0,9621 & 0,0916 & 0,0930 & 0,1680 \\
2,43 & 0,8061 & 0,7998 & 0,5118 & 0,2101 & 0,2119 & 0,3044 \\
2,91 & 0,6054 & 0,5997 & 0,3428 & 0,2725 & 0,2744 & 0,3659 \\
3,24 & 0,4990 & 0,4937 & 0,2541 & 0,3089 & 0,3108 & 0,3997 \\
4,86 & 0,1726 & 0,1687 & 0,0089 & 0,4315 & 0,4330 & 0,5036 \\
\hline
\end{tabular}

De modo a analisar a influência do posicionamento dos dissipadores metálicos na estrutura, foram modificadas suas quantidades e posições. Analisou-se todos os anagramas das combinações de 7, 6 e 4 dissipadores para cada um dos pavimentos. As combinações realizadas com seus respectivos valores de confiabilidade são 
apresentados na tabela abaixo, sendo que a combinação (X,Y,Z) se refere respectivamente aos dissipadores (\#DM1, \#DM2, \#DM3) segundo nomenclatura da Figura 5.3. Para os dados apresentados utilizou-se uma amplitude máxima de aceleração de $2,42 \mathrm{~m} / \mathrm{s}^{2}$ obtida a partir do valor quadrático médio do histórico de acelerações da excitação sísmica da Figura 5.1.

Tabela 6.8- Valores de confiabilidade e probabilidade de falha em função do posicionamento dos dissipadores

\begin{tabular}{ccccccc}
\hline \multirow{2}{*}{ COMB } & \multicolumn{3}{c}{ Confiabilidade $-\beta$} & \multicolumn{3}{c}{ Probabilidade de Falha $-P_{f}$} \\
\cline { 2 - 7 } & $\begin{array}{c}\text { Bottle } \\
\text { Shape }\end{array}$ & X Shape & $\begin{array}{c}\text { Sem } \\
\text { Controle }\end{array}$ & $\begin{array}{c}\text { Bottle } \\
\text { Shape }\end{array}$ & $X$ Shape & $\begin{array}{c}\text { Sem } \\
\text { Controle }\end{array}$ \\
\hline$(6,4,7)$ & 0,8283 & 0,8219 & 0,5158 & 0,2038 & 0,2056 & 0,3030 \\
$(7,4,6)$ & 0,8216 & 0,8169 & 0,5158 & 0,2057 & 0,2070 & 0,3030 \\
$(7,6,4)$ & 0,8109 & 0,8045 & 0,5158 & 0,2087 & 0,2106 & 0,3030 \\
$(6,7,4)$ & 0,8058 & 0,8017 & 0,5158 & 0,2102 & 0,2114 & 0,3030 \\
$(4,6,7)$ & 0,7966 & 0,7828 & 0,5158 & 0,2129 & 0,2169 & 0,3030 \\
$(4,7,6)$ & 0,7900 & 0,7766 & 0,5158 & 0,2148 & 0,2187 & 0,3030 \\
\hline
\end{tabular}

De forma a facilitar a visualização dos resultados, um gráfico com os dados da Tabela 6.8 é apresentada na Figura 6.7.

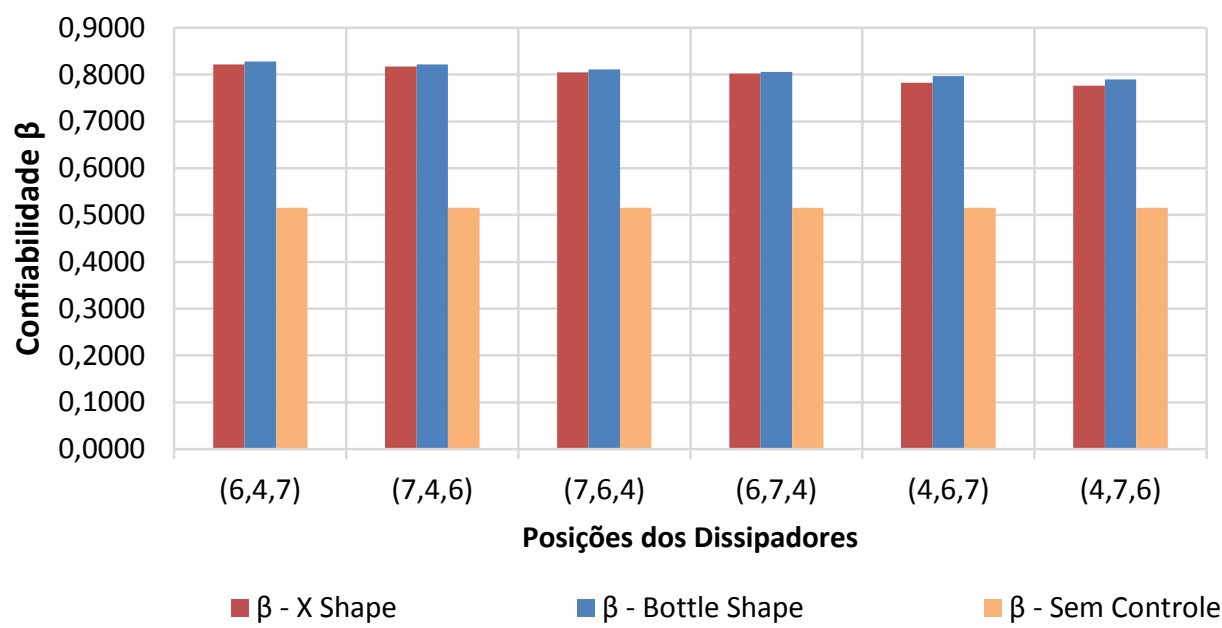

Figura 6.7 - Valores de $\beta$ em função do posicionamento dos dissipadores

Foi analisada uma segunda configuração dos dissipadores metálicos variando suas posições e quantidades de forma que o total de dissipadores utilizados continue sendo igual a 17. Foram analisados todos os anagramas das combinações de 8,6 e 3 dissipadores para cada um dos pavimentos. As combinações realizadas com seus respectivos valores de confiabilidade são apresentados na Tabela 6.9 no mesmo formato 
da Tabela 6.8. De igual modo, utilizou-se $2,42 \mathrm{~m} / \mathrm{s}^{2}$ como amplitude máxima de aceleração.

Tabela 6.9 - Valores de confiabilidade e probabilidade de falha em função do posicionamento dos dissipadores

\begin{tabular}{lcccccc}
\hline \multirow{2}{*}{ COMB } & \multicolumn{3}{c}{ Confiabilidade $-\beta$} & \multicolumn{2}{c}{ Probabilidade de Falha $-P_{f}$} \\
\cline { 2 - 7 } & $\begin{array}{c}\text { Bottle } \\
\text { Shape }\end{array}$ & $X$ Shape & $\begin{array}{c}\text { Sem } \\
\text { Controle }\end{array}$ & $\begin{array}{c}\text { Bottle } \\
\text { Shape }\end{array}$ & $X$ Shape & $\begin{array}{c}\text { Sem } \\
\text { Controle }\end{array}$ \\
\hline$(6,3,8)$ & 0,8367 & 0,8241 & 0,5158 & 0,2014 & 0,2050 & 0,3030 \\
$(8,3,6)$ & 0,8175 & 0,8121 & 0,5158 & 0,2068 & 0,2084 & 0,3030 \\
$(8,6,3)$ & 0,8072 & 0,8052 & 0,5158 & 0,2088 & 0,2104 & 0,3030 \\
$(6,8,3)$ & 0,8016 & 0,7990 & 0,5158 & 0,2114 & 0,2121 & 0,3030 \\
$(3,6,8)$ & 0,7705 & 0,7436 & 0,5158 & 0,2205 & 0,2286 & 0,3030 \\
$(3,8,6)$ & 0,7550 & 0,7286 & 0,5158 & 0,2251 & 0,2331 & 0,3030 \\
\hline
\end{tabular}

Os resultados das análises demonstram de maneira geral que, conforme esperado, a confiabilidade é maior quando um maior número de dissipadores metálicos estão localizados mais próximos do térreo, região em que as solicitações são mais elevadas e que, portanto, necessitam de maior rigidez. No entanto, observa-se que é necessário um estudo mais detalhado que leva em conta a maximização do índice de confiabilidade baseado num posicionamento ótimo dos dissipadores, tal constatação é, inclusive, apresentada como sugestão para trabalhos futuros no item 7.1.

De forma a facilitar a visualização, os dados de confiabilidade e probabilidade de falha para as combinações realizadas são apresentados de forma agrupada na Figura 6.8 e na Figura 6.9.

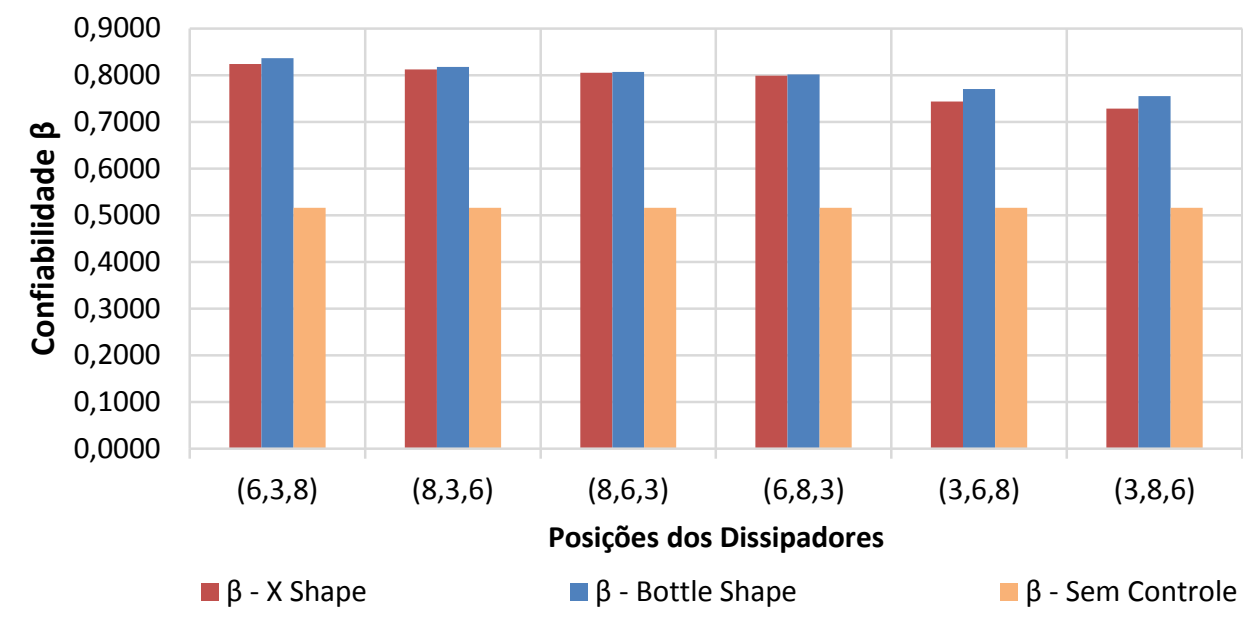

Figura 6.8 - Valores de $\beta$ em função do posicionamento dos dissipadores 


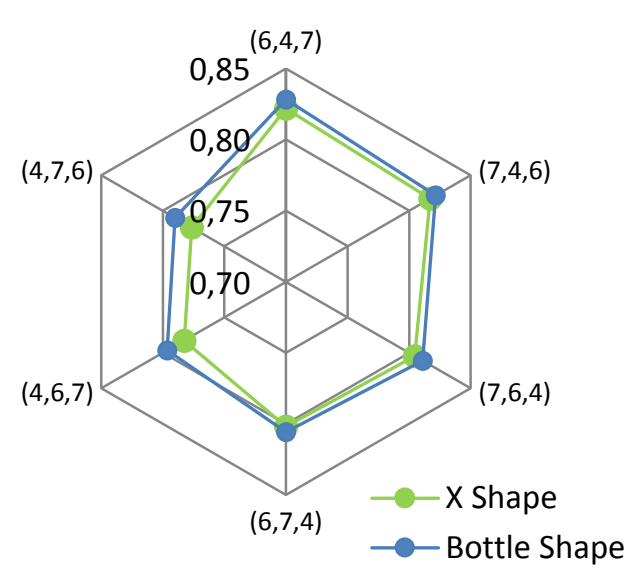

(a) $\beta$ para $(\# 6, \# 4, \# 7)$ dissipadores

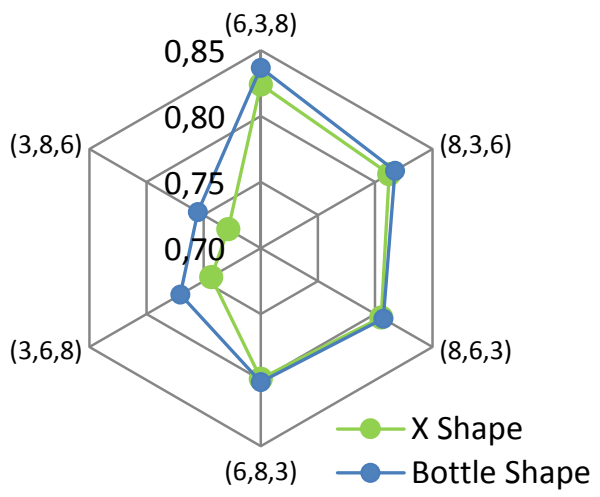

(c) $\beta$ para os (\#8,\#6,\#3) dissipadores

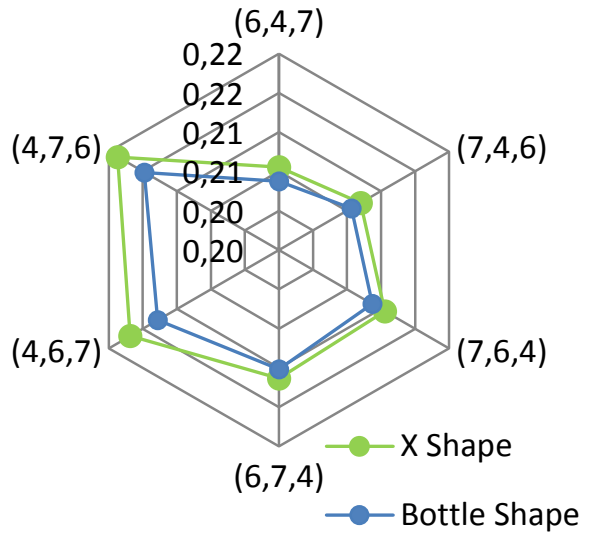

(b) $P_{f}$ para os $(\# 6, \# 4, \# 7)$ dissipadores

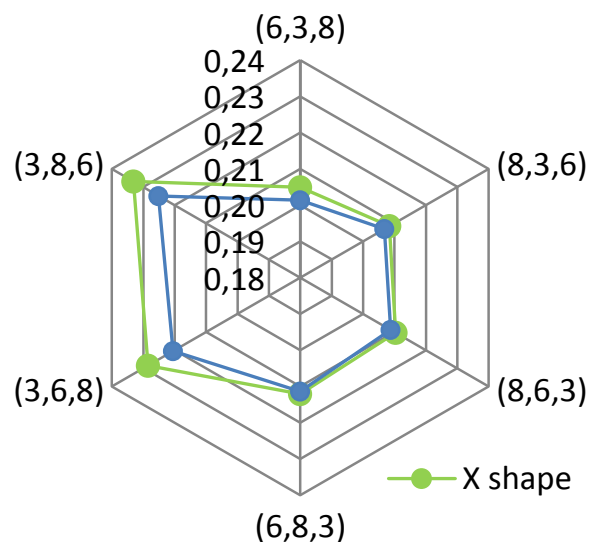

(d) $P_{f}$ para os $(\# 6, \# 4, \# 7)$ dissipadores Figura 6.9 - Valores de $\beta$ e $P_{f}$ em função do posicionamento dos dissipadores 


\section{CONCLUSÕES E SUGESTÕES}

A seguir apresentam-se comentários, observações e conclusões sobre a pesquisa realizada a partir dos estudos realizados.

Realizou-se inicialmente uma revisão bibliográfica a respeito dos dispositivos de controle passivo envolvendo dissipadores metálicos e em seguida estudou-se a otimização topológica de forma a utilizá-la como ferramenta.

Buscou-se, através da otimização topológica, uma geometria alternativa para o amortecedor histerético amplamente utilizado denominado $X$ Shape. O dispositivo modelado, obtido dessa otimização, chamado de Bottle Shape, tornou-se o objeto de estudo e comparação com o dispositivo já existente.

Nesse sentido, foram realizados estudos experimentais em laboratório para determinar o comportamento do dissipador de topologia otimizada frente a diferentes tipos de solicitações. Dessa forma, as placas metálicas utilizadas como corpos de prova, modeladas no formato Bottle Shape e $X$ Shape, foram produzidas fisicamente através de um sistema de corte automatizado a plasma e, em seguida, esses corpos de provas foram instalados na Máquina Universal de Testes MTS 810, onde foram submetidos a diferentes tipos de carregamentos.

A partir das ações dos carregamentos e das reações das placas foi possível obter os diagramas de histerese de cada um dos dispositivos, foi possível também determinar os dados necessários ao modelo de Bouc-Wen, que representa numericamente o comportamento histerético dos dissipadores.

Posteriormente buscou-se realizar análises numéricas em que se considerasse os dissipadores metálicos incorporados em modelos estruturais completos, submetendo as estruturas com os dissipadores instalados a uma excitação sísmica.

Foram analisados dois modelos estruturais, um mais simples, de três pavimentos, denominado Sistema Estrutural I, e outro mais completo, de dez pavimentos, denominado Sistema Estrutural II. Ambos os modelos estruturais foram submetidos à uma aceleração na base de forma a simular a ação de um sismo. 
Foram realizadas análises dinâmicas desses sistemas estruturais, nessas análises as estruturas foram submetidas a uma excitação sísmica correspondente ao registrado no terremoto El Centro com dados normalizados para uma aceleração máxima de projeto de $0,33 \mathrm{~g}$. Nas análises foram determinados os deslocamentos dos nós das estruturas para os sistemas sem nenhum controle, com o dispositivo $X$ Shape e também com o Bottle Shape. Foram determinadas também as forças atuantes nos dissipadores metálicos para que se pudesse comparar o desempenho dos mesmos.

Os dados encontrados demonstraram que ao se comparar as ações das forças nos dissipadores metálicos, ou mesmo os deslocamentos nos nós da estrutura, ambos os modelos, Bottle Shape e X Shape, se comportaram de forma semelhante, apresentado pequenos percentuais de diferença entre as variáveis comparadas.

Observa-se ainda que as posições dos dissipadores, assim como as quantidades utilizadas no sistema estrutural, influem de forma considerável no comportamento da estrutura, uma vez que é grande a diferença entre os deslocamentos analisados ao se alterar o número e as posições dos dissipadores

Com base nas análises e ensaios realizados, constata-se que a geometria alternativa proposta ao dispositivo $X$ Shape, denominada Bottle Shape, apresenta resultados satisfatórios, servindo, a princípio, como solução para utilização em edifícios sujeitos a ação de sismos. Conclui-se também que ambas as tecnologias reduzem de forma considerável a dissipação de energia em relação à estrutura que não possui nenhum tipo de controle.

Ressalta-se que a geometria alternativa desenvolvida para o dissipador metálico coaduna com a inovação e originalidade, uma vez que é apresentada uma nova geometria, com desempenho adequado, para um dispositivo já consolidado quanto ao seu uso e comportamento.

Pode-se considerar ainda que, a partir da conclusão de Tena-Colunga \& Vergara (1996) que aponta que a diminuição do custo de comercialização dos dissipadores é uma boa alternativa técnica e econômica, o dispositivo Bottle Shape, distribuído com taxas de comercialização mais compatíveis com a realidade dos países subdesenvolvidos e em 
desenvolvimento, pode garantir maior capilaridade ao uso de tal tecnologia, disseminando-a nas regiões sujeitas às ações dos sismos.

Em seguida realizou-se uma análise de confiabilidade para o pórtico denominado Sistema Estrutural I. A análise de confiabilidade se deu a partir da integração do programa Ferum (Finite Element Reliability Using Matlab), que possui um módulo que utiliza o método FORM para realização das análises, com o programa de análise estrutural SAP 2000. Essas interfaces foram integradas através de uma rotina do tipo API - Application Programming Interface, tornado possível a realização de centenas de análises sem a entrada manual de dados.

O estudo de confiabilidade se deu a partir de uma equação de estado limite baseada nos requisitos da ABNT NBR 15421:2006 - Projeto de Estruturas Resistentes a Sismos, que prevê a limitação para deslocamentos relativos entres elevações das edificações.

Após a execução das análises observou-se que ambos os modelos apresentam baixa probabilidade de falha com valores bastante similares, já a probabilidade do modelo estrutural Sem Controle, relativa aos modelos equipados com os dissipadores, aumenta em cerca de $30 \%$. Portanto fica clara a importância da instalação dos dissipadores metálicos para a redução das vibrações de estruturas sujeitas a sismos.

\subsection{SUGESTÕES}

O controle de vibrações em estruturas é uma área de pesquisa com grande expansão. Apesar do grande avanço que tem ocorrido nas últimas décadas, pode-se observar ao longo deste trabalho que existem vários tópicos importantes cujo estudo deve ser aprofundado. Dentre esses, pode-se enumerar como continuação natural desta tese de doutorado, os seguintes tópicos:

- Análise crítica entre diferentes dissipadores metálicos disponíveis na bibliografia, como forma de subsidiar a melhor escolha para cada sistema estrutural específico;

- Avaliar o desempenho de dissipadores metálicos em sistemas estruturais com elevado número de pavimentos; 
- Consideração do efeito da temperatura nos dissipadores metálicos tendo em vista que durante a ação de um terremoto, uma parte significativa da energia dissipada será convertida em calor, elevando a temperatura do dispositivo;

- Avanço na normatização dos dispositivos de controle estrutural, tornando assim mais fácil para o mercado utilizar os dados obtidos a partir de pesquisas acadêmicas;

- Estudo de maximização da confiabilidade estrutural em função do posicionamento dos dissipadores metálicos;

- Estudo da relação custo benefício, avaliando a diminuição do custo de utilização desses dispositivos com incrementos crescentes de desempenho.

Além dos tópicos mencionados, observa-se que o problema considerado nessa tese se limitou a uma única equação de estado limite, o que corresponde a um único modo de falha. No entanto, os elementos ou membros estruturais que compõem a estrutura analisada apresentam múltiplos modos de falha, por exemplo: instabilidade, ruptura frágil de seções, perda de equilíbrio por falha de vinculações em apoio, recalque de apoios, etc. Dessa forma, recomenda-se para a continuidade desse trabalho a determinação da confiabilidade do sistema estrutural sujeito a múltiplos modos de falha, considerando o grau de redundância dessa estrutura, sujeita à falha progressiva dos elementos estruturais avaliados de forma associada. 


\section{REFERÊNCIAS BIBLIOGRÁFICAS}

ABNT NBR 15421:2006 Projeto de Estruturas Resistentes a Sismos - Procedimento

ANSYS® Help Viewer. Version 15.0.0.

ARORA, Jasbir. S. Introduction to optimum design - Third Edition - Elsevier Inc. 2012.

AVILA, S. M. Controle híbrido para atenuação de vibrações em edifícios. Tese de doutorado, Pontifícia Universidade Católica do Rio de Janeiro, Rio de Janeiro, Brasil, 2002.

BAGHERI, S. BARGHIAN, M. SAIERI, F. FARZINFAR, A. U-shaped metallicyielding damper in building structures: Seismic behavior and comparison with a friction damper. The Institution of Structural Engineers, 2015.

BAYAT, M.; ABDOLLAHZADEH, G. Analysis of the steel braced frames equipped with ADAS devices under the far field records. Latin American Journal of Solids and Structures. p. 163-181, 2011.

BECK, A. T; Curso de Confiabilidade Estrutural. Departamento de Engenharia de Estruturas, Escola de Engenharia de São Carlos, Universidade de São Paulo, São Paulo, Brasil, 2004.

BOARDMAN, P.R; WOOD, B.J; CARR, A.J. Union House - A Cross Braced Structure With Energy Dissipators. BULLETIN OF THE NEW ZEALAND NATIONAL SOCIETY FOR EARTHQUAKE ENGINEERING, VOL.16, № 2, 1983.

BOURINET, J. M. Ferum 4.1 User's Guide. Institut Francais de Mecanique Avancee, Campus de Clermont Ferrand les Cézeaux, France, 2010.

CARMONA, J. E. C. Plataforma de ensaios dinâmicos: estudos preliminares, projeto e construção. Dissertação de Mestrado - Departamento de Engenharia Civil, Universidade de Brasília, Brasília, 2011. 
CARNEIRO, R. B. Controle de vibrações em edifícios altos utilizando amortecedor de massa sintonizado múltiplo (AMSM). Dissertação de Mestrado - Departamento de Engenharia Civil, Universidade de Brasília, Brasília, 2004.

CARNEIRO, R. B. Controle semi-ativo de vibrações em estruturas utilizando amortecedor magnetorreológico, Tese de Doutorado, Universidade de Brasília, Brasília, 2009.

CARPINETO, N; LACARBONARA, W; VESTRONI, F. Hysteretic tuned mass dampers for structural vibration mitigation. Journal of Sound and Vibration Department of Structural and Geotechnical Engineering, Sapienza University of Rome, Italy, 2013.

CHALCO, D. M. Análise Sísmica de Pórticos Planos com Dissipadores Metálicos de Energia. Dissertação de Mestrado - Departamento de Engenharia Civil e Ambiental, Universidade de Brasília, Brasília, DF, 2014.

COMPUTER AND STRUCTURES INC. CSI Analysis Reference Manual For SAP2000, ETABS, and SAFE. Computers and Structures, Inc., 2009.

CONSTANTINOU, M. C. and SYMANS, M. D., Seismic response of structures with supplemental damping. Struct. Design Tall Build., 2: 77-92, 1993.

CONSTANTINOU, M. C; SOONG, T.T; DARGUSH, G.F. Passive Energy Dissipation Systems for Structural Design and Retrofit. Multidisciplinary Center for Earthquake Engineering Research, New York, 1998.

DEN HARTOG, J. P. Mechanical vibrations. McGraw-Hill, New York, 1956.

DYKE, S. J. (1996). Acceleration feedback control strategies for active and semiactive control systems: modeling, algorithm development, and experimental verification, $\mathrm{PhD}$ Dissertation, Department of Civil Engineering and Geological Sciences Notre Dame, Indiana. 
FERUM - Finite Element Reliability Using Matlab®. Disponível em: $<$ http://www.ifma.fr/Recherche/laboratoires_recherche/FERUM> Acesso em $15 / 05 / 2015$

GHABRAIE, K., CHAN, R., HUANG, X. XIE, Y. M., Shape optimization of metallic yielding devices for passive mitigation of seismic energy. Engineering Structures 32, 2258-2267. 2010.

HALDAR, A.; MAHADEVAN, S. Reliability Assessment Using Stochastic Finite Element Analysis. John Wiley \& Sons, 2000.

IKHOUANE, F.; RODELLAR, J. Systems with hysteresis: analysis, identification and control using the Bouc-Wen model. John Wiley \& Sons Ltd, 2007.

ISO 3010 Bases for design of structures - Seismic actions on structures. $2^{\circ}$ Ed. International Organization for Standardization, 2001.

KALOS, M. H.; WHITLOCK, P. A. Monte Carlo Methods. Courant Institute of Mathematical Sciences. New York, 1986. 195 p.

KELLY, E. E. Improving Seismic Performance - Add Stiffness or Damping? NZSEE Annual Conference in Palmerston North,p. 24-30, 2007.

KELLY, J. M.; SKINNER, R. I.; HEINE, A. J. Mechanisms of Energy Absorption in Special Devices for Use in Earthquake Resistant Structures. Bulletin of N.Z. Society for Earthquake Engineering, Vol. 5 N³, 1972.

KITAGAWA, Y., MIDORIKAWA, M., Seismic isolation and passive response-control buildings in Japan. Building Research Institute, Department of Structural Engineering, Japan, 1997.

LARA VELENCIA, L. A. Controle de Vibrações em Vigas Metálicas com Distintas Configurações de Apoio Utilizando Amortecedores de Massa Sintonizados Departamento de Engenharia Civil, Universidade de Brasília, Brasília, 2007. 
LARA VALENCIA, L. A. Estudo de Algoritmos de Controle Semi-Ativo Aplicados a Amortecedores Magnetorreológicos. Tese de Doutorado - Departamento de Engenharia Civil e Ambiental, Universidade de Brasília, Brasília, DF, 2011.

LIMA, D. V. F. Controle de Vibrações Induzidas em uma Laje de Academia de Ginástica com a Utilização de Amortecedores de Massa Sintonizados - Departamento de Engenharia Civil e Ambiental, Universidade de Brasília, Brasília, 2007.

LIU, Y.; SHIMODA, M. Shape Optimization of Shear Panel Damper for Improving the Deformation Ability Under Cyclic Loading. Springer-Verlag Berlin Heidelberg, 2013.

MALDONADO, J. C. Passive and active control of structures. Dissertação de mestrado, Department of Civil and Environmental Engineering, Massachusetts Institute Technology, 1995.

MELCHERS, R. R.; Structural Reliability: Analysis and Prediction. Ellis Horwood Series in Civil Engineering, 1987. 400 p.

MORESCHI, L. M.; SINGH, M. P. Design of yielding metallic and friction dampers for optimal seismic performance. EARTHQUAKE ENGINEERING AND STRUCTURAL DYNAMICS. 32:1291-1311. 2003.

MTS Systems Corporation Headquarters - Station Manager Application. Disponível em: <http://www.mts.com/ucm/groups/public/documents/library/mts_010175.pdf>. Acesso em 15/08/2015.

OLIVEIRA, B. A. Desenvolvimento de um Isolador de Vibração Pseudoelástico. Dissertação de Mestrado em Ciências Mecânicas, Departamento de Engenharia Mecânica, Universidade de Brasília, Brasília - DF, 2008.

OLIVEIRA, F. S. Critérios de Projeto para Amortecedor Tipo Pêndulo para Controle de Vibrações em Edifícios Altos. Dissertação de Mestrado, Departamento de Engenharia Civil e Ambiental, Universidade de Brasília, Brasília - DF, 2012. 
OLIVEIRA, J. C. A. Avaliação da Rigidez de Pórticos Tridimensionais de Concreto Armado. Tese de Doutorado, Departamento de Engenharia Civil e Ambiental, Universidade de Brasília, Brasília - DF, 2009.

OSPINA, C. S. Otimização de amortecedores de massa sintonizados, múltiplos e interligados, para controle de vibrações em edifícios altos - Departamento de Engenharia Civil, Universidade de Brasília, Brasília, 2008.

PANTOJA, J. C. Geração Automática Via Otimização Topológica e Avaliação de Segurança de Modelos de Bielas e Tirantes. Tese de doutorado, Pontifícia Universidade Católica do Rio de Janeiro, Rio de Janeiro, Brasil, 2012.

PENG, P., LIEPING, Y., WEI, S. \& HAIYUN, C., Engineering practice of seismic isolation and energy dissipation structures in China. Science China Press and SpringerVerlag. Berlin, Heidelberg. 2012.

PERRY, C. L., FIERRO, E. A., SEDARAT, H., AND SCHOLL, R. E., "Seismic Upgrade in San Francisco Using Energy Dissipation Devices," Earthquake Spectra, Vol. 9, No. 3, pp. 559-579.1993.

RAO, S. S. Engineering Optimization - Theory and Practice. Published by John Wiley \& Sons, Inc., Hoboken, New Jersey, 2009.

RIOS, M. P. Efeito de amortecedores no comportamento dinâmico de edifícios altos sob cargas de vento, Dissertação de Mestrado, Pontifícia Universidade Católica do Rio de Janeiro, Rio de Janeiro, Brasil, 2015.

SAGRILO, L. V. S. Análise de Confiabilidade Estrutural Utilizando os Métodos Analíticos FORM e SORM, Tese de Doutorado, Programa de Engenharia Civil, COPPE/UFRJ, Rio de Janeiro, RJ, Brasil, 1994.

SAGRILO, L. V. S., LIMA, E. C. P., Confiabilidade Estrutural Métodos Analíticos FORM/SORM - Notas de Aula, Programa de Engenharia Civil, COPPE/UFRJ, Rio de Janeiro, RJ, Brasil, 2002. 
SHARPE, R.D., GRINLINTON, K.E. Should the chimney have rocked? NEW ZEALAND SOCIETY FOR EARTHQUAKE ENGINEERING, 2013.

SIGMUND, O. A 99 line topology optimization code written in Matlab. Struct Multidisc Optim 21, 120-127 Springer-Verlag, 2001.

SIGMUND, O.; BENDSØE, M. P. Topology optimization, theory, methods and application. Springer - Verlag, Berlin Heidelberg, 2002.

SKINNER, R. I., KELLY, J. M. AND HEINE, A. J., Hysteretic dampers for earthquake-resistant structures. Earthquake Engng. Struct. Dyn., 3: 287-296. 1974.

SKINNER, R.I., SHARPE, R.D. The seismic design of an industrial chimney with rocking base. Bulletin of the New Zealand national society for earthquake engineering, Vol. 16, N², June 1983.

SOONG, T.T. (1990). "Active structural control: theory and practice", Longman Scientific \& Technical, England.

SOONG, T. T.; CONSTATINOU, M, C. Passive and Active Structural Vibration Control in Civil Engineering. Department of Civil Engineering, State University of New York at Buffalo, Buffalo, NY, 1994.

SOONG, T. T.; DARGUSH, G. F. Passive Energy Dissipation Systems in Structural Engineering. John Wiley \& Sons, 1997.

SOUZA, O. L. C. Aplicação da teoria da confiabilidade às vigas de concreto armado reforçadas à torção com compósitos de fibras de carbono. Tese de doutorado, Universidade Federal Fluminense, Niterói, Brasil, 2011.

TAKEWAKI, I. Building Control with Passive Dampers: Optimal Performance-based Design for Earthquakes. Kyoto University, Japan. John Wiley \& Sons, 2009.

TENA-COLUNGA, A., 1997. Mathematical Modeling of the ADAS Energy Dissipation Device. Engineering Structures, v. 19, n. 10, p. 811-821. 
TENA-COLUNGA, A.; VERGARA, A. Seismic Retrofit of a Mid-Rise Building Using Steel Bracing or ADAS Energy Dissipation Devices: A Comparative Study. Centro de Investigación Sísmica, AC, Fundación Javier Barros Sierra, México, 1996.

WEN, K. Y. Method for Random Vibration of Hysteretic Systems. Journal of the Engineering Mechanics Division, ASCE, v. 1-02, n. EM2, p. 249-263, 1976.

WHITTAKER, A. S.; BERTERO, V. V.; ALONSO, L. J.; THOMPSON, C. L. Earthquake Simulator Testing of Steel Plate Added Damping And Stiffness Elements. Report N. UCB/EERC-89/02.Earthquake Engineering Research Center. University of California at Berkeley, 1989.

XIA, C.; HANSON, R. Influence of ADAS Element Parameters on Building Seismic Response. Journal of Structural Engineering ASCE, v. 118, n. 7, p. 1903-1918, 1992.

XUE, S.; TOBITA, J.; KURITA, S.; IZUMI, M. Mechanics and dynamics of intelligent passive vibration control system. Journal of Engineering Mechanics, v. 123, n. 4, p. 322-327, 1997.

YORIYAZ, H.; Fundamentos do Método de Monte Carlo para Transporte de Radiação, 2010.

ZULUAGA GÓMEZ, A. L. Controle de Vibrações em Edifícios Submetidos à Ação de Cargas Dinâmicas Utilizando Amortecedor de Massa Sintonizado na Forma de Pêndulo. Dissertação de Mestrado - Departamento de Engenharia Civil, Universidade de Brasília, Brasília, 2007. 


\section{APÊNDICE A}

Descrição do problema: Este exemplo avalia o comportamento histerético de um elemento de um grau de liberdade segundo as formulações de Wen. Uma carga estática não linear é utilizada para deslocar em $+10 \mathrm{~cm}$ um elemento de mola, posteriormente o elemento é deslocado $-20 \mathrm{~cm}$ em relação à última posição.

Fonte: CSI Computers \& Structures Inc. modificado (Computer and Structures, 2009).

\section{Z}

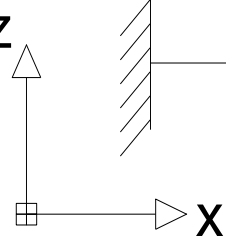

Grau de liberdade: $U_{z}$

Rigidez: $k=350 \mathrm{kN} / \mathrm{cm}$

Força de escoamento: $f_{y}=250 \mathrm{kN}$

Taxa de escoamento: $r=0,05$

Expoente de escoamento: $n=1$

A relação força deslocamento é controlada pela seguinte equação:

$$
f=r k d+(1-r) f_{y} z
$$

Sendo:

$k, r$ e $f_{y}$ definidos anteriormente

$f$ : força

$d$ : deformação

$z$ : variável histerética, sendo $-1 \leq z \leq 1$ com valor inicial igual a zero, $z$ evolui de acordo com a seguinte equação diferencial:

$$
\begin{array}{cr}
\dot{z}=\frac{k}{f_{y}} \dot{d}\left(1-|z|^{n}\right) & \operatorname{se} \dot{d} z>0 \\
\dot{z}=\frac{k}{f_{y}} \dot{d} & \text { caso contrário }
\end{array}
$$

$\dot{d} z>0$ se $\left\{\begin{array}{c}z>0 \text { e d é crescente } \\ z<0 \text { e d é decrescente }\end{array}\right\}$

Encontrar uma expressão para $z$ quando $\dot{d} z>0$ e $z$ é positivo

$$
\begin{array}{crl}
\dot{z} & =\frac{k}{f_{y}} \dot{d}\left(1-|z|^{n}\right)=\frac{k}{f_{y}} \dot{d}(1-|z|) \operatorname{com} e & =1 \\
\dot{z}=\dot{d} \frac{k}{f_{y}}-\dot{d} \frac{k}{f_{y}}|z| & \dot{z}+\dot{d} \frac{k}{f_{y}}|z| & =\dot{d} \frac{k}{f_{y}}
\end{array}
$$

Encontrar uma solução homogênea para $\dot{z}+\dot{d} \frac{k}{f_{y}}|z|=0$ onde $z$ seja positivo 
assumindo

$$
\begin{aligned}
& z=c e^{\alpha t} \\
& \dot{z}=c \alpha e^{\alpha t} \\
& c \text { e } \alpha \text { são constantes } \\
& \dot{z}+\dot{d} \frac{k}{f_{y}}|z|=c \alpha e^{\alpha t}+\dot{d} \frac{k}{f_{y}} c e^{\alpha t}=0 \\
& \alpha+\dot{d} \frac{k}{f_{y}}=0 \quad \alpha=-\dot{d} \frac{k}{f_{y}}
\end{aligned}
$$

Portanto, a solução homogênea quando $z$ é positivo é: $\quad z=c e^{-\dot{d} \frac{k}{f_{y}} t}$

Agora, determinar uma

solução particular para

$$
\dot{z}+\dot{d} \frac{k}{f_{y}}|z|=\dot{d} \frac{k}{f_{y}} \quad \text { Quando } z \text { é positivo. }
$$

assumindo

$$
\begin{gathered}
z=A+B t \\
\dot{z}=B \quad A \text { e } B \text { são cons } \\
\dot{z}+\dot{d} \frac{k}{f_{y}}|z|=B+\dot{d} \frac{k}{f_{y}}|A+B t|=\dot{d} \frac{k}{f_{y}} \\
A \dot{d} \frac{k}{f_{y}}+B\left(1+\dot{d} \frac{k}{f_{y}} t\right)=\dot{d} \frac{k}{f_{y}}
\end{gathered}
$$

A equação acima deve ser válida para qualquer valor de $t$

Para $t=0$

$$
\begin{aligned}
& A \dot{d} \frac{k}{f_{y}}+B=\dot{d} \frac{k}{f_{y}} \\
& A \dot{d} \frac{k}{f_{y}}+2 B=\dot{d} \frac{k}{f_{y}}
\end{aligned}
$$

Para $t=\frac{f_{y}}{\dot{d} k}$

Eq. 1

Subtraindo a Eq. 1 da Eq.2, resta $B=0$, substituindo $B=0$ na Eq.1

$$
A \dot{d} \frac{k}{f_{y}}+0=\dot{d} \frac{k}{f_{y}} \quad A=1
$$

Portanto, a solução particular é $z=1$, combinando a solução homogênea coma particular:

$$
\boldsymbol{z}=\mathbf{1}+\boldsymbol{c} \boldsymbol{e}^{-\dot{\boldsymbol{d}} \frac{k}{f_{y}} \boldsymbol{t}} \quad \text { Para } z>0 \text { e } \dot{d} z>0 \quad \text { Eq.3 }
$$

A relação força deslocamento pode ser calculada usando Eq.3. O valor da constante $c$ é determinada observando que quando $t=0, z=0$, e substituindo esses valores na Eq.3

$$
0=1+c e^{0} \quad c=-1 \quad z=1-e^{-\dot{d} \frac{k}{f_{y}} t}
$$

Para o trecho $01 \dot{d} t=d-d_{\text {inicial }}$, com valor de $d_{\text {inicial }}=0$, logo a expressão final para $z$ que será utilizada para avaliar o trecho 01 é:

$$
z=1-e^{-\frac{k}{f_{y}} d}
$$

Calcular um valor de $f$ para o trecho 01 com $d=0,5 \mathrm{~cm}$

$$
\begin{aligned}
& z=1-e^{-\frac{k}{f_{y}} d} \\
& Z=1-e^{-0,5 \times 350 / 250} \\
& z=1-e^{-0,7} \\
& z=0,503 \\
& f=r k d+(1-r) f_{y} z \\
& f=0,05 \times 350 \times 0,5+(1-0,05) \times 250 * 0,503 \\
& f=128,311
\end{aligned}
$$


Calcular outro valor de $f$ para o trecho $01 \mathrm{com} d=3,0 \mathrm{~cm}$

$$
\begin{array}{cccc}
z=1-e^{-\frac{k}{f y} d} & z=1-e^{-3,0 \times 350 / 250} & z=1-e^{-4,2} & z=0,985 \\
f=r k d+(1-r) f_{y} z & f=0,05 \times 350 \times 3,0+(1-0,05) \times 250 * 0,985 & f=286,438
\end{array}
$$
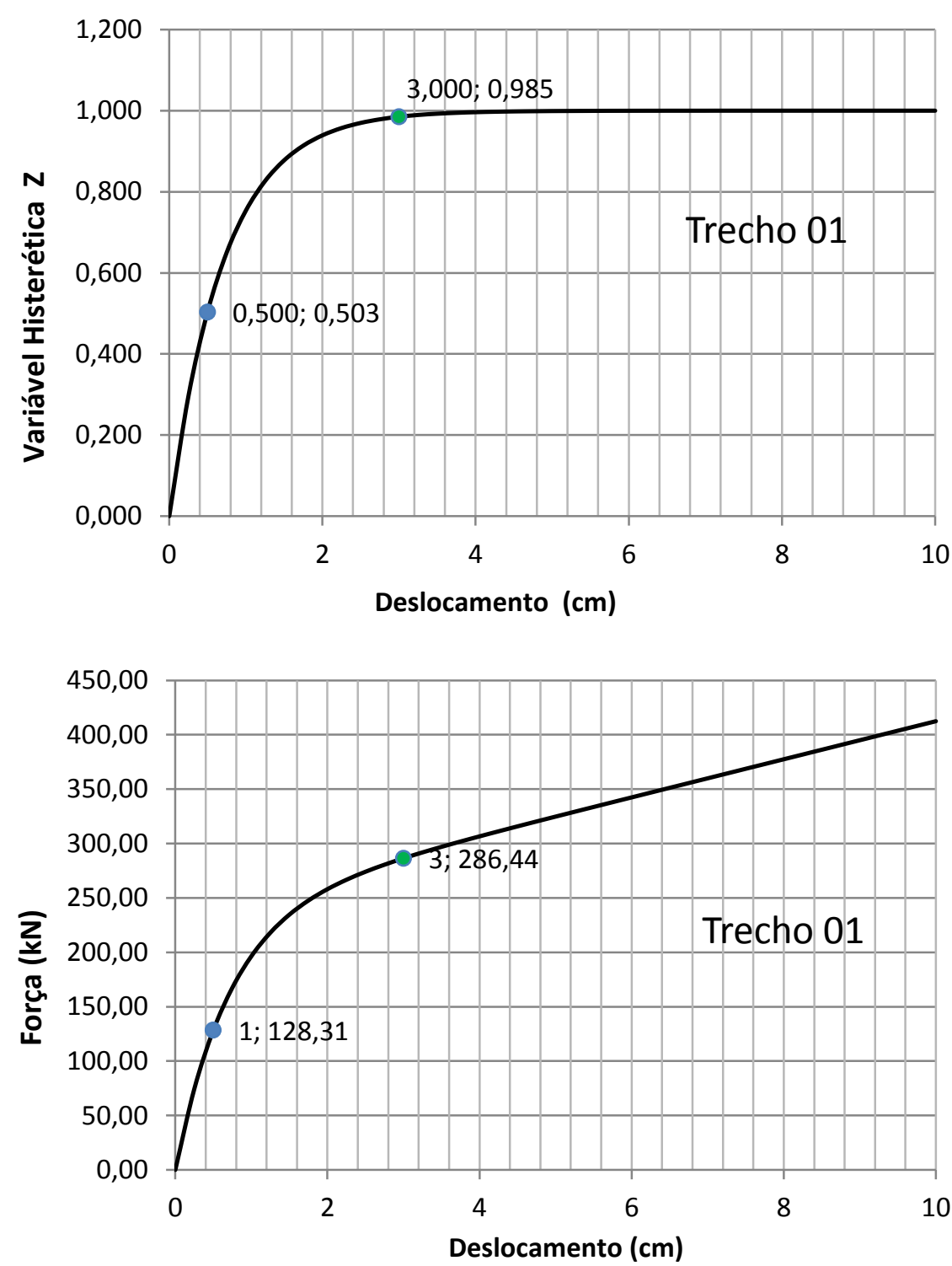

Encontrar uma expressão para $z$ quando $\dot{d} z \leq 0$

assumindo

$$
\begin{gathered}
z=A+B t \\
\dot{z}=B
\end{gathered}
$$

$$
\dot{z}-\dot{d} \frac{k}{f_{y}}=B-\dot{d} \frac{k}{f_{y}}=0
$$

$A$ e $B$ são constantes

$$
z=A+\dot{d} \frac{k}{f_{y}} t \quad \text { Eq. } 4
$$

Para a Eq.4, $\dot{d} t=d-d_{\text {inicial }}$. O valor de A pode ser determinado observando que quando $t=$ $0, z=1$ para o trecho 02 .

$$
1+A=0 \quad A=1
$$

Logo, a primeira parte do trecho 02 pode ser calculada como: 


$$
z=1+\frac{k}{f_{y}}\left(d-d_{\text {inicial }}\right)
$$

Agora, Encontrar uma expressão para $z$ quando $\dot{d} z>0$ e $z$ é negativo

Encontrar uma solução homogênea para $\dot{z}+\dot{d} \frac{k}{f_{y}}|z|=0$ onde $z$ seja negativo assumindo

$$
\begin{gathered}
z=-c e^{\alpha t} \\
\dot{z}=-c \alpha e^{\alpha t} \quad c \text { e } \alpha \text { são constantes } \\
\dot{z}+\dot{d} \frac{k}{f_{y}}|z|=-c \alpha e^{\alpha t}+\dot{d} \frac{k}{f_{y}} c e^{\alpha t}=0 \\
-\alpha+\dot{d} \frac{k}{f_{y}}=0 \quad \alpha=\dot{d} \frac{k}{f_{y}}
\end{gathered}
$$

Portanto, a solução homogênea quando $z$ é negativo é:

$$
z=-c e^{\dot{d} \frac{k}{f y} t}
$$

Agora, determinar uma solução particular para $\quad \dot{z}+\dot{d} \frac{k}{f_{y}}|z|=\dot{d} \frac{k}{f_{y}} \quad$ Quando $z$ é negativo.

assumindo

$$
\begin{gathered}
z=-A-B t \\
\dot{z}=-B \\
\dot{z}+\dot{d} \frac{k}{f_{y}}|z|=-B+\dot{d} \frac{k}{f_{y}}(A+B t)=\dot{d} \frac{k}{f_{y}} \\
A \dot{d} \frac{k}{f_{y}}+B\left(\dot{d} \frac{k}{f_{y}} t-1\right)=\dot{d} \frac{k}{f_{y}}
\end{gathered}
$$

A equação acima deve ser válida para qualquer valor de $t$

$$
\begin{array}{ll}
\text { Para } t=0 & A \dot{d} \frac{k}{f_{y}}-B=\dot{d} \frac{k}{f_{y}} \\
\text { Para } t=\frac{f_{y}}{\dot{d} k} & A \dot{d} \frac{k}{f_{y}}+0=\dot{d} \frac{k}{f_{y}}
\end{array}
$$

$$
A=1 \quad B=0 \quad \text { Portanto, a solução particular é } z=-1
$$

Combinando a solução homogênea com a particular:

$$
\boldsymbol{z}=-\mathbf{1}-\boldsymbol{c} \boldsymbol{e}^{\dot{\boldsymbol{d}} \frac{\boldsymbol{k}}{f_{\boldsymbol{y}}} \boldsymbol{t}} \quad \text { Para } z<0 \mathrm{e} \dot{d} z>0
$$

A relação força deslocamento pode ser calculada usando Eq.5 para o trecho 02 onde $z<0$. O valor da constante $c$ é determinada observando que quando $t=0, z=0$, e substituindo esses valores na Eq.5.

$$
0=-1-c e^{0} \quad c=-1 \quad z=-1+e^{\dot{d} \frac{k}{f_{y}} t}
$$

Apresenta-se a seguir os gráficos para os dois trechos 


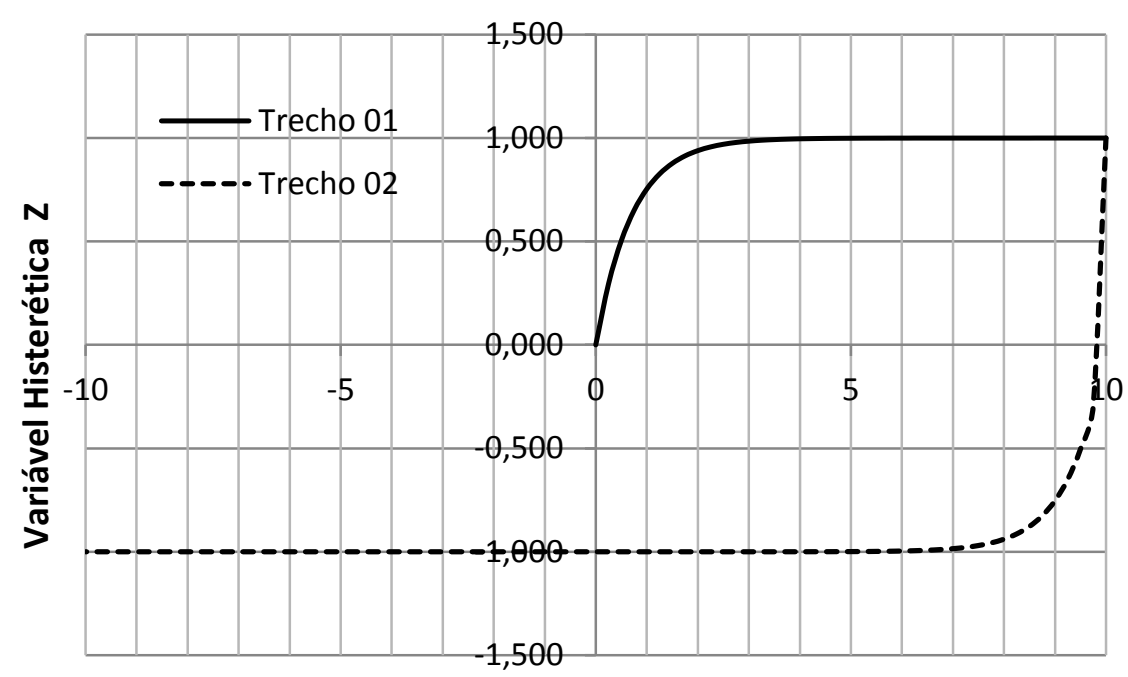

Deslocamento $(\mathrm{cm})$

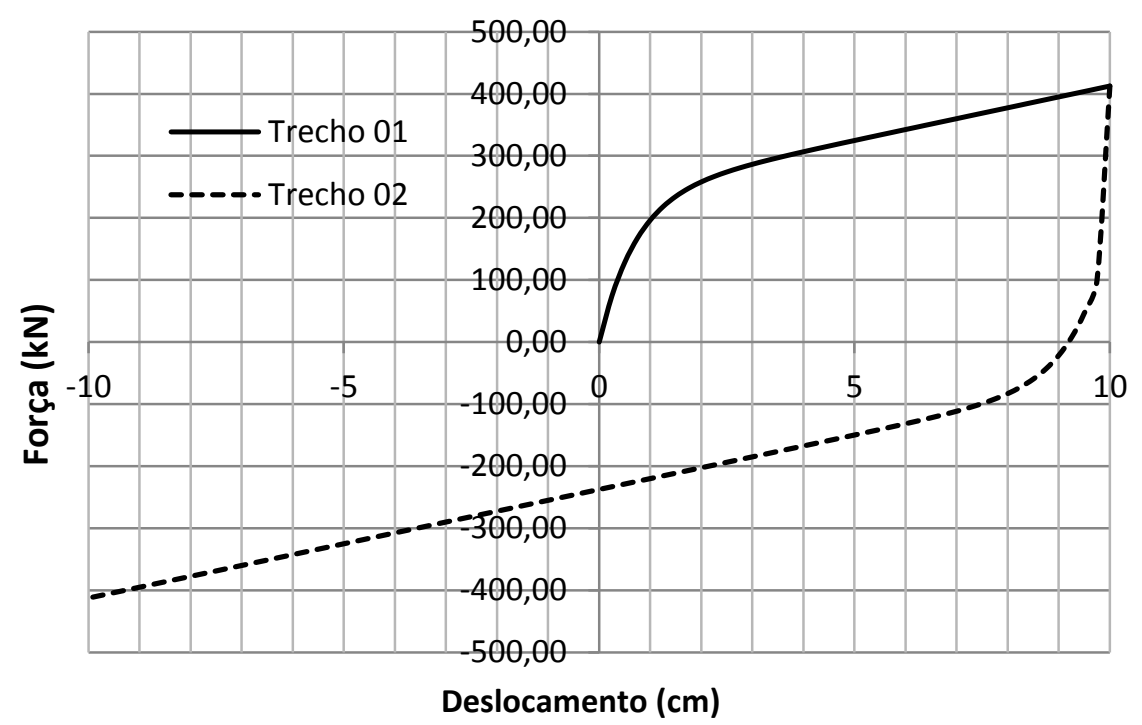




\section{APÊNDICE B}

Código Ansys APDL - Otimização Topológica

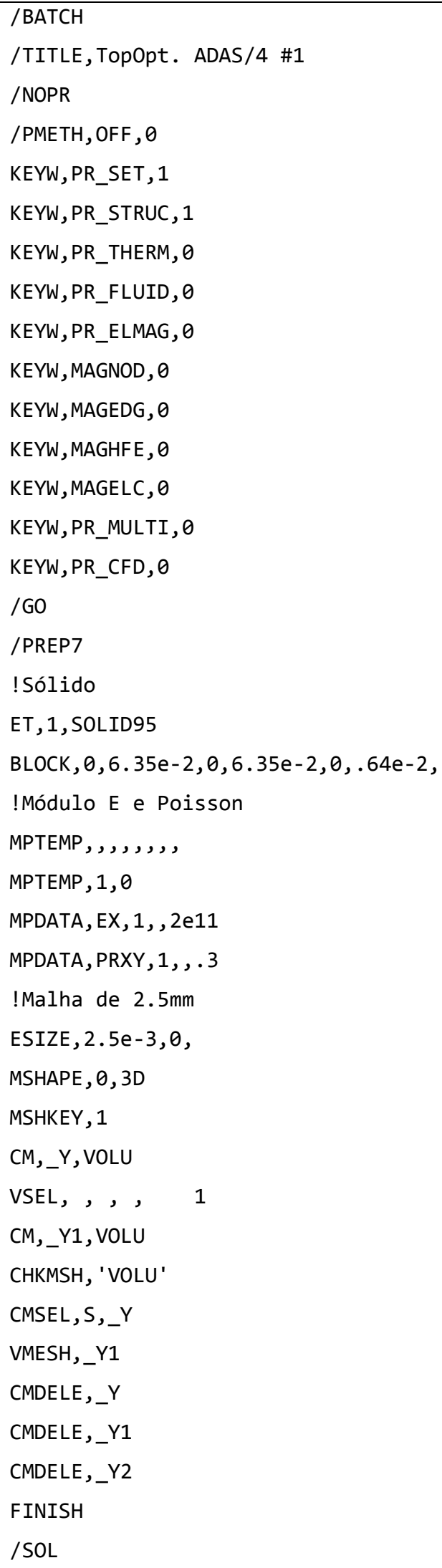




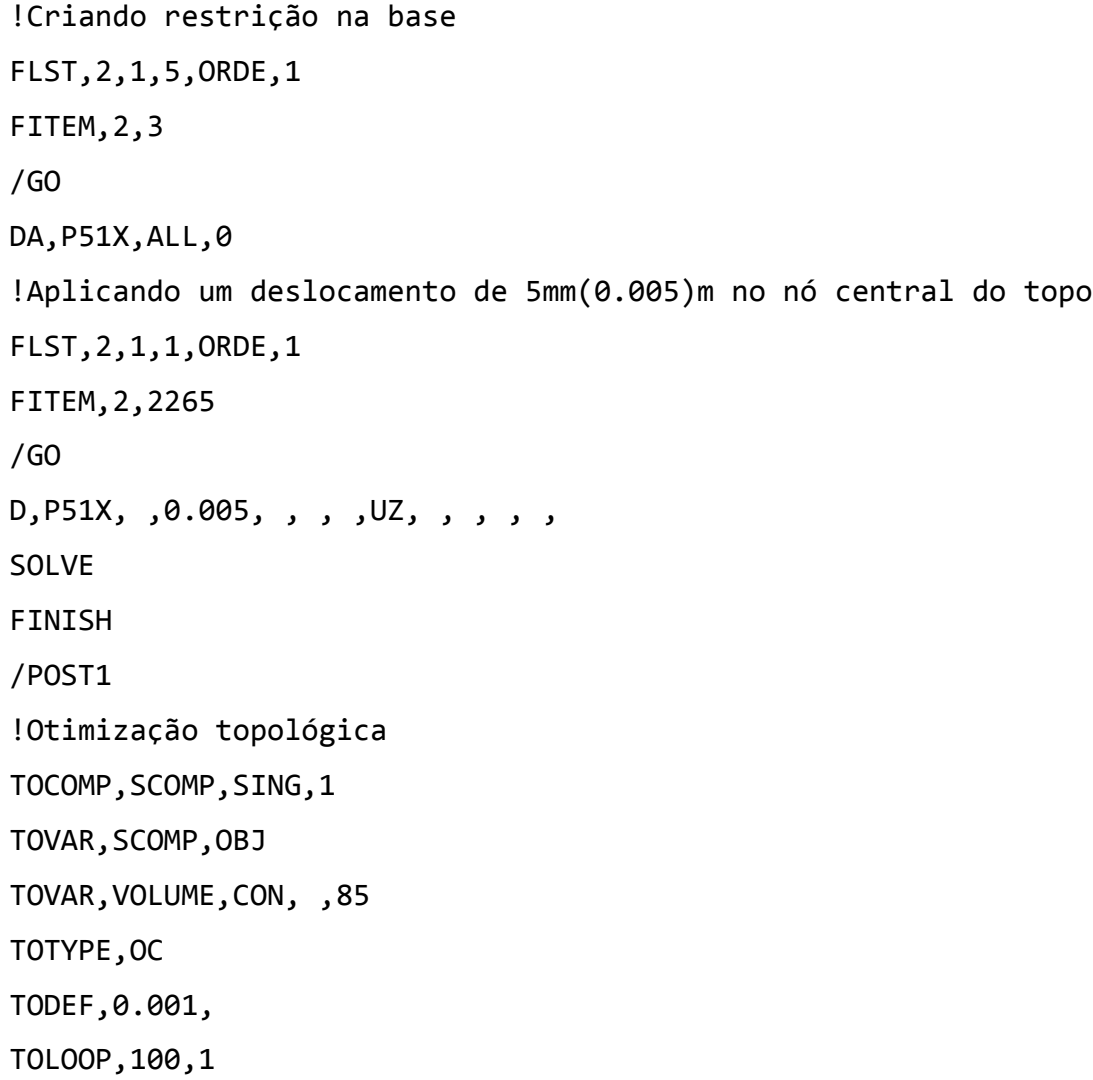




\section{APÊNDICE C}

Sistema de coordenadas para a topologia proposta:

\begin{tabular}{|ccccc|}
\hline Nó & $\begin{array}{c}\mathbf{x} \\
\mathbf{( p o l )}\end{array}$ & $\begin{array}{c}\mathbf{y} \\
\mathbf{p o l})\end{array}$ & $\begin{array}{c}\mathbf{x} \\
\mathbf{( m m})\end{array}$ & $\begin{array}{c}\mathbf{y} \\
\mathbf{( m m})\end{array}$ \\
\hline 1 & 0,5000 & 0,0000 & 12,7000 & 0,0000 \\
\hline 2 & 1,5000 & 0,0000 & 38,1000 & 0,0000 \\
\hline 3 & 2,5000 & 0,0000 & 63,5000 & 0,0000 \\
\hline 4 & 3,5000 & 0,0000 & 88,9000 & 0,0000 \\
\hline 5 & 4,5000 & 0,0000 & 114,3000 & 0,0000 \\
\hline 6 & 0,1464 & 0,1464 & 3,7186 & 3,7186 \\
\hline 7 & 4,8536 & 0,1464 & 123,2814 & 3,7186 \\
\hline 8 & 0,0000 & 0,5000 & 0,0000 & 12,7000 \\
\hline 9 & 5,0000 & 0,5000 & 127,0000 & 12,7000 \\
\hline 10 & 1,0000 & 0,5670 & 25,4000 & 14,4018 \\
\hline 11 & 1,5000 & 0,5670 & 38,1000 & 14,4018 \\
\hline 12 & 3,5000 & 0,5670 & 88,9000 & 14,4018 \\
\hline 13 & 4,0000 & 0,5670 & 101,6000 & 14,4018 \\
\hline 14 & 0,0000 & 1,0000 & 0,0000 & 25,4000 \\
\hline 15 & 0,7500 & 1,0000 & 19,0500 & 25,4000 \\
\hline 16 & 1,7500 & 1,0000 & 44,4500 & 25,4000 \\
\hline 17 & 3,2500 & 1,0000 & 82,5500 & 25,4000 \\
\hline 18 & 4,2500 & 1,0000 & 107,9500 & 25,4000 \\
\hline 19 & 5,0000 & 1,0000 & 127,0000 & 25,4000 \\
\hline 20 & 1,0000 & 1,4330 & 25,4000 & 36,3982 \\
\hline 21 & 1,5000 & 1,4330 & 38,1000 & 36,3982 \\
\hline 22 & 3,5000 & 1,4330 & 88,9000 & 36,3982 \\
\hline 23 & 4,0000 & 1,4330 & 101,6000 & 36,3982 \\
\hline 24 & 0,0000 & 1,5000 & 0,0000 & 38,1000 \\
\hline 25 & 5,0000 & 1,5000 & 127,0000 & 38,1000 \\
\hline 26 & 0,1464 & 1,8536 & 3,7186 & 47,0814 \\
\hline 27 & 4,8536 & 1,8536 & 123,2814 & 47,0814 \\
\hline 28 & 0,5000 & 2,0000 & 12,7000 & 50,8000 \\
\hline 29 & 2,0900 & 2,0000 & 53,0860 & 50,8000 \\
\hline 30 & 2,3633 & 2,0000 & 60,0278 & 50,8000 \\
\hline 31 & 2,6367 & 2,0000 & 66,9722 & 50,8000 \\
\hline 32 & 2,9100 & 2,0000 & 73,9140 & 50,8000 \\
\hline 33 & 4,5000 & 2,0000 & 114,3000 & 50,8000 \\
\hline 34 & 1,8286 & 2,0559 & 46,4464 & 52,2199 \\
\hline 35 & 3,1714 & 2,0559 & 80,5536 & 52,2199 \\
\hline 36 & 0,7177 & 2,0981 & 18,2296 & 53,2917 \\
\hline 37 & 4,2823 & 2,0981 & 108,7704 & 53,2917 \\
\hline 38 & 1,7093 & 2,2907 & 43,4162 & 58,1838 \\
\hline 39 & 3,2907 & 2,2907 & 83,5838 & 58,1838 \\
\hline & & & & \\
\hline
\end{tabular}




\begin{tabular}{|ccccc|}
\hline Nó & $\begin{array}{c}\mathbf{x} \\
\text { (pol) }\end{array}$ & $\begin{array}{c}\mathbf{y} \\
\text { (pol) }\end{array}$ & $\begin{array}{c}\mathbf{x} \\
(\mathbf{m m})\end{array}$ & $\begin{array}{c}\mathbf{y} \\
\mathbf{( m m})\end{array}$ \\
\hline 40 & 0,7885 & 2,3262 & 20,0279 & 59,0855 \\
\hline 41 & 4,2115 & 2,3262 & 106,9721 & 59,0855 \\
\hline 42 & 0,7753 & 2,7407 & 19,6926 & 69,6138 \\
\hline 43 & 1,7247 & 2,7407 & 43,8074 & 69,6138 \\
\hline 44 & 3,2753 & 2,7407 & 83,1926 & 69,6138 \\
\hline 45 & 4,2247 & 2,7407 & 107,3074 & 69,6138 \\
\hline 46 & 0,8323 & 3,1865 & 21,1404 & 80,9371 \\
\hline 47 & 1,6677 & 3,1865 & 42,3596 & 80,9371 \\
\hline 48 & 3,3323 & 3,1865 & 84,6404 & 80,9371 \\
\hline 49 & 4,1677 & 3,1865 & 105,8596 & 80,9371 \\
\hline 50 & 0,9588 & 3,6186 & 24,3535 & 91,9124 \\
\hline 51 & 1,5412 & 3,6186 & 39,1465 & 91,9124 \\
\hline 52 & 3,4588 & 3,6186 & 87,8535 & 91,9124 \\
\hline 53 & 4,0412 & 3,6186 & 102,6465 & 91,9124 \\
\hline 54 & 1,0659 & 4,0554 & 27,0739 & 103,0072 \\
\hline 55 & 1,4341 & 4,0554 & 36,4261 & 103,0072 \\
\hline 56 & 3,5659 & 4,0554 & 90,5739 & 103,0072 \\
\hline 57 & 3,9341 & 4,0554 & 99,9261 & 103,0072 \\
\hline 58 & 1,0736 & 4,5052 & 27,2694 & 114,4321 \\
\hline 59 & 1,4264 & 4,5052 & 36,2306 & 114,4321 \\
\hline 60 & 3,5736 & 4,5052 & 90,7694 & 114,4321 \\
\hline 61 & 3,9264 & 4,5052 & 99,7306 & 114,4321 \\
\hline 62 & 1,0659 & 4,9550 & 27,0739 & 125,8570 \\
\hline 63 & 1,4341 & 4,9550 & 36,4261 & 125,8570 \\
\hline 64 & 3,5659 & 4,9550 & 90,5739 & 125,8570 \\
\hline 65 & 3,9341 & 4,9550 & 99,9261 & 125,8570 \\
\hline 66 & 0,9588 & 5,3917 & 24,3535 & 136,9492 \\
\hline 67 & 1,5412 & 5,3917 & 39,1465 & 136,9492 \\
\hline 68 & 3,4588 & 5,3917 & 87,8535 & 136,9492 \\
\hline 69 & 4,0412 & 5,3917 & 102,6465 & 136,9492 \\
\hline 70 & 0,8323 & 5,8239 & 21,1404 & 147,9271 \\
\hline 71 & 1,6677 & 5,8239 & 42,3596 & 147,9271 \\
\hline 72 & 3,3323 & 5,8239 & 84,6404 & 147,9271 \\
\hline 73 & 4,1677 & 5,8239 & 105,8596 & 147,9271 \\
\hline 74 & 0,7753 & 6,2697 & 19,6926 & 159,2504 \\
\hline 75 & 1,7247 & 6,2697 & 43,8074 & 159,2504 \\
\hline 76 & 3,2753 & 6,2697 & 83,1926 & 159,2504 \\
\hline 77 & 4,2247 & 6,2697 & 107,3074 & 159,2504 \\
\hline 78 & 0,7885 & 6,6842 & 20,0279 & 169,7787 \\
\hline 79 & 1,7093 & 6,7196 & 43,4162 & 170,6778 \\
\hline 80 & 3,2907 & 6,7196 & 83,5838 & 170,6778 \\
\hline 81 & 4,2115 & 6,6842 & 106,9721 & 169,7787 \\
\hline 82 & 0,7177 & 6,9122 & 18,2296 & 175,5699 \\
\hline
\end{tabular}




\begin{tabular}{|ccccc|}
\hline Nó & $\begin{array}{c}\mathbf{x} \\
\text { (pol) }\end{array}$ & $\begin{array}{c}\mathbf{y} \\
\text { (pol) }\end{array}$ & $\begin{array}{c}\mathbf{x} \\
(\mathbf{m m})\end{array}$ & $\begin{array}{c}\mathbf{y} \\
(\mathbf{m m})\end{array}$ \\
\hline 83 & 4,2823 & 6,9122 & 108,7704 & 175,5699 \\
\hline 84 & 1,8286 & 6,9544 & 46,4464 & 176,6418 \\
\hline 85 & 3,1714 & 6,9544 & 80,5536 & 176,6418 \\
\hline 86 & 0,5000 & 7,0103 & 12,7000 & 178,0616 \\
\hline 87 & 2,0900 & 7,0103 & 53,0860 & 178,0616 \\
\hline 88 & 2,3633 & 7,0103 & 60,0278 & 178,0616 \\
\hline 89 & 2,6367 & 7,0103 & 66,9722 & 178,0616 \\
\hline 90 & 2,9100 & 7,0103 & 73,9140 & 178,0616 \\
\hline 91 & 4,5000 & 7,0103 & 114,3000 & 178,0616 \\
\hline 92 & 0,1464 & 7,1568 & 3,7186 & 181,7827 \\
\hline 93 & 4,8536 & 7,1568 & 123,2814 & 181,7827 \\
\hline 94 & 0,0000 & 7,5103 & 0,0000 & 190,7616 \\
\hline 95 & 5,0000 & 7,5103 & 127,0000 & 190,7616 \\
\hline 96 & 1,0000 & 7,5773 & 25,4000 & 192,4634 \\
\hline 97 & 1,5000 & 7,5773 & 38,1000 & 192,4634 \\
\hline 98 & 3,5000 & 7,5773 & 88,9000 & 192,4634 \\
\hline 99 & 4,0000 & 7,5773 & 101,6000 & 192,4634 \\
\hline 100 & 0,0000 & 8,0103 & 0,0000 & 203,4616 \\
\hline 101 & 0,7500 & 8,0103 & 19,0500 & 203,4616 \\
\hline 102 & 1,7500 & 8,0103 & 44,4500 & 203,4616 \\
\hline 103 & 3,2500 & 8,0103 & 82,5500 & 203,4616 \\
\hline 104 & 4,2500 & 8,0103 & 107,9500 & 203,4616 \\
\hline 105 & 5,0000 & 8,0103 & 127,0000 & 203,4616 \\
\hline 106 & 1,0000 & 8,4434 & 25,4000 & 214,4624 \\
\hline 107 & 1,5000 & 8,4434 & 38,1000 & 214,4624 \\
\hline 108 & 3,5000 & 8,4434 & 88,9000 & 214,4624 \\
\hline 109 & 4,0000 & 8,4434 & 101,6000 & 214,4624 \\
\hline 110 & 0,0000 & 8,5103 & 0,0000 & 216,1616 \\
\hline 111 & 5,0000 & 8,5103 & 127,0000 & 216,1616 \\
\hline 112 & 0,1464 & 8,8639 & 3,7186 & 225,1431 \\
\hline 113 & 4,8536 & 8,8639 & 123,2814 & 225,1431 \\
\hline 114 & 0,5000 & 9,0103 & 12,7000 & 228,8616 \\
\hline 115 & 1,5000 & 9,0103 & 38,1000 & 228,8616 \\
\hline 116 & 2,5000 & 9,0103 & 63,5000 & 228,8616 \\
\hline 117 & 3,5000 & 9,0103 & 88,9000 & 228,8616 \\
\hline 118 & 4,5000 & 9,0103 & 114,3000 & 228,8616 \\
\hline & & & & \\
\hline
\end{tabular}




\section{APÊNDICE D}

Rotina escrita em linguagem LISP® em que é possível realizar o desenho da forma proposta (Bottle Shape) de forma automática em um programa de plataforma CAD.

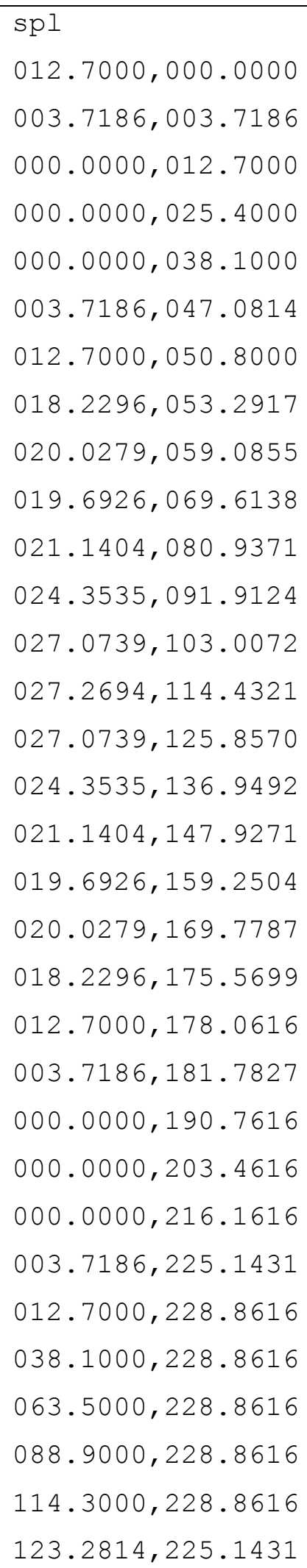


$127.0000,216.1616$
$127.0000,203.4616$
$127.0000,190.7616$
$123.2814,181.7827$
$114.3000,178.0616$
$108.7704,175.5699$
$106.9721,169.7787$
$107.3074,159.2504$
$105.8596,147.9271$
$102.6465,136.9492$
$099.9261,125.8570$
$099.7306,114.4321$
$099.9261,103.0072$
$102.6465,091.9124$
$105.8596,080.9371$
$107.3074,069.6138$
$106.9721,059.0855$
$108.7704,053.2917$
$114.3000,050.8000$
$123.2814,047.0814$
$127.0000,038.1000$
$127.0000,025.4000$
$127.0000,012.7000$
$123.2814,003.7186$
$114.3000,000.0000$
$088.9000,000.0000$
$063.5000,000.0000$
$038.1000,000.0000$
$012.7000,000.0000$

spl

$053.0860,050.8000$

$046.4464,052.2199$

$043.4162,058.1838$

$043.8074,069.6138$ 


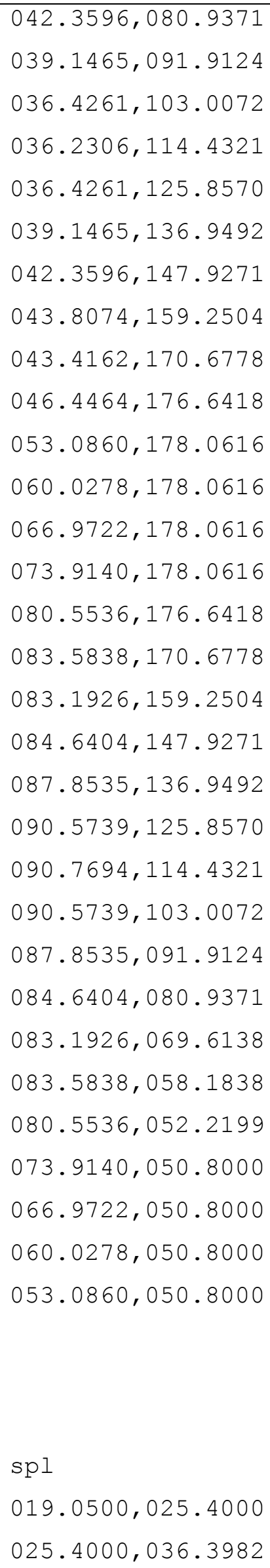


$038.1000,036.3982$
$044.4500,025.4000$
$038.1000,014.4018$
$025.4000,014.4018$
$019.0500,025.4000$

spl

$082.5500,025.4000$

$088.9000,036.3982$

$101.6000,036.3982$

$107.9500,025.4000$

$101.6000,014.4018$

$088.9000,014.4018$

$082.5500,025.4000$

spl

$019.0500,203.4616$

$025.4000,214.4624$

$038.1000,214.4624$

$044.4500,203.4616$

$038.1000,192.4634$

$025.4000,192.4634$

$019.0500,203.4616$

spl

$082.5500,203.4616$

$088.9000,214.4624$

$101.6000,214.4624$

$107.9500,203.4616$

$101.6000,192.4634$

$088.9000,192.4634$ 
$082.5500,203.4616$

REGEN 